\title{
Spectacular Struggles: Utopian Whiteness, Black Resistance, and the National Imaginary in Nineteenth-Century America
}

\author{
Courtney L. Novosat
}

Follow this and additional works at: https://researchrepository.wvu.edu/etd

\section{Recommended Citation}

Novosat, Courtney L., "Spectacular Struggles: Utopian Whiteness, Black Resistance, and the National Imaginary in Nineteenth-Century America" (2016). Graduate Theses, Dissertations, and Problem Reports. 6331.

https://researchrepository.wvu.edu/etd/6331

This Dissertation is protected by copyright and/or related rights. It has been brought to you by the The Research Repository @ WVU with permission from the rights-holder(s). You are free to use this Dissertation in any way that is permitted by the copyright and related rights legislation that applies to your use. For other uses you must obtain permission from the rights-holder(s) directly, unless additional rights are indicated by a Creative Commons license in the record and/ or on the work itself. This Dissertation has been accepted for inclusion in WVU Graduate Theses, Dissertations, and Problem Reports collection by an authorized administrator of The Research Repository @ WVU.

For more information, please contact researchrepository@mail.wvu.edu. 


\section{Spectacular Struggles: Utopian Whiteness, Black Resistance, and the National Imaginary in Nineteenth-Century America}

\section{Courtney L. Novosat}

Dissertation submitted to the Eberly College of Arts and Sciences at West Virginia University in partial fulfillment of the requirements for the degree of

Doctor of Philosophy

in

English

Tim Sweet, Ph.D., Chair

John Ernest, Ph.D.

Gwen Bergner, Ph.D.

Michael Germana, Ph.D.

Paul Gilmore, Ph.D.

Department of English

Morgantown, West Virginia

2016

Keywords: American Literature, African American Literature; Nineteenth Century; Utopia; World's Fairs; Critical Race Theory

Copyright 2016 Courtney L. Novosat 


\section{ABSTRACT \\ Spectacular Struggles: Utopian Whiteness, Black Resistance, and the National Imaginary in Nineteenth-Century America}

\section{Courtney L. Novosat}

Through an analysis of the popularity, didacticism, and rhetoric of literary utopias and world's fairs, Spectacular Struggles argues that during the latter half of the nineteenth century our national narrative makes use of an inherently and uncritically white utopian form to forge an exclusionary, white national identity as an anxious response to a tumultuous era of social change. The first chapter traces the origins of this "white (male) utopian complex" from More's sui generis Utopia to the white utopian frameworks governing our self-representation at the fair, national narratives, and even our histories. From this grounding, I turn to Edgar Allen Poe's quirky, yet poignant "Mellonta Tauta" (1850) and Hawthorne's The Blithedale Romance (1852), before focusing on Edward Bellamy's oft-centralized Looking Backward (1889). Through this comparison, I map the rise of the white male utopian complex within our historiography in contrast to a paralleled and metacritical utopian voice excluded from this historiography. To further highlight the canon's white utopian complex, chapter two turns to America's premier, most nationalistic, and most overtly-racialized fairscape, the World's Columbian Exposition (1893). While chapter one looks to the way in which the Philadelphia's Centennial International Exhibition (1876) informs Bellamy's architectural imagining of the future and helps to establish the fairscape's relationship to the literary utopia, chapter two looks at the role the Columbian Exposition plays in institutionalizing and nationalizing a neoclassical white aesthetic not merely for architecture or art or literature, but for national identity. I focus here on the fair's "White City" as a racialized articulation of the "City Beautiful" movement in literature, architecture, and ultimately urban planning. I argue that the salience of the "race question" at these spectacular nationalized utopias highlights utopian scholarship's avoidance of race history and how such an omission skews the historiography of the period. With an eye toward recasting race history as central to this historiography, chapters three and four take up two under-discussed bodies of utopian literature: the Southern utopia and the African America utopia. Chapter three argues that we've long overlooked utopias set in the South or written by Southerners precisely because they, like the fairs held therein, aggressively and openly reassert whites' proprietary claims over the South's history and its future. These oft-excluded white supremacist utopias not only advance a more militant Anglo-Saxon national identity, but they inform a Southern fairscape that sentimentally rewrites the Old South by forcibly whitewashing the New. In contrast to the previous chapter's focus on white supremacist works, chapter four argues that a nascent black nationalism begins to emerge in black spectacular fictions that appear at the century's end and that these fictions collectively reclaim an American past, present, and future in which black Americans play an integral role. I argue that these black utopists use the hybridity of the utopian form to articulate a black philosophy, history, and critical study of whiteness that simultaneously exposes how the inherent whiteness of the utopian form has long-advanced within the national imaginary an American utopia contingent upon its whiteness. Spectacular Struggles offers a starting point for recovering a previously-evaded race history and significant body of utopian works long pushed to the margins of the contemporary canon. It offers a starting point for acknowledging how the racially-unmarked historiography presently defining the scope of utopian study distorts a nineteenth-century reality. 


\section{Acknowledgements}

This dissertation would not have been possible without the encouragement and support of many people. Foremost, I would like to thank my dissertation director, John Ernest, for generously sharing his time and wisdom as both a professor and mentor. While the breadth of his knowledge of racial history in the U.S. and of nineteenth-century American literature have been an inspiration, his sound, practical counsel in academic matters both large and small has been invaluable to me in negotiating this project and the discipline in general. This project would be a shadow of itself without John's direction and, quite simply, I would not be the same person without his guidance. I would also like to heartily thank Tim Sweet, whose expansive historical knowledge is rivaled only by his sincere dedication to his students' development. I am greatly indebted to the care he has taken to offer me thoughtful, complex, and challenging feedback both as a professor and as a primary reader of this dissertation. His insights have helped me to become a more nuanced thinker and a better scholar. I also owe a great deal of thanks to Gwen Bergner, who has meticulously read my work with keen attention to helping me refine both the structure of my argument and the precision of my writing. I am tremendously grateful for her clear, concrete advice for revision, which has helped me to tighten my argument and strengthen my writing. I would also like to thank Michael Germana, who directed me to helpful primary and secondary sources as I began this project and who has offered me invaluable written feedback on my final draft. I am also grateful to Paul Gilmore of the California State University at Long Beach for graciously agreeing to serve on my committee and for his own work in The Genuine Article (2001), which first demonstrated to me the importance of considering the relationship between nineteenth-century literature and cultures of exhibition. I would also like to express my gratitude to my peers at WVU, particularly to Cara Snider, Andrea Bebell, Douglas Terry, and Jason Stupp. They not only extended their friendship, but shared their intellect. During our years of course work, they challenged and advanced my thinking in the most productive ways. I would be remiss if I did not also thank professors Magali Michael, Linda Kinnahan, Frederick Newberry, Dan Watkins, and the late Albert Labriola for guiding my study of literature as an undergraduate and master's student at Duquesne University. And I also owe a debt of gratitude to my peers at Duquesne, particularly to Claire Barbetti and Lee Ann Glowzenski. For more than a decade, Claire has been both a touchstone and an inspiration while Lee Ann has been an ardent ally and beacon in my times of doubt. I am honored to call these brilliant women my friends. Finally, I would like to thank my family. None of this work would have been possible without their support. My parents, Debra and George Novosat, have been steadfast in their commitment to my education at all levels. For the last five years of this project they have driven countless miles and across state lines to be second parents to my son, so that I could write. My gratitude and love for them is simply immeasurable. My husband, Damon Clark, has been my greatest advocate and fervent ally for more than fifteen years. He has been my sounding board. He has been my calm. He has been the most selfless, loving, and devoted partner and father one could hope to find. And, lastly, I am grateful to my son, Liam, whose growth alongside this work has given me a greater sense of its purpose. I dedicate this work to him with the hope that he might always strive to realize a better world. 


\section{Table of Contents}

Introduction:

Defining Spectacular Struggles: Utopian Whiteness, Black Resistances, and the National Imaginary in Nineteenth-Century America

Chapter One:

"A Favoring Providence, Calling Our Institutions into Being": Re/Historicizing the White Utopian Complex in Nineteenth Century America

Chapter Two:

Exhibiting (In)Civility: Reframing the Eugenic Logics of the White City Beautiful and Reclaiming a Space for Black Resistance

Chapter Three:

Separate and Unequal Utopias in the Landscape of Plessy: the "Atlanta Compromise," AngloSaxon Masculinity, and Militant Segregation

Chapter Four:

Articulating a Black Utopia: Intellectualism and a Black National Imaginary in Fair and Fiction

Conclusion:

Toward a New Historiography, Toward a New Utopian Narrative

Appendix:

Works Cited: 


\section{Introduction:}

Defining Spectacular Struggles: Utopian Whiteness, Black Resistances, and the National Imaginary in Nineteenth-Century America

In other commonwealths, every man knows that unless he provides for himself...he must die of hunger, but in Utopia, where every man has a right to everything,...no private man can want anything; for among them there is no unequal distribution, so that no man is poor, none in necessity; ... for what [else] can make a man so rich as to lead a serene and cheerful life, free from anxieties...?

-Sir Thomas More, Utopia

\section{Mapping the Literary Utopia from More to America ${ }^{1}$}

Ingrained across cultures and epochs in our very mythos of origin and destination, the idea of utopia has existed from time immemorial. In its most rudimentary form, utopia, the hope for a more-desirable world than our own, is thought to be one of the fundamental forces compelling humans to act. ${ }^{2}$ In fact, when we look at recorded history, we are hard-pressed to find a society whose citizens have not consciously worked toward a more-ideal organization or a better nation well before terms like "utopia" or "citizen" or "nation" came into parlance. ${ }^{3}$ Yet the word "utopia," which traces its origin to Sir Thomas More's sui generis Utopia (1516), has a much different history, one bound to the idea of "nation."

More's Utopia, "scarcely ever out of print" in its 500-year history, not only coined the term "utopia," it gave rise to a philosophically-grounded, politically-invested, interlocutory genre that "plays a crucial role in the constitution of the nation-state as an original spatial, social, and cultural form" (Davis 29, Wegner xvi). Almost at once More's utopia generated both a generic form and a didactic political "program" for nation-building, one inextricably tied to the colonization of America and to making its settlers a homogenous (and soon a white) citizenry (Jameson 3). ${ }^{4}$ In fact, given the genre's carving of a "conceptual framework" for the nation-state, it may be most accurate for me to speak about my project here as one of mapping (Wegner 55). Indeed, Spectacular Struggles is a mapping of this utopian framework as a dialectic of hope and 
anxiety as it developed in an American landscape. It is particularly a critical mapping of the racialized anxiety and restrictive utopian frameworks in nineteenth-century articulations of an American utopia long overlooked in our historiography of the period.

Beginning with Sir Thomas More's Utopia, a work directly engaged with intervening in English history and politics, utopia was from its origin a hybrid genre of travelogue and romance, political tract and history. Reinforcing the form as motivated and programmatic, we find in Utopia's pages a concrete political plan for nation building drawn from historical sources such as the journals of Amerigo Vespucci and Christopher Columbus as well as Martin Waldseemuller's World Map (1507), one of the earliest known representations of America (see fig. 1). ${ }^{5}$ Imagining an egalitarian, democratic, and socialist society in the New World, More's work criticizes the exploitative class systems in Europe and England. From this generic origin, far from being merely a fictive distraction from the everyday, utopia became a motivated literary form engaged in direct, didactic dialogue with its historical moment. More's work shaped a new literary genre that sought to intervene in history, systematically shape a new nation, and offer its readers a program for change. And Utopia does so in a self-reflexive manner aware of its precarious position between reality and fiction. Indeed, More carefully chose the ambiguous name "utopia" to conjure a contradiction among the homophonic Greek words for "good place" (eutopia) and "no place" (outopia), meanings that More seemed to choose precisely for their near-opposition, a choice that also wryly ensured the reader's necessary role in deciphering a utopia's intent. ${ }^{6}$

Following in the footsteps of More, literary utopias have continued to take on Utopia's hybrid formal conventions and political features. Like More's Utopia, the nineteenth-century successors this dissertation will discuss are complex literary forms at the "boundary between 
reality and fiction" as they "created imaginary geographies" of nation (Vieira 8, Pohl 52). Just as More drew from and replicated conventions from travel journals, Plato's dialogues, and legislation to forge a hybrid literary work categorically between fact and fiction, so have those writing in his wake continued the genre's flux between imagination and intervention. ${ }^{7}$ Given that such sources were intimately engaged with the politics of their present moment, utopias do not merely tell a story, they put "forward projective ideas that are to be adopted by future audiences"; they wish to elicit change and to found new societies (Vieira 8, Jameson 3). And as a dialogic form, the literary utopia is an intimate interlocutory act guiding its reader to intervene and participate in its elaboration of a new system. The utopist and the reader enter into "a kind of pact," a kind of reciprocal agreement in which the author imagines a society that doesn't yet exist and the reader participates in believing the author (Vieira 8) ${ }^{8}$ Guided by a utopian traveler who narrates in the first person, this figure becomes the reader's surrogate as the reader becomes a participant of utopia - and perhaps an active agent of the utopian system outside of the text. Given the form's desire to inspire action, that its "fiction cannot defy logic" is among its most important political features (8). Indeed, the most successful utopia relies on "objects and structures that already exist in the real world" (8). The literary utopia it blurs the line between fiction and reality for readers to give them a sense of their own ability to intervene in history. From its inception, then, utopia aimed to be a guidebook for a new nation.

To that end, it's unsurprising that we find a fundamental connection between utopia and America's national narrative. For not only did the romantic appellation of the Americas as the "New World" inspire More's imagining of Utopia or Francis Bacon's Bensalem in New Atlantis (1624) or Elihu Hubbard Smith's "The Institutions of the Republic of Utopia" (1798), this utopian framework it inspired the very political idealism of the nation's founding documents. ${ }^{9}$ 
Such romance led Thomas Jefferson, long believed to have drawn some measure of inspiration from More's radical notion of egalitarianism, to proclaim the "unalienable rights" of men. It would lead James Madison to ensure More's Utopia was part of the first Library of Congress, informing the founders' notion of a "more perfect Union." For if the eighteenth century was dedicated to forging the political system of a more utopian nation, the nineteenth century, it might be said, was dedicated to theorizing, extending, and narrating the vision of this new nation, this new America. ${ }^{10}$ In other words, Utopia's influence on American political thought and social formation was profound and far-reaching; it helped to establish a nationalized—and, as I will argue racialized—utopian rhetoric.

This utopian rhetoric of nation not only proved to be protean and elastic, but also overtly white. For the lore of the "New World" soon found new currency in terms like "Manifest Destiny" and "American Exceptionalism," which paired utopian thought with the nation's imperialist progress over non-whites in the expansion of slavery and removal of Native Americans, for example. It even took visual form, as a neoclassical white Goddess Columbia became the iconography of nation and symbol of its identity. Melding the nation's Columbian “discovery," a belief in Providentialism, and a preoccupation with whiteness, the divine Columbia became a herald of the nation's progress toward a white American destiny (see fig. 2). And soon, early historians came to naturalize this utopian racialized rhetoric as American history. As I will later discuss, George Bancroft's multi-volume History of the United States of America (1834), which defined the study of American history into the twentieth century, recasts the "discovery" of the New World as the fulfillment of a religious prophecy. There he historicized America as a new, white Eden, as one of the foretold "empires beyond the ocean" called "into being... by a favoring Providence" and carved into nationhood by the Anglo-Saxons, 
the "hope of the new world" (Bancroft 1: 4, 1:612). In this way, Bancroft's long influential work reimagines the mythos of a divinely-ordained new world for whites as a fact of the nation's history for generations of readers and writers.

However, as Spectacular Struggles will argue, race is rarely discussed in our history of the literary utopia despite the centrality of "the negro question" and "the immigrant question" to the nineteenth century. Although questions of the 'sovereignty' of whiteness preoccupied American thought, aside from noting the whiteness and maleness of the field's dominant canon, the issue of race remains undiscussed. Yet, as I will argue, even More's Utopia aligned a utopia's success with cultural homogeneity. Further, while scholars have noted overtly racialized histories such as "communalism of the labor movement..., attempts to preserve the antiracist legislation of the Reconstruction years," the general post-Civil War turmoil, the Haymarket riot, strikes, immigration, and "urban sprawl," their readings largely avoid discussing the racialized dimensions of these anxieties (Pfaelzer 5, 11; Roemer Audiences 73). And yet, More overtly rendered anxiety as central to the shape of utopia, as the force compelling utopian thought. For utopia is an imagined world "free from anxieties," which renders anxiety and hope as the rival dialectic forces defining the literary form. ${ }^{11}$ And while scholarship looks to the nineteenthcentury utopia's hopeful "confrontation with social deficiency" born "of a given set of [historical] circumstances," it almost entirely overlooks an anxious complement of those visions: an anxiety to preserve whiteness (Davis 29, Vieira 8). For, as I will argue here, we must look at the ways in which a utopian author's fear of blackness and foreignness informs the design of his utopia imagining. This white anxiety of the racialized other, arguably an articulation of Said's "orientalism" within an American setting, is central to the canonical utopia's reimagining of what "historians and political scientists" have characterized as a "a basic loss of order" amid a 
chaotic society, yet it remains undiscussed (Roemer Audiences 74). As a genre that "emphasizes the desirability of order and organization," utopia became a means to stabilize reality, and, I would add, a means to cordon-off the hope for a white utopian future from the anxiety of the nineteenth-century's threatening racial landscape (74).

Spectacular Struggles argues that by overlooking the whiteness of the nineteenth century canon, we do a disservice to history and skew our historiography of the utopian novel. It argues that we must place the nineteenth-century utopian novel in a longer tradition of literary and cultural utopian works. Using the American display at the first international world's fair in England's Great Exhibition of 1851 and "Black Chicago's" Lincoln Jubilee of 1915 as historical bookends, I read Edward Bellamy's Looking Backward in light of the oft unconsidered skeptical utopias of Edgar Allan Poe's “Mellonta Tauta" (1841) and Nathaniel Hawthorne's The Blithedale Romance (1852) that self-consciously question the motives of the form, to question the motivations of the white utopian frameworks governing our national narrative. I consider how alternative visions of utopia by women such as Sara Josepha Hale's Libera; Or Mr. Peyton's Experiments (1853) or Annie Denton Cridge's Men's Rights; or, How Would You Like it? (1870) may be excluded from our historiography precisely because their idea of utopia reflectively questions the white male logics of nation-building or refuses to evade discussion of the race question. I look to how American world's fairs render in visual forms these white utopian logics to advance the notion that an American utopia is predicated on whiteness. Finally, look to the fair and displays organized by black intellectuals such as The Exhibition of the American Negro at the Paris Exhibition Universelle in 1900 alongside novels by black utopists such as Frances Harper's Iola Leroy (1892), Sutton E. Griggs's Imperium in Imperio (1899), and Pauline Hopkins Of One Blood (1902). I argue that these works highlight the systemic white 
supremacy of the utopian form and the national narrative it supports. Drawing these excluded works into conversation, I maintain, carves out an important and necessary space for black utopian thought in the national imaginary that our historiography — and canon — problematically overlooks.

\section{The Contemporary Historiography of $19^{\text {th }}-$ Century Literary Utopia}

To more fully address a potential deficiency in the study and historiography of the nineteenth-century American literary utopia, we must have a clearer picture of its present canon and shape of its scholarship. Perhaps the most telling part of this historiography is that the formation of its canon has long been predicated upon specific textual exclusions and critical inattentions. For example, Glenn Negley's and J. Max Patrick’s The Quest for Utopia: An Anthology of Imaginary Societies (1952), one of the first anthologies of literary utopias written between 1850 and 1950, openly excluded science fiction, which the authors called a "bastard literary device" that "exploited [...] utopian fantasy" (588). Despite excluding an entire branch of utopian work, this anthology largely defined an initial utopian canon until the early 1970s. When the turmoil of the civil rights movement, the Vietnam War, and the women's rights movement, led to another spike in utopian writing, particularly among women, and a resurgent academic interest in the form's emerging "politics of hope" (178). ${ }^{12}$ Importantly, this period culminated in Lyman Tower Sargent's publication of British and American Utopian Literature 1516-1975: An Annotated Bibliography (1979), which generated the canon of nineteenth-century utopian literature we study today, and, arguably, remains definitive of it. Sargent's bibliography was revolutionary. It put utopian studies on the proverbial map and its importance cannot be overestimated. And, to its credit as a forward-thinking text, it reflected the burgeoning paradigm shifts of the time by including many works by women and a number by African Americans. 
Unfortunately, despite this inclusivity the field of study maintained much of its early exclusivity by continuing to focus on works authored by white middle- and upper-class men. ${ }^{13}$ In fact, in what is perhaps an echo of the trenchant traditionalism masking as progressivism in many nineteenth century utopian novels, the field itself would not see the publication of an anthology of women's nineteenth-century utopias until Carol Farley Kessler's Daring to Dream (1984) was published and would not see a book-length study of those works until Darby Lewes published Dream Revisionaries (1994) a decade later. And, as recently as 2009, at least one scholar notes that the black literary utopia—nineteenth century or otherwise - "has yet evaded serious study" (Ahmad 131). In other words, there seems to be a precedent of exclusion within the field, or, at the very least, a hesitation to broaden the traditional canon of study.

However, recent scholarship has broadened its focus. While Dohra Ahmad's Landscapes of Hope (2009) gave voice to the works of several African- and Indian-American anti-colonialist writers printed in periodicals at the turn of the century, other racially attuned scholarship has come from the parent field of studies in nineteenth century American literature (68). Here Thomas Peyser's Utopia \& Cosmopolis (1998) reads Bellamy's Looking Backward and other utopias in the context of globalization, beginning an important discussion of the literary utopia "as an attempt to contain [a racialized] cosmopolitan threat" (20). Likewise, the concluding chapter of Susan Mizruchi's The Rise of Multicultural America (2008), characterizes the literary utopia as actively reacting to the threat of a multicultural America. Mizruchi astutely observes that while the literary utopia may have sought to "equalize the proceeds of progress," it wanted to do so only after employing "eugenicist measures [to] homogenize the citizenry"-a citizenry decidedly meant to be Anglo-Saxon, an observation that, in part, confirms the relevancy of my own work's focus on whiteness $(8,9)$. 
Yet, despite these racially-attune readings, little has changed in the historiography of the nineteenth-century utopia. In the recently-published The Cambridge Companion to Utopian Literature (2011), a work influential in defining the field for a wide range of readers, the historiography uncomfortably avoids race. ${ }^{14}$ For example, Lyman Tower Sargent's "Colonial and Postcolonial Utopias" offers a comparative discussion of themes within colonial and postcolonial utopias without any mention of race (201). Instead, he twice uses the term "ethnicity," which as Matthew Frye Jacobson has usefully points out has been a long-troubled term signaling a racial history of "variegated whiteness" (Whiteness 41). And although he mentions the treatment of Native North Americas in white-authored utopias discussing the colonial period and postcolonial works that First Americans wrote in response, he entirely overlooks enslaved blacks as a colonized people, and, therefore, overlooks black-authored American utopias. Significantly, with only slight alteration, the traits of postcolonial utopias he identifies would aptly characterize those of the nineteenth and early twentieth century black utopias as well. ${ }^{15}$ Kenneth Roemer, too, eschews significant discussion of the black utopia. In "Paradise Transformed: Varieties of Nineteenth-Century Utopias," he offers an ardently-traditional, Bellamy-centered historiography of the nineteenth century. For after a useful contextualization of utopian philosophies and some discussion of literary utopias prior to Bellamy's, he turns to a history of industrialism that nevertheless makes little mention of slavery or the racialization of immigrant labor strikes. More disconcerting, though, is Roemer's scant four-line mention of Sutton Griggs's Imperium in Imperio (1899), which he characterizes as the "only ... pre-1900 American utopia...focused on African Americans" only to promptly undercut its importance (100, emphasis added). He writes dismissively that "African Americans were typically ignored, but the real invisible men and women of American utopias were the first Americans" (100). While perhaps factually accurate, 
his rhetoric trivializes both minority groups and emphasizes how our historiography continues to gloss over a critical assessment of utopia's whiteness as well as utopias by writers of color (100, emphasis added).

\section{Enlarging the Historical Frame: Literary Utopia, the World's Fair, and the Fairscape}

Part of a critical assessment of the nineteenth-century utopia's whiteness would come as a matter of necessity if we enlarge our historical frame of reference to include world's fairs, which often showcased the display of non-white peoples. In fact, these fairs seem to be a curious omission, since utopian studies has long-advocated reading utopia as "a multi-dimensional phenomenon" (Sargent “Three Faces” 222). In fact, Lyman Tower Sargent even outlined a "tentative taxonomy" of utopian phenomena that included "ideal cities," "urban planning," and "visionary architecture"— phenomena whose early histories, as Spectacular Studies argues, are intimately tied to world's fairs, which are not named $(3,11)$. Yet, as I will argue, the World's Fair is a multi-dimensional and didactic utopian spectacle that makes overtly clear the whiteness of the utopian frameworks of both novel and nation. Given their white neoclassical architecture, displays of non-white peoples in "human zoos," and active exclusion of black Americans even after Emancipation, world's fairs clearly align an American utopia with whiteness.

Significantly, fair scholarship has often described exhibitions as utopian spaces for transmitting national identity. In fact, this scholarship almost always draws a thematic correlation between the popularity of fairs and the "flood of utopian writings at the century's end," suggesting a kinship between the two phenomena (Rydell 4). Their kinship is less surprising when we consider that their rise to prominence occurs amid the same tumultuous era. Like the literary utopia, the thirty acutely-managed and hyper-organized international exhibitions held in America between New York's Crystal Palace Exhibition of 1853 and Chicago's Lincoln Jubilee 
Exposition of 1915 were preoccupied with re-ordering the reality of a chaotic present to control the narrative of the past and direct the narrative of the nation's future. ${ }^{16}$

It's also important to note that the utopian novel gained momentum and prominence after a "utopian fairscape" enrapt the American press. For, years in advance of becoming a physical site, the fair was an imagined spectacle in the press. The press literally landscaped the event in verbiage, offering readers a narrative lay of the land that we might term a "utopian fairscape."17 Making use of utopian literary conventions, the press ekphrastically forged the fair as a literary utopia. It gave descriptive life to blueprints and designs, rendered images of the fair from mere descriptions, generated a nationalistic white narrative of meaning and purpose for the event often symbolized by the Goddess Columbia, and directly addressed readers only to interpellate their response. ${ }^{18}$ The fair was not a single event—it was a collection of utopian writings, of imaginings and descriptions, accounts and reflections. And in this way, the reach of a fair extended far beyond its historical moment. For it may have originated in periodicals, but it persisted in guidebooks and histories, and, in some cases, in museum collections and new fields of academic study. ${ }^{19}$ As exhibition scholars argue, world's fairs were instrumental in "the classification and ordering of knowledge, the production of ideology, and the disciplining of a public," one that formally advanced scientific racism, a national white identity, and white middle-class decorum (Henning 1). ${ }^{20}$ In fact, late-nineteenth fairgoer and famed historian Henry Adams held "education to be a blind impossibility" without fairs, which as modern historians note "desired" a working class audience for "education exhibits" that often bordered on nationalist propaganda (Rydell 3, Greenhalgh 21). As one scholar recognizes, these fairs came to "function as promissory notes" for the nation's future, “embodying, if just for a season, utopian principles of social organization" that "would eventually be realized in perpetuity" (Bennett 95). 
Yet that "utopian" social organization almost always excluded those of color, who were often welcomed only on particular days of the fair (if at all) and were excluded from organized representation until the Atlanta Cotton States and International Exposition of 1895. With all of this in mind, I suggest that the fairscape not only draws on the frameworks of utopian thinking in America, but, by the fair's very nature, helps to nationalize an official image of a utopian America for an even wider readership and fair-going audience. In fact, as I document herein, we can trace the fair's influence on utopian imagining in a number of utopian novels that signal, include, or, at times, culminate in a fair or exhibition. ${ }^{21}$

The overlap between the exhibition and utopian novel suggests they were party to a much larger ideological phenomenon of Americans navigating and ordering a tempestuous historical reality of nineteenth-century America. And it is for this reason that I suggest we consider both the utopian novel and the fairscape "vehicle[s] for social and political speculation" (Kumar 24, emphasis added). For the fair was an elaborate physical construction that could literally transport fairgoers to an immersive new landscape in a manner that the utopian novel could only manage through ekphrasis. And, instead of being a communal outlier to the nation as intentional communities were, the fairscape was a central part of the national identity, giving state authority to its representation of the nation. As some have argued, if the utopian novel could demand its readers "experience vicariously an alternative reality" and "perceive the realities and potentialities of their [own] culture in new ways," then the exhibition would certainly have made similarly-compelling demands through immersion (Roemer Audiences 20). Both of these "spectacular fictions" created for their audiences an immersive and "cohesive unity that includes [a] past, present, and future" and allowed the reader or the fair patron "to conceive of themselves as belonging to a meaningful universe" that existed before them and will continue to exist after 
their demise (Rydell 2). In this way, both of these fictions generate what sociologists Peter L. Berger and Thomas Luckmann have called a "“symbolic universe,"” a formation that replicates society's institutionalized construct of reality and extends the "authority of the country's corporate, political, and scientific leadership" (Rydell 2). Further, because of their ties to nationalism and production by a white, male ruling class, we might also think of the fairscape and the utopian novel in more overtly political terms, as what Louis Althusser termed an "ideological state apparatus" (Althusser 121). Similar to what Berger and Luckmann term “conceptual machinery," Althusser's ideological state apparatus politicizes this process as the means by which state structures transmit and replicate the ideology of the ruling class (Althusser 121). ${ }^{22}$ I bring together these two theories of ideological assent to suggest that the fairscape and novel are not merely social manifestations, but political articulations that acculturate their audiences to the white supremacist practices and policies of nation. ${ }^{23}$

\section{On Race Theory, "Spectacular Fictions," and the White Male Utopian Complex}

It is, of course, rather obvious to argue that a body of utopian works by white, middleclass, male authors would imagine a more ideal nation of the future that maintains the white supremacist ideology governing the present and past. However, little if any scholarship on the utopian novel offers a critical discussion of how whiteness informs these utopian imaginings. Yet, I would argue that through these utopian imaginings we can map how whiteness acts as a “conceptual machinery” that normalizes itself. These works, I suggest, acculturate readers to whiteness as the American identity_ultimately reinforcing a national ideology of white supremacy. And while scholarship on world's fairs has been much more attentive to the fair as a means of transmitting "scientific ideas about evolution, race and culture... from academic circles to the level of popular consumption," the literary fairscape, itself akin to a documentary utopian 
novel, remains largely undiscussed (Rydell 5). By bringing together these immersive and compelling spectacular fictions, I argue that we cast in relief a more pervasive pattern of thought that we might aptly term a white (male) utopian complex. ${ }^{24}$ As I will define it, this complex, which advanced implicitly and explicitly in future-thinking works ranging from literature to legislation, is the publically-shared cultural mythos that an insular, white national identity would ensure a scientifically- and socially-advanced American utopia in the future.

When we consider the extent to which racial identity politics define the nineteenthcentury generally, we find reason to reconsider the significance of race studies to our conception of utopian studies. For if the literary utopia is a fundamental reimagining of the nation and its identity through a close observation of the present, then the nation's increasingly racially-diverse population was a salient_-if silenced - part of this imagining. In other words, I am suggesting that literary utopias did not merely "turn a blind eye on the existence and value of racial diversity"; rather, their futurescapes (re)actively rejected it (Roemer 100). Yet little scholarship has interrogated the whiteness of the form or the racial composite of the utopian society imagined therein. In fact, when scholarship on the literary utopia occasionally points to "race" as a concern, the word "race" is typically (and problematically) used to signify non-whiteness. It is for this reason that we cannot overlook the significance of Looking Backwards's "faithful" and only "colored man" perishing in a fire in the nineteenth-century or why historicizing Griggs's Imperium in Imperio as the "only...pre-1900 American utopia...focused on African American" doesn't quite ring true, especially in an era marked by an increasingly-visual culture and an acute visual economy of race (Roemer "Paradise" 100).

For readers and fair-goers alike these "spectacular fictions" prioritized a white American future and acculturated a white supremacist ideology as the means of national progress, an 
ideology further systematized and literalized by the acutely-visual and didactic fairscape. Fairs, which by mid-century had enrapt the public imagination, were the most obvious spectacle of cultural and racial difference within the era. And, like the utopian novel, there were a means of "chang[ing] readers [or viewers] perceptions of what is factual" (Ahmad 6). More than that, they were a means of "disciplining" the public eye to understand the world in a nationalized way (Henning 1). Overseen and funded by the United States Congress, fairs commemorated significant events in the history of nationhood. From the Centennial International Exhibition's commemoration of American Independence in 1876 to the World's Columbian Exposition's commemoration of Columbus "discovery" of America in 1893, fairs sanctified and iconized narratives of the past, present, and future (see fig. 3). The international fairscape immersed a predominately white, middle- and working-class body of American readers and fairgoers in a didactic new world that exorcised their anxieties by replicating the ideology of the ruling class and imagining a white national identity fostered in perpetuity. ${ }^{25}$ The fairscape coursed them in official international narratives of progress and stagnation, encouraged cross-cultural comparisons that were explicitly hierarchized and racialized, and advanced an atemporal evolutionary mythos of advancing white cultures in juxtaposition to stagnating "primitive" cultures populated by persons of color. In other words, the very idea of "national progress became laced with scientific racism" through the overt and unquestioned racial engineering of white writers and organizers (Rydell 5). ${ }^{26}$

By bringing the fairscape into conversation with the literary utopia and the fair into dialogue with the utopianism of the era, we begin to recognize how and why nineteenth-century utopian thought enrapt and nationalized the white imagination. For in an era of anxiety about women's rights, class unrest, redoubling immigrants, and black citizenship, utopian conventions 
authorized—even naturalized—America's ability to take extreme measures to quell these anxieties so that it might ensure a more utopian future. By mid-century, the national conversation was preoccupied with characterizing, categorizing, and hierarchizing racial (which included the European immigrant body) and gender difference in legislation, culture, and education. And, for the working-and middle-class masses, the fair and its attendant fairscape were not merely a microcosm of the nation, they were a nationalized educational site for coursing nascent citizens in the taxonomies of racial prejudice and they promised a forthcoming utopian future should these fairgoers merely embrace the narrative and their roles within it. Is was a narrative of necessary sacrifice for a common good, a narrative of appropriate citizens, a narrative of racial hierarchy that would underwrite legislations prohibiting miscegenation and advancing eugenics. And it is from this vantage point that we might come to see nineteenth-century utopianism as an example of how race, in this case whiteness, is systemic. For race is not merely evidenced in ideology or cultural works, it is how our system operates, it forges the conceptual machinery from fairs to novels through which a system replicates and maintains itself. And, as contemporary theory helps us to understand, "white supremacy is itself a political system, a particular power structure of formal or informal rule" that privileged and benefited whites in the nineteenth century as it does today (Mills 3). From this vantage point, it is important that we discuss how the national narrative made use of utopian thought as well as the means by which the nation's utopian frameworks acculturate, nationalize, institutionalize one of the most spectacular fictions of all, that is, white supremacy itself.

\section{Mapping Spectacular Struggles}

Spectacular Struggles takes the first steps toward revising our historiography of the nineteenth-century American literary utopia. It argues that we can no longer overlook how the 
'race question' and an attendant anxiety to preserve whiteness play in a dominant and crucial role in how literary and cultural works imagine and American utopia. The first chapter traces the origins of what I term the "white (male) utopian complex" from the racialized nationalist rhetoric and ideology of More's Utopia to the white utopian frameworks of our national narratives and histories. From this critical framework, I turn to Edgar Allan Poe's quirky, yet poignant “Mellonta Tauta" (1850) and Hawthorne's The Blithedale Romance (1852), before centering on Edward Bellamy's oft-centralized Looking Backward (1889) to understand the rise of the white male utopian complex. I argue that despite Bellamy's apparently reform-minded criticism of nineteenth century society, he markedly defers to a conservative, heroic, and white representation of the past and the future. I further suggest that the trope of conservatism in the guise of reform speaks to the work's profound success among middle-class white readers in an era of national uncertainty about immigration, labor unrest, women's suffrage, and postReconstruction organizing among black Americans. I also argue that Bellamy’s nationalist vision of utopia draws aesthetically from the Centennial International Exhibition (1876), perhaps as a means of reinforcing a progressive impulse despite the text's ultimate conservatism. I complicate this trajectory of utopian studies and the pall of the white male utopian complex by looking to Sara Josepha Hale's Liberia; or Mr. Peyton's Experiments (1853), Annie Denton Cridge's radical and largely-overlooked Man's Rights; or, How Would You Like It? (1870), Louisa May Alcott's “At Forty” (1873) and, finally, Mark Twain's lesser discussed "The Curious Republic of Gondour" (1875) and often displaced A Connecticut Yankee in King Arthur's Court (1889) as they offer an alternative cultural history of the period. By comparing these two trajectories- the historiography that is and the one that could be-I conclude that the white utopian complex has 
helped to maintain representations of American identity as white identity for a national and international audience.

To further explore the cultural currency of the white utopian complex, chapter two turns to America's premier and most nationalistic fairscape, the World's Columbian Exposition (1893), and to its role in institutionalizing a neoclassical whiteness as the ideal aesthetic not merely for architecture or art, but for science and nation. I focus here on the fair's "White City" as a racialized personification of the "City Beautiful" movement in literature and architecture and suggest that these works wax eugenic in commenting on an ideal (white) citizenry and nation by extension. Arguing that the idea of the "city beautiful" developed as a direct response to the racialized immigrant slums well before the Columbian, I begin with Oliver Bell Bunce's "The City Beautiful" (1889) and the press to map the relationship between the racialized "immigrant question" and calls for urban reform. I then turn to William von Swartwout's The Beginning, A Romance of Chicago as it Might Be (1893) and William Dean Howells's "Letters of an Altruian Traveler" (1894), whose works offer accounts of the Columbian, to argue that these dominant, white-authored works point to the Columbian fairscape as the realization of the American utopia. I then turn to Ida B. Wells's and Frederick Douglass's The Reason Why the Colored American is Not in the World's Exposition (1893), as critical work of resistance to the fair's exclusion of black Americans and fallacious representation of the nation as a whole. Finally, I turn to Frances Harper's Iola Leroy (1893), a wryly metafictive utopian work, which I argue indicts patterns of systemic white supremacy and thereby wages a significant ideological challenge to the nation's dystopian reality for those of color. Through this juxtaposition I argue that while the fair helped to codify and nationalize a racial hierarchy for the masses as Wells and Douglass feared it would, it also signaled a growing, organizing body of black American resistance. Importantly, that 
resistance helped to establish a pattern of black intellectual thought targeting whites' proprietary claims on the nation and helps us to reframe the City Beautiful Movement as an anxious white reaction to this black resistance.

If chapter two reads the Columbian's "White City" as a passive-aggressive reassertion of white supremacy in the North, we might characterize chapter three as an aggressive reassertion of whites' claims over the South's history and future. This chapter focuses on long overlooked utopias set in the South or written by Southerners precisely because they, like the fairs held therein, aggressively and openly reassert whites' proprietary claims over the South's history and its future. These oft-excluded white supremacist utopias not only serve to highlight an inherent anxiety to advance a more militant Anglo-Saxon national identity within the canonical nineteenth-century utopia as well, but inform a Southern fairscape that sentimentally rewrites the Old South by forcibly whitewashing the New. However, this chapter also focuses on the Cotton States and International Exposition held in Atlanta in 1895 as a momentary site of progress as it welcomed the first "Negro Building," I quickly refocus on how the fair's enduring legacy as Booker T. Washington's now-infamous “Atlanta Compromise Speech” ultimately bolstered white supremacy. I argue here that the South and control of the region's history became a focal point in white-authored, spectacular fictions in the wake of an increasingly-legislated black resistance to white supremacist practice and violence. ${ }^{27}$ A developing black infrastructure in the South not only enabled African Americans to orchestrate Homer v. Plessy (1896) as a litmus test of black liberties, but inspired Sutton E. Griggs's to imagine a militant, territorial black resistance to a white regime in Imperium in Imperio (1899). In contrast to Griggs's work and the tale of Plessy's attempt to challenge the inequities of segregation, I look at W.H. Bishop's The Garden of Eden USA, A Very Possible Story (1895), Benjamin Rush Davenport's Uncle Sam 's 
Cabins (1895), and Frank Purdy Williams's Hallie Marshall, True Daughter of the South (1900). With these works at the fore, the chapter maps a trajectory of white anxiety over black political and social gains, from Lost Cause Sentimentality to another incarnation of the Ku Klux Klan. This exploration, I conclude, reveals yet another significant and problematically-unexplored path in the historiography of the nineteenth-century utopia's anxious relationship to whiteness.

In contrast to the previous chapter, chapter four focuses exclusively on black spectacular fictions as they collectively reimagine an American past, present, and future that black American play an integral role in shaping. As a body, these works are as much philosophical as historical; they grapple with the white narratives of history, science, and nation to careful recovery and reframe an absent black-authored past. I argue that this shift in perspective is guided in no small measure by W.E.B. Du Bois's growing prominence in the movement for equal rights. From his criticisms of Washington's approach, to his unparalleled sociological study of black Americans, to his publication of The Souls of Black Folks (1903), a critical study of both blackness and whiteness, his work informs the black intellectualism in the black spectacular works of the early twentieth century. Importantly, Du Bois also recognized the importance of world's fairs in advancing a black-determined history and narrative of black Americans, leading him to help curator T.J. Calloway organize the award-winning "The Exhibit of American Negroes" at the Exposition Universelle in Paris in 1900. Against this rich recovery of black history and reframing of the past and present, I discuss the metafictive impulses in Pauline Hopkins's Of One Blood (1903), E.A. Johnson's Light Ahead for the Negro (1904), and Lillian Jones Horace's Five Generations Hence (1916) as they recast the utopian form as a critical study of whiteness. Guided by Calloway's assertion that fairs were a means to offer "substantial proof" of black advancement to a wide audience, I turn to the black-organized National Half-Century 
Anniversary Exposition and the Lincoln Jubilee held in 1915 Chicago, arguing, too that it rhetorically carves out a space for black Americans in the memory of the White City. I conclude that by recovering these works we begin to redress the vexed exclusion of black utopianism from our historiography of the nineteenth century utopia as well as our problematic reluctance to discuss how race—white and black—has long shaped utopian thought.

There is something hopeful in every spectacular fiction, yet that hope, as More long ago recognized, is rarely extricable from the anxiety fostering it. For the white male spectacular fictions of this period, that hopefulness resides in the belief that the American present prefigures a forthcoming - and white - utopian era. And although this seems a rather obvious observation, it's one that remains undiscussed in contemporary utopian scholarship's avoidance of "the negro question." It is with a meditation on our avoidance of questions of race — and their profound effect on our understanding of literary history—that Spectacular Struggles begins and ends. 


\section{Chapter 1: "A Favoring Providence, Calling Our Institutions into Being": Re/Historicizing the White Utopian Complex in Nineteenth Century America}

It is the object of the present work to explain how... the fortunes of a nation are not under the control of blind destiny... [of how a] favoring Providence, calling our institutions into being, has conducted the country to its present happiness and glory.

-George Bancroft, A History of the United States, Volume 1

For the nineteenth-century reader, George Bancroft's work popularized the idea of America as a new Eden "call[ed]...into being" by a divine hand, a rhetoric that influenced the writing and perception of national and cultural history for decades thereafter. Bancroft, a household name among middle-class black and white society, is widely considered the "master historian of the last five decades of the 1800s" and his authoritative and best-selling History of the United States of America, From the Discovery of the American Continent grew to ten volumes and was published in countless editions from 1834 to 1888 (Billias 508). ${ }^{28}$ His Providential rhetoric of a white utopian American utopia as preordained quite literally devised a utopian framework for conceiving of the nation's past, present, and future. And, as I will argue here, this framework profoundly shaped the national imaginary as well as the reimagining of the nation in literary and cultural utopias.

But Bancroft's work was far from unprecedented. Its rhetoric grew from a long history of envisioning the "New World" as utopia, one tied to the sui generis literary utopia itself, Sir Thomas More's Utopia (1516). By drawing from the journals of Amerigo Vespucci and Christopher Columbus, More explicitly connects the New World to his blueprint for a utopian nation, a blueprint that would also come to map the formal conventions of a literary genre. Wedding the ideological with the formal, Utopia inspired works thereafter to mimic its interrogation of national policies and governance through the imagining of a more ideal nation elsewhere arranged otherwise. And participating in the growing discourse of imperialism, 
More's island of Utopia was not merely the blueprint for a nation, but for a nation-state. Although predicated on the ideals of egalitarianism, national education, and elected representation, Utopia also viewed racial and cultural homogeneity as necessary to sovereignty and used natural law to justify the enslavement or exclusion of the "other." Central to the formation of More's utopia, I argue that this notion of exclusionary sovereignty helps to forge an unexplored racial convention in both America's founding texts and the literary utopia thereafter.

In this chapter, I sketch the rhetorical development of the exclusionary and white utopian framework that undergirds utopian thought in nineteenth century America. Beginning with More's Utopia, which I argue ideologically and formally melds the sovereignty of a nation-state with racial exclusion and enslavement, I move to touchstone texts that advance a similar ideology within the national narrative. From the nation's founding texts, to Bancroft's History, to our literary and cultural visions of an American utopia, I argue that white supremacy and the preservation of whiteness are central themes in nineteenth century utopian form long-excluded from discussion. For this reason, I maintain that it is imperative that we look to the way in which More's Utopia. Although imperialism had long advanced a racial hierarchy that would inform America's national narrative, More's Utopia develops alongside the very idea of the nation-state and ultimately gives form to both a political concept and a literary genre. As one scholar has usefully put it, “More's Utopia helps to usher in the conceptual framework or representation of...'nationness' within which the particularity of each individual nation can then be represented," particularities such as egalitarianism and education, but also racial homogeneity and enslavement (Wegner 55). While scholarship has noted the spike in an order-minded genre amid the tumult of the late nineteenth century as unsurprising, little, if any, scholarship points to a link between the era's racial anxiety and the whiteness of the future these works imagined, 
works, I argue, that range from Bancroft's history to the Centennial Exposition of 1876 to Edward Bellamy's Looking Backward.

Yet, there were also works that highlighted, even questioned the white anxiety central to the century's framing of the nation's history and imagining of utopia. But these metacritical utopian narratives, such as Edgar Allan Poe's “Mellonta Tautua" (1849) and Nathaniel Hawthorne's The Blithedale Romance (1852), are also largely overlooked in our modern historiography, arguably because of their cynical use of the utopian form. Arguing that these skeptical works offer a metacritical approach for analyzing the late-century utopian form, I juxtapose them to Edward Bellamy's wildly-popular Looking Backward. For Bellamy's work, which inspired "over one hundred and twenty" utopian novels, has long guided the canon formation and our historiography of the period (Pfaelzer 50). With these skeptical works in mind as a critical frame, I ask specifically: what is it about Edward Bellamy's work that accounts for its popularity?

In the final section of this chapter, I attempt to complicate utopian studies' Bellamycentered historiography. I argue that by situating Poe's and Hawthorne's skeptical utopias as an alternative starting point for our historiography we highlight the centrality of white male anxiety to Bellamy's work and can also recover the excluded works of several well-known women writers. Works like Sara Josepha Hale's Liberia; or Mr. Peyton's Experiments (1853), Mark Twain's lesser discussed “The Curious Republic of Gondour" (1875) and often displaced $A$ Connecticut Yankee in King Arthur's Court (1889), Louisa May Alcott's “Transcendental Wild Oats" (1873) and Work: A Story of Experience (1873), as well as Annie Denton Cridge's radical and largely-overlooked Man's Rights; or, How Would You Like It? (1870) predate Bellamy's novel and also record a critical and metafictive strain of utopian fiction excluded from our 
historiography. When read in juxtaposition to Looking Backward, these works highlight the way in which white, male, middle-class identity politics limit Bellamy's imagined utopia. It is no wonder, then, that such a tack become central in the works of women, and, as I will argue in subsequent chapters, in the works of writers of color. Here I conclude that by turning to an intersectional and "palimpsestic... practice" of re-reading our cultural history we can forge a new historiography of the nineteenth-century utopian form — one that remains continually open to revision as we continue to recover the traces of our past (Levine 244).

\section{Bancroftian Design, More's Utopia, and the National Imaginary}

As the definitive "pre-history" of the nation for the duration of the nineteenth century, George Bancroft's History of the United States of America, From the Discovery of the American Continent influenced nineteenth-century readers' and writers' rhetorical understanding of the "New World." Although even in Bancroft's era some balked at his rhetoric of national origin, of an Anglo-Saxon nation having been "called" into being by a divine Providence, for many the notion was compelling. And for these supporters, Bancroft's rhetoric not only naturalized America's whiteness, it also justified the displacement, enslavement, and even occasional slaughter of the indigenous peoples who lived there as necessary to the preservation of God's will. Bancroft even imagines his own work "naturally arrange[d] itself” from the period's "perfect unity and completeness," as though his narrative of nation were the work of a divine guiding hand (1:iii, emphasis added). Although many of America's founders-Thomas Jefferson, for example — believed that "structure in nature...might aid them in constituting the nation," Bancroft's work literalizes the relationship between the natural world and the political

order (Looby 255). Bancroft suggests that divine law, as the architect of natural law, established the political order of the nation, which rendered America's Providential design—and its 
whiteness - a "historic truth" (qtd in Ernest 7). For Bancroft the narrative of a "favoring Providence, calling our institutions into being" was not a mere metaphor or Edenic allusion, it was a fact of history and of science, as he perceived his “"comparison of document with document" to be a scientific "“analysis of facts" (1:3, 1:iii). ${ }^{29}$ Through his errant logics confusing belief with fact, Bancroft understood his work as irrefutably demonstrating “" the superintending providence of God"' in organizing American affairs, a belief advanced to a wide nineteenth century readership that included utopists like Bellamy (qtd in Ernest 7). Suggesting the perception of the works didactic value for its readers, by 1885 an abridged version of this argument appeared in History of the Colonization of the United States, which was organized as a type of textbook. Each section ended with a series of questions to check comprehension, questions written using Bancroft's own phrasing to overtly lead readers to the "correct" answers and reinforce Bancroft's interpretation of history, such as: "What decided the home of the black man in the new world?" and "Who was selected by God to give an impulse to human affairs?" While the leading phrasing directs readers to retell the story they've just read, the scope of the question is designed to reinforce Bancroft's white Providential worldview. In answer to the first question, readers are prompted to recall that "the physical constitution of the negro decided his home" in the South and that "Providence entrusted his guardianship" to whites, while the second question directs readers to answer Anglo-Saxons. Indeed, in the romantic concluding chapter of History of the United States, which he recasts in Colonization, Bancroft explicitly resolves that "the Caucasian was in nearly exclusive possession of the elements of civilization" and that Anglo-Saxons were "the hope of the new world" (1:612). And he not only naturalizes the civility of whiteness, but the savagery of nonwhites. For he argues that the "Ethiopian" and the Native American "remained in insulated barbarism" and further fosters the mythos of the red man's 
"few scattered tribes" disappearing into obsolescence and of the black man's elevation through enslavement (Bancroft 1:4, 1:612). In this way, while Bancroft nods to the racial rhetoric of the Jacksonian Democracy many critics agree greatly influenced his work, he also confirms the popularity of a rhetoric of white nationalism among nineteenth century readers.

But Bancroft's rhetoric of divine providence and its tacit dependence on racializing the nation was hardly unique to the Jacksonian Era. In fact, we find a similar iteration in Thomas More's Utopia (1516), the work that defined the utopian genre and the first to formally imagine America as a utopia. Although far from the only philosophical work informing the founders' notions of a more-ideal nation, it's important to note that James Madison and Thomas Jefferson had read Utopia, classified it as work of political theory, and included it on the list of texts for the first Library of Congress, a list read to Congress in January 1883. Significant, too, is that the founders' believed such a library was necessary to offer guidance in making informed decision at a formative time in the history of the nascent republic. ${ }^{30}$ Seen as a political work and in conversation at a pivotal time, we must consider that both the egalitarianism and racial restriction of More's Utopia were part of the utopian rhetorical frameworks informing the formation of American identity in both narrative and nation. In this way, we cannot overlook the potential influence of More's utopia over the "impulse" and "programs" taking shape as the founders constituted the nation. Indeed, the documents and practices of the new nation bear some "lines of descendency" in their conception of the nation-state traceable to "More's inaugural text" (Jameson 3). It is important to consider, for example, that More's work offered philosophical justification and formal conception for the necessity of a racially homogenous citizenship as well as the use of natural law as a basis for structuring political practice (Jameson 3). 
Notably, More's text may have offered the founders a philosophical blueprint for the relationship between an exclusionary nation-state and its sovereignty. For More's ideal nationstate, predicated on egalitarianism and education was still be justifiably racialized and classed through natural law, a justification the nascent America, too, used to determine enfranchisement and citizenship. Indeed, More's Utopia may have imagined a commonwealth of elected representatives as the antithesis of the English and European monarchies, but that freedom did not extend to all. From its inception, as traveler Ralph Hythloday explains, Utopia was rooted in subjection and exclusion. Mirroring Columbus's conquest of the new world, once Utopus conquered the "rude and uncivilised (sic)," given their "slavish disposition to obey" he "subdued" them through a mixture of enslavement and trickery "designed to separate them from the continent, and bring the sea quite round" (More 43-44). Here, More nearly echoes Columbus, who boasted he would make slaves of the Caribbean natives since they could "be subjugated and made to do what is required of them" (14 October 1492). While both gesture to an Aristotelean pre-disposition to enslavement, More's characterization hints at the early linking of rudeness and in/civility with skin color, to an emerging system of colorism. But significantly, More moves beyond Columbus's establishment of a colony to comment on the governance of a nation-state. Utopia may have begun with the forcible captivity, assimilation, or expulsion of natives, but it continued to write assimilation and captivity into the narrative of the nation-state. Utopia advanced the argument that the "domination of inferior by superior was considered a natural condition" necessary to preserving the good of the commonwealth (Goldberg 25). It provided for the subjugation of those from neighboring nations as well as the disenfranchisement and enslavement of its own inferior countrymen who could not be educated into accord with the society's ideals. In the history of the early republic, as early as May of 1776 John Adams 
forcefully argues against expanding the franchise as a means of preserving the commonwealth by way of natural law. He implies that those of the lower class, women, and the young "have[n't] any Judgment of their own" and that giving "every man who has not a farthing... an equal voice with any other" would "prostrate all ranks to one common level" (Adams). Similar interpretations of natural law allowed the founders to envision the rule of landed white-men as necessary to the sovereignty of the nation, as in the $3 / 5$ ths clause in the U.S. Constitution, which resolved with certainly that blacks were not fit for citizenship, and the 1790 Naturalization Act, which limited citizenship to "free white person[s]" and officially legislated a white America. Yet, by mapping Utopia alongside the early republic I do not mean to suggest a direct correlation between the two. Rather, I want to suggest that from one of the earliest conceptualizations of the nation-state in from More's Utopia to the utopian frameworks of the founding narratives of nation, nineteenth-century readers' - and utopists' — ideas of both America and the utopian form were built on a rhetoric of natural law and exclusion.

\section{From Ideological Narrative to Physical Nation: Exhibiting Utopia}

To this point, I have examined several salient ideological narratives of the nation that I suggest influence the rhetoric and racial character of the late nineteenth-century utopia. I have argued that they conceive of both America and utopia as racially-restrictive spaces from the start, a restriction that manifests - though remains undiscussed - in these later utopias. But the nation was not merely being organized as an ideological experiment or through a series of documents, it was being built in brick and mortar. ${ }^{31}$ And it was ostensibly an exhibition of the utopian nationstate on the world stage. In this section, I turn to exhibition scholar Tony Bennett's notion of the "exhibitionary complex," to form the term "white utopian complex," which I use to characterize

this co-emergence of a physical and ideological structures of an ideal America (73). ${ }^{32}$ Mirroring 
Bennet's focus on the physical and ideological, I suggest that the original physical structures of the nation, from the White House to the Capitol to Peale's American Museum, emerge as a "set of educative and civilizing agencies" with a distinctly utopian character. I argue that these physical sites reinforce the restrictive rhetoric of the national narrative and write an exclusionary "ordering [of] objects for public inspection into an ordering of the public that inspected" into visual representations of the nation long after $(79,74)$.

The nation's early architecture was fundamentally a visual exhibition of an idealized national identity. It was consciously selected to represent the ideology of the nation and, as such, coursed its citizenry in the visual logics of utopia. Suggesting the importance the founders placed upon the nation's architecture, it held open competitions seeking the best designs for both the White House and the United States Capitol Building, buildings that would symbolize the ideology of the nation. Significantly, the works that were chosen were grand, neoclassical palaces visually heralding the coming of a new Rome, giving image to "the citty on the hill." And given the way in which visual preferences would fall in line with racial hierarchy, it hardly seems coincidental that two years after first defining its citizenry as white the nation would whitewash both buildings and even dub one the White House. ${ }^{33}$ However, it is perhaps the history of America's first public museum that best exemplifies the convergence of physical and ideological representations of an ideal nation. Formed at the urging of Thomas Jefferson and Benjamin Franklin and founded by Charles Willson Peale within a decade of the American Revolution, the nation's first museum soon came to be called Peale's American Museum. ${ }^{34}$ Although ostensibly a museum of natural history, it also reflected a national ideation of social order and decorum well beyond the sciences, impressing upon patrons a "natural" and nationalized hierarchy of gender, class, and race. ${ }^{35}$ For as one exhibition theorist aptly explains, 
"science displays are never, and have never been, just representations of uncontestable facts" to the contrary, "they always ... have cultural, social, and political implications" (MacDonald 1). From this vantage point, the museum's 1802 relocation to Independence Hall is a markedly significant extension of state authority to the museum's content and arrangement. By the time of its relocation, Peale had begun to envision itself as "a moral and educational center for the entire nation" while the press had come to present it in utopian terms as "the pride of our country" (Miller 2.1: 11, 1 January 1824).

Recognizing how exhibitionary sites could be harnessed to advance knowledge and an ideal narrative and image of nation, affiliate museums operated by Peale's sons soon opened in New York and Baltimore. ${ }^{36}$ Shortly thereafter, state fairs began to contribute to the visual discourse of national identity. And by 1850, at least one self-proclaimed nationalist publication, The Scientific American, would openly acknowledge the use of such exhibitionary sites for the transmission of an authorized national narrative for an international audience. Indeed, three years in advance of America's first international fair and a year prior to London's Great Exhibition of 1851, the publication conjectured that an exhibition could prove America had become "a great empire...as noble and grand as any other nation" and show the nation was a veritable utopia "far in advance of every other" (9 Mar 1850, emphasis added). And when the nation's first official world's fair opened in 1853, the rhetoric of this Exhibition of the Industry of All Nations reinforced these earlier utopian superlatives in both narrative and display. For New York's Crystal Palace, build to rival London's at the Great Exhibition of 1850, proclaimed the nation's regality and positioned the fairscape to advance the visual rhetoric of a utopian nationalism that began with the very first buildings of state. ${ }^{37}$

\section{Skepticism in the Mid-Nineteenth Century}


In the previous sections, I have mapped some of the ways in which the documents and structures of nation naturalize a white utopian complex for nineteenth-century Americans, a complex most readily informed in the nineteenth century by Bancroft's rhetoric of providential design. Here, I want to cast in relief Bancroft's detractors, significantly starting with Edgar Allan Poe, whose work helps to usher in an intellectual skepticism that inherently targeted Bancroft's faulty logics of a verifiable “superintending Providence.” Further, I suggest that within Poe's "Mellonta Tauta" specifically we find the roots of a critical utopian tradition overlooked by the modern historiography of the nineteenth-century literary utopia and its canon.

Although as a historian and public figure Bancroft maintained significant popularity throughout the nineteenth century, his detractors and their works were plentiful. In fact, from $A$ History's initial publication, many "had no trouble reading the Jacksonian democrat's biases" in either historiography or design, particularly in an emerging culture of intellectual skepticism that would "accompany, rather than oppose, the growing authority of science" and reject the religious teleology of Bancroft's history (Ernest 7, Lee 13). For, as Maurice Lee usefully explains through Poe's ratiocinative tales in Uncertain Chances (2012), by the mid-nineteenth century a “probabilistic revolution" gave rise to a worldview that challenged definitive supernatural pronouncements such as Bancroft's “transference of belief in divine Providence...to historical method" (Lee 4, Ernest 8). As Lee observes, "the psychological and supernatural possibilities of the Gothic" as well as "the unbounded subjectivism of romanticism, and the epistemological and moral quandaries that roil the literature of slavery and race" all "undermine" the naïve optimism and universalism of "Enlightenment reason" guiding Bancroft's work (10). At the same time, Lee notes that "cultural pluralisms" and "the ever-accelerating pace of economic and technological change...drive nineteenth-century literary skepticism" to a "crisis of skepticism 
and belief," one that I suggest is recorded in several mid-century literary utopias self-consciously critical of the utopian form (Lee 10, 13).

Importantly, Poe's "Eureka," to which Lee directs our attention as a primary iteration of this crisis of skepticism and belief, may also implicate Bancroft's work. For Poe openly identifies the work as "challeng[ing] the conclusions, and ... question[ing] the sagacity, of many of the greatest and most justly reverenced of men," among whom we might include Bancroft and his errant notion of providential design (1268). Significant for my own work, parts of "Eureka" are reproduced verbatim in Poe's utopian tale "Mellonta Tauta" to which I suggest we might tentatively trace a metacritial strain of literary utopianism. In "Eureka," Poe differentiates between belief and faith, implicating Bancroft's wild imaginings near-scientifically verifiable superintending Providence. For Poe, when we claim to "believe in a God...our belief, in such cases, is more properly designated as faith" while faith "is a matter quite distinct from that belief proper-from that intellectual belief — which presupposes mental conception" (1274-5, emphasis added). As Poe argues, belief is a form of intellectual work toward knowing, an idea that foregrounds a human-centered epistemology rooted in observable fact, one that recognizes the “infinite" as a fundamental uncertainty, and, as such, a matter of faith $(1276,1275)$. Poe balks at the notion that we could "comprehend God" in the way that Bancroft claims (1276). In this way, we might read Poe's criticism as targeting directly his claims to have methodologically proven the nation's divine ordination (Lee 7). From this vantage point, it is little wonder why intellectual skeptics might find flaw with Bancroft's divine rhetoric. When one believes one's work is ordained by God, there is no room for questioning; error would be, by design, impossible. And, as Lee wryly reminds us, to a growing lot of American skeptics, Bancroft's "taming" of chance 
by claiming to have empirically proven the nation's divine ordination would have seemed "a science fiction" (Lee 7).

While Lee may not have intended to invoke science fiction and its utopian kin as a genre of writing per se, he nevertheless gestures toward how the anxiety of chance may drive one to utopian thought, a philosophical partnering traceable to More's work. For utopia, as a literary genre, offers a way tame the chance — and its attendant anxiety—by allowing one to pre-write the future. And, as I will suggest, the canonical utopia, typically written by white, middle-age, middle-class men, is best read as an extension of the "social system of which it is a part," rooted in that identity politics (Jameson xv). However, utopian studies often focuses on the ideas of these works as though they are free from identity or self-interest, as though they are free from a voluble white male anxiety about the chance that their America will be overpowered by immigrants, or blacks, or women, and as though they don't harbor a salient fear of this possibility. To that end, I argue that within Poe's skeptical work we may also find a metacritical meditation on the utopian form, one that renders visible another possible historiography of the literary utopia that foregrounds the white utopist's anxiety about the 'chance' for change.

To understand how we might read Poe's "Mellonta Tauta" as a skeptical metacriticism of the utopian form, we must first understand Poe's skepticism of romantic literary inventions, inventions that Bancroft used as well. In fact, Poe may have openly criticized Bancroft's History for its distortive use of such literary convention. ${ }^{38}$ In 1835, a review of Bancroft's A History questionably attributed to Poe appeared in the Southern Literary Messenger. Among other criticisms, the review lamented the loss of "plain story" histories like Hume's and scathingly criticized Bancroft's tone as that of a "'moonish youth" given to whims of fancy that led him to "error" and "misrepresent[ation]" (June 1835). In other words, the review impugned Bancroft's 
divine ordination by metacritically targeting the manner in which the story was told, aligning Bancroft's romantic rhetoric with historical misrepresentation. However, it is probably black abolitionist William J. Watkins who best underscores the problems of Bancroft's style for a recitation of fact. After hearing an 1854 oration wherein Bancroft pronounces that "'our country is bound to allure the world to liberty by the beauty of its example,'” Watkins cannot help but wonder: "Where has Mr. Bancroft been living" (qtd in Ernest 8)? In sheer incredulity Watkins marvels at how Bancroft "with all his wisdom and erudition"” can imagine the nation as a bastion of liberty when its economy is rooted in slavery, in a system of "“"oppression, aptly characterized as the vilest that ever saw the sun"' (qtd in Ernest 8). What I am suggesting here is that the manner in which Poe and Watkins disagree with Bancroft's work is important; it reinforces the growing conflict between a romanticized faith (mistaken as intellectual belief) and empirical fact. They do not merely question the veracity of Bancroft's work, they raise skeptical brows to the method of his telling, to a romantic discourse errantly casting a rosy ideal as the nation's reality, to casting a matter of faith as a fact of history.

We also cannot dismiss intellectual skepticism as a niche market. If we look to the popularity of the "hoax" or "humbug" in Poe's work or to P.T. Barnum's newly-formed American Museum, which welcomed more than 38 million white museum-goers between 1841 and 1865 , skepticism seems a new norm. ${ }^{39}$ At nearly the same time Bancroft was offering a keynote address on the "Patriot Farmers of New York" at the 1844 State Fair earnestly and romantically declaring those farmers "the glory of the world," P.T. Barnum was declaring himself the "Prince of Humbugs" to swarming crowds (Bancroft in Blake 52, emphasis added). And this juxtaposition, which typifies the era's tension between belief and skepticism, may be best exemplified at Barnum's museum itself. Not only was it at the physical crossroads of 
Broadway's respectability and The Bowery's coarseness, but it was at the intellectual crossroads of exhibition and exhibitionism, history and hoax. Finding an emerging white middle class as eager for entertainment as edification, Barnum juxtaposed hoaxes, like the popularly-recalled "To the Egress," with educational displays drawn from Peale's recently-closed museum. ${ }^{40}$ But Barnum's museum also recognized and reinforced certain facts thought beyond skepticism, such as a white cultural and racial hierarchy, for he refused African Americans admission until the 1860s and included a variety of "racialist displays" that "routinely elicited white ridicule for routinely dehumanized African Americans" (Looby 253, Harrison 27). ${ }^{41}$ Indeed, displays that confidently asserted a white national order beyond question were housed alongside deceptive hoaxes sometimes reinforcing the same, as in Barnum's hoax exhibit of George Washington's enslaved wet-nurse Joice Heth. ${ }^{42}$ In these ways, the museum's tension between entertainment and education, between hoax and history enacted for patrons a metacritical microcosm of modernity's own contemporary drama of belief and skepticism, reinforcing the increasing visibility of such tensions within mid-century culture.

\section{Skepticism and a Utopian Counter-canon}

From this visible and popular crisis of skepticism and belief in our culture, I approach Edgar Allan Poe's "Mellonta Tauta" and Nathaniel Hawthorne's The Blithedale Romance. As I will argue, both of these utopian works seem to fall outside the current historiography of utopian literature precisely because they engage with this rising tide of skepticism and challenge the naturalized and systemic white male supremacy of the utopian form. In this way, their works may also be read as challenging a Bancroftian nationalism, for the authors, who were contemporaries of Bancroft and certainly knew his work, recite a much more critical history of America ${ }^{43}$ Significantly, their skepticism also waxes metacritical and meditates on the 
limitations of the utopian form. With this in mind, I argue that Poe's and Hawthorne's skeptical engagement with the utopian form, overlooked in our historiography, generates a path of inquiry for assessing the falling away of this skepticism in the century's later utopian works, which, arguably, re-embrace a romantic Bancroftian rhetoric as a panacea for the labor tumult and racial uncertainty in fin de siècle America.

Set a millennium in the future, Poe's utopian "Mellonta Tauta," which translates to the prescient pronouncement: "these things belong to the future," is a cautionary satirical utopia that criticizes the effects of Bancroft's beloved Jacksonian Democracy on national history in the future. Told through the "long gossiping letter" of Pundita, the wife of an antiquarian studying the history and artifacts of an America whose national narrative has been long forgotten, the action of the narrative occurs during an airship journey over Paradise (what remains of America), which is now governed by an Emperor. Amid a passel of ridiculous inferences made about America's history (from its ancient Knickerbockers to its churches of Wealth and Fashion) and risible phonetic misnomers of notable surnames (Neuclid, Cant, Aries Tottle), there is not only a grating jibe about women's impertinence and ineptness (likely a dig at both his audience in Godey's Lady's Book and response to the Seneca Falls Convention which occurred in the year the tale was written), but a "vivid effect" lurking in the margins, that is, the quiet terror about how such a world came into being (Poe 883, 874, 1373). Beneath the farcical nature of the narrative lies a spate of anxiety-inducing incidents that compel the century's "participatory reader" to contemplate further the threat of its farce and, as with any utopia, its relationship to the present (Roemer, Utopian Audiences 84).

Poe's well-known focus on his works' effect on readers, which he outlines in “The Philosophy of Composition" (1846) is reinforced here by the participatory contrivances of the 
utopian genre. For nineteenth-century readers, books had "transformative powers," an effect only partly explained by the lack century's lack of other entertainment or means of edification (Roemer, Utopian Audiences 84). But the interlocutory utopian form, with its conventional confessional style, often transformed readers in more significant ways by implying an interpretive and participatory reader (Roemer, Utopian 125). Like many utopias, "Mellonta Tauta's" call for participation begins with Poe's preface. From the preface's feigned authentication of the story (which tacitly calls for a skeptical reader), Poe encourages further participation through his humorous contrivance of famous historical surnames in need of decoding and mistaken tales of well-known history that demand deciphering. However, I would also argue that by disorienting readers in this way, Poe interpellates a skeptical reader and nearly metafictively highlights the significance of the reader's participatory role. For Poe's story can only proceed through readers' engaged recollection of a corrective history through which they can interpret the erroneous history he offers them, an effect largely measurable by readers' laughter. Indeed, the narrative's humor operates precisely because the reader debunks the tale's history. In this way, Poe's use of utopian convention demands that readers confront how stories are told and interpreted, a metacritical turn that may also highlight Poe's skepticism of the utopian form.

As a magazine editor and avid reader, Poe's works often openly and critically engage with their cultural moment. In "Mellonta Tauta," for example, I would argue that Poe confronts immigration (Chinese), race and class anxieties, and the romantic rhetoric of burgeoning utopian communities (Oneida and Icaria were founded in the late 1840s) with a bitterly-satirical negative utopia. With this in mind, "Mellonta Tauta's" displacement to a negative utopian future might be read as a criticism of the utopian form's escapist tendencies, which displaces the threat of the 
present by idealizing an anticipated future. Poe positions the nation's “voracious appetite for cheap labor" heralding immigration and the advancement of universal suffrage as the cause of the nation's destruction and the nightmarish history he tells (Jacobson 41). From the very start of the narrative America is a relic and its "Amriccans" are a long-forgotten civilization, which Poe further distances by rendering protagonist Pundita's "present" narrative/manuscript is an artifact as well. However, even more unsettling than the loss of American culture for nineteenth-century readers, may be the suggestion of its replacement with a non-white civilization, an idea planted by Poe's introductory note. There readers learn that the Mare Tenebrarum, where the manuscript was found, was charted by an African (Nubian) geographer. In other words, Poe immediately shifts the tale's racial hierarchy by literally suggesting Africans now define the world, a shift that presages the racialized threat of immigrants/migrants in the tale itself. When we meet Pundita, she is "cooped up in a dirty balloon" filled with "two hundred canaille (sic)" and surrounded by boats of more travelers below, images that evoke a persistent threat of encroachment by other classes and races (Poe 871). Emphasizing the precariousness of her position, we soon learn that the "shamefully crowded" boats below refuse to "permi[t] on board again" a man whom Pundita's craft "knocked...overboard," suggesting not only their degree of overcrowding, but perhaps a struggle for survival. However, what is most threatening is the tale's indeterminate conclusion amid the perilous collapse of Pundita's balloon which causes her to "tumble into the sea" $(873,872,884-5)$. In this way, Poe's unresolved ending formally highlights the immediacy of white anxieties borne of race and class struggles, tacitly criticizing the utopian form's typical displacement to an assured future. In other words, Poe seems intent on redirect readers' gaze to the present. For the tale's overcrowded boats and airship gesture to his readers' own sense of America's harbors soon to be flooded with "'the most degenerate races of olden day Europe,"” as 
Arthur Comte de Gobineau would put it a few years later in The Inequality of the Human Races (1855) (qtd in Jacobson 44). Likewise, the appelation "Amriccan" and the fact than an Emperor, who like More's Utopus carved this island from a larger nation, now reigns over the former nation suggests the imperial success of the Far East. This scattershot approach highlights Poe's xenophobia and, in thematically gesturing to More, implicates the utopian form as waging a "threat to democratic institutions," despite its being a "stupid institution" in Poe's estimation (qtd in Jacobson 44, 43; Lee "Absolute Poe" 757).

Poe's overt preoccupation with the relationship between race and genre in "Mellonta Tauta," also serves to highlight later utopian works' apparent silence about the 'race question. ${ }^{44}$ In fact, I would argue that "Mellonta Tauta's" skeptical impulse and refusal of a cathartic conclusion casts in relief the white escapism of later utopian works — and scholarship's oversight of it. Indeed, scholarship rarely comments on the racialization of the scenes compelling the action of Bellamy's Looking Backward, for Julian West's future is distinctly an escape from striking immigrant laborers and his "faithful colored man" is left to perish in the past. By contrast, Poe uses the utopian form to highlight the encroachment of race and class as pathways to America's lost future. For in Poe's logic, the call for "universal suffrage," labor reform, immigration, utopian communities, and abolition all advance a utopian impulse that enables a formerly-elite white America to succumb to "Mob (a foreigner, by-the-by)" and "degenerate into brown" (Poe 880, 873, qtd. in Jacobson 1). Poe's tale also suggests that this degeneration is amplified by those like Bancroft who distort and recast history through romantic interpretation, as in a game of telephone ever distorting the original fact. Concluding with a well-known history, that of Lord Cornwallis's surrender to George Washington at Yorktown, Poe points to the way in which retellings can augment interpretation to the point of absurd fiction. As gleaned 
from the cornerstone of a monument dedicated to George Washington, Pundita's antiquarian husband Pundit, who translates the inscription misinterprets every facet of his discovery. He not only believes the cornerstone is a replacement for "actual monuments [that] had fallen into disuse," but that it commemorates the surrender of a "wealthy dealer in corn" to Washington and his "savages," who "were undoubtedly cannibals" (884). Although on the surface laughably absurd, the mistaken history unsettlingly casts the founders as "savages" and "cannibals." More than that, it metacritically casts suspicion over history as a discipline by raising the question of how easily a story may be bent to the whims of the teller. At the core of Poe's short, satiric, forgotten utopia lies the nearly-panicked question: and what will become of us? What will become of us when, as his titles asserts in translation, "these things belong to the future"? However, let us be clear that Poe's "us" would be quite narrow, as his anxious nativism suggests he is really asking: what will become of the white American man when his stories of the past, governance of the present, and plans for the future spiral, like an airship, out of his control? By comparison to the anxious temporal displacement of later white male canonical works to an ideal (white) future, Poe highlights the silent terror at their margins: the racial identity of the nation's future when confronted by a perilous present of defiling denizens. Read in this way, I would suggest that Poe's "Mellonta Tauta" is a negative utopia, a utopia that, as Frederic Jameson explains, "serve[s] the negative purpose of making us more aware of our mental and ideological imprisonment" and also turns a skeptical eye on the utopian form itself (xiii, emphasis added). And it is far from the only one.

Like Poe's "Mellonta Tauta," Hawthorne's The Blithedale Romance engages metacritically with the utopian form. In fact, as More's Utopia did, Hawthorne's incisively questions whether or not an ideal society is possible ${ }^{45}$ For as More aptly observes of his own 
time and history, rather than altering the shape of their society to espouse truly Christian virtues, humans have "fitted [even Christ's] doctrine...to their lives" (More 38). Although Hawthorne asks the question more secularly, the sentiment of his skepticism remains the same: how can we expect to change the nation when even our representations of the future perform the biases of the past and present? Suggesting Hawthorne's investment in critiquing both the literary form and its iteration in our culture, Blithedale is also a very loose roman à clef of Hawthorne's experiences at the transcendentalist utopia Brook Farm a decade prior, which lends the work an ekphrastic quality, and renders the utopian impulse as a sort of exhibition, contemplating reform alongside the growing culture of exhibition. For Blithedale is written amid the growing popularity of the American Museum and "Lyceum-halls, of which almost every village ha[s] now its own," after Seneca Falls and Emerson's public abolitionism, and after London's Great Exhibition (1851) and amid the planning of America's first international exhibition (Hawthorne 134-135). Profoundly aware of these cultural developments, I argue that Hawthorne's Blithedale uses the utopian form to intepellate a skeptical reader, who, in turn, skeptically critiques - as he does - such reforms as performances that draw from and ultimately reinforce the "settled systems" of nation (98).

Like Poe's "Mellonta Tauta," Hawthorne seems to cast Blithedale, the tale of Miles Coverdale's experiences and observations within a utopian community in New England, as a course in American skepticism. Inhabiting the distant and contradictory persona of "The Author" in the work's preface, Hawthorne proceeds to "disavow" at length the work's connection to his own time at Brook Farm, a disavowal that ultimately "provoke[s] readers to hunt for historical antecedents" (Borgstrom 370). While The Author "begs" readers not to read the novel as a "faithful shadowing" of Brook Farm or as an illustration of "a theory or...conclusion...in respect to socialism," The Author nevertheless introduce these sites of comparison and inquiry to readers 
(Hawthorne 4). In fact, Hawthorne's Author even introduces by name Brook Farm community members to whom readers should not compare "the personages" of his "fancy-sketch" —even as the term "personage" finds itself on the fuzzy boundary between fiction and reality (4). In other words, I am suggesting in a very Poe-esque manner, Hawthorne explicitly asks us to see and explain what is not there, as Poe's conclusion to The Murders in the Rue Morgue (1841) entreats, to see Brook Farm within Blithedale, and to see stale ideologies of nation in the guise of utopian reform. In fact, Hawthorne nearly ensures skeptical readers by taunting them. He antagonistically suggests that American readers are deficient dupes who cannot distinguish between "the beings of imagination" and "actually living mortals," or, categorically, between fact and fiction (Hawthorne 3, 4). In this way, Hawthorne encourages skeptical readers who will continually attempt to parse fiction from fact to prove their mettle, a keen reader who would interrogate the very forms and systems of narrative and nation. ${ }^{46}$

For these reasons, Blithedale arguably rings truer as a metacritical utopia skeptical of the "settled systems" of American thought than as the "romance" its title announces (Hawthorne 98). And I would suggest that a reading deferential to the novel's utopian conventions helps us to better understand Miles Coverdale's perplexing character. As one scholar has meticulously documented, Miles Coverdale is met with "scholarly [and readerly] hostility" because of the character's persistent “refusal to square with readers' perceptions of what he (and the book) should be," perceptions and expectations that I would argue are aligned with reading the work as a romance (Borgstrom 363). Conversely, when one looks to the novel's play with utopian conventions - its interpolation of a participatory reader and its interlocutory first-person narration-Coverdale becomes a variation of the utopian traveler. In this way, his "inconsistent and erratic" narration become a means for readers to observe the inconsistencies of both society 
and reform, which begins with the novel's opening sequence on the exhibition of the Veiled Lady (365). In fact, I would argue that our interpretation of this scene is pivotal to how we read the remainder of the novel. For it is not just a facile introduction to important characters, rather it courses the reader to critically engage with the discourse of skepticism and belief, of exhibition and performance that Priscilla (later revealed as the Veiled Lady) quite literally carries into Blithedale when she joins the community. ${ }^{47}$ For when we first meet Coverdale at the outset of chapter one on the eve of his departure for Blithedale, he is contemplatively - and pointedly-ambling home from an exhibition, "the wonderful exhibition of the Veiled Lady," as he puts it (Hawthorne 6). And although interrupted almost immediately by Old Moodie, Hawthorne delays this character introduction to allow Coverdale to discourse on the nature of exhibitions and to position the reader as his intimate_-"my readers," he calls us. More than that, while Hawthorne's Coverdale acknowledges that the Veiled Lady has "little to do with the present narrative," he nevertheless proceeds to offer readers a cultural history of veiled ladies and courses us in the growth of skepticism to explain their waning popularity. He also insists that we, collectively, now understand such performances as works of exhibitioners, as the "skillfully contrived circumstances of stage-effect," an effect that reflexively applies to The Author's contrivance of Brook Farm as "a theatre" for Blithedale $(6,3)$.

Given the Veiled Lady's prominence in the text's inaugural scene, Hawthorne's consideration of The Veiled Lady as a potential title, and his focus on visual culture, we might also read the veiled figure as symbolic of the Blithedale's central rumination over skepticism and belief. Notably, Raffaelle Monti's "The Veiled Vestal” and the "The Circassian Slave," two veiled sculptures, and, as I will argue, the typological analogues of the novel's two central female figures, had just gained international attention at London's Great Exhibition of 1851 
"chiefly by their novelty" (see figs. 4-5) ("The Veiled Vestal" 135).$^{48}$ Despite the modern onlooker's likely astonishment at the works' technical proficiency in rendering figures simultaneously visible and concealed, they were considered "skillful mechanism" "deficient in...great attributes of sculpture" such as "the beauty of the human form" (135). And yet, philosophically, they were a marvel; the works were an ever-suspended duality of phenomenological revealment and concealment, of something naggingly ever within and ever evading our grasp that compels us to keep searching for its truth. In other words, the veiled lady might be seen as a symbol of skeptical inquiry weighing belief against fact, a setting of an "apparent miracle in the strongest attitude of opposition to ordinary facts" (Hawthorne 7). For several times in the book, the Veiled Lady/Priscilla functions as a limn, preceding Coverdale's "departure for Blithedale," and his departure from Blithedale, a second symbolic departure from the exhibitionary theatre. More significantly, Coverdale's leave-taking is rooted in his own feelings of having become, in effect, veiled. For he felt "insulated from the material world, from time and space," and as though he was "beginning to lose the sense of what kind of a world it was among [the] innumerable schemes of what it might or ought to be" (98). And significantly Coverdale's awareness takes on an imperative tone, pronouncing that "no sagacious man" can live "exclusively among reformers and progressive people, without periodically returning to the settled system of things" (98). In this way, Hawthorne provocatively points to the "intangibility and mistiness" of our seemingly "settled systems," another iteration of the paradox of the veil. Despite what the "writers of the North American Review, the merchants, the politicians, [and] the Cambridge men" would have us believe, Hawthorne encourages the skeptical reader to see the very foundation of the nation as unsettled, in flux, and able to be changed (98). 
Blithedale is as critical of the "settled systems" of mainstream society as it is of utopian reformers, whom, Hawthorne suggests, fashion equally-settled systems. And Hawthorne was not alone in this thought. Indeed, Karl Marx and Friedrich Engels would charge in the Manifesto of the Communist Party (1848), a work that an avid reader such as Hawthorne likely encountered in its 1850 English translation, Critical-Utopian Socialists "hold fast by the original views of their masters, in opposition to the progressive historical development of the [actual] proletariat" (41). These socialists, Marx and Engels charge, merely replace the old Gospel of the elite with the "new gospel" of isolated communities, which by necessity still "appeal[ed] to the feelings and purses of the bourgeois" (42). And, in nineteenth-century America, that socialist ideology took on a Bancroftian character, for Blithedale's reforms show an entrenched white, male nationalism, believing their work of a divinely-ordained nature, explaining aspects of their project as that which "God meant" or "God assigned" $(85,111)$. And just as Hawthorne calls our attention to the instability of the "settled systems" of nation, he likewise draws our attention to how the "original views of their masters" shape reform at Blithedale. Through Coverdale's "inconsistent and erratic" observations and appraisals, Hawthorne renders visible the problems of a reform ideology overseen by a white elite patriarchy.

Coverdale's appraisal of the novel's women is one way in which we see Hawthorne's skepticism of utopian reform as systemic ideological change. For Coverdale consistently describes Priscilla not as a person, but as an object. Literally the Veiled Lady, she is an ekphrastic representation of Monti's Vestal Virgin who is routinely described as less than a woman, even less than a person. For Priscilla is described as not yet "among the creatures of flesh and blood," as a "slight mist," and an unformed "creature" ever under the control of men (36). She is first the captive audience of her father's fairytales, then the mesmerized object of her 
exhibitor (Westervelt), and finally the "especial charge" of Hollingsworth (54). And Coverdale perpetually marks her quietude and submission as "pleasant weaknesses" and her inability to "look after her own interests or fight her battles with the world" as endearing (54). Revealing the limitations of his progressivism, Coverdale does not speak of Priscilla alone, he indicts young women generally. He charges that Priscilla is merely "as unserviceable a member of society as any young lady in the land," which suggest he sees an epidemic of women unable to look after their own interests (54, emphasis added). More damningly, the novel's male "reformers" idealize the weak, virginal, not-quite human Priscilla, preferring her to Zenobia, Priscilla's feminist, progressive, sister and foil, who is ultimately "murdered" - arguably martyred — by the systemic implications of even utopia's rejection of her.

If Priscilla is Monti's Vestal Virgin, then Zenobia, with her exoticized name and “preternatural” beauty is Monti's Circassian Slave, the novel's dichotomous whore, and another means by which Coverdale's observations advance Hawthorne's skepticism among readers (33). ${ }^{49}$ While Coverdale first acknowledges Zenobia's strength and intellect in her "tracts in defence (sic) of the sex," he nearly immediately renders her as an object to mollify the threat she poses (24). He ekphrastically imagines her as a silent, cold, and nearly-naked sculpture, so that he might "chastely" take pleasure in his lascivious gazing at "her material perfection" in the "utmost scantiness of drapery" that marble allows (32). In fact, given her Greek nom de plume and her tracts' notable argument that woman is the bond-slave of man, Coverdale's ekphrastic description of Zenobia conjures not only Monti’s Circassian Slave, but Hiram Powers's The Greek Slave (see fig. 6). By rendering Zenobia in this manner, Hawthorne seems to draw readers' critical attention to how even exhibits of "moral nudes," as Powers's work is called, advance such objectification of women. ${ }^{50}$ Arguably, through readers' conflicted experience of 
Coverdale's quick devolution in thought from reformer to sexist, Hawthorne suggests that persistence of patriarchal patterns of thought in even the most reform-minded of men. In this way, Hawthorne offers another means by which reform is undermined by its growth from and within the settled systems of a patriarchal master class. ${ }^{51}$

Coverdale's narration of the working class, too, allows Hawthorne to foster readerly skepticism of utopian reform. Indeed, for the "master class" reformers at Blithedale, labor is a dalliance they may play at, a tourism of race and class. In contrast to the philosophical and physical play of the reformers, lies the stalwart work ethic of the farm manager and laborer in earnest, Silas Foster. Unlike the reformers, Foster, with his "palm[s] of sole leather" and "joints of rusty iron," always speaks "to some practical purpose," such as the need to acquire livestock, for which Coverdale immediately chides him_- "Pigs! Good heavens! Had we come out from among the swinish multitude for this?" $(15,17)$. While Coverdale's response emphasizes the disconnect between the philosophical reformer and the material reality of labor, more indicting is that Zenobia reinforces class distinction to treat Foster as a servant, beseeching that he "leave an armful of firewood and a pail of water at her chamber door" (29). And despite his skills and practical knowledge, which Hawthorne seems to have Coverdale recount in juxtaposition to the floundering reformers, Foster is described as "uncouth" and as having a brain of "Savoy cabbage." As a whole, these descriptions and treatments of Foster render him as less white than the 'true' Blithedaleans and degrade him as less civilized and less intelligent because of his laboring class. Through the novel's treatment of Foster, Hawthorne indicts Blithedalean's class tourism as another cynical illustration of reform maintaining society's settled systems, as they often did in practice (48). 
However, it is a chapter entitled "The Masqueraders" that most explicitly literalizes this critique of reform tourism. The scene begins when Coverdale, who left utopia to rejoin society, returns to visit Blithedale to find them amid a costumed fete. Observing from a distance, he recounts the costumes of those at the masquerade, which are largely of laborers and racial others: a Bavarian broom girl, a woodsman, shepherds, a gypsy, and even "a negro of the Jim Crow order" (144). Jarring readers from the novel's professed aspiration to become a society determined "to lessen laboring man's great burthen of toil by performing our due share of it," this pantomime literally makes labor and abolition play, a performance (16). Running from the party once spotted, in Coverdale's retreat Hawthorne reaffirms the gravitas of the true laborers' plight. Tripping over a long-abandoned pile of firewood, Coverdale is called to imagine the "long-dead woodsman and his long-dead wife and children coming out of their chill graves...to make a fire with this heap of mossy fuel" (146). Reinforcing a shift in mood, the risible performance becomes a haunting grotesque of the reality of labor. Coverdale's physical distance from the "merriment and riot" recasts the sound of revelry as "a kind of mournfulness," a plaintive cry (146). In other words, Coverdale's observations reground readers-if only momentarily - in the material condition and experience of laborers whose lives were soconsumed by work that they might wake from their graves to work again. And from this critical distance, we might also wonder what to make of a Blithedalean dressed as "a negro of the Jim Crow order," an attention to enslavement and the abolition movement not raised elsewhere in the novel despite the dominance of abolitionism among the New England reform movements. Although arguably the oblique reference is a symptom of Hawthorne's apprehension about abolition and other calls for race reform, he nevertheless renders a reformer performing in blackface, while the term "Jim Crow" calls attention to both the literal enslavement of Southern 
blacks and their popular minstrelsy in Northern white theatres. Even if we consider the Jim Crow figure mentioned here an allusion to T.D. Rice's transgressive and "aggressively-integrationist" mid-century blackface performances, Hawthorne's iteration is to some degree silenced by the context in which it appears (Lhamon). In keeping with Hawthorne's criticism of superficiality, the passing reference does not conjure the dynamic transgressive performance of a trickster figure, but a static image of exaggerated racial caricature. Regardless of how we interpret its inclusion, the mention of such a specific character type like the specter of the real laborer Coverdale imagines cannot be overlooked. For the masquerade literalizes the Blithedaleans' burlesque of labor, drawing reader's attention to both the need for reform and the privilege of the reformers.

It seems important to note here that I don't mean to call Hawthorne a labor activist or a feminist or to weigh in on his antagonistic, yet mutually-influential relationship with Margaret Fuller. Instead, I want to suggest that Hawthorne's characteristically ambivalent and detached observations of society within a work that makes use of utopian conventions advances what we might call a skeptical "Hawthornian" readership. Indeed, just as readers and scholars bristle at Coverdale's inconsistencies, they feel uneasy about the novel's form. In fact, one early review asks: "what induces Mr. Hawthorne to give us in a romance, not the actual conversation of his characters, but an avowed imagination of it?" ("The Blithedale Romance: Hawthorne”). In answer, I would argue that the work's titular misnomer, too, is meant to reinforce a questioning and participatory readership. Readers are to become a Hawthornian anatomist who skeptically regards Coverdale's observations about the "settled systems" of society, reform, and the utopian form. 
Although I would argue that Blithedale remains a politically ambivalent work and characterize Poe's "Mellonta Tauta" as xenophobic, they nevertheless render skepticism as a valuable critical method for interrogating the limits of the utopian form. Well before contemporary critics would argue that the utopia novel was a "potentially dangerous diversion from the difficult task of forging a new society," Hawthorne's Blithedale and Poe's "Mellonta Tauta" seemingly wage that very critique (Pfaelzer 4, emphasis added). ${ }^{52}$ While Poe's "Mellonta Tauta" acknowledges a white male terror to maintain control is at the core of the utopian form, Blithedale suggests the form is subterfuge, that it perfects the performance of progress while ultimately maintaining the status quo. In fact, although Blithedale's ending is rather bleak, Hawthorne's attention to the social construction of "settled systems" devised by the "respectable old blockheads" signals the possibility to change them, which may nominally overcome Hawthorne's tendency toward "benign moral conclusion[s]" (Reynolds 121). Although the works do so in different ways, Poe and Hawthorne both use the utopian form to question the possibility of the nation's Providential ordination by raising readerly skepticism of the nation's seemingly-ordained "settled-systems" and their implications for the nation's less than ideal future. And, more significantly, their negative utopias point to a skeptical, metacritical utopian form largely overlooked in our historiographies and, I would argue, necessary to recover.

\section{Looking Backward at the Formation of a Bancroftian Canon}

To this point I have suggested that, as the nation's most prominent historian nineteenthcentury historian, George Bancroft's American Providentialism influences the imaginings of America and its history in the century's utopian works. I also have suggested that a mid-century rise in skepticism questions Bancroft's divine-utopian rhetoric of nation, and, more than that fosters a skeptical readership of literary and cultural utopian forms. Turning to the negative 
utopias of Poe and Hawthorne, I further argue that we find a metacritical strain of utopian thought, arguably traceable to More's inaugural work, that is curiously omitted from our historiography of the field. Here I will argue that while the late century boom in the literary utopia following Edward Bellamy's Looking Backward (1888) partly explains the omission of this earlier skeptical utopian strain, such an omission also reflects a renewed Bancroftian preoccupation with preserving a white America in a racially-tumultuous era.

Unlike the "failure" of Poe's and Hawthorne's negative utopias, that, arguably, make us "more aware of our mental and ideological imprisonment," Looking Backward relocates readers to a "positive" utopian future of fulfilled reform (Jameson xiii). However, displacing the actions of reforming, as others have suggested, is a "potentially dangerous diversion" from the work of "forging a new society" (Pfaelzer 40). ${ }^{53}$ And so is, I would add, displacing the identity politics of white male authorship when appraising a work's idea of utopia. Reconsidering these dangerous diversions, I argue that Looking Backward overtly reintroduces the American literary utopia as a white, male escapist fantasy, one that is almost entirely unexplored as such. For Bellamy’s imagining of a white future reacts to an increasingly racially-diverse American present and as it frames whiteness as the path to a utopian future. Further, given the work's popularity and its inspiration of more than one hundred novels and Nationalist Clubs in its wake, I would argue the work has a long ideological reach. To that end, I suggest, too, that Looking Backward invigorates the notion of an American utopia predicated on whiteness among its manifold audiences at the century's close. $^{54}$

The success of Looking Backward in its time and as the centerpiece of our historiography of the period is, I would argue, a symptom and sign of a Bancroftian nationalism in a post-Civil War America. For Bellamy was the child of a Reconciliationist era that found renewed 
significance in the heroic Bancroftian history of the nation's Providential design. ${ }^{55}$ As some historians have suggested, the "search for an American identity" fostered "an age of Christian nationalism and moral mission...that reached a climax in the Civil War" (Thomas 34). And for an adolescent Bellamy, the Civil War was a heroic romance; in fact, even in response to the journals and notebooks of his adulthood some scholars have characterized him as "an unbridled romantic" (40). By Bellamy's coming of age in 1872, the "triumphal reelection" of Ulysses S. Grant "marked the grand opening of the Gilded Age" and signified "a smoothly functioning party system [that] repaired the sectional damage of the Civil War"- from a white perspective, that is (Thomas 37, 1, 37). For many black leaders, Radical Republicans, and reformers, Grant's reelection did not erase the increasingly-conservative Republican party's "contemp[t]" for "the activist state that radicals...had fashioned out of the war" (Blight 123). More than that, the party's determination to "curb what they perceived as the dangers of mass politics and universal suffrage" signaled a renewed conservatism, one with which we might align Bellamy given the Looking Backward's rejection of both radical reform and universal suffrage as "ruinous" (Blight123, Bellamy 111). ${ }^{56}$ Perhaps the grandest example of the white reconciliationist attitude permeating Looking Backward and the nation, was Philadelphia's Centennial International Exposition of 1876, to which I suggest the novel gestures. For, as one scholar convincingly argues, the Centennial was a "calculated response" to the "political uncertainties of the Reconstruction years" that sought to "restore confidence in the vitality of America's... government" as well as its "social and economic structure" after the war (Rydell 11). And, of course, chief among those political and social uncertainties was the so-called "negro question." It is not by happenstance that the major action of Bellamy's narrative begins on Decoration Day, a national holiday commemorating the casualties of the Civil War, nor that it 
supplants the holiday's black history with a white one. For this meaningful backdrop enables Bellamy to evoke a raw, divisive history for his readers and to kindle a sense of nationalism in the face of a new divisive faction: immigrant laborers. For it is after a full day of commemorative ceremonies that the tale's white, upper-class nineteenth-century protagonist Julian West is transported through a mesmeric sleep from 1887 Boston to the twenty-first century. After having spent more than a century asleep in a "vault equally proof against violence and flames," a protection indicating "the nervous tension of the public mind" in the aftermath of the Civil War, the Haymarket Riot, labor strikes, and the stirrings of racial uplift, he is discovered and awakened in the year 2000 by Doctor Leete and his daughter Edith (14). For, as we soon learn, West's house "perished by fire" in the nineteenth century and he was thought to have perished along with it (20). But the fire is certainly not represented as accidental. Instead, Bellamy's focus on labor strikes and the neighborhood's "invasion by tenement" slums directs readers to blame the "anarchists" or the encroaching "alien race," who were "nothing but dynamite in disguise" $(11,13) .{ }^{57}$ In positioning racial encroachment as the catalyst for the novel's utopian travel to a distant future, Bellamy renders West's home - and the entire era — as "undesirable for residence" (9). For as historian Matthew Frye Jacobson explains, by the 1840 s a "series of distinct "white races"” emerged and the previously "unquestioned hegemony of a unified race of "white persons"” soon became "a contest over [each nationality's] political 'fitness"” that fostered animosity between nationalities (Whiteness 42-43). In this way, the discourse of race began to change and overlap with what were formerly class distinctions. For the "real" whites of English descent were differentiating themselves as Anglo Saxons, while the European immigrant laborers were becoming "hierarchically arranged... white races" by contrast, a racial logic apparent in Bellamy's description and characterization of those who had taken residence near West's family 
home (Jacobson 43). And, significantly, when West and his reader awaken, it is within a new world where the chaos induced by such collisions of class and race had been long forgotten. In this new America of the future, there appears to be an egalitarian socialist government, though rank- and gender-based separations among citizens remain, of course. There is some semblance of gender equality and a state-organized army of laborers, though women are separately governed and work fewer hours because of the natural weakness of their sex. There is also still some semblance of private property and the conspicuous consumption of specialty goods, though they're not discussed as such. And there appears to be no discord among the races, though, with the ominously Aryan physical descriptions, there also appears to be no black people.

Despite what many modern scholars consider overwhelmingly conservative reforms, Bellamy's version of an American utopia was hailed by William Dean Howells and others among the "literary left" for its progressivism (Pfaelzer48). Although it is credited for inspiring reform among progressives which reinforces the "dangerous power of the book," this may be partly explained by the book's silence about the reform process, which allowed reformers to "project their diverse causes into the novel" (Roemer, Obsolete 13). However, I would argue that the same silence might also explain its widespread popularity among average white middle-class readers as well. For the novel not only leaves the work of reform to readers' imaginations, it entirely displaces them from the process of reforming. In fact, one Bellamy Club Nationalist put it in terms waxing Bancroftian, when he averred that the novel assures us "'the promised land exists" if only we "'labor and wait,", a response the also suggests Looking Backward harbors an “ambivalence about change” (qtd in Pfaelzer 48-49, Roemer Utopian 124). ${ }^{58}$ If even a Nationalist reads the work as advocating passivity, we cannot overlook how displacing reform to the next century in actuality preserves the systems of the present. In this way, the work appears 
antithetical to progress, reinforcing an important criticism that Hawthorne wages of the literary utopia in Blithedale: it's inherently static. For Bellamy's work actually supports the status quo by convincingly dissuading action in the present; it forthrightly notes that activists like communists and anarchists "had nothing to do with" change "except to hinder it" and explains that "labor parties never... accomplished anything on a large or permanent scale" (148-149). In fact, it imagines the most conservative, top-down revolution possible, that is, the rise of a new political party that rearranges the "industrial and social system on a higher ethical basis" (149). In this way, Bellamy courses his readers to reject agitation and organizing among the nominally- or non-white laboring classes as a means to reform, in part, by promising an indistinct "rearrangement" at an indeterminate time orchestrated by the white elite. In this way, Bellamy reinforces for readers a paternalistic belief in natural law, of the superior's right to exercise dominion over the inferior. More than that, his "progressivism" seems an iteration of the unreformed-reforms of the "master class," a doomed utopian scheme according to Marx and Hawthorne that ultimately reifies the status quo. While Looking Backward may have appeared progressive to some reformers projecting their cause within it, a renewed exploration of its displacement of reform as white escapism and continued deference to a master class suggest its conservative.

In my estimation, a reconsideration of Looking Backward's conservatism and white escapism, as I've alluded to above, begins with how we interpret Bellamy's mentioning of Decoration Day, the very day on which West is transported to the future. When we see the novel as part of a white utopian complex, I would argue that this the holiday and West's "escape" from it reasserts historical and racial control for a white, middle-class reader. Although the holiday was begun by "Black South Carolinians and their white Northern abolitionist allies," a fact that 
Bellamy's professed admiration for Thomas Wentworth Higginson ${ }^{1}$ suggests he would have known, Bellamy nevertheless recasts Decoration Day as a holiday to "honor the memory of the soldiers of the North" who fought in "the war for the preservation of the union of the states" (Blight 65, Bellamy 12) $\cdot{ }^{59}$ Revealing a degree of sectarian bias by casting the day as a Northern holiday, Bellamy's focus on the North and on the "preservation of the union," allows him to side-step any mention of the South and slavery. In fact, not only does he avoid mentioning the slavery-linked textile industry likely to have built his great-grand-father's fortune, he leaves his "faithful colored man...Sawyer," the novel's only black character, to perish in flames in the nineteenth century ${ }^{60}$ More than that, the adjective "faithful" and the potential connection to textiles and Southern cotton may signify a lineage of servitude or enslavement in his family. In fact, at least one early reader of Looking Backward commented on the whiteness of Bellamy's imagined utopia in an unsigned letter to The New Nation, Bellamy's Nationalist newspaper. Responding in the same forum, Bellamy argued that none of his characters are identified as white and that "“the people referred to in its [the novel's] pages, so far as we remember, might have been black, brown or yellow as well as white"' (qtd in Peyser 56). Yet the novel's sequel, Equality (1897), tells a much different, much less racially-progressive tale. As Bellamy once explained to a Southern audience: Equality's “"new system involved no more commingling of the races than the old had done"” and was "“perfectly consistent with any degree of racial separation" that "'the most bigoted local prejudices might demand"” (qtd in Peyser 56). While Bellamy's explanation of racial politics in Equality are certainly a more damning response to the race question, as one scholar points out, the very fact that Bellamy identifies Sawyer as a “"colored man" marks the "disingenuous[ness]" of his remarks on the racial politics of Looking

\footnotetext{
${ }^{1}$ The Bostonian colonel of the first regiment of black troops in South Carolina.
} 
Backward (Ahmad 27). Further, if a decade later segregation becomes a key to maintaining a utopian America, Equality's back-peddling on race underscores the notion that he "quite deliberately creates a whites-only twenty-first century" in Looking Backward and aligns utopia with whiteness (27). More fundamentally, one cannot mere dispose of its only "colored" character and remain silent about the "comingling of the races" in the future when the racialized "invasion" of his neighborhood and Decoration Day were the catalysts transporting West to the future. And these overtly racialized catalysts do not suggest an uncertainty about the race question or the effect of immigration on national character, they suggest that a utopian America requires a racial cleansing.

Suggestively, the same narrative interval that mentions the "color man" and his demise almost anxiously reassures readers of the whiteness and traditional gender roles of the future. Just before introducing Sawyer, West meditates on the "purity" of Edith's "complexion" and confirms her pedigree as the ancestor of the former Edith. For Edith Leete also has "deep blue eyes" and "delicately tinted complexion," reassuring readers that the bloodline has maintained its elite, or, perhaps E.Leete, whiteness $(11,13,25)$. However, Edith Leete doesn't merely assure readers of the future's whiteness, she assures them of its patriarchy. Edith's demeanor reassures readers that a "cult of True Womanhood" remains, as she displays the "four cardinal virtues" of “piety, purity, submissiveness, and domesticity" and "renders the twenty-first century comfortable, desirable, and productive for West and for the reader" (Welter 151, 152; Ahmad 34). With her racial purity verified and her Christianity assured by the text's mention of a Sunday sermon, Edith's “blushing” in moments of benign intimacy with West confirm her chastity while her deference in conversation to both West and her father show her submission. Likewise, her continued association with the home, gardening, and expressions of concern for 
West's well-being evince her domesticity. In fact, we never learn what Edith's occupation is or what her mother's occupation was; we know only that Edith is working "on commission" for her father, a job that doubly-ties her to a patriarchal, conservative, and middle-class order (57). But Edith's story is far from unique. While women do have their own "woman general-in-chief” in the industrial army, we quickly learn that women have little to no legislative or judiciary sway, that they are still viewed as the weaker sex, and that they are assigned "lighter occupations," keep shorter hours, and must "rest when needed" (151). ${ }^{61}$ But, perhaps the most insidious reassurance of the future patriarchy is how and why women entered the workforce in the first place. As Bellamy explains, women did not merely enter the workforce because men "permit[ted]" them, but that men chiefly permitted them for their own benefit, that is, because working helped women to maintain their physical and metal fitness, their "beauty and grace" for men (151). Further, the notion that men permit women to work also suggests the future's continued patriarchy in men's implied power to revoke that permission. Although women would gain economic freedom (and thereby a modicum of sexual freedom) in Bellamy's utopia, they remain fragile, limited, and politically inert, a representation that aligns utopia with patriarchy.

But the fundamental logistics of Bellamy's future are not merely white and patriarchal, they're capitalist. For Bellamy's "Nationalist" future assures its nineteenth-century readers that the niceties of capitalism—-private homes, conspicuous consumption, and caste-based segregation - remain in the future. Although private property does not technically exist in Bellamy's society, the Leetes' relationship to their home mirrors that of middle-class and upperclass nineteenth-century private property owners. For they live in a private residence with a "large garden," grounds, a library, and room enough to take in a houseguest. Likewise, Dr. Leete even seeks to make a permanent, substantial addition to the residence: a laboratory that he even 
goes so far as to call "my cellar" (20, emphasis added). Rather than having chosen a house "no larger than we need," as Mrs. Leete explains most families do, their residence suggests they live in luxury, but the novel gives no sense of a sacrifice made elsewhere to maintain it, given the operations of the society's credit system. In Bellamy's schema, the credit extended to each person is equal, which means consumers would need to balance indulgence, such as acquiring luxury houses or specialty "products of high skill or rare materials," with moderation elsewhere, a point the novel side-steps here (109). In fact, we are given quite the opposite impression. Since we have no indication that Mrs. Leete has worked outside the home, that Dr. Leete is building an addition, and that Edith is an "indefatigable shopper," their lifestyle would seem impossible to maintain on a single income only lately doubled when Edith enters the workforce (58). Perhaps most indicative that the future maintains some sense of the class sensibilities of a capitalist society, it the organization of the industrial army itself. While the novel takes pains to assure readers that social class has been eradicated, there are rankings within each guild of industrial, technical, or liberal professions and separate vacation "clubhouses," suggesting that a professionbased segregation remains (93). Dr. Leete even alludes to a sectarian partisanship, admitting that "there is a tendency on the part of each guild to vote for its own general" for the presidency (71, 112). And although the extension of credit is equal, there are still intra-professional rankings and coveted awards given to the "famous," all of which are a means of segregating workers by rank and sect — the very foundation of social hierarchy and class dispute. In other words, Bellamy's Nationalism (he rejected the term socialism) feels very much like middle-class white society in the late nineteenth century — a reassuring stability in an era of upheaval.

Like the logistics of his future, Bellamy's ekphrastic representations redirect readers to a conservative and Reconciliationist model of America: Philadelphia's Centennial International 
Exhibition of 1876. Although Bellamy would critique the Columbian Exposition of 1893 as a "sham pretense of patriotism" whose "underlying motive" was "business" and "individual money-making," his cityscape in Looking Backward nevertheless draws aesthetically from the Beaux-Arts style of world's fairs, and, I would argue, from the Centennial in particular (qtd in Trachtenberg 215). For his technologies of telephone wires and pneumatic tubes were first popularly displayed at the Centennial, while his imagining of pristine streets, fountains, statuary, gardens and ornate neo-classical architecture mirror the burgeoning design of fairscapes. ${ }^{62}$ As Julian West describes, the store in the Leete's ward was a "spectacle"; there one found a "lifesize group of statuary" with the "female ideal of Plenty" at its center heralding the entrance, which opened to a "vast hall full of light from the windows on all sides" (60). In the middle of the market place stood "a great dome, the point of which rose a hundred feet above" and beneath it was "a magnificent fountain... around which...on sofas and chairs...many persons were seated conversing" (60). Significantly, his description of the "hall" does not mirror the more austere facades of Faneuil Hall or Quincy Market, which would have been well-known to the Bostonbased Bellamy, but resemble instead the fountain- and light-filled exhibitions halls of world's fairs (see figs. 7-10). Indeed, the illustrations of the New York Crystal Palace's exterior, the London Palace's interior, and the replica of the Centennial Exhibition's Arts \& Industry Building's central fountain mirror Bellamy's descriptions of vast, light-filled halls, magnificent fountains, statuary, and a great dome. Moreover, readers soon learn that such architectural grandeur was not isolated to the stores of the future. As West explains, the city was filled with "public buildings of a colossal size and an architectural grandeur unparalleled," for it was "a glorious new Boston with its domes and pinnacles, its gardens and fountains" that happened to look very much like the neo-classical architecture of the fairscape (22). In fact, Bellamy's 
descriptions of the interior of the dining hall with its "grand staircase" and the Goddess statuary of the hall and the store, likely conjured popular images of Columbia (the Centennial's central icon) rendered in popular periodicals like Harper's Weekly and Frank Leslie's Illustrated (see figs. 11-12). In other words, for Bellamy's nineteenth-century middle-class readers, who had been coursed for years in the architectural wonders of world's fairs, these descriptions doubtlessly recalled the fairscape.

But Bellamy’s heavy-handed gesture to the fairscape was not merely aesthetic, it was, arguably, political. As many fair historians have noted, fairs "represent the most important international mass events of the modern era" and because they were well-attended and meticulously documented they "shed light on how public perceptions were formed or new initiatives forged" (Boisseau and Markwyn 2). For the Centennial Exhibition that meant welcoming "almost ten million" patrons to a fair that was intended to "teach a lesson about Progress," "restore confidence in the vitality of America's system of government," and unify an American identity (Rydell 11, 17, 11). And with the fair's acute racialized hierarchy of nations and exclusion of blacks from exhibiting, that identity was assuredly white. More than that, one of the fair's prime concession was "The South," an homage to the Old South wherein one could find a "band of old-time plantation "darkies"” (Rydell 11, 28). Speaking to the reach of Reconciliationism in the North, the inclusion of such a nostalgic display also suggests that one way the fair sought to "restore confidence" in the nation's "system" was through the reassertion of an old order. It would seem that just as Frederick Douglass imagined it would be, the Centennial was a "“hosanna of peace and good will to all the white race,"” one that begged his follow-up question: "“what will peace among the whites bring?"” (qtd in Blight 132). ${ }^{63}$ Bellamy may offer us answers in his reimagining of Decoration Day and in gesture to the fair: it would 
bring the restoration of a peaceful, orderly, and white future the fair represented - so long as we can leave the colored man to perish in the past or, as Equality suggests, ensure there will be no more "comingling of the races" than that of the past.

Looking Backward was undeniably a revolutionary literary utopia, but many of the implications of its white male escapism remain undiscussed. As I have suggested here, scholarship rarely if ever considers how the novel engages with a growing discourse of Reconciliationist nationalism or with the so-called 'race question.' It overlooks how readers' ability to "project their diverse causes into the novel" obscures Bellamy's own reactive conservatism in the face of the perceived threats posed by Emancipation, immigration, and even gender reform to white, middle-class American men. Arguably, perhaps scholars, too, have "projected" onto Looking Backward in seeing its popularity as rooted in reform, rather than in its reassurance of an American utopia predicate on maintaining the status quo.

\section{A Canon in the Margins: Toward a Revised Historiography}

In pointing to the negative utopias of Poe and Hawthorne and to a reevaluation of Looking Backward, I'm suggesting that there is a different historiography of the nineteenthcentury American literary utopia that has been pushed to the margin of our current canon. And a revised historiography would both highlight the canon's white male utopian complex and recover a sizeable number of works by women and African Americas. ${ }^{64}$ This historiography would not exclude Bellamy's inordinately successful Looking Backward or ignore the work's cultural significance, but look at it in juxtaposition to these categorically negative utopias, those that often fail commercially but are successful in the Jamesonian sense. That is to say, works that are successful in making us away of our "ideological imprisonment" to society's "settled systems"and of the need for reform (Jameson xiii, Hawthorne 98). In line with the skeptical use to which 
Poe's "Mellonta Tauta" and Hawthorne's Blithedale put the utopian form, I argue that several other utopias predating Bellamy's, particularly those by women, highlight by comparison the limitations of utopian reform in Looking Backward and in the numerous utopias penned by white men it inspired. Notably, women utopists saw the nineteenth-century utopia as a white male generic form, just as our historiography first did, suggesting there were only "a handful of women" writing and that other minority writers were "notable exceptions," too (Roemer Obsolete 11). However, even as we discover and recover works by women or those of color, our historiography shows little change, despite the fact that the inclusion of works by women, and as I argue in later chapters by writers of color, significantly changes the story we tell. Because these minority writers were excised from the nation's governance, often denied citizenship, and restricted in the social realm, their notions of utopia understandably differ drastically from those in our current canon. More than that, their imaginings of the nation's future often cast in relief how our present historiography has naturalized the reactive white male identity politics as the century's idea of utopia. I argue that only by addressing the way in which scholarship and our historiography has naturalized this white male vision as the vision of an American utopia can we begin to see a larger white male utopian complex informing the era's governance, policy, and practice.

The anxiety to preserve whiteness that undergirds Looking Backward becomes clearer by comparison to Sara Josepha Hale's Liberia; or Mr. Peyton's Experiments (1853) in which the preservation of a white America lies at the core of the novel's utopian resolution to segregate American society through re-Colonization. However, Hale's work has long evaded critical discussion in utopian historiography despite her status as the first American woman novelist, her prolific writing career, and her influence "over the reading, learning, and even the political 
consciousness of [white, middle-class] women across the American continent" as the acclaimed editor of Godey's Lady's Book for a forty-year tenure (Hoffman 47). But Liberia is rarely discussed among American utopias despite Hale's reputation, which compels us to ask: why? While the work is not easily aligned with the skepticism of Poe's and Hawthorne's, her immediate contemporaries, its utopia is grounded in a central skepticism of the possibility of racial equality in America. In this way, her exclusion from our present historiography reinforces the ways in which "society had made it painfully clear that women-even women of the dominant race and class_-were nonetheless outsiders" even today (Lewes 16). And since Hale's utopia is fundamentally a treatise on race relations, I would argue that her exclusion also highlights utopian studies' reluctance to have more nuanced discussions about race.

The inclusion of Hale's Liberia within our historiography would raise significant questions about the under-discussed role whiteness played in shaping white authors' imaginings of a utopian future and scholars' imaginings of our literary past. Unlike Hawthorne, Poe, and even Bellamy who take sidelong approaches to the so-called "negro problem," Hale confronts headlong the preservation of white identity as a precondition for American utopia. Hale's Liberia may fail as a feminist text by upholding many traditional gender roles (perhaps why even now it remains overlooked), but it raises to the fore of readers' consciousness the nation's inability to afford "the colored man in America" the means to "attain the functions and enjoyments of a man among us," that is, among a white citizenry (Hale 226, emphasis added). In imagining a series of freedom "experiments" and their failures conducted by the "benevolent" white slave owner Charles Peyton, the novel concludes that recolonization in Liberia and the spread of white Christian "civilization" by the emancipated to the "savage and heathen" Africans is the only means to maintain the Union and ensure the "honor, safety, and peace of our [white] country" 
$(227,226)$. While her treatment of colonization expresses "condescension, [a] fear of blacks, and the desire conveniently to be rid of the 'race problem' by expelling non-whites from the United States," she nevertheless grounds her utopian in the present and makes metacritical use of the utopian form to identify systemic racism as a national condition (Ryan 565). Through utopia's conventional critical recitation of past history, Hale resolves forthrightly that "the colored man...never can obtain freedom and equality before the law" nor before the "still more imperious law of society" (Hale 226). In other words, Hale critically observes systemic white supremacy as both fundamental to the nation and an essential element of utopian nationalism. Further, by including a lengthy appendix of letters "written by colored persons" colonizing Liberia "to show that the statements in the preceding work have not been exaggerated," she openly offers readers a blueprint for a white utopia in the present rather than one displaced to a distant future (247). In these ways, Hale's inclusion in the historiography of the nineteenthcentury American literary utopia would open critical inquiry into the whiteness of the period's vision of a utopian America. It also points to the didacticism of the utopian form and openly highlights the way in which the form enables writers to reimagine the facts of history. To that end, it also points to the important role of outlying texts - even by and 'insider-outsider' like Hale - play in offering "alternatives to the historically central male vision" even in scholarship (Lewes 2). Although Hale's utopia relocates black Americans to Africa, its discursive and metacritical use of the utopian form nevertheless draws necessary attention to how the naturalized and nationalized white male utopian thought.

Of course our historiography also excludes utopias by dominant white males like Poe, Hawthorne, and, as I suggest here Mark Twain. Indeed, these exclusions, too point to the field's hesitancy to broach the racial politics of utopia. For Twain's lesser-discussed "The Curious 
Republic of Gondour" (1875) and his often-displaced A Connecticut Yankee in King Arthur's Court (1889) find ideological affinity with the earlier metacritical utopias I've identified, particularly with Hale's direct confrontation of the nation's "negro problem." While I will focus on Yankee here, a few key ideas from "The Curious Republic of Gondour" shed light on how we might read the later Yankee. First, "Gondor" was published anonymously in the Atlantic Monthly. This choice may signify Twain's desire for the work's proposed reforms "to be taken at least half seriously" and signal that he approached the work and genre as warranting serious attention (Ketterer n.2 344). Significantly, "Gondour" raises the question of systemic white supremacy as an impediment to universal education, universal suffrage, and utopia, questions that Yankee raises as well. ${ }^{65}$ Published only a year after Looking Backward, and I would argue in dialog with it, Yankee openly rejects Bellamy’s distant, orderly, seemingly-egalitarian future. In fact, by literalizing an inverse look backward to an equally-distant past, Twain suggests the impossibility of Bellamy's future by pointing to the lineage of systemic inequalities as an inescapable fact of history and, therefore, of the future.

Many have read A Connecticut Yankee, the story of nineteenth-century superintendent of the Colt revolver factory Hank Morgan's sleep-induced travel to sixth-century England, as a “utopian satire gone awry” or as an “apocalyptic utopia” (Roemer, "Paradise Transformed” 90). Scholarship focuses on the novel as a response to the shock of increasingly-violent labor demonstrations or on its "burlesque... of technological progress," but few have discussed its criticisms of systemic racism, political stasis, and the utopian genre as a form (90). Signaling from the start Twain's exploration of race and its dialogue with Looking Backward, the action in Yankee, too, begins with a racialized nod to the Civil War and the violence of labor unrest. ${ }^{66}$ For the word "Yankee" intentionally draws readers' attention to the nation's sectarian partisanship 
and, likewise, the novel's traveler/protagonist Hank Morgan is transported to the sixth-century on June nineteenth, or Juneteenth, one of the oldest known commemorations of Emancipation. ${ }^{67}$ These narrative gestures seem a veritable hat tip, a gesture suggesting both Twain's engagement with Bellamy and his recognition (and criticism) of Bellamy’s white escapism.

Twain's most overt criticism of Bellamy's escapism, I would argue, is linked to the manuscript's form: a palimpsest. For by describing the manuscript as a "palimpsest," a new work written over older works that bear an indelible mark of the previous, Twain emphasizes our inability to escape the past. The palimpsest also functions metaphorically, allowing him to confront the recursiveness of exploitation. Twain stresses that exploitation is systemic by linking it to the state and blurs distinctions between types of exploitation to emphasize this pattern of treatment varies by degree rather than kind. As Morgan observes, “most of King Arthur's British nation were slaves, pure and simple, and bore that name, and bore the iron collar" while "the rest were slaves in fact, but without the name" though they "imagined themselves men and freemen," they nevertheless "slave" for the nation (41). Twain also emphasizes the connection between exploitation and systemic white supremacy; for it is not by happenstance that Twain selects the sixth century - the very start of Anglo-Saxon England - as a temporal setting precisely as the term "Anglo-Saxon" came into common use to crown the whites atop the nation's growing hierarchy now variegating whiteness. More than that, Twain's marking of the manuscript as a "palimpsest," his caricature of P.T. Barnum's mansion as Camelot, and his inclusion of Dan Beard's sideshow-esque interpretive caricatures such as "The Slave Driver" and "Brother! —-To Dirt Like This?," overtly overlay historical periods to stress the systemic continuity of exploitation, even as they troublingly conflate chattel slavery with wage slavery (see figs. 1314). ${ }^{68,69}$ Although Twain's spectacle of overlaying chattel slavery, wage slavery, and medieval 
servitude is problematic in many ways, his suggestive return to the roots of Anglo-Saxon England implicate the dialectic of oppressed and oppressor as an infinite — and racialized—cycle. Yet, amid this barrage of white-told histories and problematic conflation, Twain does importantly and deliberately turn to a black voice by using fugitive slave Charles Ball's Slavery in the United States (1837) as source material for a chapter entitled "The Yankee and the King Sold as Slaves." In this way, I would argue that he signals the brutalities of chattel slavery as the pinnacle of exploitation (Williams 381-382). If we are to trust Twain's prefatory remark that one exploitive civilization was almost always "competently filled by a worse one," systemic injustice is, as his persistent overlapping suggests, impossible. More than that, in actually looking backward at "the unbroken history of the powerful exploiting the weak," he indicts the possibility of Bellamy's pristine future, and arguably the possibility of utopia (Twain 4, 256).

Although Yankee may signal the impossibility of utopia, it also signals the usefulness of the utopian literary form. Rather than a utopia "gone awry," we might read the work as taking up the metacritical mantle of Poe's or Hawthorne's or even Hale's work to point out both the limitations of Looking Backward and the utopian form. From the work's preface Twain critically engages with utopian formations. Although he begins by remarking that the question of "whether there is such a thing as divine right of kings" remains unsettled, he proceeds to outline the logical flaw in the claim, implicating Bancroft's notion of America's Providential design in the process. For in explaining why he cannot "settle" the question, Twain points out that the claim itself is a tautology. He recognizes that what appears "manifest and indisputable" in the logics that the head of a nation should be a person of good character and the "none but a Deity ought to make that selection" ultimately lead to the "unavoidable deduction" that the Deity "does make that selection" (4). In tracing the "logic" in this manner, Twain signals the flaw: one merely infers 
that a Deity has selected one's leadership, just as Bancroft merely infers America's divine ordination. Twain makes this connection more explicit when Morgan observes that "inherited ideas are a curious thing to observe and examine" (40). Here Morgan points to the overlapping narratives of religion, nobility, and nation, declaring that the coexist "for one object, and only one: to grovel before king and church and noble" rendering all "gods in this world" (40-41). In this way, reading the temporal conflation of "Sir" and "Boss" as emblematic of a new society reforging the systemic privileges and prejudices of the old, Twain reflect the utopian form's potential to fundamentally serve and re-structure exploitation.

From this metacritical vantage point, we might also consider the novel's conclusion, titled "Final P.S. by M.T.," as Twain's explicit confrontation with the utopian form. Herein Morgan's concluding fevered sleep seems a direct critique of Julian West's final dream-return to the nineteenth century in Looking Backward. Further, by casting the word "effects" in quotation marks, M.T. draws attention to Morgan's uses of the word to characterize his performative and spectacular manipulations of Camelot's inhabitants throughout, aligning Yankee with Hawthorne's criticism of "stage-effect" to criticize the spectacle of reform in Blithedale (Hawthorne 6).$^{70}$ While West's return to the nineteenth century attempts to encapsulate the ills of period by reinforcing its "cruel sights" in the fresh eyes of the reformed reader, Twain refuses such a neat conclusion. Instead, Twain suspends Morgan in time amid his fevered state, in the middle of a sentence, and even in a space between life and death. And this refusal of an easy resolution, I would argue, comments on the inefficacy of the utopia form to affect real change and recasts the form not as a blueprint for change, but as a spectacle of unfinished "'effects."” Perhaps even more so than Twain, women writing utopias in the 1860s and 1870s challenged the notion of the stage-effects of reform. Excluded from political and social 
participation because of their sex, several important utopias by white women metacritically challenge the notion that an egalitarian future could be rooted in the oppressive systems of the past. From the outset of "The Harmonists" (1866), a scathing criticism of the Rappite colony in Economy, Pennsylvania, Rebecca Harding Davis points out that there is little difference between the "ruling class" of contemporary society that of that real intentional community imagined by white men, a sharp critique Davis wages forthrightly, particularly by comparison to Hawthorne's oblique conclusion of the like in Blithedale. For in the very first paragraphs of the tale, Davis defines the white ruling class as "men who...go through life with moderate, inflexible, unrepenting steps," who the character Josiah, our protagonist and narrator Zachery's brother, represents (534). In contrast, Zachery collects “queer bits of men's histories," such as that of "Fremont's Proclamation" or "Shaw's death" or of any man who would "give his place" and "buy with his life the slave's freedom" (534-35). In this juxtaposition of brother and type, Davis suggests the intimate struggle over the narrative of history. For while Zachary's queer deeds betray race and station to recover a historical counternarrative, Josiah recasts them as "mere facts," as self-interested attempts to solve the "great problem of Capital vs. Labor" not that of combatting black oppression (534-35). ${ }^{71}$ For Davis points to the ease with which ruling class narratives subsume the subversive and to the historical Harmonists as an illustration of the same exploitive pattern. Rather than a reform-centered utopian community, Davis charges that Rapp was a "harsh and tyrannical ruler" whose community was not a utopia, but a "corporation...to make money" (535-37). More than that, by depicting the white, overfed "gross men" as exploiting the "pale" and "poor withered women" within their community, she reinforces Josiah's contention that ideals were secondary to profit. Analogously, this suggests the potential hollowness of the community's call for black emancipation, which was likely born not of high- 
mindedness, but of economic advantage (534-37). However, despite reaching a wide audience with publication in The Atlantic the work is rarely discussed. And, curiously, it too, turns a metacritical eye to the utopian form and its potential to replicate the systemic oppressions of patriarchy's "settled systems" in narrative and nation and present them as utopia.

Louisa May Alcott’s “Transcendental Wild Oats: A Chapter from an Unwritten Romance" (1873) is yet another popular utopia (it was republished several times) that indicts the white male utopian complex that our historiography critically overlooks. ${ }^{72}$ Focusing again on the unreformed-reforms at real intentional communities like Davis and Hawthorne do, Alcott's "Transcendental Wild Oats" confronts the inability for utopia to overcome systemic inequity at her father Bronson Alcott's experimental Fruitlands community. Writing in a metacritical space, Louisa observes that "reform conventions" are a disconnect between espousing "many wise things" and doing "many foolish ones," which indicts utopian schemes "of all sorts," including Fruitlands. For this reason, most read Alcott's wry comedy as a scathing critique of her father's community's patriarchal exploitation of women's labor. Unable to escape the settled system of patriarchy in Alcott's imagining, the work of the community falls ceaselessly to the "overworked Sister Hope" who is helped by only one person (notably a man) in her "endless succession" of baking, child rearing, and "the many tasks left undone by the brethren" (n.pag.). Unlike Sister Hope, the "brethren" were "so busy discussing and defining great duties that they forgot to perform the small ones," suggesting the persistence of gender roles in both labor and intellect even amid a reformed utopian community (n. pag.). Like Davis, Alcott also makes use of the utopian form to illustrate the disconnect between espousing and enacting racial equality. While Alcott mentions at the tale's outset that a "brown boy" is among the "modern pilgrims" en route to the community which "liberates from human ownership," the brown boy is notably alone 
(n.pag.). ${ }^{73}$ He sits beside the driver (rather than in his lap as a second young boy does or playing in the back of the wagon as other children do) and carries "a bust of Socrates" rather than a doll or toy as do the other children of the party. While he later "slumbers peacefully," he does so by "pillowing his head" atop the hard bust, an image of awkward self-comforting that reinforces his otherness to the family's children. Although the child's freedom will be secured at Fruitlands, the thought of that "system of human ownership" outside the community remains, suggesting still his otherness. In fact, Alcott further implies that he will remain distinctly "other." For he is outside the embrace of the family and is tasked with labor (albeit minor) for the driver, who presumably owns the bust. Nevertheless, Alcott's brown boy is welcomed at Fruitlands, while Bellamy's Sawyer is left to perish in the past.

However, to Alcott's credit, she does take up more directly the question of utopia's potential for racial equality in the closing chapter of Work: A Story of Experience entitled "At Forty." Herein the novel's protagonist Christie Devon Sterling imagines a "loving league of sisters, old and young, black and white, rich and poor," but only after directly and openly criticizing the systemic mistreatment of black women and endemic problems of class. Although at times Christie's discussions with Hepsey, the novel's central black character and a fugitive slave with whom she works, are troublingly caricatured, I would argue that Alcott arranges the interactions to demonstrate and critique white privilege, by highlighting Christie's. For example, Hepsey's stories of her enslavement redefine the word "degrading” for Christie, helping the white woman to understand the systemic injustice of race. More than that, Christie then reflexively and reflectively comments on Hepsey's experiences through admonishing another maid the women work with. Although in the immediate Christie's thoughts scold Katy, Alcott generalize them as a systemic indictment anti-black racism. For Alcott calls out in the simplest of 
terms the absurd logics of racism: that "white skin" gave anyone the "right to be disrespectful" to another "just because she was black" (n. pag.). ${ }^{74}$

Alcott also calls to readers' attention to the disconnect between women of different classes within advancing labor and right's reform. Although Alcott's criticism of workers "pour[ing] out their wrongs and hardships" bears some of the "unconscious condescension" she charges of her characters, I would argue that she successfully uses the utopian form to wage a metacritical analysis of the discourse of reform. Arguably, when Christie rises to speak at a meeting of working women, having learned the lessons of systemic racial and class privilege, she is an embodiment of a utopian voice for reform, "a mediator to bridge across the space that now divided them" (n.pag.). For when Christie addresses the crowd from within it, eschewing the stage, and offers a short speech of experience with "no learning, no statistics, and no politics" of the esoteric speeches preceding it, the "women felt" she "was one of them" (n.pag.) Although Alcott problematically positions the white, trans-class Christie whose relative privilege allows her to choose work and move rank as a messianic female figure, Christie nevertheless allows Alcott a critical position from which to openly reject the white male utopian complex's prejudice of race and rank. In fact, Alcott arguably displaces Bancroft's notion of America's Providential design. For as she centralizes the quest to "'get religion,"” she critiques Churches and creeds as "cold and narrow" or "theatrical and superficial" or even "stern and terrible" (n.pag). For she suggests that their "machinery...walls, laws, and penalties" reforge the settled systems of white male supremacy, the very "institutions" Bancroft sees as the work of a divine hand (n.pag). Perhaps even more progressive is Alcott's longing for a "natural religion which has no name but godliness" that she likens to a "mother's love," another profound reframing of systemic 
patriarchal oppression unimaginable, even in Looking Backward, whose twenty-first century sermon, given by a (white) male remains of the "stern and terrible" variety (n.pag).

However, it is perhaps Annie Denton Cridge's largely-overlooked Man's Rights; or, How Would You Like It? (1870), a role-reversal satire wherein women oppress men, that most explicitly maps and targets systemic patriarchal oppressions through the utopian form. Set on the planet Mars and written as a series of dreams that span twenty years, Annie our narrator/author/traveler identifies with the oppressed Martian men and their efforts to organize a men's rights movement, yet Cridge, I would argue, subtly suggests waging war on systemic inequality. For Cridge sets the utopia on the planet Mars, whose name is taken from the Roman god of war, and thereby rejects the feminine-aligned and nearly-equidistant Venus. In fact, even the novel's titular sneer "How would you like it?" arguably wages an affront to readers. Yet, it is perhaps the premise — a radical gender role-reversal — that most clearly reimagines the utopian form as a way to confront the inefficacy of hierarchical systems for human progress. Clearly a metacritical utopia, Cridge highlights throughout the text the means of oppression-intellectual, emotional, physical, domestic, social—and the effect each has on society's beleaguered men. The shock of these ekphrastic images of oppressed middle-class (white) men was one to which no reader of Woodhull and Claflin's Weekly, where the work was first published in serial, would have been accustomed. In this way Cridge's approach redirects readers' attention to the relatable and familiar within such images, that is, to the structure of oppression itself. Importantly, she draws attention to oppression as a construct, and to the contortions of oppression-from the denial of education to (wo)men's fashion - as unnatural. Usefully, Cridge also turns a critical eye to phrenology, the pseudo-scientific discourse underwriting scientific racism and later eugenics, as unnatural. ${ }^{75}$ Through her attention to systemic formations of oppression, Cridge points out the 
fallacies of science that circumscribe and delimit women's potential and the means by which they are naturalized. Highlighting the errant logics of phrenology, Cridge explains that since "woman has phrenologically a larger organ of language than man" and is therefore "the natural orator," women serving as "senators and representatives, as lecturers and orators" is precisely as "Nature intended" (31-32). By means of such a reversal, readers' attention is drawn to the discourse of phrenology, to how singular physical observations have lead American men to disproportionate, unfounded, and unverifiable conclusions about the intellect and "moral" character of both women and people of color, which I would argue Cridge wittingly conflates as a mutual target given her later gestures to racial oppression as well given her focus on phrenology (Stanton, Leopard's... 33). For it is through phrenology the Samuel P. Morton's Crania Americana (1835) noted that the cranium of the male "Caucasian was distinguished for 'the highest intellectual endowments"' while, by contrast, those skulls of Ethiopian tribes "constitute[ed] "the lowest grade of humanity" (33). And, as the novel suggests, Cridge recognized the importance of indicting scientific discourse as a constructed means of oppression. For in an increasingly science-minded culture, such errant "discoveries" were not only rendered as natural, as proof that patriarchy was as "Nature intended," was a Providential design. ${ }^{76}$ In this way, Cridge importantly uses the utopian form to highlight both women's oppression and systemic oppression as a discursive construction, not a natural condition.

Further, just as Cridge targets rigid gender roles and pseudo-science as means of systemic oppression, she also targets religion. Perhaps waxing blasphemous for a more conservative reader, Cridge not only reimagines women translating the bible, but implicates Biblical translation as a discursive means through which men have long-manufactured systemic inequity; for as one men's rights advocate reminds us "those who wrote the books of the Bible...wrote as 
they believed" (43). Here, Cridge again uses the voice of a men's rights advocate to link systems of gender and race oppression, adding that "God...never utters the word inferior," adding that "no color" is "inferior or superior to any other" in his "blending of color" to create humanity (43, emphasis added). While Cridge's main focus is women's rights, like many former abolitionists she draws on the rhetoric of abolition, while largely avoiding a simplistic equation of the two. Instead, I would argue that she calls attention to how such systems are mutually manufactured and manipulated to maintain white male supremacy. In fact, the very gender reversal the utopian form allows her points to the liberating malleability of these systems, to how they, like the utopian form, can be reimagined, a threatening notion for the white male utopian complex.

Finally, I would suggest that the significance of Cridge's work lies not only in her critique of the present, but in her imagining of the future. Well before Julian West fell into a mesmeric sleep and Bellamy ekphrastically gestured to fairscape architecture as the symbol of the utopian future, Annie's dreamscapes culminate in a fair. Indeed, the fiftieth annual "Women's Agricultural Fair" not only returns readers to Earth, but to the America of the future. In fact, Cridge's work may be the first to recognize the discursive relationship between the utopia, the fairscape, and national identity. Cridge even provocatively uses the fair to propose a remedy to the problem of removing the intentional utopian community from mainstream society. For, as she explains, while the fair began with a "movement for placing [poor working] women on the land" and its instantiation resembled an agricultural utopia, it did not seek to remove women from mainstream society. Instead, it physically removed women to develop a livelihood that would allow them to participate in a larger economy. Indeed, rather than removing women from dominant society, in Cridge imagines these women and their husbands moving freely between farm and city, where women were employed as lawyers, doctors, bankers, and other 
esteemed professionals. Yet, despite Man's Rights's inventive plot and its serial publication in the notoriously-controversial feminist periodical Woodhull and Claflin's Weekly, the work, like its metacritical mates, remains largely overlooked, or, at best, in the margins of our present historiography. ${ }^{77}$

\section{A Revised Historiography, a Revised History}

The object of the present chapter has been to explore and discuss how and why we have overlooked the 'race question' in our discussions of nineteenth century utopian forms. As I have argued here, there is a fundamental relationship between nation-building and racial exclusion.

For the founders' fundamental utopian aspiration to "form a more perfect union" is nearly immediately limited by exclusionary discourses on the 'race question' and the 'gender question,' as they give the nation physical and ideological form. From this perspective we see from inception how government buildings and schools, libraries and museums not only transmit those selfsame ideologies of white male supremacy, but were the earliest exhibits of a white utopian complex. ${ }^{78}$ Tracing this early historiography of utopian thought in America, I suggest that we find a different sense of our own history. We find a lineage of thought that prepares us for understanding the appeal of Bancroft's sense of (white) America as the fulfillment of a Providential destiny. We find a continuity of thought that explains the nearly-unmatched popularity of Looking Backward's tale of a white utopian future, free from the conflicts of race and class. We find a context for the almost-entirely overlooked and unexamined whiteness still governing the historiography of the nineteenth-century American utopian novel.

Although the whiteness of the nineteenth-century utopian canon and its scholarly historiography is a rather obvious point, little scholarship has critically discussed this whiteness. And far less has consider how this fundamentally national imaginary affects our cultural history 
even today. For rather than turning to the first third of the nineteenth century when utopian communities flourish or shortly thereafter to the spate of reflective and reactive utopian narratives that I discuss here and emerge in response, the historiography of the era's utopia nearly always centers late in the century on Bellamy's work. While I do not wish to diminish the significance of Bellamy's work, we need to reframe our historical understanding of it. As I have argued here, such a reframing helps us to cast in relief both Bellamy's anxious preservation of whiteness and the nation's. When we return to the variety of co-emergent phenomena in the middle of the nineteenth century - to the birth of the international exhibition, to the beginnings of history as a discipline, to some of the earliest skeptical, self-reflexive utopias by well-known writers still largely outside the historiography we tell—we find a remarkably different trajectory. More than that, we find that our inattention to the genre's whiteness and its relationship to the ideological and physical nation-building has helped to maintain systemic white supremacy. For, if any genre demands we consider the whole of our national history and the systems and people who defined it, it is the utopia. For utopia is the genre that straddles the line between fiction and reality precisely to engage with history to explicitly reimagine the nation, its systems, and its citizens.

Rather than calling for the displacement or replacement of Bellamy's monumentallysignificant work, we need to reevaluate its whiteness, reassess its "reform," and reconsider why it has remained such a formative part of our historiography and history. Rehistoricizing Bellamy in this way is a step toward recovering a lost and fundamentally racialized, gendered, and classed intellectual history long overlooked. It allows us to refocus on how the conventions of the utopian form helped to naturalize white supremacy in literature and culture. It allows us to reconsider the long-excluded works of women and blacks in a lineage of metacritical utopian 
thought that has long recognized and questioned the white utopian complex. Our reading can no longer focus on utopists' hopes for the nation of the future to the exclusion of their pronounced racial anxieties about their present. For it is only through a "palimpsestic reading practice" rooted in recovery and comparison that we might glean a more-complete understanding of the nineteenth-century, reading practice that has overt implications for our own era's imaginings of a more - and less — utopian America (Levine 244). 


\section{Chapter 2: Exhibiting (In)Civility: Reframing the Eugenic Logics of the White City Beautiful and Reclaiming a Space for Black Resistance}

Of the opening of the Crystal Palace, no pen...can do justice to the whole display. It has never, in all its parts, been before excelled, and probably never will be. ... The United States, I am sorry to say, have not fulfilled our expectations [but] ... we have, I think it is admitted generally, the finest piece of sculpture- “The Greek Slave," by Powers.

-Mr. Johnson in The Cultivator, July 8, 1851

The Americans, as far as appearance goes, are behind every other country in the Exhibition. The "Greek Slave" is the only production of Art which the United States has sent. And it would have been more to their credit had they kept that at home.

-William Wells Brown, Three Years in Europe (1852)

$* * *$

The things most impressive at the Chicago World's Fair are by this time common property. [But the first is] an ideal of Beauty never before created in a square mile on this earth. This ideal must strongly and permanently affect the nation.

-Charles Dudley Warner, "Impressions of the World's Fair" in The Critic (1893)

We cut no great figure at this fair. We do not seem to be a part of it. Our time does not seem to be yet. When it will come no man can tell-and yet, I feel sure it will come though it seems like hoping against hope.

-Frederick Douglass, Letter to his daughter Rosetta Sprague (1893)

Joseph Paxton's Great Exhibition building was the centerpiece and defining structure of the world's first international exhibition, held in London, England, in 1851. It was also a defining symbolic and philosophical structure for the international exhibitions held in America beginning shortly thereafter. The Great Exhibition introduced the fairscape as a site for contriving a grandiose utopian image of its host nation that would be echoed in perpetuity. Indeed, Paxton's building remained in use as an exhibition site for more than eighty years in London's Hyde Park and then in Sydenham Hill. For decades afterward, the building, recalling the mythos of the fair, had "the impact of a fairy story on all those who saw it open" (Gideon 249). In fact, although the satirical Punch Magazine may have jokingly dubbed the structure the 
"Crystal Palace," the moniker stuck. The Crystal Palace was soon widely adopted and reverently used by the periodicals of the time. And while Paxton had merely intended the building to characterize the event's grandeur and originality, his 'Crystal Palace' soon became a metonym for the event itself, which was often called The Crystal Palace Exposition. But the meaning of the structure soon redoubled when the exhibition was rumored to be the idea of Prince Albert himself. Conceived as a celebration of England's industrial progress, the rumor soon authenticated the fair as an official representation of the nation itself. ${ }^{79}$ And the exhibition could easily characterize England in idyllic terms. For the nation was amid an industrial boom, experiencing a decline in crime rates, and had just successfully emerged from a bloodless Age of Reforms to voting rights, labor, education, and poverty—so long as one overlooked the abuses of the "national prison system," continued disenfranchisement of women, exploitive labor of children and the poor(Meier 1). ${ }^{80}$ Nevertheless, to the onlooker the Crystal Palace and the organization of exhibits therein appeared to be emblematic of the nation's acute civility and progress toward utopia.

Perceiving aesthetic beauty as a means of maintaining social order, the exhibition also helped to engineer urban planning. For the rationale of the exhibition drew from England's public gardens movement, which was "one of the earliest responses to the social and environmental issues raised by industrial urbanism" (LeGates ix). The English reasoned that these issues, which included the unsavory aspects of development such as labor strikes, overcrowding, and poor sanitation, could be mitigated by landscape design. In fact, reinforcing the link between the public gardens movement and the fairscape, Joseph Paxton also designed Birkenhead Park. Conceived as a means "to defuse social unrest," Birkenhead became the first park open to the general public in 1844 (Quest-Ritson 205). Seen in the context of this earlier 
social engineering, the exhibition and its narrative of nation might be seen as national propaganda. For the exhibition was a means by which the England could control its national narrative for a world audience; at the Crystal Palace, the nation could emphasize its civility and progress toward utopia. Yet contemptuous radical reformers would tell a much different story, one of women refused suffrage, inhumane prison conditions, exploited colonies, and the continued exploitation of the 'civilized' nation's laborers, the poor, and its children, among others.

Yet, the nationalistic zeitgeist and spectacular grandeur of the Great Exhibition predominated. How could such a grand display herald anything less than a nation having found the path toward utopia? A path, the exhibition suggested, lying in the engineering of cities-and, tacitly, of citizens. For the Great Exhibition began the "habit of seeing cities as...grand neoclassical architecture and orderly, planned environments" (Judd 6). In fact, given its influence over the American public, I would argue that the Great Exhibition laid the foundation of America's later City Beautiful movement, which many trace, perhaps erroneously, to the Columbian Exposition of 1893. Regardless, the Great Exhibition offered its visitors a "millennial dream of a peaceful and progressive new world order" (Rydell 3). But to America, it also offered a framework for melding urban planning with social engineering reaching well beyond the fairscape, a utopian framework that would underwrite social theory, policy, and practice from scientific racism to restrictive immigration legislations to social segregation. As scholars have noted, the Great Exhibition was a way to “propagate the ideas and values of the country's political, financial, corporate, and intellectual leaders" on an international stage (Rydell 3). And part of that propagation, too, was the "proper interpretation of social and political reality," a properness also determined by a nation's industrial and political leaders (3). Although on the 
surface this first exhibition celebrated English progress and paid homage to an increasingly global and competitive modern economy, it was also a means to exert social control. It was a means to excluded the voices of the resistance as perilous threats to industry—-the striking laborer, the rallying feminist, and, in America, the freed slave. It was a means to advance an increasingly-restrictive urban planning as the path to a utopia—for a white elite, that is. It was a means to design an ideal national narrative for a utopian nation.

In this chapter, I argue that the Great Exhibition offered America a conceptual framework for imagining and advancing a white nationalism. Suggesting its influence, shortly after the Great Exhibition closed, New York commissioned of its own "Crystal Palace" for its proposed 1853 Exhibition of the Industry of All Nations. And while the overt call for a "Palace" of its own reveals the Great Exhibition's architectural influence, it also registers America's sense of rivalry and desire to prove itself. And, more nefariously, I will argue it partly inspires America's mitigation of its "race problem" through urban planning (see figs. 15-16). For this burgeoning fair culture gave America's white elite a new means to advance a "proper interpretation" and proper order of the nation's social reality for both its inhabitants and international visitors. In this way the American exhibition became almost immediately a means to acculturate its population of immigrant laborers - and to demarcate their social place. It also became a way to redirect attention from the nativist fears of these encroaching immigrants that gave rise to the Know-Nothing Party and from contentious legislations like the 1850 Fugitive Slave Bill. In this way, I suggest that envisioning the Great Exhibition as a starting point for the American fairscape helps us to understand the latter's history of gendered and racialized exclusions. 
However, I also look to organized black resistance to the American exhibit in London as establishing a pattern for resisting the white supremacist narratives the fair naturalized as national progress. For this reason, I read fugitive slaves William Wells Brown's and William and Ellen Craft's orchestrated challenges to America's silence about its slave economy at the Great Exhibition as establishing a precedent for black intellectual resistance to the white-imagined national narrative. For we later see this type of organized intellectual resistance reiterated in Ida B. Wells's and Frederick Douglass's The Reason Why the Colored American is Not in the World's Exposition, printed in response to the 1893 Columbian Exposition's exclusion of African Americans from participation. For Brown and the Crafts as well as for Wells and Douglass, the fairscape was not simply a fair for black Americans and Chicago's "White City" was not exclusively an architectural marvel. It was a city for whites and a starting for a City Beautiful that would call for a more aesthetic urban design largely by removing immigrants and blacks. Indeed, while the fair and its 'White City Beautiful' "paraded the nation's history as the natural outcome of an exceptional [white] people destined to be great," under its guise of beautification and sanitation, I argue that it also anxiously targeted those of color, envisioning a design for a white American future predicated on their exclusion (Wilson 6).

However, as I argue here, the fairscape was not the only didactic, white-authored work imagining and promoting a utopian future predicated on whiteness. In order to more clearly map the formal relationship between the City Beautiful, the American fairscape, and the so-called "race question" we must look to the literary utopia. The literary utopia magnifies the anxious logics of white supremacy reacting to a tumultuous period of increasingly organized resistances to them among women, immigrants, and blacks. More than that, the literary utopia seems to have both generated and clearly racialized the term "city beautiful." Predating the Columbian 
Exposition's White City, I argue that Oliver Bell Bunce's utopian short story “The City Beautiful" (1889) clearly maps and racializes the movement's preoccupation with sanitation and beautification. More than that, the novel clearly positions the "city beautiful" as a means to manage America's negro and immigrant "problems," both of which were distinctly "race" problems, as our visual cultural records. ${ }^{81}$ Indeed, by the late 1880 s, a Harper's Weekly cartoon penned by Thomas Nast titled "The Ignorant Vote...," documents the convergence of these two "problems" (see fig. 17). Literally balancing a scale to equate the Irish immigrant voter of the North to the Black voter of the South, the cartoon makes overtly clear the tendency to conflate 'immigrant' with 'black' in the national imaginary as a threat to the white racial order, symbolized by their voting. Mindful of this white anxiety and cultural conflation of "races," I then turn to William von Swartwout's The Beginning, A Romance of Chicago as it Might Be (1893), and William Dean Howells's “Letters of an Altrurian Traveler” (1894), two literary works that uncritically, and, I would argue problematically, embrace the Columbian Exposition's White City as the fulfillment of an American utopia. ${ }^{82}$ Significantly, these works further reinforce a generic and ideological relationship between the fairscape and the literary utopia.

Finally, this chapter takes a step toward recognizing how the unexamined narrative of a white City Beautiful in the literary utopia, at the fair, and as a national design both fosters and distorts our historiography of the nineteenth-century American utopia. Looking to our historiography as uncritically preserving the literary utopia as a white narrative form, I argue that we must reconsider that whiteness an anxious whiteness responding to a perceived racial threat. To that end, the final sections of the chapter focus on how Wells's and Douglass's The Reason Why reclaim African American history, recount black progress, and claim a space for black selfrepresentation. Further, I argue that this work also offers a black intellectual approach for 
indicting systemic white supremacy while critically highlighting the fairscape as a site advancing the white utopian complex. It is for this reason that I conclude with a discussion of Frances Harper's metafictive utopian novel Iola Leroy (1892) and her thematically-related address at the Columbian Exposition. For in both of these works Harper, too, indicts the systemic white supremacy underwriting the literary and legal imaginings of a utopian America as a white America. I argue that her work provocatively highlights the constructedness and instability of racial categories and even implicates her white and female audiences to wage a resistance to the white male utopian complex.

\section{The Influence of Great Exhibition}

In many ways, the American display at London's Great Exhibition forged the fairscape that would take shape in America. In fact, in response to news announcing England's intention to hold an exhibition, America nearly-immediately expressed a desire to hold its own international exhibition, a response that bespoke the fundamentally competitive spirit of these events and America's perception of England as both a relative and a rival. For more than a year before the Great Exhibition opened, the Scientific American published an article asking "and why cannot America have such a World's Industrial Exhibition also," asserting that the nation had "abundant means to make such an exhibition as great... as any other nation whatever" ("World's Convention of Industry in America" n.pag.). And, by 1852 the Scientific American was already reporting on the Exhibition of the Industries of All Nations's plan to build a Paxton-inspired Crystal Palace while its board of directors was already billing it as "a great affair, far greater than the London one" ("Riddle's Fair" n.pag.). Even Walt Whitman's "The Song of the Exposition," written for the National Industrial Exposition of the American Institute in 1871, would still deem the New York "Palace / Loftier, fairer, ampler than any yet" (li. X-xx) ${ }^{83}$ From America's 
architectural replications to the superlative comparisons that both Whitman and the Scientific American convey, the English fair engendered a sense of competitiveness and national chauvinism. And this chauvinism was ultimately essential to the development of an increasinglygrand, increasingly nationalistic American fairscape. By the Columbian Exposition of 1893, the scale and crowd of American fairs more than double, and, as scholarship has suggested, more so than any other nation, America treated the exhibition as a didactic site for asserting a national identity, one that was markedly white. ${ }^{84}$

In America, exhibitions were not merely an international celebration of industrial progress; they were sites to offer lessons in national history and to engineer an official (and acutely racialized) narrative of nation. Reflecting the influence of the Great Exhibition, the American fair grew as an aesthetic, social, and historical "search for order"” (Rydell 4). This is, perhaps, most visible at the Philadelphia's Centennial Exposition of 1876. With the "outbursts of open class warfare" increasing and an "intense and widespread anxiety" growing in the postReconstruction Era, fair organizers saw the Centennial as a means to advance a unified white national identity (4). Foremost, the fair directors centralized the Goddess Columbia (and later Lady Liberty) in fair literatures, as a unifying image for fair and nation. Seeking a unifying visual image of nation, American fairs cultivated Columbia as a symbol of the nation and its people and she adorned nearly every official advertisement, guidebook, and history of these Centennial and the Columbian Expositions. And in a chaotic time, she was used to evoke the nation's sense of its own unity, civility, and providential design. Moreover, as a symbol of nation rendered in a High Greek Classical style, she literally signified America's assertion of its superior whiteness (see figs. 11-12). Yet the white elites at the helm of these fairs were not only concerned with visually branding national identity, they were concerned with narrative branding 
as well. For this reason, fairs advanced both an official image of the nation and an official narrative of its past. Unlike the majority of fairs held elsewhere in the world, American international fairs often doubled as national commemorations. For example, the Centennial Exhibition of 1876 commemorated American Independence, the World's Industrial and Cotton Centennial of 1884 celebrated the earliest record of a cotton export to England, and the World's Columbian Exposition of 1893 celebrated the sesquicentennial of the nation's "discovery." In fact, perhaps in prolonged response to its underwhelming performance at the premier English fair as well as its youth as a nation, scholars note that more fully than any other nation, the United States took up the mantle of education seeing it as an opportunity to advance an official historical narrative. For America, the exhibition was a site to "morally educate the working classes" and to acculturate its immigrant inhabitants to a white middle-class American identity (Greenhalgh 19). In fact, by the 1904 Louisiana Purchase Exposition, historian Henry Adams would recognize and comment on the integral role the exhibition played in national education. As he put it in The Education of Henry Adams (1907), for a young and growing nation of immigrants, national education would have been "a blind impossibility" without the "religion of World's Fairs." As Adams explained, the exhibition offered a sense of past and future as well as a unified identity for "Germans or Slavs, or whatever their race names" as the "new American" (358). Pointedly, Adams's pronouncement was markedly racialized. In fact, his hurried collapse may of immigrant 'races' "whatever their...names" may convey a sense of anxiety of racial difference that the fairinspired "new American" could allay. Adams more concretely suggests that the fair's "chaos of education" helps to mitigate the threat that these "racial others" posed by turning the new American into a "servant of the powerhouse," a servant of industry and the state (358). In other words, Adams recognizes that the "religion of World's Fairs" was an anxious manipulation of 
national identity, an identity designed by the white elite to foster patriotism through propagandistic education and compulsory assimilation. ${ }^{85}$

As it inspired the educational impulse of the American fair, so did the Great Exhibition foster the nation's compulsive desire to appear "civilized," although some would challenge that image of civility. Nevertheless, the compulsion motivated America's mimicry of English fair's hyper-meticulous organization. Indeed, by the Centennial Exhibition scholar would argue that America was the standard for "systematically arranged and classified," a standard that also communicated an overt racial hierarchy by the time of the nation's Columbian Exposition's White City (Conn 206). However, even though scholars point to America's distinct emulations of English exhibits and exhibition practices, the trajectory of the English fair's philosophical, or perhaps, psychological, influence over the American notions of "civility" is problematically overlooked. ${ }^{86}$ This anxiety of influence seems particularly important when one considers that 1850 fostered a wave of America's own citizens impugning the nation's "civility." For at the same time England was planning the Great Exhibition as a means to usher in a new world order of design and manufacturing, politics and free trade, the United States Congress was passing its second Fugitive Slave Act. Rather the opposite of a new national order, the act vigilantly reinforced black enslavement and limited the freedoms of whites by lawfully obligating them to perpetually surveil blacks. ${ }^{87}$ Given this expanded encroachment on white freedoms, too, the law drew scorn from the general population and abolitionists alike. Even Ralph Waldo Emerson, at first a reluctant abolitionist, was moved to speak on the law's dystopian effect on the nation and its citizens. "We do not breathe well," Emerson opined to the citizens of Concord, Massachusetts, on May 3, 1851, a mere two days after the Crystal Palace opened in London; "there is infamy in the air," he continued, caused by the "painful sensation" of the "odious 
remembrance of that ignominy which has fallen on Massachusetts" and "robs the landscape of beauty" (Emerson 170). Significantly, despite the fact that slave-grown cotton accounted for nearly half of the nation's export earnings at the time and the renewed public discussion of slavery concurrent to the exhibition, the American display at the Great Exhibition made no reference to its slave economy ("Was slavery the engine of American economic growth?"). In fact, the single reference to slavery in the American department had nothing to do with the chattel enslavement of blacks in the South. Instead, Hiram Powers's The Greek Slave (1851), a sculptural lamentation of the cruel fate of enslaved, idealized white women, stood unabashedly, unironically at the center of the American department. Arguably, it even audaciously suggested that while there were appropriate slaves to mourn, the enslaved black Americans were not among them.

However, neither the exclusion of slavery nor the inclusion of The Greek Slave went unnoticed by William Wells Brown and William and Ellen Craft, fugitive slaves who visited the exhibition. For this reason, I would argue that the Great Exhibition also marks the beginning of an increasingly-organized black response to the whitened imaginings of nation within the American fairscape. Yet, this resistance goes largely unnoted in exhibition history. Even Mable O. Wilson's revolutionary Negro Building: Black Americans in the World of Fairs and Museums (2012), the first full study of black participation in fairs, overlooks this significant site of resistance. While Wilson importantly notes that "black Americans used the fairs to vigorously respond to how they were being portrayed and positioned," confronting headlong the "powerful and persuasive narratives of [white] civilization," her study begins with the Centennial Exposition of 1876, missing the what I would argue is a substantial moment in the history of black American resistance at fairs (7). For Brown and the Crafts, who visited the Great 
Exhibition a number of times, waged a vital disruption to the American department's official narrative therein. Their presence told the story of a vastly different America and drew attention to the blatant contradictions of American "civility" that Powers's "moral nude," as its centerpiece, meant to conjure. However, while the white American press and visitors alike crowned Powers's work the exhibition's “finest piece of sculpture," the irony of the nation's garish appreciation and aesthetization of an enslaved white woman while omitting any reference to its own economic reliance on chattel slavery was not lost on the fugitive slaves therein or England's Punch Magazine. Punch Magazine, the same popular publication credited with coining the term "Crystal Palace," published a scathing political commentary in the form of a caricature entitled the "Virginia Slave," which would give rise to Brown's most noteworthy resistance at the fair (see figs. $3 \& 21$ ). The cartoon, which echoed the composition of Power's sculpture, featured a partially nude black woman manacled at the wrists and ankles. In contrast to the nearly-demure countenance and posturing of the "Greek Slave," the "Virginia Slave" cowers, her face is mournful and haunting, her blank eyes gaze upward and away, as if in disbelief. Highlighting the nation's hypocrisy, the pedestal is emblazoned with the Latin words "E pluribus Unum," or, “from many, one." A proposed national motto meant to stress the nation's unity, here is stresses only the extent of its slavery. Significantly, the political cartoon made its rounds in American abolitionist papers and at the Exhibition itself, amplifying Brown's and the Crafts's demonstrations of resistance. As abolitionist William Farmer writes in a letter to The Liberator's editor William Lloyd Garrison, during one visit to the exhibition William Wells Brown "drew a small crowd" by depositing a copy of the political cartoon "within the enclosure by the Greek Slave,” and openly proclaiming: "“as an American fugitive slave, I place this 'Virginia Slave' by the side of the 'Greek Slave,' as its most fitting companion'” (Farmer, n. pag). Brown's 
juxtaposition of these two images, though short-lived, brought a semblance of gravitas to the political cartoon's wry conclusion in the moment and reflectively in the press, ultimately "counteracting the façade of philanthropy and goodwill that [white] Americans would present" at the exhibition (Blackett 32). However, black abolitionists and British satirists were not the only groups openly indicting the international exhibition as a utopian façade, mere subterfuge masking each nations' dystopian realities (n.pag.). By March of 1853, the year of America's first international exhibition, the Provincial Freeman published a short story entitled "Mrs. America Answers Mrs. England." In the satirical dialogue that ensues between the two nations personified as women, each suggests the other is less civilized for its treatment of women, laborers, and, in America, slaves. In fact, the story progresses by each goading the other to make a more accurate representation of their nation at the forthcoming New York fair. While the story concludes in no uncertain terms that "nothing" compares "to the all-blighting curse and all-encompassing horror of slavery," it also critiques the idyllic nationalism of the exhibition and draws attention to the host of inequalities undiscussed therein ("Mrs. America..." n.pag.).

Yet, the dominant white narrative of these events would continue to quash resistances to it. For The Greek Slave was again exhibited as a centerpiece of the American Crystal Palace in 1853 while nearly a quarter of the nation's population was enslaved. By the Centennial Exhibition, black Philadelphians, despite forming the "largest black settlement outside of the southern states," found little representation at the fair outside stereotyped concession or entertainment work requiring “"coon attire”" (Wilson 27, 28). And by the Columbian Exposition of 1893, despite Chicago's large and thriving black communities, Black Americans were not only denied a Negro Building and excluded from organizing boards, they were belittled by a series of racist caricatures in Harper's Weekly. Therein the typical "black family at the fair" was 
bestialized and likened to the African "savages" among the fair's ethnographic displays (Rydell 53) (see figs. 19-20). In fact, this seemingly popular comparison of the American Black to the African led at least one Columbian souvenir book to draw an infuriating apologia for slavery as "most encouraging and wonderful," since it had so "advanced social conditions of African Americans over that of their barbarous countrymen" (Rydell 53). And this sentiment was increasingly formalized by the hierarchical racial organization of fair displays. As one curator would explain, displays were arranged by nations' degree of civilization and designed "“to teach a lesson; to show the advancement of the evolution of man"” (qtd. in Rydell 57). Indeed, at the American fair, that lesson was a seemingly naturalize visual economy of race moving from savage darker people to the civility of whiteness.

Most fair scholarship overlooks how the Great Exhibition contributed ideologically to the American fairscape's anxious racialization, crystallization of a white national narrative, and even to the development of organized black resistance to the fair's production of a white utopia America. While scholarship usefully recognizes that fairs after the Civil War used the fairscape "to reaffirm their collective national identity" and fashion the future as a "synthesis of progress and white supremacy," my research suggests that the racialization of the American draws from the nation's anxious preoccupation with stressing its "civility" in the Great Exhibition (Rydell 4). Further, as I argue in the next section, resituating the Great Exhibition's insistence on the relationship between aesthetic design and social decorum allows us to reconsider the origin and hygienic preoccupation of the Columbian's White City and ensuing City Beautiful Movement. Indeed, I would argue that the nascent ideologies of the City Beautiful Movement, such as its tacit advocacy of nativist legislations and racialized slums, may lie within England's philosophy of the public garden's inspiration of social decorum. 


\section{White Anxiety and Eugenic Design in the City Beautiful}

The City Beautiful Movement was an American philosophy of architecture and reform in the late nineteenth century, but the movement was far from sui generis. As several studies of urban development have noted, it was England's Great Exhibition that began the "habit of seeing cities as...grand neoclassical architecture and orderly, planned environments" (Judd 6). Evidenced in the nation's quest to recreate London's Great Exhibition in New York in 1853 as well as in its use of the fair to reassert national unity after the Civil War, aesthetic articulations of control and containment, such as the City Beautiful, doubtlessly appealed to Americans (Judd 6). And given the landscape of a swelling immigrant population, the first black migrants heading to urban centers, and unprecedented population growth in major cities, it is unsurprising that just such a utopian movement emerges in the much less idyllic urban reality of labor unrest and racialized slums. ${ }^{88}$ For this reason, it's also unsurprising that the Columbian Exposition's racially-inflected White City comes to be seen as the first articulation of the movement. And in this way, the White City gave new life to the nationalized and racialized program of urban planning that formally became the City Beautiful Movement. Marking the fairscape as its first expression, the Movement explicitly reasoned that "the civic life of cities could be energized by the construction of monumental buildings, parks, and public spaces set aside for the middle classes," which implicitly focused on eradicating the slums and their non-white inhabitants (Judd 6). Claiming the Columbian Exposition's White City as the first true articulation of the City Beautiful also cultivated the romantic notion that the nation's cities could become a utopian 
"white city," suggests the racialized means by which white utopian frameworks might alter the nation's political realities with such a goal in mind.

As I will argue, the City Beautiful Movement was much more than architectural in design. Growing from whites’ fearful eugenic logics of immigrant encroachment and miscegenation, which strengthened during the late nineteenth century, the movement was an organized and anxious articulation of white nationalism. It was a means by which the white national order might regain control over its slum-filled cities and it relied on a utopian narrative. For, in no uncertain terms, the movement actively stressed the positive re-planning of the cityscape for (white) middle class use. And those plans simultaneously necessitated the protoeugenic removal of the laboring classes through the encoded and utopian rhetoric of "hygiene" and "sanitation" as a national panacea. In fact, even architectural scholars have argued that the City Beautiful Movement should also be considered "a complex historical force...linked to the broader sweep of urban reform in the United States" and rooted in the nation's "new citizenship ideal” (Peterson 100). In other words, the City Beautiful Movement should be considered as advancing a motivated, and I would argue white, utopian narrative of nation. For, significantly, the movement filled volumes defining itself and literally imagined and implemented new citiscapes and new rationales for their citizenry. In fact, the most famous of these was the unmistakably-nationalized 1902 McMillan Plan for the National Mall and area surrounding the Capitol. Far from the project's overt emphasis on national beautification, it quietly focused on eliminating the area's "notorious slum communities" (Gutheim 43). With this nationalized and racialized trajectory of the movement in mind, as one critic has aptly noted, "it is unimportant whether or not the World's Columbian Exposition was actually the origin" of Movement (Steffensen-Bruce 96). For, as she notes, what is significant is that "those involved in 
the movement afterward," including fair director and Daniel Burnham and fair landscape architect Frederick Law Olmstead who comprised half of the McMillan Commission designing the Mall, "believed the Chicago fair to be a starting point and the first exemplar of the City Beautiful," ever linking the nation's ideal city to the White City, with all its attendant racialization (96).

While the National Mall may be the movement's most significant project, it was the zeitgeist of the Columbian that helped to immediately establish the National Municipal League for urban reform. The League, a collection of city leaders including fair architect Frederick Law Olmstead and future U.S. President and eugenics proponent Theodore Roosevelt, first gathered in 1894 to discuss the future of American cities and elevated urban planning to a national concern. Signifying the Movement and the League's inherent anxiety to preserve whiteness, it would soon wax eugenic in its program. In his inaugural speech, the League's president emphasizes that “"the first essential for a good city government is good citizenship," gesturing not only to the movement's physical reform, but to its impulse toward social and political reengineering (qtd in Peterson 100). Such a pronouncement also raised an ominously eugenic question of just who could become a "good" citizen, what the metrics of such a measurement might be, and, relatedly, what might be done with those not making the cut. In other words, from its inception the League raised questions of citizenship and exclusion at the national level, questions that almost immediately raised others about immigration, citizenship, and race. Unfortunately, scholars of the City Beautiful Movement who stress that the movement's "Civic Reform" do not directly pursue the question of race in relation to these imaginings (Pregill and Volkman 584). In fact, while one scholar ultimately names racism among the "unintended and pernicious outcomes" of mid-twentieth century expressions of urban reforms in the lineage of the 
City Beautiful Movement, he overlooks entirely that the problems central to calls for urban reform in the late nineteenth century were widely-linked to individuals' race, class, or both (Platt 101). Instead, many of these works focus on the movement's "new citizenship ethic" as if it were transcendent of racial identity, rather than the means of affirming the whiteness of citizenship I read it as (Dowden-White 59). Despite the swift appearance of racially-encoded discussions of "cleanliness," "hygiene" and the not-so-subtle politics of "slum" identity, scholarship on the City Beautiful Movement largely overlooks the period's treatment of race as a contagion (59). Yet this rhetorical subject was overt in 1892 when medical screenings to assess an immigrant's 'fitness' and any subsequent deportations at the Ellis Island Immigration Depot targeted only steerage immigrants - markedly not those traveling First Class. Putting "fitness" and "hygiene" in conversation with the City Beautiful Movement, it becomes clear that these sites were not entirely focused on "building a metropolitan nation." Instead, they were a means of determining and prescreening one's socioeconomic and racial worth, their ability to become "good" citizens, in a White (City) America (Platt 95).

As my research suggests, scholarship on the City Beautiful Movement focused on the positive effects of urban development as a way to mitigate the rise in tenement housing, waste production, and crime for its (white) middle-class inhabitants. However, this scholarship rarely acknowledges its complementary focus: the humans implicated in such calls for "sanitation," the effects of reforming the city's "slums" on immigrant and black inhabitants, and on ensuing restrictive immigration. In fact, some empathetic treatments of slums life toward the century's end, such as Jacob Riis's How the Other Half Lives: Studies Among the Tenements of New York (1890), which exposed poverty's relationship to ruling-class corruption, or Lincoln Steffens "The Shame of the Cities," which offered a series of researched historical sketches on inner-city 
poverty to the readers of McClure's Magazine, the white middle-class conviction that slums were the inevitable result of poor breeding and a blight on the nation remained dominant. And, as I will argue here, this prevailing opinion of slums as the result of individual moral weaknesses among the immigrants and blacks therein cannot be overlooked. In fact, I suggest that our positive programmatic focus on the City Beautiful Movement and its expression at the Columbian's White City, obscures the popularity of rhetorics condemning and racializing the immigrant as a blight to be removed from the city. ${ }^{89}$ In fact, when visiting the Columbian in 1892 prior to the exposition's opening, Julian Hawthorne, son of Nathaniel, distinctly commented on the utopianism of the fairscape, once the blight of the immigrant is removed. For the younger Hawthorne characterized the fair as utopia, as "a world...in which ugliness and useless[ness] have been extirpated" and where "the beautiful and useful alone [were] admitted" (Hawthorne n.pag.). And by "the beautiful and useful alone," Hawthorne means "the countless thousands of well-dressed [white] people," since they will replace the "Micks and Dagos...who now mottle the barren spaces" (n.pag.) Here Hawthorne implies that whites, not "Micks and Dagos" should inhabit the fair and points to the fairscape, and, by extension the City Beautiful, as a restricted and white urban space. Conversely, with this relationship between a utopian fairscape and racially-restrictive cityscape in mind, it is unsurprising that the city "was a prime symbol of chaos" for the white utopian author, who often noted or alluded to the its immigrants, poverty, and crime (Roemer 151). For these authors, like the "utopian visionaries" at the helm of the City Beautiful Movement and the Columbian Exposition, "dreamed of an ideal city...of the future," an ideal city that they, unsurprisingly, linked to the exclusion of the likes of "Micks" and "Dagos" who "mottle"-literally color-the scene (151). 
Significantly, even Charles Mulford Robinson's groundbreaking Modern Civic Art; or, the City Made Beautiful (1903) recognized racialization as central to the City Beautiful Movement by the beginning of the twentieth century. Robinson, a pioneering urban planning theorist and professor at the University of Illinois, one of two universities offering courses in this burgeoning discipline, grounds his utopian description of the City Beautiful in the need for "an improved tenement" (9). He imagines the City Beautiful as a "vision of a new London, a new Washington, Chicago, or New York" and as a salvation from the very "degradation, discomfort, and baseness of modern city life" (3-4). Further linking "beauty in the city" to "moral, intellectual, and administrative progress," his work surprisingly admonishes the white elite's notion of poverty and crime as individual moral weakness (245). Instead, he meritously argues that "modern scientific studies" conclude "social problems are to a large degree problems of environment" and that civic design—not eugenic—could foster "saner minds because of stronger bodies" (245). In this way, Robinson's forward-thinking work, foundational within the field, attends directly to the intersectionality of race and class - to the poor in its "many gradations" and "rich complexions" $(254,260)$. He openly criticizes the attention paid to "considerations of hygiene and sociology [rather] than those of political justice" and advocates for integrating elements of immigrants' home nations within the design (254). Herein he proposes "street features that respectively make the German, Italian, Frenchman, and Chinaman entirely at home in the street...for the comfort of the poor," suggesting an orchestrated heterogeneity in contrast to the widespread belief in the "necessity of assimilation" to meet the nation's white-determined civic goals $(255,261)$. Further addressing the physical and psychological needs of the poor, Robinson advocates for "fresh air and sunshine," more-spacious housing, and "cheap rapid transit," so that laborers may live outside the city where "life [is] not merely bearable, but 
pleasant" $(219,248,253)$. Perhaps most progressively, Robinson calls the riotous reaction of the disenfranchised, racialized city-dweller justified. In a far cry from the nativist lament of white elites whose cities were being lost to the "the Anarchist...the most dangerous kind of criminal" that "Europe has sent to us" or "threatened by an invasion of Negroes," Robinson argues that "political iniquities are bred" of the "depressing social conditions [of]...the city slum" rather than inherent and redirects blame for such conditions to the white elite (Robinson 246). For he provocatively charges that these iniquities are "political evils" and, as such, "render revolution justifiable," an expression of empathy likely to have ranked him among the anarchists in the eyes of the white ruling class (Robinson 246). However, despite the relevancy and significance of Modern Civic Art; or The City Made Beautiful to the burgeoning field of urban studies, his nearly-activist attention to discussions of race and class exploitation, and notable shift in thought from earlier in his career, this work seems to have fallen away from modern scholarship's discussion of the City Beautiful Movement. Arguably, his earlier and less sensitive discussion of race, class, and the City Beautiful Movement at The World's Columbian Exposition reinforce the whiteness of the movement and, arguably, reach a wider popular audience.

Despite the progressive thought on injustices of race and class inherent to the City Beautiful Movement in his later work, Robinson's official historicizing of the World's Columbian Exposition's carried no such criticism, suggesting he, too, was transported by the fair's spectacle. In his essay titled "The Fair as Spectacle," the concluding entry to the first volume of Rossiter Johnson's official, board-commissioned History of the World's Columbian Exposition held in Chicago in 1893 (1897), Robinson's view is much less empathetic. In fact, the essay is fraught with an anxiety to maintain and preserve the white racial memory of the fair, which it transmits to its readership. For Robinson's rhetoric suggests the simultaneity of the 
fair's threatening comingling of classes and races and reasserts whites' official role in ordering and mollifying such a potential threat for the public. To that end, what is noteworthy are the lengths to which Robinson goes to differentiate the Court of Honor's White City from the architectural and human chaos of the Midway's "foreigners" (504). ${ }^{90}$ Although he does characterize the Midway Plaisance as a delightful and educative experience, a "rare opportunity" and "chance for mental broadening," his characterization suggests this "broadening" is a course in race hierarchy. Robinson likens the Midway's "barbarians" to a circus; he calls it "a cauldron of ... peppery savages," notes that reason was impossible therein, and deems its chaotic skyline - a metaphoric extension of its people_- "the despair of architecture" (503-504, emphasis added). In this way, Robinson clearly associates non-whites with the Midway's lack of both social and architectural reason, suggesting that neither the architecture nor its inhabitants belong in the White City. Tellingly, just after whites "rubbed elbows" with those of color at the Midway, they found they had become "an unusual exhibit" therein. Notably, Robinson's descriptions hereafter become increasingly anxious about the Midway's foreignness: the buildings become "strange," the Ferris Wheel a "monstrosity," the crowd a "tide of people," and the Midway surrounded by the "queer flags of many nations," descriptions that reactively reassert the normalcy of the white American identity appraising them (504). His reactive "othering" suggests alarm that whites could perceive themselves as an exhibit, too, signaling the plasticity of white identity as a threat to the nation. In this way, the exhibit highlights a concern central to nativist calls for immigrant restriction: the potential for the white citizen to become the "other" in their "own" nation.

However, it is Robinson's conclusion that most actively re-asserts a white agenda in its commemoration of the fair. Writing only two years after the inclusion of the first Negro Building 
at Atlanta's Cotton State's Exposition and only a year after the landmark decision in Plessy v. Ferguson ruled in favor of segregation, Robinson's conclusion seems reactive and controlling. For he pronounces that fairgoers would quickly "forget" the human exhibits of the Midway (and the threatening comingling of races and classes therein) and remember instead "the great white buildings and the grandeur of the Court of Honor," even as the images accompanying his own essay act against this contention (512). For nearly two-thirds of the images accompanying his work feature the Midway rather than the Court, asserting the Midway's significance, even its primacy in cultural memory (see figs. 22-24). From that perspective, Robinson's insistence that we focus on the overtly white Court of Honor may record the whites' ongoing cultural fear of non-white encroachment, so persistent it might even colonize the memory of the White City. Robinson's attempt to exert such control over historical memory also suggests Robinson's awareness of initial accounts of the fair, which mention the Midway nearly as often as the White City itself. If fact, some accounts transferred the prestige of the Court to the Midway by linking the latter to the esteemed Department M. Most tellingly, perhaps, is that within a collection of twenty-five "Impressions of the World's Fair" penned by authors and public figures of note, every writer comments on either the White City or the Midway, confirming a commemorative rivalry between them (“Impressions..." n.pag.). However, it may be historian Henry Adams who best describes what is at stake in historicizing and commemorating the fairscape when he writes that "Chicago was the first expression of American thought as a unity" (343). Since part of that unity included officially advancing the nation's whiteness through its exclusion of American Negroes, how history characterized the Midway and the Court of Honor mattered to maintaining the whiteness of the City Beautiful. 
With all of this in mind, I suggest that we must reconsider the role racialized anxiety played in fostering the City Beautiful Movement and its utopian cultural expression at the Columbia's White City. As I will argue in the following section, the literary utopia, White City, and the City Beautiful Movement draw from each other ideologically and map a correlative relationship between the nativist and eugenic logics driving national legislations at the century's end. Further, I suggest that all of these sites advance a white national identity that even scholars of the City Beautiful Movement today overlook. If Chicago's White City made anything clear about the City Beautiful of the future, it clarified that the "unity...of American thought" that was developing across genres and that the "Americanism" Robinson saw emerging at the fair was certainly and reactively white (495).

\section{White Anxiety \& the White City Beautiful as American Utopia}

As I have suggested to this point, the City Beautiful Movement reaffirms an ideological relationship between white anxiety and the national narrative. More than a mere architectural movement, the City Beautiful Movement is a utopian framework of press, the fairscape, and the utopian narrative that advance the systemic whiteness of nation. However, the whiteness of the City Beautiful, as the Movement comes to use the term, was established before the Columbian Exposition. For despite marking the Columbian as the origin of the City Beautiful, white male utopian narratives had already begun to forge a racialized "“city segregated," in response to what some may have considered the nation's first Midway: its city slums (Dowden-White 58). Importantly, Oliver Bell Bunce's short utopian narrative "The City Beautiful" (1889) overtly makes this connection. As he defines the "city beautiful" several years prior to the Columbian, it is an aesthetically-superior city whose (white) cleanliness eliminates (immigrant) contamination and thus preserves a national (American) utopia. In other words, the late nineteenth-century 
notion of the city beautiful may not have grown from the fairscape, but from a common perception of immigrants as a threatening contagion, a metaphor that flooded the press by the early 1880 s. In fact, my research suggests that Bunce's short story, is the third literary work to make use of the "City Beautiful" as a term and the second to align it with utopian re-imaginings of a cleaner cityscape in the $1880 \mathrm{~s} .{ }^{91}$ Notably, Bunce's work appeared at roughly the same period in which alarming critical studies of the threat posed by city slums emerged in the popular press. For example, in the late 1880s Helen Campbell's "Studies in the Slums" series cautioned Lippincott's Monthly Magazine readers that "every foul germ floating from the tenement-house to the brownstone front...doomed... all who must come in contact with them" with "no disinfection possible" (n.pag.). By the 1890s, the press would add that "whole families" of such immigrants were seen as "so degraded that mental and moral recovery seem[ed] impossible" (Dutton n.pag). For their "evil instincts" were "woven into the fiber of the nerve substance" and "taint[ed] the blood" (Dutton n.pag.). Given this quick rhetorical shift from tainting the individual to tainting the stock, we understand how the press forged an invective linking the physical contamination of the city slums with the moral depravity of the immigrant and how nativist politicians made use of such "proof" to argue for immigration restriction. As historian Matthew Frye Jacobson explains in Whiteness of a Different Color (1998) "in this period of volatile racial meanings...immigration restriction favored a scheme of hierarchically ordered white races," a whiteness that was already "freighted with political meanings and moral judgments" (75). With a glance to the slums, it seemed "peoples such as Celts, Italians, Hebrews, and Slavs were becoming less and less white in debates over who should be allowed to disembark on American shores" (75). In this way, Jacobson confirms a perceived darkening of the visual economy of race within the slums at the very same time those slums were being 
labeled a contagion. And it against this backdrop that I suggest we not only read Bunce's "The City Beautiful," but reimagine the racialized relationship between race and the utopian frameworks of nation.

Bunce's short story is among the first literary works to use the phrase "city beautiful" to characterize a distinct idea of civic reform that reacts to the growth of the city "slum" and its many-hued peoples. For Bunce, the utopian City Beautiful of the future may have gestured to the Crystal Palace of the Great Exhibition or anticipated the Columbian's White City, but it also echoed the white Greco-Roman "cities of great splendor" that remained "still the admiration of the world" (98). And, at the very same time, it condemned and racialized the "foreign" threatsthe "Micks" and "Dagos," to use Hawthorne's "races" of choice—-that would taint such beauty (98). Notably, for a nineteenth-century white audience, Bunce's admiration of Greek antiquity was a racial shorthand, as "Greek" became a metonymy for the era's perception of white racial superiority. For example, physiognomic studies like George R. Gliddon's and Josiah Nott's Races of Mankind (1854) and The Indigenous Races of the Earth (1857) made clear that the period's praise for Greek architectural and cultural superiority grew to include a praise of Greek physicality as "ideal beauty" as well as belief in the culture's intellectual and racial superiority (311). ${ }^{92}$ In fact, one illustration in the latter work clearly summarizes in a visual shorthand the crux of the scientific racism the authors were developing and that which the organization of the Columbian's now notorious Department M would later bear out (see fig. 25). For, offering comparative illustrations of Greek, Negro, and Chimpanzee profiles and their skulls, the drawing clearly places the idyllic whitened "Greek" above the darkened "Negro" and "Chimpanzee." The placement of the Greek skull and accompanying bust are minimally shaded to distinguish them from those of the Negro and Chimpanzee, whose similarity in color and bone structure is greatly 
exaggerated. In fact, the bust of the Negro depicted is disproportional to its skull, while the skull itself is obviously angled differently the other two illustrations, as if to emphasize the skull's bestial elongation. Curiously, the Chimpanzee's skull appears to be tilted in the opposite manner, as if to exaggerate the beast's comparative humanity. In other words, this single page, drawn from a work that became a primer in the fledgling field of anthropology, illustrates the typical scientific racism that would have guided the passel of graduate students collecting and organize the fair's Department M. With such powerful visual metonymy "scientifically" likening nonwhites and beasts, there is little room to wonder how non-whiteness, black or otherwise, became linked with contagion and disease in the city beautiful. In fact, an 1887 article in the New York Evangelist that advocated immigrant exclusion did so through bestializing the immigrant other. Referencing a cartoon entitled "A Class of Immigrants Not Wanted," which renders immigrants as vermin crawling to the shores of an alarmed Lady Liberty, the letter points to the power of such images to argue against immigration. These "miscreants in the form of rats and serpents" from "Germany, Russia, and Italy" are "filling the waters between...Europe and America" and "landing on our shores" ("On "A Class..."). For we must, the article asserts, "declare that it has served its time as a dumping ground ... and that the rule of exclusion be applied to others than the Chinese" ("On 'A Class..."). And it was far from the only image aligning immigrants with contamination; in fact, by 1890 Judge Magazine would run a similar graphic entitled "Dumping European Garbage" (see fig. 26). Here the exaggerated displeasure of the Statue of Liberty visually emphasizes her willingness to retaliate, as she recoils in disgust. In other words, these cartoons and editorial support the liminality of whiteness that Jacobson describes. They dehumanize immigrants as disease-carrying vermin or garbage and they clearly speak to the power of such images in an emerging visual culture to sway public calls for nativist exclusion. 
Notably, Bunce's work similarly envisions the immigrant as a contagion, suggesting that the anxious narrative of a white city beautiful may have emerged in response to the perceived threat the non-white other posed to nation. Implicating the immigrant as a threat, Bunce's utopian guide begins with a parable of urban cleanliness that he presumes is well-known to his American interlocutor, likely alluding to the increasingly-common discourse of "contagion" in the press. For he explains that the utopian fervor for cleanliness is like that of the (unquestionably-white) Dutch who once drove out "strangers," some "sacrilegious despoilers" for littering in their village (105). Here, the foreign immigrants, who would "crowd upon, tread upon, and elbow" out the citizens of the city, pose a threat to the racial order, to cleanliness, and to morality — given the religious connotation of "sacrilegious" (131). In this way, the very premise of Bunce's "city beautiful" is predicated on the removal of a foreign body conflated with the litter it bears, a removal, the narrative suggests, is necessary in America as well (101). Although the story first seems empathetic to "the starving women in the attic $[\ldots]$ the squalid children in the gutters and the painted wickedness in the saloon" that "exist in many cities" in America, the guide's empathy soon rings hollow when we learn the 'City Beautiful' solution to such problems is to blame the victim and her or his presumed weak will (101). In this classstratified utopia wherein poverty remained a potential reality, living in "rags and dirt," an allusion to the immigrant-linked practice of "ragpicking," was "assumed to be the consequences of dissoluteness rather than the misfortune of persons" (129). ${ }^{93}$ Moreover such signs of poverty—and the poor along with them—were chastised, "declared to be as much public nuisances as neglected refuse or an open sewer" (129). In fact, the reader's utopian guide adds, nearly threateningly, that "cleanliness is therefore enforced in all public places," since "good manners are as essential as good morals" (129-130, emphasis added). Ominously, the tenets of 
such enforcement remain undiscussed; however, given the prefacing parable of the Dutch rising up and driving out their "despoilers," we are led to believe such "enforcement" would be equally organized, swift, and menacing. In these ways, Bunce's little-discussed "City Beautiful," which precedes the rise of the City Beautiful Movement and the Columbian Exposition, waxes eugenic in its call to re-engineering the public and its citizenry. It offers a clear articulation of a raciallyrestrictive City Beautiful that bridges the imaginative chasm between the immigration "science" appearing in the press and the representation of nation soon to appear at the Columbian. To that end, I would argue that in Bunce's work we see how the literary utopia records an expression of white anxiety about the racial reality of the present that consciously directs the shape of the utopia it imagines. More than that, the work seems an intermediary step that clearly links the City Beautiful, and therefore its expression at the White City, to a racialized whiteness.

Speaking to the resonance of the White City, a dozen or so literary works imagined the Columbian as the pinnacle of an American utopia (Burg 290). And, as one might expect, the elimination of the non-white other featured prominently in these works, even in one notably penned by progressive William Dean Howells. However, it was William von Swartwout's utopian novel The Beginning, A Romance of Chicago as it Might Be (1893), that first envisioned the Columbian as the catalyst for ideological and structural change for the city, and, ultimately, for the nation. As the novel's narrator Wentworth imagines, the fair would foster the advent of larger scale trade and production and improve city cleanliness by relocating production outside the city limits. Rooted in capitalist commerce, he imagines a utopia of department stores that are "perfect cities in themselves," as they democratized access to goods by lowering prices, encouraged mass transit to transport goods, and beautified the city by relocating the means of production elsewhere (104-105). Yet beneath the romance of such a transformation lies a harsh 
reality for immigrant laborers. Systemic changes that might improve the status of laborers were deemed unnecessary. For, according to white middle-class logics, "everybody knew that labor was not degrading...it was only the degraded surroundings and slavish way in which the work had to be performed," which meant that mere relocation would improve conditions and render further change unwarranted (von Swartwout 50). With equal obliviousness, he callously dismisses workers' "suffering" and dehumanizes them as "labor" (the act of production) rather than "laborers" (those who produce). In fact, his rhetoric not only dehumanizes the laboring class, it racializes the language of contagion and anxiously advocates the eradication of tenements - and the "black" immigrant poor along with them. In one particularly vexed metaphor, he tellingly links blackness — both literal and metaphoric - to moral and physical contagion. As the narrator explains: "if you have a pot nearly full of black paint, putting in a little white would not make it white, but it would be less intensely black, and if you continued to put in white it would soon run over, some of the white going with it, but gradually all the black would be washed away" (65). In the broader social context of immigrant contagion and scientific racism it is impossible to read this metaphor outside of the discourse conflating class with race when it literally advocates for whitewashing - for a removal of the black (contagion of race and class) with a profusion of white (morality, good, light). Von Swartwout even waxes Bancroftian, by linking the forthcoming white utopia to "how Christ saved the world," liking whiteness to salvation from the "curse of sin" (65). Arguably, this notion of washing away an overtly racialized contagion is at the core of his utopian imagining. For he lauds the demise of lower class jobs such as newsboys to which he ties the demise of "foul smells" that no longer "poison you from foul alleys or damp cellars" where the vagrants would crowd (107). He also explicitly argues that the "degradation surrounding the poor" bred "contagious diseases" as well as "moral 
disease," both of which were the inevitable "hereditary" result of slum life (83). Yet, von Swartwout offers no suggestion of how relocation outside the city limits would change such conditions (83). In other words, although he laments the problems of the laboring classes, the inherent racialized biases of the text and its lack of a plan for reform beyond removal through relocation, firmly aligns von Swartwout's focus with reclaiming the city for the white middle class.

More than merely aligning the City Beautiful aesthetic with the interests of the white middle class, The Beginning merges the fictive and the nonfictive to imagine the Columbian as an expression of a utopian America. Envisioning the White City as the prototype for the city of the future, the reader comes to realize by the text's close that the novel doubles as the work its protagonist intended to prepare in time to sell "during the World's Fair," a work intended as a plan for reform. In this way, the conclusion redirects readers to the work's second preface, that is, to the half-dozen letters by prominent Chicagoans, including the city's mayor, that endorse the present work's plan for the city's and nation's future (124). Given the status of those to whom he circulates his work, von Swartwout's reimagining of the “'White City' (with full racial inflection)" clearly articulates the space as one bearing the interests of an American "power elite" (Bank 591). The utopia not only "simulat[es] for a mass audience its own sense of beauty, control, hierarchy, and self-secured success," it positions the plan for a racialized removal and relocation of labor as the beginning of an American utopian project (Bank 591). Although von Swartwout's work may not have influenced many, the preface suggests it reached those of influence, those in a position to ensure that "all the black," replete with all the denotative and connotative meanings such a phrase suggests, "would be washed away" from the Columbian—or perhaps be prevented from exhibiting there in the first place (124). Regardless of whether or not 
von Swartwout's work influences the decision to exclude African Americans from the Columbian Exposition — the fair's most explicit washing away of "all the black"-The Beginning again suggests a gap in our historiography of the utopian narrative made apparent only when we consider race as central to the shape of the late-nineteenth-century utopian imagination. For it is only when we look to the Columbian reimagined in narrative form and focus our attention on the increasingly anxious melding of social class and color that we clearly see the links the white elite were drawing between the immigrant-filled city slums and early black migration North, between the gated, racially pure White City and promise of a City Beautiful Movement that might eradicate the slums to ensure a white national identity.

However, von Swartwout's The Beginning was neither the only utopian work to imagine the Columbian as an American utopia nor the most popular or far-reaching. Amid the popular series of essays published in The Cosmopolitan as installments of A Traveler From Altruia (1892-1894), William Dean Howells's wrote about the fair. The letters, penned as Aristides Homos traveling the nation, extended Howells's imaginings of America from the Atruian utopist's perspective. ${ }^{94}$ Written from the vantage point of Homos, who is often interpreted as Howells's "more critical self," the letters offered readers a critical distance from which to assess the growth and development of the nation's cities, among which he included the "Fair City" of Chicago's Columbian Exposition (Kirk vii, Howells 34). Importantly, Howells not only refers to the exposition as a city, he calls it the "first great triumph of Altruian principles among this [American] people" (21). In other words, Howells considers the fair city to be the nation's first strides toward a utopian America. As one scholar has put it, Howells believed that fairgoers would "come to view the wonders" and "travel back to their small towns and villages, carrying the message of Altruianism" (viii). In other words, Howells envisioned the fair and the utopian 
form as space of public education and a didactic site, respectively (viii). In fact, Howells's even courses readers on American inequalities, despite remaining silent about race. For he laments the inevitable unemployment of "all the poor fellows...concerned in the government of the Fair City." Thinking more systemically, he even indicts the "power of the inveterate political illusion" that has rendered American economic inequality as a "natural inequality" that was "everywhere...passively accepted" $(31,31)$. Nevertheless, he sidesteps the fair's overt exclusion of black Americans as a noteworthy inequality keeping America from realizing its full Altruian potential. In fact, even as Howells's observations suggest systemic thinking about how whiteness is manipulated to facilitate a sense of "national belonging" among "variegated" white citizens precisely to serve the needs of the white elite, a consideration of blackness remains conspicuously absent $(31,21$, Jacobson 41$) .{ }^{95}$

Ultimately, even the reform-minded Howells serves the aesthetic of the white elite and reinforces the racialization of the fair's White City/City Beautiful as the nation's utopian future. For he calls the Exposition "the majestic future of the country," emphasizes that it "will whiten the hills and shores" of the nation (replete with racial suggestiveness), and dwells on the fair as an architectural marvel that he likens to that of Greek antiquity (viii, 20 emphasis added, 32). In fact, in contradiction to his criticism of the inequity of the nation's class system, Homos later agrees with his American interlocutor that the nation had enough wealth and now its "great mass" of immigrants "needed... some standard of taste" (viii, 20 emphasis added, 32). In other words, here Homos seems to contradict his professed ideals. He concedes that American wealth and immigration were managed. Despite the gaping inequities in the distribution of that wealth, the mistreatment of immigrants he previously notes, and his indictment of the nation's "inveterate political illusion" of equality, he now seems to agree that the nation's remaining 
work is chiefly aesthetic. Tellingly, this conversation occurs as Howells's characters' exercise their white, male mastery over the racialized economy of the Midway Plaisance and later assert their sense of dominion over the White City. For as the pair talk, the narration notes that the "hubbub of the Chinese theater had ceased," the "Javanese water wheel was hushed," the "Samoans slept in their stucco huts" and the "Bedouins folded to slumber in their black tents," while the white men, among "a few stragglers like ourselves," walked unchallenged amid the closing Midway grounds occupied by those of color in a vulnerable state of repose (31-32, emphasis added). The two men, as representations of the white elite, pose no threat to the prevailing social order; they could choose freely to "stroll” among the Midway's "lesser" peoples, conveying an internalized sense of their own dominion and ability to traverse culture, space, time, and class in a way others outside their race and rank could not. ${ }^{96}$ In fact, voicing their sense of entitlement and Homos's easy slip into privilege, they muse about going to "sleep in the peristyle" at the center of the white city_decidedly not within the Midway where those of color, as they markedly note, slumber (32). The suggestion makes a tacit distinction that the white men belong elsewhere. It conveys a sense of white male privilege that simultaneously permits them such access and eschews any taint of being thought lower-class vagrants unable to afford lodging (32). In other words, to some degree Howells's work seems to reflect the commonplace truism that actions speak louder than words. Here, the agency and activity of Howells's characters in juxtaposition to the recumbent, inactive, and Midway-contained people of color reinforce a distinctly racialized fairscape that represents the nation's "majestic future" as a continuance of active white dominion.

In the context of Howells's nearly-contemporaneous novel An Imperative Duty (1891), Howells's position on blackness seems more certain. The "tragic mulatta" novel, which recounts 
Rhoda Algate's experience of learning of and coming to terms with her "partially black ancestry," has long-stood at the center of a "controversy among critics, both black and white, as to whether it undermines racial stereotypes or covertly reinforces them" (Daugherty 53). In the narrative, Rhoda, is rescued from the cruel fate by a kindly white gentleman, Dr. Olney. He marries her despite her black ancestry and whisks her off to Florence wherein she "is thought to look so very Italian" (Howells, Imperative 150). In this way, Howells both reinforces the trope of the white messiah and again bespeaks the anxiety-producing slippage between racial and ethnic identity at the time. Of note, too, is that the racial threat is removed from America, a relocation that not only saves her, but the nation. And although this marriage and concluding relocation suggests some degree of race acceptance, the novel reaffirms white supremacist thought throughout. Foremost, Rhoda's ancestry is bestialized as she's described as stemming from "savage" and "cannibal" Africans (86). And suggesting the degree to which scientific racism adhered to mistaken notions of racial inheritance, any flare in her temper is deemed an "outbreak of the ancestral savagery" (72). More than that, linking behavior to heredity suggests the traits are tied to her future, an infinitely inescapable black savagery. However, Howells's clearest articulation of what is to be done about the so-called race problem comes when Dr. Olney states resolutely that "our [white] race must absorb the colored race," so that "it will obliterate not only the color but its qualities" (38). Meaningfully, despite advocating interracial coupling Howells's eugenic engineering nevertheless expresses a white male anxiety that would ultimately preserve whiteness (Daugherty 53). Whites must not merely "absorb" those of color, but "obliterate" that color and the savagery scientific racism ascribes to it (Howells, Imperative 38). From this vantage point, I would argue that the conclusions and recommendations An Imperative Duty makes about racial identities reinforce a racialized reading of Howells's assessment of the 
Columbian fair. For Howells's observation that the fair city portends the forthcoming "capitals which will whiten the hills and shores of the east and the borderless plains of the west," suggests more than an architectural engineering of the cityscape. It suggests a physiological engineering of its people, particularly when moments later Howells employs naturalized metaphors of inheritance, noting that "like produces like" and the fair would bear fruit among future Americans. Indeed, in light of the eugenic means of whitening Howells suggests in $A n$ Imperative Duty, the notion of immigration conjured by the "shores of the east," and the attention paid to the distinctions between the White City and the inhabitants of the Midway, one cannot help but think beyond architectural design to the social and racial implications of such whitening for the nation of the future.

To better understand the development of the white utopian complex in the late nineteenth century, this section has suggested that we must reconsider the period's racial history. It argues, specifically, that we must map how white anxiety — from press to page, from pageantry to politics - recasts the motivation and effect of the City Beautiful Movement. It argues that we must understand the City Beautiful Movement as growing, in part, from the threat of immigrant and black encroachment. More than that, I have suggested that we must recognize that the literary utopia played a role in allowing the white utopists and white utopian culture to process their fear of "the other" through scientific, cultural, and fictive imaginings. For the white elites who designed the anxiously white fairscape recognized, as historian Henry Adams did, the fair's monumental potential for unifying American thought. They recognized, as Columbian exhibition organizer G. Brown Goode did, that "to see is to know" (qtd in Rydell 44). Indeed, for more than 27.5 million visitors, the Columbian's representation of the City Beautiful was a means to 
will "national activity toward a determined utopian goal," a utopian goal that seemed, unmistakably, as white as the fair's city (Rydell 48, emphasis added).

\section{White Anxiety, Black Exclusion, \& The Reason Why}

More than anything else the White City affirmed the anxiety of a white elite struggling to represent the nation's identity as white. And this engineering was immediately noted in the black press. More than one black visitor would describe the Columbian as the "great American white elephant” or "the white American's World's Fair" (qtd in Rudwick and Meier). For whiteness was perceived as conveying a nation's superiority and civility, particularly to the long-dominant English. And while utopian dreaming of the New World may have once signified social and political possibility, by the late nineteenth century the thrust of that thinking was firmly in the hands of a white elite. And that elite believed whiteness - and acculturating others to such a racial hierarchy_-was the key to engineering the nation's social, industrial, and political dominance with the fairscape as its prime publicist. ${ }^{97}$ And this racialized thinking haunts the margins of the flood of white literary imaginings of a utopian American, writings wherein a distant, idyllic white future can escape from the "undesirable immigrants" and "the Negro Problem" constantly in the mainstream white press. $^{98}$ The popular press, as I have earlier shown, fueled such behaviors by "scientifically" linking poverty with criminality and inferiority to race. And far from inert, these anxieties provided the basis for restrictive immigration legislation, elevated racial pseudoscience to the science of anthropology, reactive urban planning on the national level under the guise of aesthetic improvement, and the exclusion of Black Americans from the Columbian's official narrative of nation.

And the nation's politics would soon internalize and react to these "facts" of racial inferiority as a means to secure a white American future. For unlike many immigrants whose 
whiteness would, in time, would prove malleable for political need and the discourse of meltingpot assimilation, Black Americans would remain in the immediate among the "races most alien to the body of the [white] American people," as Representative Henry Cabot Lodge would write in 1891 (qtd in Jacobson 77). For Lodge, who openly introduced race as a measure for restricting immigration argued that some immigrants would not "assimilate" or "promise well for the standard of civilization in the United States" (qtd in Jacobson 77). And while Lodge may have merely been a representative in the U.S. House at the time, he rose to become a U.S. Senator from Massachusetts, Senate Majority Leader, and Chairman of the Senate's Committee on Foreign Relations. And his political progress suggests the popularity of his thought and that of the Immigration Restriction League, of which Lodge was a powerful ally. In other words, Lodge's rise to prominence and the openness with which Congress would debate race should be read as part of a trend in advocating eugenic measures to protect American citizenship. For this trend in reasoning, also mapped within the canonical literary utopia and put in practice at the fairscape, documented the history of "exceptional [white] people destined to be great." And this image of whiteness stood in juxtaposition to the white-determined representation of blackness, of a people "incapable of reason and judgment" and to some degree still thought to be "unworthy of basic human and democratic rights" (Wilson 6,7).

Yet, by the Columbian's 1893 opening, middle and upper class African Americans in particular were thriving members of American society. While Northern blacks had long been free, the passage of the Reconstruction Amendments a little more than two decades prior to the fair had assured African Americans freedom, a vote, and citizenship. More than that, it allowed enough time that black Americans in Chicago had "already developed a social infrastructure of associations, businesses and newspapers" (Wilson 161). In fact, by the late 1890s, they 
"accounted for 7.5 million of America's 63 million people," or, around 11 percent of the population (Rosenberg 262). ${ }^{99}$ In other words, there was a long and redoubling history of African American infrastructure, particularly in Chicago to where "black migrants" relocated "shortly after the Civil War." In fact, by the early twentieth century, Chicago would come to be called a "Black Metropolis" and was "home to forty thousand black residents" forming " 2 percent" of the city's total population by 1910 (Wilson 15, 160-161). Despite this burgeoning Black Metropolis and a class of noteworthy black professionals more than willing and able to contribute to the fair effort and organize a Negro Building, "not one of the 200 planners of the American exhibits was black," when, statistically speaking, equitable representation based on the national population would suggest that at least twenty planners should have been (Rosenberg 262). In fact, while a few African Americans were employed as construction workers prior to the fair, if employed at all at the fair they were "waiters...or porters" (262). Given these subservient roles, it's unsurprising that blacks who visited the fair found the Haitian Pavilion, "representing the only independent black nation in the New World, was one of the few places at the Fair where people of color felt comfortable eating," gathering, and even protesting (262). For it was here that Ida B. Wells distributed 20,000 copies of The Reason Why the Colored American is Not in the World's Columbian Exposition. The pamphlet was more than an organized protest of their exclusion, it was an exhibit in words giving voice to the progress of "the colored people of this great Republic" (Rosenberg 263).

Although a Negro building in physical form "would have been the greatest tribute to the greatness and progressiveness of American institutions," such an exhibit would have threatened the white racial logics envisioned as central to American progress (Wells, "Preface" 3). For such an "exhibit of the progress made by a race in 25 years of freedom against 250 years of slavery," a 
progress that I. Garland Penn recounts in the pamphlet's fifth chapter, as a guidebook would, was nothing short of revolutionary (Rosenberg 263). For, as Penn tallies, in only twenty-five years blacks produced more than 100 books and 206 periodicals, began educating more than 1.5 million students, applied for more than 70 patents, and gained control of more than 263 million dollars in wealth $(49,45,57-60,53)$. This seemingly-impossible measure of progress did not evidence the nominal advancement of a backward race as whites imagined, it catalogued the strides of an intimidating new American citizen.

But a display of such revolutionary progress would challenge white narratives of nation. More than that, such progress could raise public doubt about the certainty that some immigrants were "undesirable" or that blacks were so acutely inferior. ${ }^{100}$ In fact, Frederick Douglass seemed to suggest as much. Although he explains, in short, that "slavery" was the reason "why we were excluded from the World's Columbian Exposition," he quickly clarifies and elaborates. He suggests that it was not America's "shame" over slavery that kept whites from welcoming blacks to exhibit, but their shock over Black Americans' progress (10). For a physical display would have been "proof that the Negro is not standing still" that despite having "lost ground and [meeting] with increased and galling resistances since the war of rebellion" the Negro still "dares to nobly break away... and hew out a way ... for himself in defiance of all opposing forces" (Douglass 14, emphasis added). In other words, the redoubling of black progress was likely terrifying for whites not only of itself, but in its implication for the potential of nonwhite others to challenge white-determined narratives of identity and nation.

With these implications in mind, we might come to understand the white logics of exclusion. For the exclusion of a Negro Building was not the only tactic deployed to reinforce white narrative control. For the government waged and extensive and imposing control over 
Native American displays at the fair. To ensure official Native American displays at the fair were either assertions of inferiority or assimilation, a planned Indian Congress was cancelled and its chair, Emma C. Sickels, was dismissed for failing to toe the party line. And Sickels made her opinion known in the press where she explicitly indicts white narrative control. For she calls the fair "one of the darkest conspiracies ever conceived against the Indian race," asserting that "every means was used to keep the self-civilized Indians out of the fair" (New York Times 1893). In other words, the fair was arranged and controlled precisely to ensure a white-controlled narrative of nation. ${ }^{101}$ And, of course, the political aims of the racial and social engineering of the fairscape were transparent to the authors of The Reason Why, as they were to Sickels. Black Americans were excluded to advance a white national identity, to reinforce white's contention that blacks were ignorant and unassimilable, and, as Douglass notes, to emphasize their savagery in comparison to the included African Dahomeyans (see fig. 27). And these racial logics governed the rationale for organizing the villages at the Midway Plaisance, the Smithsonian's ethnological display of Native Americans in the Government Building, and the entirety of Department M. In fact, these latter two sites were organized to show an evolutionary progress from "the very early stages of the history of civilization" to the present and this was done, in part, by placing the "'lower races [like the Native Americans] in costume"” and showing them "living an outmoded life" (Rydell 56, qtd in Rydell 58). Perhaps more significantly these displays gave and air of credibility and accuracy to the immersive Midway villages. Even Fredric Ward Putnam, who organized Department M "attested to the anthropological value of the Javanese, Samoan, and Dahomeyan villages" on the Midway while the national government's Committee on Ways and Means had suggested locating the Midway village attractions within Department M, noting their “"ethnological and historical significance”” (Rydell 61, qtd in Rydell 
62). In each of these examples, and particularly at the Midway, the central thrust was distinctly one of racial evolution that placed the Anglo-Saxons at one end and "the negro types" wholly at the other with the "semi-civilized races,"” like the Javanese and Native Americans, in between those extremes (qtd in Rydell 65-66, Rydell 58). But the official organization of the fair was not alone in advancing this hierarchy. So compelling were the racial logics of the narrative told therein that we find it advanced in nearly every official guidebook or commemorative. In fact, one periodical published at the fair World's Fair Puck, circulated images of the same racial hierarchy at the fair. Its "Darkies Day" illustration not only reinforces the relationship between the Dahomeyan and the Black America, but employs every exaggeration of minstrel caricature in so doing (see fig. 28). ${ }^{102}$ In other words, the fair was organized on all fronts to foster a definitive, government-sponsored narrative of "the advances made during the past four centuries," as one guide put it, that was given greater force by the "comparison between aboriginal customs and modern civilization" (Flinn 53, 55). More than that, this governing white logic made restrictive immigration and Jim Crow legislations seem rational for a white majority. In the national narrative whites had created, their exclusion, which meant protecting America from the barbarism of the "lower races," was also directly tied to the nation's continued progress and prosperity. And preserving this cultural logic was predicated on quashing outliers to it, on quashing the idea of a growing and flourishing culture of Black Americans whose inclusion at the fair might shatter the very foundations of nation. ${ }^{103}$

Yet, perhaps the most important sections of The Reason Why for shattering the dominant mythos of the (white) American utopia was Ida B. Wells's "scathing indictment of statesanctioned white-supremacist violence" (Wilson 50). For Wells not only maps this violence, she wages an expose that rewrites both the nation's history and its present. While Penn's meticulous 
calculus of black advancement and F.L. Barnett's documentary account of the discriminatory actions that "practically" rendered the fair "literally and figuratively a "White City"” record a palpable resistance to the white eugenic logics organizing the fair's racial hierarchy, Wells's direct confrontation of those narratives wage an affront (80). Arguably, Wells's work here literalizes a threat to the white world order in both her distribution of The Reason Why and in her documentary indictment of the idyllic nation fabricated at the fair. In three sections titled by topic, Wells provides concrete data that makes it abundantly clear that class legislations, convict leasing, and lynching disproportionately target blacks. She also notably advances a dystopian view of contemporary America, an alternative history that rivals the white fair's imaging of a progressive, acutely-civilized nation. Wells explains that the Reconstruction Amendments "have been largely nullified in the south" which "leaves the entire political, legislative, executive and judicial machinery of the country in the hands of the white people" who also govern "the religious, moral, and financial forces of the country as well" ("Class Legislations" 17, 19). In each section she reinforces that the very systems of American governance, especially in the South, have been corrupted by racial prejudice. Given this systemic white supremacy, she argues, whites have made another organization impossible. For how can a society change when the "judges, juries, and other officials of the courts are white men who share these prejudices [against blacks]" and "also make [the] laws" ("The Convict Lease System" 24). Again stressing systemic prejudice, she even rhetorically equates the "midnight outrages of the Ku Klux Klan" to "state legislative enactment" as the means by which black Americans are deprived of their rights (“Class..." 18). To what end, she documents myriad incidents of state-supported violence, noting, for example that " 90 per cent of [Georgia's] convicts are colored" and that over 400 blacks had been "burned alive" or "lynched" within the last six months. Significantly, recording 
the severity and increase in the lynching of blacks in the last six months stresses the immediacy of her work and overtly offers an entirely different view of the present nation than being exhibited. Her concern for skewed representation also draws attention to the ongoing ideological war whites have waged against blacks (“Class..." 18). Not only have whites "deliberately shut him out of everything which tends to make for good citizenship," the fair included, but the press, literature, and scientific research alike routinely "blast[s] the race's good name," particularly as a threat to "white womanhood and childhood" and by means of this misinformation "robs us of the sympathy of the world" (“The Convict...” 24, "Lynch Law” 31, 29). In this way Wells speaks directly to how white-controlled discourse, like that advanced by at the fair, misinforms and misleads an international audience. As Well recognizes, by depriving fairgoers of a physical site to judge black progress, whites can perpetuate an anxious mythos of black inferiority and maintain their political dominance over both the nation and its official narrative.

However, The Reason Why... made important strides for black self-definition at the fair. It helped to foster the inclusion of a Negro Building at the Atlanta's Cotton States and International Exhibition of 1895, paved the way for an Exhibit of American Negros at the Paris Exposition of 1900, and eventually to the month-long, black-organized Lincoln Jubilee Exposition also held in Chicago in 1915. Although, as I will discuss in the next chapter, the Atlanta Exposition may have caused more problems for the history of African American progress in the white imagination than it resolved, the fact of these events made clear the march of Black progress and gave voice to a black history. And while world's fairs' remained subject to the intercession of whites who were anxious to reassert their control over the nation's future, the inclusion of self-determined narratives of American blacks acknowledged, albeit reluctantly, their role in the nation's future. 


\section{Narrative Exclusion, National Resistance}

The fairscape was not the only site wherein black Americans began to wage a resistance to anxious white narratives of nation. Particularly in the wake of Looking Backward's success, the literary utopia was for an early black utopist a means to advance an alternative historical narratives and to define — and even inspire - reform. More than that, to black feminist activists like Ida B. Wells or Frances Harper, whose incisive critiques focused on institutionalized white supremacy, it was likely readily apparent that these white, male-authored literary utopias were undertaking in language what the "White City" did in display, that is, they reimagined a utopian white America predicated on black exclusion. For this reason, it is unsurprising that Frances Harper's utopian Iola Leroy (1892), written amid the planning of the World's Fair where Harper would ultimately speak, might be read as a metafictive commentary on the white utopian frameworks of the politics of the White City writ large, a framework her speech would also clearly indict. ${ }^{104}$

Iola Leroy is not a traditional utopia. ${ }^{105}$ Instead, Harper blends genres to interrogate the conventions of the utopian form and forges a metafictive hybrid, a narrative that makes use of utopian convention to critique the genre itself. In fact, as one scholar argues the novel was motivated a philosophical interrogation of the relationship between literature, genre, and society. She suggests that the novel seems to participate in "a call-and-response literary conversation [William Dean Howells was having] with popular women writers about race, gender, and genre" (Rosenthal). For this reason, Howells's An Imperative Duty is “often [mistakenly] cited as a precursor to Iola Leroy" (Fabi 61). However, Harper's work is better characterized as a critical and formal response to Howell's novel, for her rewriting of "many of his views" in Iola Leroy suggests she found it quite infuriating (Rosenthal $\mathrm{x}$ ). Yet even these illuminating treatments of 
the novel do not give much consideration to genre Harper, nor to how her choice of genre, too, might grow from a desire to critique Howells's thought in An Imperative Duty. For Iola Leroy does reimagines Howells's "tragic mulatta" narrative as a heroic mulatta tale. But, more than that, as a deft and seasoned writer and activist, Harper was likely responding to the body of Howell's work rather than a single novel. For at the same time Harper was writing Iola Leroy, Howells began to pen a series of essays and letters for The Cosmopolitan that would ultimately comprise the utopian work A Traveler from Altruia, 1889-1894 (1892-1894) and Letters of an Altruian Traveler (1892-1893), respectively. However, the idea to write a utopia, if we trust the dates Howells's gives, seems to have arisen in 1889 and was likely circulated in the literary conversations to which Iola Leroy responds. ${ }^{106}$ In other words, I argue that Iola Leroy wages both a critical response to the white male paternalism of the tragic mulatta tale told in $A n$ Imperative Duty and to the related patterns of systemic white supremacy of the utopian form that would come to define Howells's Altruian works.

Reading Iola Leroy as an engaged response to Howells's works as well as to questions of the politics of identity and genre resonates with Harper's activism and offers a clear reason to further consider the work's hybridity, didacticism, and metafictive use of the utopian form. Unfortunately, even recent scholarship seems to overlook the activism of the work. Arguably missing the nuance with which Harper renders her characters, one scholar even argues that the work offers "apparent concessions to white readers" that "mask the author's fundamental discontent with white supremacy," a tactic that he links to her experience as a "race activist" who "understood the need to appease whites" (Borgstrom 782). Yet, I would argue nearly the opposite. In my estimation, the novel is an overt criticism of systemic white supremacy. I would 
argue that it wages a challenge to the literary and political forms that harbor such thought and even implicates the reader in their indictment.

From the novel's conception, Harper reimagines utopian convention as a way to interrogate and correct white conceptions of blackness among her readers. For Iola Leroy is the heroic mulatta tale of its eponymous title, but it is also the utopian narrative of an apparentlywhite female traveler who is transported by "race travel" to a dystopian enslavement when the black "cross in her blood" is revealed (Fabi 46-47, Harper 85). For the crux of the tale begins after her father's sudden death when a white relative reveals Iola's "cross." Aided by Mississippi law he deprives Iola of her inheritance and sells her into slavery. ${ }^{107}$ Liberated soon thereafter by an encampment of Union troops, the narrative focuses not on her enslavement or victimization, but on her autonomy, her personal growth and work as a nurse in the regiment. Importantly, this experience leads to an epiphanic moment for Iola as she rejects a marriage proposal from the white Dr. Gresham with whom she works. In this way, Iola embodies a clear rejection of Howells's Rhoda, whom he imagines as acquiescing to pass as white and live in Italy with the white Messianic figure, Dr. Olney. Harper rejects the idea of passing and uses Iola's rejection to wage a feminist critique of the white male paternalism she likely sees governing Howells's text. For Rhoda is denied complete personhood; Dr. Olney routinely calls her "child" and she is compelled to live in gratitude and "silence...concerning her origin" $(144,150)$. Further, his scientific racism persists, as her flares of temper remain marks of her "ancestral savagery," a contention that remains unchallenged and uncorrected in the text. In this way, Iola's refusal of marriage not only rejects this white male paternalism and reclaims the autonomy denied Rhoda, it marks a turning point in the novel's activism wherein black characters begin addressing white characters directly with scathing criticisms of systemic white supremacy. Iola refuses the 
opportunity to pass as white and resume her previous "school-girl notions" of race, slavery, and politics held when she was a 'white elite' in the 'utopian' Plantation south. She then proceeded to debate Dr. Gresham and, metacritically, the contradictions of ardent white abolitionist thought he represents. Through Iola's voice Harper charges slavery reveals the moral degradation of white character. She rejects the notion of a distinct "cleavage" between racialized sentiments in the North and South. She indicts the logics that enslavement and "social bans" were the work of "a few" since "the whole nation" long "consent[ed] to our abasement" (96). Perhaps most shockingly, she even tells the white doctor that she "believes the time will come when the civilization of the negro will assume a better phase that you Anglo-Saxons possess" (96-97). From this point onward Harper clearly wages a dialogic affront to white supremacist thought governing both literary and political forms. As her black characters confront and refute whites who believe that blacks are incapable of advancement, unfit for employment, scientifically proven inferior, and that miscegenation would constitute "a deathblow to American Civilization," she doubly implicates her reader in both the project of refuting and the refutation (177). In this way, Harper's feminist, racially-sophisticated, and generically-complex work confronts both Howells's novel and the implications of his paternalistic logic. More than that, the systemic savvy of her critique recognizes that this logic lies at the core of white supremacist thought, a logic that her characters artfully dismantle to literally rebuild their families and form a utopian black community-cum-society by the novel's close. ${ }^{108}$

While the novel's conclusion amid a burgeoning black society Reconstruction-era North Carolina is clearly its notion of utopia, more important to our reading of the test is the use to which Harper puts utopian convention. Indeed, I would argue that her use of the utopia's traveler trope that is the novel's most significant development. Harper's reimagining of the utopian 
traveler wages a metafictive parody of the use to which white men have put the utopian genre. As such, it provocatively destabilizes the seemingly-impenetrable categories of race for the century's participatory reader. While others may read the trope as a convention of passing or mistaken identity, I would argue that Iola's lack of knowledge about her racial identity resists its consideration among the former while a lack of skepticism about her "whiteness" firmly denies it categorization among the latter. Instead, Harper conjures the trope of the utopian traveler and even prefigures Iola's passage from whiteness into blackness, from one world to another, with her literal travel from North to South. Then, as genre dictates, Iola arrives in a 'new' land to explore its systems, culture, and ideology. Further, by using racial identity as the device that transports our apparently-white traveler to her dystopian enslavement, Harper wryly asserts the significance of race to conceptions of utopia. Moreover, by situating the novel in the near past and reintroducing the familiar as a foreign land, she knowingly notes and rejects the white escapism central to the literary form. For instead of passing to a distant land and an idyllic discourse of the utopian future, Iola — and the reader alongside — is didactically reintroduced to the nation and to systemic white supremacy from the vantage point of a black slave. In other words, Harper's revision of generic utopian convention is metafictive. It casts in relief how white anxiety defines the conventions of the form and compels the exclusionary and escapist imaginings of a utopian future.

Harper's combination of utopian convention with her unique metafictive approach enables her to highlight the systemic white supremacy of the present. For upon the learning of her racial identity, Iola immediately inquires about the systems of civilization that formerly protected her personhood. She asks about contracts, legal rights, even her connections in Southern society, only to find that they now all treat her as property. More than that, she learns 
that mere clerical errors - "a flaw in the marriage" license and "an informality in the manumission"-compelled a judge hold her "manumission...unlawful" and her parent's "marriage a bad precedent and inimical to the welfare of society" (81). This tack, rendered possible by utopia's conventional exploration of social systems, allows Harper to highlight for readers that the very fabrication and manipulation of social reality, of science and law, reside in the hands of whites (81). More importantly, although enslaved and abased by these systems, Iola's inquiry also allows Harper to provocatively draw attention to the constructedness of "nation" and "citizen," and, therefore, to the instability of racial categories. The novel very premise asks reader to contemplate how there can be a significant tangible difference between the races when Iola can seamlessly transform from one into the other. In this way, Harper's variation on the conventional utopian traveler, even more so than her revolutionary conclusion amid a utopian black community, bespeaks the work's activism. For Harper not only highlights the means by which the utopian genre fosters an escapist white fantasy, she positions readers as a disillusioned traveler alongside Iola. In this way, she interpellates readers who interrogate the fundamental misconceptions of white supremacist thought, thought that not only governs the genre, but the nation.

Pointing to Harper's recognition of the continuity between whites' political thought and their use of the utopian form, Harper's activism mirrors Iola Leroy's pattern of critique in her address at the Columbian Exposition. Speaking during the World's Congress of Representative Women, her speech, delivered May 20, 1893 and titled "Woman's Political Future," both drew from the politics of Iola Leroy used utopian imagery to reimagine a national utopia that centralized the role of women and those of color. For Harper asserts that in women's "hand[s] are [the] possibilities... of unborn ages" and brazenly reminds her audience that they have 
already shown their "influence and opportunity" in advancing women's labor, swaying legislators, and as educators ("Woman's... n.pag.). She charges that woman's "aristocracy of character" is necessary in the political sphere to blot out the "evils" of "lawlessness...in our republic," the "lawless and brutal cowardice that lynches, burns, and tortures [its] own countrymen" (n.pag.). For it is women, Harper argues, who must assert that it is the "right of every race" to "demand justice"; she must condemn the white "hands of lynchers... red with blood" who nevertheless "determine the political character" of the nation and she who must recognize that it is only in "uplifting the human race" that "Eden would spring up in our path" (n.pag., emphasis added). In all of these lines, Harper draws attention to the under-considered parallels between contemporary politics and utopian works and she indicts the systemic white supremacy of both. More importantly, Harper reimagines an American utopia (Eden) that would meld feminism with antiracism and then provocatively calls women to arms. For she charges them to act, that is, to "demand," "create," and "brand with everlasting infamy" both the politics of the white republic and its misguided image of itself as a utopia (n.pag., emphasis added). In this way Harper publically wages a national resistance to the whiteness of nation, the political exclusion of women and the physical exclusions of the "Colored American." And given the occasion of the speech, she wages a resistance to the Columbian's representation of systemic white supremacy and to the thought that whites alone could continue to have "the ear of the world" and continue to "depict us just as they please" (Harper, Iola 96).

\section{Conclusions}

More than anything else, the Columbian Exhibition's White City suggested that a utopian American future lay in a properly engineered civilization. Although the American fairscape grew from a philosophy of social order drawn from London's Great Exhibition of 1851 that was 
admirable in the abstract, the anxious compulsion to advance America's image as a civilized, white society became its driving force, arguably most visibly at the Columbian. As I have argued here the Columbian's White City and the utopian City Beautiful Movement emerged reactively to reassert a white social order. They advanced a white national narrative that predicated the nation's future on engineering its present through legislating exclusions ranging from Jim Crow to immigrant restrictions. Yet, as my research suggests, our historiography overlooks racial anxiety as an impulse guiding utopian thought. Resultantly, scholarship insufficiently explores the eugenic logics underlying these utopian sites and overlooks entirely a literary utopia, Bunce's "The City Beautiful" that highlights these logics. For, as I have argued here, it is not only significant that we can trace the emergence of the term "city beautiful" to a literary utopia, but that the tale draws directly from the press's discourse of immigrant "slums" and their "squalor" to imagine a neoclassical white utopia literally predicated on removing "foreign elements." In the abstract, this utopia renders the logics of nation clear. Utopian frameworks cast nonwhite bodies as an explicit threat to the order of the state and white bodies as indispensable to the state's maintenance, a patterning visible at both the Columbian's White City and, more nefariously, within the City Beautiful Movement. In this way, consideration of race in the literary utopia lays bare the logics of how biased representations of the nonwhite other hold sway enough to inform the exclusionary practices and legislations shaping the nation's actual future.

However, as I have argued here, the white supremacist ends to which utopian frameworks were put in the Columbian's White City and the ensuing City Beautiful Movement were certainly not lost on the nation's black citizens. Excluded from organized participation and tacitly represented by the Dahomeyan "savage," it was abundantly clear that whites alone had "the ear of the world" and the ability to "depict [black Americans] just as they please" (Harper, 
Iola 96). More than that, excluding black Americans from organized self-representation at the fairscape allowed whites to promulgate the dual logics of white superiority and nonwhite inferiority as scientific facts therein, giving teeth to the thinly-veiled racialized reforms advanced by the City Beautiful Movement and demonstrating the nation's "need" for continued white male paternalism. Recognizing that such an exclusion was a means by which whites would maintain exclusive control over the national narrative I argue that Wells's The Reason Why..., nearly an exhibition in book form, injected a black American voice into the fairscape in perpetuity. And while reaching an audience of little more than 20,000 at the fair, a fraction of the exposition's 27 million attendees, it found an audience nonetheless. More importantly, the volume asserted that black resistance had obviously organized and grown since William Wells Brown and William and Ellen Craft's ephemeral demonstrations in the American department at London's Great Exhibition, which seem to have been forgotten as easily as the "Virginia Slave" was "removed" following Brown's demonstration therein. The Reason Why waged a lasting indicted the white supremacist nationalism of the mythic White City and it confirmed that black America had a thriving infrastructure and a growing civilization that whites could no longer contain.

In fact, perhaps even more provocatively than The Reason Why, Frances Harper's speech at the Columbian Exposition, like her novel Iola Leroy, waged a confrontational affront to the systemic white supremacy engineering American civilization and the forms that maintained it. Reimagining utopian conventions, Harper lays bare the whiteness of both form and nation, a charge that she carried into her speech the Columbian. She indicts a white narrative that argues that "the great distinction between savagery and civilization is the creation and maintenance of law" when its whites "habitually trample" that law to "murder, lynch, and burn their fellowcitizens" (Wells 20, Harper 169). In this way, Harper impugns the white logics of the black 
'savage' and the 'civilized' white by offering striking evidence of the convers, of whites "retrograding toward barbarism," not advancing toward utopia (Harper 169). For in both her address and novel Harper reclaims the terms "savagery," "evil," "brutality," "ignorance," and "incivility" long-used to "prove" the "Negro" was a "savage" amid white "civilization," and recasts them to indict the savagery of white lynch mobs. Consistent with Iola Leroy's activism, Harper's careful attention to the language and genres of oppression highlights the white engineering of scientific racism. It points toward recasting language and reimagining genres as paths through which black works might make strides in re-imagining the nation's future. For, arguably, Harper's metafictive turn indicts a white utopian complex more than a century in advance of my own work, a turn that, I would argue, reinforces our need to place Iola Leroy within the dominant historiography of the nineteenth-century utopia. Placing Harper's work within our historiography is more than an isolated recovery a single black utopia, it's another step toward recovering a black utopian voice that recognizes the "race problem," in its apparent absence, as central to white utopian formations of narrative and nation. 


\section{Chapter 3: Separate and Unequal Utopias in the Landscape of Plessy: the "Atlanta Compromise," Anglo-Saxon Masculinity, and Militant Segregation}

The destiny of the two races, in this country, are indissolubly linked together.

-Supreme Court Justice John Harlan, Plessy v. Ferguson

In all things that are purely social we can be as separate as the fingers, yet one as the hand in all things essential to mutual progress.

-Booker T. Washington

In the final chapter of Frances Harper's Iola Leroy (1892) the Leroy family, reunited and free, settles on a former plantation in North Carolina, establishes a community, and resolves to work toward "the uplifting of the race" (217). The scene, which reclaims the Southern plantation as a site for black uplift, also signals Harper's knowledge of Reconstruction North Carolina. For, during Reconstruction, North Carolina seemed a beacon. Making strides in combatting systemic white supremacy and advancing black infrastructure, its "Black Second" Congressional District would even elect four black Congressmen between 1870 and 1901. Although the federal government excluded organized black participation in the Columbian Exposition and although the North remained complicit in lynching by continually eschewing the responsibility of passing a federal law, at least in North Carolina it seemed black citizens could add to the "quota of good citizenship" and "to the best welfare of the nation" as Harper imagined (219). But Harper's utopian hope that blacks might make strides as citizens and become part of the governance of that state and the nation would soon be dashed by a reactive tide of white anxiety turning to agitation in the South.

Although still embittered by the North's imposition of Reconstruction, white Southerners were soon emboldened by a culture of national reconciliation stressing the "passion and heroism" of war "immunized from motive" (Blight 96). More than that, this Reconciliationism encouraged the utopian rhetoric of "a New South on the course of revival," a revival that 
simultaneously rekindled the Old South's dystopian conditions for African Americans (139). Indeed, in the wake of the 1898 Wilmington Riots wherein white supremacist democrats threatened the lives of black politicians, the expiration of black North Carolina Congressman George Henry White's term in 1901 unofficially marked the end of an era of black political uplift. More than that, it signaled a nationalized preservation of systemic white supremacy in the Jim Crow South, which would not elect another black official for 72 years. Indeed, as prominent Civil War historian David Blight has argued: "the civil and political liberties of African Americans were slowly becoming sacrificial offerings on the altar of reunion" between the North and the South (139). By the 1890s the rhetoric of the New South was rebranding itself and making use of "the Lost Cause as a...weapon against radicalism," "social diversity," and the national "disorder" white Southerners perceived widespread immigration and black citizenship fostered $(139,276)$. Wryly conflating "foreigners and blacks" as national threats, Southern whites in particular manipulated the already-racialized rhetoric of nativism to strengthen the case for segregation and were ultimately successful when the U.S. Supreme Court effectively legalized a policy of national segregation in Plessy vs. Ferguson (1896) (276). As I will argue here, this landmark decision gave federal legitimacy to the Jim Crow South, reflected whites' fears of black organizing, and marked the extent to which Reconciliation and the racialized framework of white utopian thought underwrote national policy.

The Supreme Court's decision in Plessy attested to an ideological proximity between the "progressive" North and the "regressive" South. It affirmed the success of national white Reconciliationism and assured whites that an American utopia could be secured through legally excluding blacks from white spheres. And Plessy's ruling was not singular. Rather, it was emblematic of a growing body of discrimination cases waged by blacks against unjust state laws, 
particularly in the South. With this in mind, Homer Plessy and his associates saw the reach of Jim Crow extending and resisted. For Plessy was not merely another black man victimized by a white system, he was a black rights' advocate at the center of a test case orchestrated to raise public consciousness about Jim Crow violations of black rights and to make legal strides in changing them (Hoffer 3). Plessy, along with a group of other Afro-Creoles in New Orleans, arranged his arrest in 1892 as a violation of Louisiana's Separate Car Act (1890), an Act requiring separate accommodations for black and white passengers. As a test case, the seveneighths white Plessy sought to draw national attention to colorism in the South, that is to the persistence of "one-drop" legislations and the threat they posed to blacks' equal protection before the law. The case was a centerpiece in the black press and inspired black intellectuals to write numerous pamphlets and speeches on the matter of segregation. ${ }^{109}$ While it was tried, the case was also the central preoccupation of the newspaper the Daily Crusader and would become the crux of Charles Chesnutt's novel The Marrow of Tradition (1901). However, the case and decision garnered little attention in the white press, affirming black citizens' condition as a politically-inert body within a white State. The silence also suggested that whites expected America to remain segregated, to remain a distinct nation of and for whites that allowed some accommodations for blacks. In this way, Plessy demonstrated more than whites' continued success in manipulating the legal and ideological frameworks of white supremacy, it demonstrated whites' ability to literally carve the nation into utopian enclaves emblazoned "Whites Only," and maintain as Plessy put it, their "exclusive privileges."

Plessy not only ushered in the decline of national protections for black political and civil liberties, it also marked the degree to which whites could manipulate the philosophical frameworks of utopia to alter the nation's political realities. For as one scholar explains, 
“American law and American custom conspired to punish African American men and women in the post-Reconstruction years," a punishment that Plessy not only supported but extended nationally (Sundquist 225). And more than a short-lived architectural movement like the City Beautiful or the passage and emendations of immigration or naturalization acts, the decision in Plessy rendered white privilege legal and confirmed it was systemic. For in their decision the Court chooses to interpret the Fourteenth Amendment as protecting only political equality, overlooking the clause stating that "no state shall make or enforce any law which shall abridge the privileges" of its citizens. Here the Court insists that "social prejudices" could not be "overcome by legislation" and that "equal rights" could not be "secured...for the negro...by an enforced commingling of the two races," yet it rules in favor of the social prejudicial, that is, it rules in favor of whites' preference to remain racially and socially “separate." In other words, while the decision argued that prejudices could not be "overcome by legislations" it nevertheless confirmed that in a post-Reconstruction era, white prejudices would continue to underwrite law and its interpretation.

The decision in Plessy was a way to ensure a white political future in an era negotiating an increasingly political body of black Americans and its largest-ever influx of immigrants. By ruling that segregation posed no conflict to the Fourteenth Amendment, Plessy declared that the white public sphere could remain white in perpetuity, while largely avoiding the fact that the white public sphere determined the nation itself. In this way, Plessy ensured the political inefficacy of its black citizens. And as black Americans' 72-year excision from holding national office in the South would prove, Plessy gave political weight to the increasingly-popular notion that the nation's sovereignty and utopian potential were tied to its whiteness. With this in mind, we might read the court's ruling in Plessy as a national confirmation of Reconciliationism, or 
even as an indication of the national success of Lost Cause sentimentality. Indeed, the decision helped whites "solidify the new legal edifice of Jim Crow" by modeling the means of metaphorically recasting enslavement through "sinister legislation" (Gross 107, Harlan n.pag.). Plessy became a federal foundation for the already extant and racist Jim Crow statutes of the South and the similarly-exclusionary — if unlegislated — practices of segregation in the North (Hoffer 1). In this way, the Supreme Court's ruling in Plessy confirmed, as Mark Twain's wryly observed in The Tragedy of Pudd'nhead Wilson (1893), that race is indeed a "fiction of law and custom" (9). It demonstrated that both the success of Reconciliationist narratives and the fictions of nation were squarely in the hands of a white elite.

With Plessy's verdict and sentiments of reconciliation forging the ideological backdrop of the mid-1890s, this chapter explores how the racialized cultural imaginings of nation began to express racist articulations about the nation's future. For such a test case's ability to rise to the Supreme Court bespoke the influence of a growing black infrastructure, suggesting the root cause of a reactive white anxiety, as evidenced in the Wilmington Riots, the persistence of lynching in the South, and in Plessy's verdict. And these tensions are clearly visible at Atlanta's 1895 Cotton States and International Exposition. ${ }^{110}$ In this chapter I turn to the Atlanta Cotton Exposition as a record of the racial climate motivating the verdict in Plessy and reaffirming the whiteness of the New South. Speaking to the fair's ideological success for whites, history most clearly recalls it as the birth of black accomodationism, that is, as the site of black educator Booker T. Washington's famed (but arguably strategic) acquiescence to what was effectively the order of the Old South. In the wake of a rising tide of violence against blacks in the South, Washington seemed to surrender to the authority of the white national narrative. His speech, quickly dubbed the "Atlanta Compromise," urged blacks to defer to whites, segregate socially, 
and to largely comply with the white national order. And whites immediately celebrated Washington's ideas. In fact, the white press and white histories of the fair nearly render the Atlanta Exposition as synonymous with the Atlanta Compromise, dwarfing the fair's inclusion of a Negro Building and black members on its managing board. And, as I will argue here, this lasting rhetorical association confirmed the white social order that Plessy's verdict would nationalize, that is: blacks" "place" was behind whites, separate from them and not yet equal to them.

The Atlanta Exhibition was far from the only anxious, white re-imagining of a New South shaped by the racially-violent climate surrounding Plessy. As I will also argue in this chapter, at least five white-authored utopian novels advance white segregation fantasies. These novels, I suggest, intentionally distort whites' perception of blacks, North and South, as threatening to the social order. They capitalize on an amnestic national culture of Reconciliationism to reimagine Emancipation of Reconstruction as endangering white sovereignty. And they strive to reassert the ideology of the Old South as the core of the New. Ranging from W.H. Bishop's transformation of a Southern plantation to a white utopia in The Garden of Eden USA, A Very Possible Story (1895) to the patently white supremacist race wars in Benjamin Rush Davenport's Uncle Sam's Cabins (1895) and Albert Adams Merril's The Great Awakening (1899) to Frank Purdy Williams's re-imagining of a southern victory in the Civil War in Hallie Marshall, True Daughter of the South (1900), I argue that white-authored utopias in the aftermath of Plessy were emboldened by what effectively became a national support for the Jim Crow South. Moreover, their segregation fantasies not only suggest the ideological proximity — rather than distance_-between the "progressive" North and the "regressive" South. 
Looking at these works in sequence and juxtaposition, I argue that they reflect whites' growing and reactive national hostility to blacks' increased role in the public sphere. Their retellings of history reflect a desire to reassert the racial order of the past as the means to a utopian white future. Given the tenor of this work, it's unsurprising that Anglo-Saxonism "reached new heights of confidence in the last years of the nineteenth century" (Horsman 302). For this turn toward the term 'Anglo-Saxon' seemed to be a millennialist outcry to reclaim the mythic "racial destiny" of a "chosen people," one overtly reiterated in these utopian works (Horsman 77). ${ }^{111}$ By the century's end, these white works advocated militant protection of the nation's white racial destiny. In both legislation and social practice, the nation began to actively "check" the "entrance of new stocks" — and mitigate the negro problem through increased segregation - "before the American Anglo-Saxon race was polluted by the presence of inferior strains” (302). Meanwhile, works such as Walter G. Cooper's Official History (1896) of the Atlanta Exposition would emphasize the term Anglo-Saxon in rewriting the South's history and destiny, linking Southern identity with American Anglo-Saxonism. Therein Cooper flagrantly claimed that "the Anglo-Saxon as a race has never mingled its blood with a darker people" and urged that the "true policy of our [Southern] people is to ignore the [negro] question" since it "disturb[s] the good feeling between the races to advance their political ends" (104). As the fair's chief of publicity and promotion, Cooper's fallacious pronouncement became, as the work's title suggests, its official history and confirmed the frightening extent to which whites shaped the cultural memory of the fair for generations thereafter.

But these white utopian imaginings were not without their challengers. Just as Frances Harper targets systemic white supremacy amid Iola Leroy's (1892) metafictive turns, so does Sutton E. Griggs's Imperium in Imperio (1899). As I will argue here, Imperium metafictively 
engages with the utopian form as a means to challenge the millennialism of Anglo-Saxonism. More than that, I suggest that it forewarns of the increasingly-militant racial divide segregation could foster and ends indeterminately, precisely to draw black readers into engaging with it. By concluding with a rhetorical question of when true black freedom will come, I argue that the work entreats readers to respond, to participate in the work's subtitular "study of the Negro Race," and even to engage with the possibility of an organized and militant black response that, notably, a world's fair could enable. With this in mind, I also argue that Griggs uses the utopian form as a means to envision, discuss, and advance more and less feasible possibilities for organization and resistance among his black readers.

Putting Griggs's work in conversation with other long-ignored white-authored segregation fantasies as well as the Atlanta Exposition necessarily changes the present historiography of the nineteenth-century utopian narrative. The inclusion of works that are overtly preoccupied with preserving America's whiteness or organizing blacks to combat that whiteness again signal the limitations of our present history. They suggest our need to map the significant role race has played in how utopists imagined utopia — and wanted to re-imagine America - in the period. In this way, these works also highlight the rhetorical use to which utopian frameworks were put to maintain a systemic white national narrative. Our historiography's exclusion or mere casual mention of these overt racial fantasies of an American utopia predicated upon its whiteness reinforces the field's reluctance to broach racial identity and undermines the accuracy of our literary—and cultural—-history.

\section{The Culture of Plessy: Racial Climate \& Racial Contest at Atlanta's Cotton States International Exposition (1895)}


In the year before the U.S. Supreme Court would rule in Plessy, another sort of test case would take place in Atlanta, that of including a Negro Building at the world's fair-and what it might mean for our national narrative. As I have suggested in the previous chapters, expositions functioned as immersive (white) utopias for a vast national and international audience, so the inclusion of a Negro Building was revolutionary. It meant that for the first time black Americans would be afforded literal and figurative space within the nation on a national and international scale. And it meant that the exhibition's role as a white, state-scripted space that "categorized the world by race and provided a template that white organizers believed should structure race relations both nationally and internationally" faced a significant challenge (Perdue 1). And for the Atlanta Cotton States Exposition, the South was at stake as well. Atlanta was both the honorary capital of the New South and the center of Southern black intellectualism, which meant that the Negro Building could pose a formidable challenge to the white representations of the South and the nation therein. For Atlanta boasted six renowned black colleges, numerous black grade schools, and was home to a large, organized community of professional and working-class blacks. As one Atlanta fair historian summarizes: the "African American community prospered" in Atlanta; it included “doctors, lawyers, dentists, undertakers, and skilled laborers" and members of the community "owned stores, restaurant, bars, and hotels... and invested in banking, real estate, and insurance" (Perdue 10). And this thriving black community, whose wealth was "reportedly...increasing more rapidly than that of whites," would face formidable white resistance in this implicit contest over who could define the New South (Perdue 10).

Perceiving the black community, and, by extension, its Negro Building, as a threat, it is unsurprising that white fears led to reactive legislations and violence. For Georgia was among the first southern states to pass legislation segregating streetcars and was the state with the 
second highest rate of black lynching in the South. Signaling the extent to which white fear would grow, by 1906 white supremacists fearing " "negro domination"” waged an act of domestic terrorism by starting a race riot in Atlanta that would kill more than a dozen black citizens (LeeAnn Lands 75). ${ }^{112}$ And this attack was notably encouraged by the weight of white rhetoric. For increasing public attention to the "negro-question," race-baiting political campaigns, and the publication of racist novels like Thomas Dixon's The Clansman (published in the Atlanta Journal in the year prior) shaped the rhetorical landscape and encouraged a fear of negro domination among whites (75).With this racialized trajectory in mind, the Atlanta Cotton States Exposition was a pawn in a much larger racial contest over the nation; whites, who previously had exclusive control over representing and imagining the nation's future through the fairscape, would have a rival in Atlanta. For whites, the inclusion of blacks signified a deeper threat to the white social order and signaled competition over defining the New South. In this way, I argue that for the 800,000 fairgoers and countless others vicariously experiencing the fair through its literature, the exposition became a physical manifestation of the rivalry between the races, a contest over the national imaginary and the future "place" of its black and white citizens played out in real time.

The rhetoric of exposition histories bespeaks whites' insistent attempts to control the reception and memory of the fair and the image of the New South. We find a salient example of this attempted control on the very cover page of The Cotton States and International Exhibition and South, Illustrated (1896). Although some might dismiss it as a sales ploy, the commemorative boasts that it's Cooper's Official History and doubly asserts the work's authority, as it is certified by the signature of Director General C.A. Collier and billed as the "only" official history of the fair. And, significantly, that Official History clearly characterizes 
the inclusion of a Negro Building as an act of benevolent paternalism. As Cooper explains, white organizers "were determined to give prominence to the Negro race" and he even credits S.M. Inman, a former Confederate soldier and businessman "who had always taken a deep interest in the Negro," with suggesting the building's inclusion (8). Cooper argued that it would also "stimulate the race," as though black Americans lack self-motivation, and resolved that it would offer "substantial evidence of the good will of the white people," rather than, of course, the progress of black Americans (8). Further, the history summarizes the event as having "ushered in ...a veritable era of good feeling between white and black" (8). It was imagined as contributing to sectarian healing, since the "good feeling extended to the Northern friends of the Negro," who would then see "the Southern people were the real friends of the black man" and their inclusion of the Negro as an act of "good faith" (8, emphasis added). In this way, Cooper's "Official" History meant, like any "official" work of the time, a white narrative. It frames the white Southerner as a veritable hero who recognized and corrected the wrongs perpetrated to black Americans by correcting the "singular oversight [of] all previous exhibitions" that "had failed to give the Negro such an opportunity" (8). Reinforcing whites' control over the national narrative, black inclusion despite their advocacy for representation and the funding they secured for themselves, is represented as a kindness extended by whites rather than an act of black citizens' own volition.

Significantly, Cooper's narrative — and other white narratives like it—denied black citizens a voice within fair record and cultural memory for nearly a century and distorts the notion of race relations in the South. ${ }^{113}$ For the notion that the Southern people were the "real friends of the black man" and that the exposition ushered in an "era of good feeling" whitewashes the decade's rising rate of lynchings and the abuses of (almost entirely black) 
convict labor that built much of the event (Purdue 24). Perhaps most problematic, however, was Cooper's framing of slavery in the chapter titled "The Negro Exhibit." Although the lengthier portion of the chapter is dedicated to Chief of the Negro Department I. Garland Penn's "The Awakening of the Race," Cooper's supervisory introduction attempts to control the reception of Penn's work. Indeed, for white readers, Cooper casts the 'negro exhibit' in the familiar terms of scientific racism; by referring to the exhibit as a "sociological study" of "ethnological fact," the building becomes an artifact of white assessment rather than a site of black self-determination. In the rhetoric of a Lost Cause-cum-Reconciliationist Southerner, Cooper appallingly casts slavery in the rhetoric of uplift as the "gigantic experiment involving millions of human beings" that, ultimately, made possible the progress witnessed at the Negro Exhibit (57). He even noted that the exhibit could "forecast the future... of many more millions of the same race on other continents," which tacitly advocates slavery's extension (57). In other words, Cooper's Official History anxiously exerts rhetorical control over the past, present, and future of the New Southand particularly over this threatening New Negro.

However, many black Southerners, including those spearheading participation in the fair, recognized the importance of articulating a black voice in response to whites seeminglyceaseless discourse of the "negro problem." For black Americans, the Atlanta Exposition was a space for generating the vision and vocabulary of a black utopian thought. It was a site wherein black Americans could boast of their recent accomplishments, showcase their abilities within a building “"built by negroes, under the supervision of negroes,"” and project their development as part of America's future (qtd in Perdue 23). The exposition was a way to advance the term and image of the "New Negro," a utopian moniker used to distinguish the new black American from the image of the black slave, for an inter/national audience. The New Negro was an active 
rhetorical response to whites' incessant discourse on America's "Negro Problem." Although its tenets and meaning varied widely, it functioned symbolically as a unified and utopian selfassertion of the new black American.

Articulations of the New Negro at Atlanta signified that blacks were Americans who had their own history to tell and who intended to play a fundamental role in the formation of the New South. As Bishop Wesley J. Gaines, who would become one the fair's Negro Commissioners, argues in the Introduction to African Methodism in the South (1890) the "fact that the colored question is the question of the day...makes everything pertaining to the negro... all the more important." Here Gaines not only attentively recasts the white rhetoric of the "negro problem," he turns his attention to the rhetoric of national identity. He argues that "the negro" could not and must not "lose his identity in the heterogeneity of the American people" and seeing racial identity as part of his American identity, he asserts that the "negro" must "hold his own" and recognizes that "he has a future, and that, too, [is] in America" (ix). In other words, the rhetorical politics of identity are at the fore of Gaines's philosophical thought, a thought that would inform his perception of the exposition. He points to the need to maintain a racial identity, suggests that asserting black identity is also a nationalist project, and offers an in-road to reimagining the long association of American identity with white identity. In this way, Gaines suggests that America's "negro problem" is a "white problem," a problem of white America's continued resistance to recognizing black identity as now part of American identity as well. In fact, merely two years afterward Gaines would publish a historical study titled The Negro and the White Man (1897) to “put his views on the so-called 'Negro Question' in permanent form," which he suggests had been his "purpose for years" (7). ${ }^{114}$ 
Like Gaines, I. Garland Penn was acutely focused on the need to redefine the white rhetoric of race and nation at the fair, which he did in "The Awakening of a Race," his contribution to The Cotton States and International Exhibition and South, Illustrated (1896). Disadvantaged by Cooper's introduction to the "The Negro Exhibit" chapter and by the work's exclusion of photographs and biographies of the Negro Commissioners from the fifty pages of biographical sketches of white men and women commissioners included, Penn's work nevertheless challenges the white-defined image of blackness pervasive elsewhere in the text. Redirecting Cooper's charge that black progress ultimately stems from the benevolent paternalism of the slave system, Penn gently reminds readers that "the negroes were set free... without a place to lay their heads, without food or raiment" and thus the race has "fought nobly" in their "but thirty years of freedom" and has "hewn out for itself a place...in our own America" (58, emphasis added). Penn rejects Cooper's white-centered tale of black progress. Laying claim to America with the possessive phrasing "our own," he rhetorically asserts black Americans' sense of national identity and belonging. Affirming black citizenship and refuting Cooper's contention that whites had first suggested a negro building at the fair, Penn reminds readers of blacks struggle for representation. He reminds readers that black Americans were "refused" representation at the World's Columbian and that representation at New Orleans was "not sufficient," making the representation at the Atlanta Exposition "justly deserved" (59). More than that, he stresses that black Americans were "entitled to representation every time," an assertion of black citizens' rights to representation at a national, State-sponsored event (59, emphasis added). ${ }^{115}$

More importantly, however, Penn's work openly acknowledges the didactic force of the fairscape in shaping cultural knowledge and memory. Penn emphasizes that black self- 
representation at the fair is clearly necessary in a region that "doubts" black Americans' "capabilities and accomplishments" (59). Importantly, he also notes the rhetorical influence of fairs on public opinion, arguing that such self-determined representations were even more necessary since previous fairs messages about black Americans, which ranged from exclusion to willful misrepresentation, have fostered these doubts "all over the country, North and South" (59). After speaking to both the right to and need for self-representation, Penn wryly shifts his focus to offering readers an ekphrastic panorama of the building's exhibits, recording its contents for posterity. Mindful of the need to stress the American Negroes' capabilities for a doubtful white audience, he characterizes the exhibit as "very extensively educational" and includes a rather lengthy section on the "Colored Congresses" held to showcase the Negroes' on-going "progress in medicine, law, ministry and churches, teachers and educators of their own people" $(60,62)$. Penn's choice to shift from passive and past-centered representation of physical objects to oratorical meetings planned for the building reinforces Penn's desire to highlight the intellectual capabilities of blacks and their on-going projections of the future for both black Americans and the nation itself. As he explains, the profound yet "abstract progress" to which the Congresses attest "could not be told by the objective exhibit" (63). Recognizing that the "sum total published" would determine the "shape of history," Penn intervenes in the exposition's history, rhetorically writing in a space for black Americans' future. As Penn's essay concludes in the future tense, he stresses his own intervention: "the history of the colored exhibit will be written" and "the pages of this book will glisten with the facts of a brilliant success, of a brilliant period in negro life - indeed in the life of the South" (63, emphasis added). Harkening to that space black Americans have "hewn out" for themselves in America, Penn carves his own. He 
lays claim to a future, to black citizens' integral role in the formation of the New South, and to black Americans' future in the nation's official history.

Like Penn's history, the Negro Building's two-hundred-sixty-nine exhibits offered a tremendous challenge to the white-defined image of the Negro, even as exhibits elsewhere at the fair undermined these self-determined representations (Official Fair Catalogue, Frank Leslie's Nov 1895). Aiding this undermining, the white press paid little attention to the Negro Building. ${ }^{116}$ Although periodicals that did mention the building at least noted it as "one of the most interesting exhibits on the grounds," most overlooked it entirely. More problematic, though, were the white-determined representations of black identity outside the Negro Building. For example, at least two works in the Fine Arts Building were racist caricatures of black Americans. And in this setting, these exaggerations would have been amplified by their juxtaposition to pristine neoclassical white bodies figuratively and literally placed on pedestals therein. One such work, titled "The Negro Leaned Exhausted Against the Wall," was penned by A.B. Frost, best known as the illustrator for Joel Chandler Harris's Uncle Remus and His Friends (1892) (see figs. 29-30). As one might expect given Harris's claim to fame, the work originally appeared as an illustration in a race-baiting short story. And the illustration is replete with the tell-tale pop eyes, slack jaw, and vaguely-bestial countenance of Uncle Remus (see fig. 31 ). ${ }^{117}$ Exhibited nearby, illustrator A.F. Jacacci's "Negro Type" similarly dehumanizes its black subject. ${ }^{118}$ More than that, the work is juxtaposed to a second of his work titled "Arab Type," titles suggestive of scientific illustrations of comparative racial "types" central to works of anthropology at the time. While images of these works appears to be lost to time, it is worth noting the illustrator's connection to a later work titled Art and Man: A Comparative Type (1918), a text that 
hierarchizes artistic works by nation and subject and in so-doing draws on a host of phrenological and eugenic-minded assumptions.

However, it was the Midway's representations of black Americans that posed the greatest challenge to black Americans' self-definition within the Negro Building. Unlike the organizers at the Columbian Exposition who had tried to make a distinction between the carnival of the Midway and the science of the Anthropology Building in the fair proper, Cooper's history deems the Atlanta Exposition's Midway “an odd collection of strange nationalities forming a unique anthropological experiment" (89). In fact, Cooper's history imagines the Midway as both scientific anthropology and entertainment, describing it as the "great pleasure ground of the fair," before adding that it was a "live flesh and blood" representation of "the Smithsonian Institution['s] ...various types of man" (89). In contrast to the Negro Building's realism, fairgoers met at these commercial concessions the "primitive" African at the Dahomeyan Village and the black slave of the past at the "The Old Plantation." And, tellingly, the Plantation concession was "one of the most popular features of the Midway" (91). In fact, Cooper's history finds it noteworthy to add that it was also the "only" Midway concession "President Cleveland honored with his presence" (Official History 91). Ever mindful of his rhetorical presentation of the fair, Cooper may have hoped to conjure W.A. Rogers's popular rendering of "The President in the Negro Building at the Cotton States and International Exposition, Atlanta Georgia" featured in Harper's Weekly (see fig. 32).

Perhaps more than anything else, W.A. Rogers's "The President in the Negro Building at the Cotton States and International Exposition, Atlanta Georgia" best encapsulates the fair as a racialized contest over the national gaze. Eliding past and present, the realist rendering is set in the Negro Building with W.C. Hill's sculpture "The Negro with Chains Broken but Not Off" 
prominently positioned in the background, as if recalling Cleveland's visit to the Midway's plantation. Cleveland and a group of seven white men, many distinguished as wealthy by their attire and proximity to the president, stand in the foreground facing a group of three African Americans, two men and a woman. The whites, with looks ranging from neutrality to scorn, gaze in the direction of the black citizens, rather than toward the sculpture, which suggestively positions black citizens (rather than their works) as the central object of the Exposition. The President looks away from the statue of the past and beyond the black citizens of the present toward the distance, perhaps toward the future. Significantly, however, the president's gaze seems markedly unfocused, distant rather than to the distance, as if his is not looking toward a future for black Americans at all, but symbolically continuing to overlook them. All of these white images of blacks at the fair reveal the generalized "doubt" of the "capabilities and accomplishments" of black Americans. They point to the Old South as black citizens' rightful place in a white nation, a utopia to which America might return if we merely continue to follow the gaze of the President, if we overlook the trials of present — taken literally, even Plessy itself — to the verdict's reaffirmation of the future's whiteness.

Despite black Southerners' successful interventions, if the Atlanta fair was a contest over national history, white Southerners won in the long term. Perhaps the most telling testimony of whites' success is, ironically, the memory of Booker T. Washington's “Atlanta Compromise” speech. Little is remembered of the fair today aside from Washington's speech, for, as one historian aptly put it, the speech "obliterated the historical memory of...virtually anything else about the fair" (Perdue 8). However, its centrality in our recollection is not a testimony to Washington's success, but, rather, to whites' interpretation of his message. Indeed, the speech, which was instantaneously embraced by whites and many blacks, would come to dwell in a 
racialized space between fame and infamy. To whites, whose embrace and depiction of the oration would define its place in history, Washington's speech accurately articulated their imaginings for the utopian frameworks of a New South. To white Southerners, Washington spoke to white concerns about immigration and loyalty, effectively contrasting black Americans to immigrants as having "a devotion that no foreigner can approach" (n.pag.). He also appeared to acknowledge that black Americans must recognize and defer to white superiority and he criticized blacks' focus on seats in the legislature as "ignorant and inexperienced." To whites, Washington's message effectively and indefinitely yielded national governance to white Americans, and even promoted black deference as part of the nation's Providential design. Indeed, he suggests whites' charge over the South and black American was divinely ordained when he intones: "in your effort to work out the great and intricate problem which God has laid at the doors of the South, you shall have at all times the patient, sympathetic help of my race" (n.pag.). And, most significantly for white ears, Washington clearly supported segregation, asserting in the speech's most recalled and cited line: "in all things that are purely social we can be as separate as the fingers, yet one as the hand in all things essential to mutual progress" (n.pag.). In other words, Washington's speech is not remembered because it was a work of a grand black orator, but because the speech was easily parsed by the white political machineand later by black critics—-for upholding the white supremacy of the New South.

For it was only after years of whites' laudatory recycling of Washington's oration that W.E.B. Du Bois, who first called the speech “"fitly spoken"” and said Washington had “"admirably...represented the colored people,"” would, along with a host of other black intellectuals and publications, volubly criticize its accommodationism (qtd in Purdue 28). By 1903, in The Souls of Black Folks he would charge that Washington "practically accepts the 
alleged inferiority of the Negro races" and that he even encourages "black people give up...three things - First, political power; Second, insistence on civil rights; Third, higher education" (5051). More importantly, however, Du Bois's critical turn suggests his recognition that Washington's speech dominated historical memory of the fair, as even modern scholars note, and armed whites with a black-sanctioned rhetoric of support for white supremacy.

However, I would suggest that we must frame both the laudatory and critical assessments of the "Atlanta Compromise" within the reactive white utopianism of the rhetoric of the New South and within what we might call the culture of Plessy. For the Atlanta Cotton States Exposition is a record of the racial climate in the New South, a climate that attested that black racial progress seemed to whites a threatening contest over both national and sectional identity. In this way, I would argue that we cannot read Washington's speech outside of the fact that Georgia "had tallied at least eight lynchings" that year, that the chair of the Women's Building committee "personally supported lynching," or that while black Americans built and oversaw a Negro Building at the fair, they did they did so under the watchful eye of an ex-Confederate general who chaired a "white "committee on the work of the colored people" (Perdue 14, 2122). Neither can we forget that the fair's Woman's Building “barred exhibits from African American women," and that some buildings posted placards that read "'Dogs and negroes not admitted," a note that not only bestialized blacks, but gave the privilege of the series to the animal (Perdue 39, 30). More than that, only a few months prior to giving his address Washington had secretly offered aid to a black attorney fleeing a lynch mob in Alabama (Perdue 14). Although Washington allowed public record to report that he had turned away the would-be lynch victim, he covertly "arrange[d] the man's transport out of town and his medical care" (Perdue 14). From this vantage point, while I would not dismiss the criticism of his detractors, I 
would argue that Washington's speech conveys a wizened understanding that the New South remained a racial tinderbox wherein any celebration of black progress could become an incendiary among whites. And as a former slave and life-long Southerner who had recently encountered a lynch mob, Washington well knew the signs of a rising tide of racial violence and "deteriorating race relations" swiftly eroding protections of the law for blacks (Perdue 10). In fact, in the ensuing two decades white animosity for black progress in Atlanta would become strong enough to foster a second rise of the Klan.

To an attuned ear, however, I would argue that Washington's rhetoric warns his black audience of the constant threat of violence that the oration's poignant, if covert, imperative on justice also bears an encoded criticism of white supremacy. In lines that begin his conclusion, Washington asserts: "The wisest among my race understand that the agitation of questions of social equality is the extremest (sic) folly, and that progress in the enjoyment of all the privileges that will come to us must be the result of severe and constant struggle rather than of artificial forcing," (n.pag., emphasis added). Washington's word choice here is curious, arguably encoded in the manner slaves often used to communicate covertly among whites. ${ }^{119}$ I would argue that he suggestively signals a particularly thoughtful hearer, speaking of and to the "wisest," a word that truisms commonly applied to the older members of a society for whom slavery would have been a reality. More than that, Washington's phrasing in "extremest folly" allows us to read "extremest" as both an adjective, and a noun, implying that "agitation," a word signaling anger and the potential for violence, is the folly of extremist groups, by which I would argue he implies white extremists. ${ }^{120}$ For the latter part of the warning again uses words signaling violence"severe," "struggle," and "forcing"— but also seems to suggestively authorize the use of retaliatory violence, not swift and erratic as an extremist might, but calculated and constant, as 
his use of "severe struggle" implies black Americans inflict the severity (as they would be the subjects struggling constantly). While to a white or to 'unwise' black hearers, the message may seem more benign or even deferential, an encoded reading reinforces a covert imperative on justice throughout. While he asserts that there is "no defense or security for any of us except in the highest intelligence and development of all," he also wittingly prays that "God will come...in a determination to administer absolute justice" (n.pag.) While on the surface a seemingly supplicant prayer, the wish that God might "bring into our beloved South a new heaven and a new earth" is a rather ominous utopian desire when paired with the suggestion of "blotting out of sectional difference and racial animosities and suspicions," which might be read as a literal removal by darkening, raising the question of why the South would have both a new heaven and earth — and just who would be sent to that heaven. In other words, I am suggesting that we reconsider Washington's delicate rhetorical performance as a cakewalk in a minstrel show, a sort of grotesque pantomime of expectation masking a more incisive critique of white supremacy for the wizened ear. While a far cry from the "problem of the color line" the younger Northerner Du Bois would volubly decry in scholarship and display in Paris in 1900, in the rabidlysegregationist, lynching-riddled capital of the New South the call to blot out "sectional difference and racial animosity" may nevertheless be read as a covertly revolutionary call for a black utopian voice, one black utopist Sutton E. Griggs may entertain in Imperium in Imperio (1899), which I will later discuss.

\section{Anglo-Saxon Utopias in Narrative and Nation}

The Atlanta fairscape offers a useful cultural snapshot of the increasing white anxiety over "negro domination," but it was far from the only one. Arguably more problematic was the growing sense that Anglo-Saxon masculinity defined American identity. Supporting a 
Reconciliationist agenda by harkening to a mythic racial past bridging the sectarian divide between Northern and Southern identity, American Anglo-Saxonism, too, underwrites the white supremacy of Plessy's ruling, of utopian narratives, and of national identity. Perhaps the clearest indication of this growing culture, or cult, of Anglo-Saxon masculinity is Theodore Roosevelt's rise to nearly-mythic status by the century's end.

Roosevelt's name was synonymous with hunting and rugged outdoor sporting by the late 1880 s, that is, with what would come to characterize American Anglo-Saxon virtues. Attesting to his popularity with readers, he wrote numerous books on hunting and outdoor gaming; he even published series of articles on hunting and ranching in both Outing, an Illustrated Monthly Magazine of Recreation and Century Illustrated Magazine, before writing - and makingAmerican history. Indeed, Roosevelt was already becoming a significant political figure. And, pointedly, his hyper-masculine self-fashioning, influenced by his lifestyle and military service, rekindled a rugged Jacksonian individualism reaching beyond his presidency and into the first decades of the twentieth century. Indeed, Roosevelt's life, work, and ardent imperialism fostered an American Anglo-Saxonism, a term that asserted white racial superiority as a historic fact and veritable proof that Manifest Destiny was divinely preordained. Roosevelt, a lay historian who privileged the heroic racial histories of whites, believed that the "American type...combined the best racial characteristics of the Anglo-Saxon and Teutonic pasts," privileging English and Germanic whiteness as a national identity (Dyer 46). And, as Reginald Horsman usefully explains in Race and Manifest Destiny (1981), this “American Anglo-Saxon ideology was used internally to bolster the power and protect the status of the existing population and externally to justify American territorial and economic expansion," a rationale that seemed to be Roosevelt's credo (191). 
More than that, the term Anglo-Saxon reemerged to define national character in Roosevelt's time, signaling its overt tie to immigration and the racial politics of the era. Although Horsman maps American Anglo-Saxonism earlier in the century, historian Matthew Frye Jacobson explains its resurgence as tied to white anxiety in a political landscape of "uppity" blacks and immigrants perceived as ever-darker and more-foreign. As a term, American AngloSaxonism or simply Anglo-Saxonism acted as unifying force among lighter races. Through the logics of colorism, in the wake of the "darker," lighter 'races' like the Irish now participated "in a politics of white supremacy...alongside the Anglo-Saxons with whom, in other settings, their racial equality was so vigorously denied" (Jacobson 13). And for Roosevelt, it seemed American Anglo-Saxonism, replete with whiteness and masculinity, should be central to American identity. For in 1899 he penned a laudatory letter to controversial educator G. Stanley Hall who advocated "boyhood savagery" and openly criticized the "effeminacy" of the Kindergarten classroom at an education conference in Chicago (Bederman 98). ${ }^{121}$ In this letter Roosevelt expressed his eager support, agreeing that "over-sentimentality" and "over-softness" were "great dangers of this age and this people" and urged that Americans "keep the barbarian virtues" or "the civilized ones will be of little avail" (qtd in Bederman 101). In Roosevelt's praise for Hall's work, we find a romanticism of a "barbarian" Anglo-Saxon past, and a nearly-militant hope for the future of white American identity, one that it seemed the white public ardently embraced.

Testifying to a national racial climate reactively asserting its white identity, it is not merely the foreigner from afar who raised the ire of Anglo-Saxon Americans, but the black "foreigner." In fact, Roosevelt would again make history in 1901 by extending an unprecedented invitation to Booker T. Washington to dine at the White House. Although Washington had become his de facto advisor about black Americans, the dinner, seen as a symbol of social 
equality met a volatile response nationally, especially in the South. Despite Roosevelt's esteem for Washington and some valiant moments supporting the rights of black Americans, he nevertheless subscribes to typical 'negro problem' ideology and continued to rhetorically cast the 'Negro' not as an American but as a foreigner in an American homeland perceived as white. ${ }^{122}$ Indeed, while Roosevelt publically insisted on "treating every human being on his or her merits and capabilities" on several occasions, he would also agree with Sir Harry Johnston's assessment of the racial deficiencies in The Negro in the New World (1910), which he reviewed in Outlook magazine (n.pag.). Here Roosevelt agreed that an honest assessment of the races in America can have "no delusions about the negroes or Amerindians' defects of character and racial drawbacks," a point similar to that which he made nearly fifteen years prior when reviewing Benjamin Kidd's Social Evolution (1894) for The North American Review (n.pag.). Revealing a continuity in Roosevelt's thought, he concludes his review of Kidd's book affirming that "a perfectly stupid race can never rise to a very high plane; the Negro, for instance, has been kept down as much by lack of intellectual development as by anything else" (n.pag.). Although in the 1895 review he does concede black Americans' rapid evolution and argue that "character is far more important" than intellect for whites and blacks, he nevertheless calls blacks "perfectly stupid," a clear expression of a core belief in black inferiority difficult to overcome. Further, in both book reviews Roosevelt's rhetoric naturalizes the whiteness of Americans. In commenting on the Negro or the Amerindians "defects of character" it is precisely their differences from white American character that concern Roosevelt and, notably, even his 1910 review is titled "The Negro in America" rather than a less rhetorically-distanced "The American Negro" (n.pag). As Roosevelt's rhetoric of American Anglo-Saxonism converged with the 'race question,' it reified a militant national white identity. Indeed, several scholars suggest that by the 
end of his presidency the preservation of whiteness in America became a salient concern. As cultural anthropologist Lee D. Baker notes, Roosevelt became "increasingly focused on 'race suicide"” which was "prompted by the decreasing birthrate of White Americans," a concern directly linked to the preservation of a white American future (Baker From Savage to Negro 93, n.24). By 1913 Roosevelt would write to premier American eugenicist Charles B. Davenport that "the prime duty of a good citizen of the right type is to leave his or her blood behind him in the world" (qtd in Baker 93). Herein Roosevelt feared for America's racial future, criticizing the nation for seemingly "permit[ting] unlimited breeding from the worst stocks," stocks commonly understood to mean criminals and the disabled as well as blacks and immigrants (qtd in Baker 93). And coming in the year after Davenport began using IQ tests to screen for and exclude immigrants displaying "feeblemindedness" at Ellis Island, Roosevelt's letter expresses tacit approval for a national eugenic program to preserve a white national future (qtd in Baker 93). ${ }^{123}$ For at a time when increasingly "foreign" immigrant groups and black Americans were volubly lobbying for rights and citizenship, Roosevelt helped to recast American Anglo-Saxonism as a national identity unifying variegated whites against new and 'more foreign' stocks. As a soldier and politician he became an icon, a unifying symbol of American Anglo-Saxonism's brute, white strength; he seemed to the masses a defender of the nation's utopian future against the danger of foreign stocks, a national narrative that utopian novels would thematically take up.

Unlike Edward Bellamy's Looking Backward (1888) and the other white male utopian novels by Northerners it inspired, several overtly racist white-authored utopian novels confront racial difference and reflect this Anglo-Saxon masculinity headlong. However, they are almost universally excluded from our historiography of the nineteenth century utopian, doubtlessly because of their racial politics. In fact, our historiography of the period which suggests that 
Griggs's Imperium in Imperio is the "only ... pre-1900 American utopia...focused on African Americans," problematically excludes overlooks these works-although their focus on African Americans is much different (Roemer Paradise 100, emphasis added). Nevertheless, their exclusion highlights the whiteness of our own historiography and continue to reveal utopian studies' reluctance to broach the 'race question.' However, if we are to better understand the ways in which whiteness intervenes in and influences the utopian frameworks of national thought, works like W.H. Bishop's The Garden of Eden USA, A Very Possible Story (1895), Benjamin Rush Davenport's Uncle Sam's Cabins (1895) and Anglo Saxons, Onward! (1898), Albert Adams Merrill's The Great Awakening (1899), and Frank Purdy Williams's Hallie Marshall, True Daughter of the South (1900) cannot evade our study and must necessarily alter our historiography. They highlight the militancy of a nationalized rhetoric of American AngloSaxonism that we cannot overlook in light of the era's racialized violences of strikes, riots, and lynching. Their inclusion would highlight the salience of the 'race question' for the era and necessitate a reconsideration of race our historiography has long evaded.

While I cannot focus at length on all of the novels listed above, I would like to briefly characterize and categorize the similarities within these works before focusing on three as representative. At the core of these works lies an imperialist white masculinity that often depends on eradicating those of color and sacrificing the autonomy of its female characters, themes that are almost entirely overlooked in our historiography of the nineteenth-century utopian novel and those which vastly change how we imagine the politics of the utopian form. By turning to W.H. Bishop's The Garden of Eden USA, A Very Possible Story (1895), Benjamin Rush Davenport's Uncle Sam's Cabins (1895), and Frank Purdy Williams's Hallie Marshall, True Daughter of the South (1900), I argue that an amended historiography would allow us to map how the white 
utopian form harnessed American Anglo-Saxonism to advocate for a militant white intervention to black advancement as a means to preserve America's white utopian future. Far from the white escapism of earlier works, these works, spurred by black political development and by an organizing black infrastructure and culture, wanted to intervene in this history. These white works sought to reassert the supremacy of a white culture and the whiteness of the nation. Advocating everything from military infiltration to black genocide, imagining everything from white enslavement to a Southern victory in the Civil War, this body of utopian novels overtly links the literary utopia to preserving a white America by any means necessary, imagining 'race war' as a means to an American utopia, a theme not addressed in our present historiography. By the Atlanta Exposition, at least two white-authored utopian works, W.H. Bishop's The Garden of Eden USA, A Very Possible Story (1895) and Benjamin Rush Davenport's Uncle Sam's Cabins (1895), offer racially-motivated interventions into the nation's present and future that use the utopian form to confront their readers' understanding of the past. While these works are occasionally referenced in scholarship for their progress toward gender or class equality, discussion of racial identity within the novel remains conspicuously absent. Approaching these works with an eye toward racial identity, I argue we might read Bishop's Eden as a purposefully, if cover response to North Carolina's "Black Second" while Davenport's Cabins overtly argues that the emancipation of black slaves has single-handedly paved the way for white enslavement. Reactively rejecting the idea of black Americans playing a role in the nation's advancement, these worlds advocate segregation as the means to facilitate national progress, centralize a 'Rooseveltean' traveler, and employ the term "Anglo-Saxon" to overtly appeal to readers' sense of an American Anglo-Saxonism as the nation's utopian future. 
Although in some ways Bishop's Eden is profoundly progressive, it progressiveness is limited to white Americans. As Bishop imagines, Eden City, the non-sectarian Christian utopia conceived by wealthy Northerner Wayne Morrison, is set on a former plantation in Goldsboro, North Carolina. Gesturing to Bellamy's Looking Backward but critical of it, Bishop positions Eden as a remedy to the earlier novel's limitations which, in Bishop's estimation, does little to change the conditions of labor. In Eden, Morrison recognizes that "workingmen” don't want charity, but "help that really changes conditions and enables the weaker and less fortunate to obtain a more equal chance in life" (179). To that end, Bishop reimagines Bellamy’s state-owned industry and sex-separated labor force outside a capitalist frame. In Eden, while Morrison is the initial benefactor, his scheme is explained as a low-interest loan that allows the city's ten thousand inhabitants to labor toward collective ownership by paying him a three percent profit $(130,180)$. More than that, Bishop's women are "fully emancipated" and the utopian form allows him to fashion a sustained argument for their liberation (148). For they are all workingwomen and voting citizens who are educated and welcomed to attend college; they participate in a collective workforce and military, often dress in slacks and are socially liberated from the Cult of Domesticity that still frames Bellamy's future Boston (148). Although one of the most progressive utopias imagined for (white) women by a white male utopist, men remain the architects of the public sphere, men easily confuse and exchange one love interest for another, and the text's ardently sexist character who likens women to cuts of meat is forgivingly married to a progressive Edenite. Of course their promise of marriage can occur only after she literally recovers her skirt from a field at his behest, reasserting a patriarchal order. However, in Eden, characters of color_-black and immigrant_-do not fare as well. In fact, we are led to infer by the community's imposing gate, emphasis on Anglo history, and suggestions of exclusivity 
that Eden was for white "American workingmen" (and women) not "the cast-off offspring of the dregs of humanity" whom they "do not take" nor the "colored" slaves-cum-servants who appear distinctly outside of its borders (284).

From the outset of this 'progressive' novel we find overt gestures to American AngloSaxonism and covert suggestions that its utopian community is a haven for Old South ideology. From the outset, Bishop introduces utopist Wayne Morrison and traveler Stanley Brown as masculine American scholars of Rooseveltean form, for we find that they are both college athletes, scholars, and well-equipped to embark upon the expedition necessary to locate land for Morrison's proposed utopian endeavor when they reconnect a few years after their graduation. Soon after choosing a Southern setting for their utopia, the novel's overt comment on the race question begins. While we overtly learn that immigrant "dregs" will be barred, the Southern setting, quiet militancy of utopia's defenses, and our encounters with black characters announce the utopia's segregation (6, emphasis added). It is not by coincidence that Bishop selects a former plantation near Goldsboro, North Carolina, as the site of a white fortress of the future, a choice that tacitly positions the future in the Old South of the past. For the site was in the heart of a region well known as the "Black Second," the state's Second Congressional District, which became its first black-majority district in 1872 and resultantly elected three black men to Congress. From the vantage point of this history, it is difficult to interpret the text setting as anything other than an attempt to militantly reassert a white majority within the region. For as Bishop explains, Morrison's chosen site was among the plantations of the "better class," was likened to "Anglo-American castles," and ensured the natural security of "the Mountain barriers [that] seemed to almost enclose it," which was "an important consideration" $(56,54,55)$. We might read here a convergence of anti-black racism and nativism. For beginning in the $1880 \mathrm{~s}$ 
Northern capitalist development in the South began to replace the "traditional Southern stress on racial caste" with the language of social class used to frame the immigration question, reinforcing a rhetorical bond between the two (Frederickson 213). Suggesting the militancy of this protectorate for the "better class" of whites, the utopia's ten thousand residents applied for residency, signed a "pledge of secrecy" harkening to the secret societies of whites in the era, and, if admitted, are surrounded by a ten-foot wall $(100,102,104)$. Indeed, even the river is strung with a "barb wire fence" as a guard line that raises a gate in the river (106). In fact, as Stanley tries to infiltrate the community to surprise Wayne, he notices that the closer he gets the "thicker the guards became" making him feel like a "marked man," a man to whom harm would come should he breech the perimeter (103). Arguably, one could read the term "marked" as racialized as well. Stressing the militancy of the exterior, when inside the utopia we learn that while multifaceted, the education system is based on that at West Point, teaching, too, "patriotism and the art of war" (253). In other words, despite the utopia's professed focus on Christianity in establishing a new Eden, the utopia's militant perimeter, secrecy, and education suggest an Anglo-American castle preparing to wage a race war within the Black Second. In fact, Bishop envisions the city, which he suggests made the overtly racialized "White City" of the Columbian Exposition seem "small and cheap beside," as the nation's future, as our traveler Stanley Brown puts it, Eden "was clearly not a city of the past or even of the present, but of the future," a future that was overtly — and militantly—white $(118,130) .{ }^{124}$

In addition to the secrecy of its admission and the militancy of its borders, the novel's placement and treatment of non-white characters reinforce utopia's segregation. Stressing the novel's Anglo-American nativism, the immigrant "dregs of humanity" are barred from Eden City and the Jewish, rendered as Shylock, are exemplars of extortion and greed (190). For according 
to the novel's logics, the Jews "make money out of people," which suggests their likely exclusion as well (190). Indeed, Bishop's emphasis throughout is on “American workingmen," which his nativist nods reinforce as Anglo (6). More than that, Bishop's treatment of Colonel Green conveys a certain reverence for the Old South—and likely its racial logics. While the Colonel's title is a vestige of his role in the Civil War, he is also routinely called a gentleman and his family "holds a pass to the valley," suggesting they remain the right sort of people to populate utopia (161).

However, perhaps what is most telling of utopia's segregation is Bishop's treatment of "darkys" throughout (57). Significantly, Bishop places his characters in direct contact with a black character upon their arrival on the outskirts of the Green plantation. As readers' first and only direct encounter with a black American, it is significant that we encounter a character who is little more than a racist caricature, a "picaninny" or "coon" variety lazing at the river fishing (rather than working). For the boy, who rhetorically devolves from "young negro" to "darky" to "my boy" and three times calls Wayne "Massa," is rendered as a dialect-speaking, purchasable, wide-grinning imp (57). The young black man, the only character to speak in dialect despite the Southern locality, wears a persistently-noted grin on his face that eventually "broadened to mammoth proportions" and jumps at a coin to do the men's bidding, becoming at that moment the "slave" of the two men (57). ${ }^{125}$ Here Bishop rather flippantly use the term "slave" and his rhetoric of "Massa" and "darky" suggests the Old South remains alive and well on Colonel Green's plantation. Further, despite recording the presence of black slaves-cum-servants in the region and on the Green's plantation, this episode is the only one in the novel that gives a black character a voice. And that voice speaks volumes as it affirms the Northern author's belief in white supremacy and sympathy with the Old South. Further, the walls of Morrison's fortress are 
later imagined as cordoning off the river where the unnamed black boy sits, concretely reclaiming the single space of black autonomy as the purview of the white utopia. Lending further evidence to claims of exclusion and segregation, our other encounters with characters of color are always on the periphery of the utopia. For example, we meet a "colored girl" and a "dusky messenger" who are not only voiceless, but without choice since they are the servants of Colonel Green and his family $(159,67)$. In fact, maintaining "barbarian servants" may mark the reason the Greens do not reside in Eden City (69). For the benevolent paternalism of the Old South seems alive and well in the region surrounding the lush and verdant Green Plantation, a plantation fertile enough to foster a white separatist community in the heart of the Black Second and to reassert that the nation's future lies with the American Anglo-Saxon $(69,159,67)$.

Although it was published in the same year as Bishop's Eden, as an ardent Southerner Benjamin Rush Davenport's Uncle Sam's Cabins: A Story of American Life Looking Forward a Century (1895) even more clearly sympathizes with the racial order of the Old South. From the novel's immediately recognizable titular nod to Harriet Beecher Stowe's Uncle Tom's Cabin (1852), one of the most widely-read works of the century, Davenport's preface suggests he engages with Stowe's work precisely to criticize abolition as a threat to Anglo-American freedom. In this preface and in the utopia he imagines, framed by the title as an inevitable future history, he argues that the liberation of the black slaves created "conditions pregnant with danger to the freedom of a large class," that is, to the Anglo-Saxon, "an enslavement more painful...to even contemplate" (n.pag.). Fanning the flames of white animosity to black advancement, Davenport directly correlates black freedom with white enslavement or, at least, its potential in the future. In this way, from its preface the novel announces itself as a white supremacist work of American Anglo-Saxonism. Resituating readers' frame of reference to the antebellum South and 
rhetorically positioning "those [black] slaves" a distinctly "other" from the collective "Nation," Davenport positions the Anglo-Saxon as the American identity to be defended and preserved, as "the majority" and "the population" of concern (n. pag., emphasis added). In fact, Davenport's later works Anglo-Saxons, Onward! (1898) and Blood Will Tell (1902) even more vehemently and militantly articulate the notion of American Anglo-Saxonism Cabins begins. Reacting to the threat of miscegenation that both black advancement and immigration seemed to pose to the nation's white identity, the latter novel is even dedicated "to all Americans who deem purity of race an all-important element in the progress of our beloved country," and proceeds to literally frame a "mulatto" population as a eugenic curse upon the white elite of the nation (Davenport, Blood 86). Nevertheless, it is Cabins, the first of Davenport's oeuvre of white supremacist utopias, that starts to articulate a millennialist American Anglo-Saxonism.

Echoing the charges that many Southerners made in the Reconstruction Era and following, in Cabins Davenport argues that the future of America has been threatened by abolition, a centralized federal government, and the sallow and sickly men leading it. In this way, Davenport uses the utopian form and a near future setting to suggest that white masculinity and the nation, by extension, were at imminent risk of becoming unsovereign, since they have been so curtailed by the nation's deference to black advancement. Here Davenport imagines, as many whites did prior to Emancipation, that American manufacturing would fail to cheaper wares from "Africa, Asia, and South America" (20). Marking the extent of Davenport's racialized logics, the list of nations articulates another symbolic loss of white strength to brown peoples (20). In this imagining, Davenport makes manifest Southerners' fears of a centralized federal power taxing states into bankruptcy and dissolution. For the future's largely-agrarian nation, divided into Districts overseen by proprietors, have almost entirely collapsed into white slavery to maintain 
the wealth of the proprietor and the solvency of the federal government at the expense of its' Anglo-Saxon citizens' freedom (31). To stress the sense of a danger still imminent in the postReconstruction South, the story centers on the Lawton family, whose patriarch John, the proprietor of the Ohio District, is on the cusp of enslaving his Anglo-Saxon tenants to maintain his own position. Expressing his criticism of the federal system black Emancipation ushered in, Davenport renders John Lawton and his elder son and apparent successor Henry, as slight and pale, physical manifestations of the future's systemic sickness. And when both men succumb to illness, emphasizing their inability to lead the nation, the Rooseveltean Jack Lawson with his "bulldog tenacity and combativeness" becomes the proprietor. Suggesting he "might serve as a model for a statue of Hercules," Davenport stresses his peek Anglo superiority, and, thus, his role as savior of the Anglo-Saxon race. For Jack frees the white slaves his father had just conscripted and marries the formerly-enslaved Mollie Hollister, whose development as a character is wholly sacrificed to her use as a symbol. She is the tragic epitome of the AngloSaxon beauty and goodness lost in the Anglo oppression ushered in by black freedom. In this way, Davenport also encourages cross-class alignment as a means to thwart the real threat to America: the non-white racial other. More than that, through a reassertion of state power that pays homage to the arguments of the Old South, Jack's restores a white racial order by bucking the federal system and advancing nativist economy. A wide endorsement of his plan then allows other American proprietors to free their white tenant farmers who "had been enslaved for years" (120). In these ways, Davenport's utopian rhetoric courses white readers to reject the advancement of those of color and to see black freedom as a still-extant threat to the sovereignty and freedom of as Anglo-Saxon American future. 
Significantly, Davenport also alludes to black emancipation as having advanced a new social order of miscegenation. For emancipation, Davenport explains ushered in systemic changes, "conditions ... [that] designing men [used] for more than a century to rob and enslave Anglo-Saxons" (238). And one such theft was that of racial purity. For these conditions, Davenport suggests in a cautionary tale against integration, was a degree of social equality between the races that hastened the demise of a nation, by hastening the demise of the race (238). In this way, Davenport's focus on Mollie renders her as a 'tragic Anglo,' displacing the trope of the mulatta, whose tale, in Davenport's estimation would have only been tragic in its corruption of whiteness. For this reason, Davenport continually admires the rarity of Mollie's racial purity, encourage readers to fear its potential loss in their own future. Davenport's point is not only that all "gazed with admiration upon" her as the "highest type of womanly loveliness that the world ever knew," but that her Aryan beauty, "once common but now almost unknown," was nearly a lone and "pure pearl" in a "foam of jet" (139). Characterizing Mollie's "pearl" whiteness in a "foam of jet" presumably caused by generations of miscegenation, Davenport prizes white beauty and frames its passing, too, as a sign of the nation's devolution, toward that of the "African savages" and "naked, grub-worm eating black barbarian[s]" (55,88). Arguably, however, in resonance with his later work's demonizing of the mulatta, Davenport already frames racial passing as the greater threat to American Anglo-Saxonism because of its cunning motivation to target whites. We see this terror of the mulatto emerge in Davenport's marked racialization of the novel's villain: the Lawton's attorney, Mr. Weaving, who gleefully advocates for white enslavement and whose designs facilitate another character's sexual advances toward Mollie (79). Lacking a sense of propriety, and, arguably, of personhood, he is called only "Weaving," and is described as a "Shylock in disguise," a "brown, parchment-like old-young 
man" with "the beadlike eyes of the deadly rattle-snake" (18). For our villain, marked by brown skin and a bestial simile, also side-steps the question of his race, overtly stating that "the race whence I come is no matter" (179). In Davenport's estimation, the conniving Weaving, who might weave whatever tale of race he pleases to weasel into a position of authority, poses the most danger to the very spirit of Anglo-Saxonism through the literal and symbolic threat he poses to Mollie. In this way, Davenport, who even exculpates the Lawton family for ordering their white tenants into servitude, directs all blame to the racially-indeterminate Weaving. For Weaving, as a representative of the new system and a stand-in for the ills of black Emancipation, signals in Davenport's estimation the very real threat of white enslavement in the nation's future.

But Cabins was neither the only utopia (nor the only utopia of Davenport's) to envision American Anglo-Saxonism as the only way to preserve the nation's - or even the world'sfuture in a present imperiled by black citizenship and rampant immigration. Written only a few years later, as if to affirm the righteousness of the Supreme Court's national preservation of segregation in Plessy, Davenport's Anglo-Saxons, Onward! (1898) and Albert Adams Merrill's The Great Awakening (1899) reassure us that American Anglo-Saxonism is the path to American, if not a global, utopia predicated on whiteness. In Onward!, Davenport figuratively moves onward from Cabins. With Plessy and the ever-strengthening Jim Crow laws of the South mitigating the threat blacks posed to whites, Davenport focuses on global Anglo-Saxonism. Romanticizing America's kinship with England, Davenport uses Anglo-Saxon rhetoric to weave a racially unifying tale of Anglos uniting against non-Anglo foreigners who plot to wage war against them. ${ }^{126}$ To that end, the novel's ruggedly masculine American soldier George Howard, is described as a "fair-haired, tireless giant" who aids the English troops in Turkey and foils an assassination plot against the Russian Prince by the Tartars meant to have been seen as the fault 
of the English. An important signifier of the racialized threat foreigners posed, the plot is orchestrated by the Russian Princess whose "Tartar blood" links her to the threatening and unassimilable Turks and Mongols by the racial logics of the time $(226,29)$. Concluding in a dual ceremony of military award and marriage wherein even the British honor American AngloSaxon supremacy, Davenport stresses the ardent and racialized alliance between "the mighty brother nations, sprung from that grand ancestor, the Anglo-Saxon" as the means to defeat any foreign threat $(13,8) .{ }^{127}$ In fact, by centralizing American heroism — and English deference to it-Davenport arguably asserts the supremacy of the American Anglo-Saxon stock.

Similar to Davenport's Onward in its argument, northern writer Albert Adams Merrill's Awakening centralizes global Anglo-Saxon dominance as necessary and inevitable. Signaling pockets of an equally-zealous Jim Crow North, Merrill renders a homogenous white America as central to realizing a global utopia. Awakening tells the story of a nineteenth-century man whose consciousness is transported to a citizen in the apparently-egalitarian Anglo-Saxon republic of twenty-second century America. ${ }^{128}$ There he quickly learns that an "army of emigrants" colonized Africa and "fence[d] in their country... with police stations," that Russia fell and that the Chinese were "annihilate[d]...through famine and pestilence" after which "the Anglo-Saxon race quickly overspread the earth and war ceased forever" $(165,188,338)$. In other words, in no uncertain terms Merrill envisions an Anglo-Saxon future wherein Africans are militantly overtaken by whites, the Russians have fallen, and the Chinese are dead. More than that, as if to stress the American Anglo-Saxon's recovery of America and its history, our narrator/traveler becomes a professor of "medieval history [which he clarifies now means the eighteenth and nineteenth century] in Howard College" (340). Given the scope of the novel, we would be remiss if we didn't read Merrill's choice of college an overt nod to whites' reclamation of Howard 
University, which was founded as a college for black Americans in 1867 (340). For Merrill clearly aligns an American utopian with the eradication of the world's other races, suggesting that whites must reclaim both the institutions and history gone awry in the hands of black Americans. However, in a clear alignment with Davenport's thought, Merrill, too, traces America's past decline to its "mixture of foreign blood" and offers as a remedy an assertive Anglo-Saxon society that wages war to prevent miscegenation and resultant incivility (Merrill 327, 326). ${ }^{129}$ Given these utopists overt attention to racial identity as the lynchpin of utopia, including Merrill's and Davenport's works the tenor of our historiography would necessarily change. We could not avoid the 'race question' when a body of works clearly converges around the themes of nativism, advocacy of segregation, and, most ardently, American Anglo-Saxonism as a precondition for a utopian American future.

By the turn of the century, Anglo-Saxonism would fuel "Lost Cause" sentimentality in the South as well. In fact, white orations at the opening of the Atlanta Exposition cleaved to the rhetoric of Anglo-Saxonism in reasserting Southern white superiority, proudly "boast[ing] that 'Southern people present the largest percentage of the old Anglo-Saxon stock' in the United States” (qtd in Perdue 90). Likewise, Southerners were emboldened by President McKinley’s “explicit... furthering of sectional reconciliation" and thereafter by President Roosevelt's “fond[ness] of Southerners" (Blight 351, Brown n.pag.). And, most explicitly, Plessy’s political estoppel of black advancement had largely proven that the South's "cause ... was not lost...especially in racial terms" (Blight 350). To many black Americans, these concessions seemed an embrace of the new millennium as a blank slate for rewriting the Old South (Dyer 92). In fact, in the first year of the twentieth century Frank Purdy (F.P.) Williams's Hallie Marshall, True Daughter of the South (1900), did just that: it rewrote the system of the Old 
South for the new millennium. More than just a utopia, Hallie Marshall is one of the earliest known speculative histories, that is, a reimagining of the past, a fact that should ensure it a place in the historiography of the American utopia. Yet the work, like the others I've discussed here is rarely mentioned.

In Hallie Marshall, F.P. Williams uses the utopian form to reimagine Southern history and overtly advocate for the re-enslavement of black Americas. More than merely romanticizing the Old South and ennobling the sentiment of the Lost Cause, Williams transports his readers to the Southland where the restoration of black enslavement—rather than Davenport's mere suggestion of it in Uncle Sam's Cabins - is the solution to the white wage slavery of the Northern factory. After a wearying day of work at a mill, Northerner Ralph Marshall is transported by way of a dream to the Confederate States of America wherein he becomes a Northern cousin visiting the Marshall plantation in a Southland where Southerners won the Civil War and slavery remains. Through Ralph's shock and curiosity, Williams uses the utopian form to retell history from the South's perspective and to reshape readers' understanding of their own present. Williams frames re-enslavement as necessary to free Northern whites, since black enslavement, unlike wage slavery of whites, is acceptable because blacks are inferior and childlike. Assuring readers that the "evils that belonged to slavery as it was have been abolished" since after the war, he explains that the present slavery is "a system of tutelage" rooted in Southerners" "real love" for their "dependents," whom they "think of... as children committed to our care" $(16,20)$. Like Uncle Sam's Cabins, Hallie Marshall blames the North and abolition for the "impoverishment of the white working classes." Similarly, Williams castigates the North for its inhumanity by using the same terms that the North once used to scold Southern slavery. He argues that Northern laws are "radically wrong" and that white "men are driven like beasts" in a 
system where the "supply of labor exceeds the demand" and drives them into poverty $(59,83)$. Harkening to tales of slaves' escaping North, Williams's northern refugees flee to the South. Readers learn of these harrowing escapes, when the northerner John Sawyer and his young son from arrive on the Marshall plantation seeking refuge. For they lost their wife/mother to exposure along the way, as the Northern system forced them from their "decent neighborhood" to the "tenement louse district" to "the great army of tramps" (57). Merging the genre of the utopia with tropes borrowed from the slave narrative, Williams aligns white readers with Ralph's empathetic responses to Sawyer. More than that, he attempts to evoke a pattern of empathy once aroused for blacks and redirect it toward impoverished whites. For, in contrast to the infinite caricatures of the happy and childlike, yet ignorant "negro" cum "darky" cum "nigger," Williams positions the "emaciated" white refugees, whose pathos is amplified by the death of John Sawyer's child $(80,88)$. Indeed, despite the success and progress of many blacks in the South (evidenced in Atlanta, the center for black intellectualism, and at the Atlanta Exposition), Williams refuses to countenance blacks as anything other than slaves and certainly not as the black Americans they were. In fact, the novel's estimation of its black characters devolves when the white refugees arrive. Tellingly, just as the novel emphasizes the noble plight of whites, its esteem for its black wards declines; indeed, the text slides from "negro" to "nigger," suggesting the ease with which the South's new system would backslide to the Old. Further, the arrival of the white refugees also enables Williams to clearly redraw the line between free whites welcomed to live in Marshall's house and blacks relegated to "Negro quarters."

Although Ralph eventually wakens from this Southern dream to his life in the North, Williams's, Lost Cause conclusion suggests that the South will rise again. For he asserts that the "conceptions of noble minds," such as those of the heroic antebellum South "never die" but 
become "real manifestations" to "favored mortal eyes" (97). In this way Williams, too, implicates the eyes of his white readers, who, having seen a potential utopian future, might now manifest those visions, might recognize, as he has, that the poverty of the noble Anglo-Saxon stems from the freedom of the black. For Williams, the Old South's "social conditions" of enslavement and segregation, of black inferiority and white supremacy were the "natural conditions" of an American utopia, conditions that Plessy's assurance of segregation doubtlessly brought Williams's white readers one step closer to recognizing as such (59).

\section{Supplicating To or Soldiering Against? : Resistant Black Identity in a White Utopian}

\section{Ideology}

To this point I have suggested that American Anglo-Saxonism took a militant turn in society and in literature, a turn marked by Roosevelt's ascendency to the presidency. As the emblematic figure of "Rough Rider" masculinity and champion of American imperialism, his popularity bespoke the embrace of this new American credo. And this credo helped to foster sectarian reconciliation as well as a cross-class alignment among American whites against the new immigrant "stock." Indeed, by the century's end the Immigration Restriction League had formed and their rhetoric became increasingly eugenic in defining both the ideal American identity and those unfit for inclusion. And this rhetoric, which I suggested in the previous chapter began as one of contagion, now manifested as multi-front attacks conflating race with intellectual disability, "effeminacy," a general 'queerness' that led even Roosevelt himself to laud the necessary restoration of “"barbarian virtues"” (Bederman 98). It manifested, too, as a type of intra-national imperialism. It fostered sectarian reconciliation to reclaim white territory seen as lost to black Americans and to new immigrant stocks. And it culminated in a national refashioning of Lost Cause sentimentality, particularly popular among Southern works. And it 
was this rhetorical turn to American Anglo-Saxonism that allowed whites to justify the advancement of a New South aesthetic that harbored all the trappings of the Old at the1895 Atlanta Exposition. It facilitated the Supreme Court's decision in Plessy, figuratively reenslaving black Americans. And it propelled several cultural visions of the literal re-enslavement of blacks as the means to an American utopia. From this vantage point, then, there is little wonder why Booker T. Washington's “Atlanta Compromise” speech was parsed by whites into its most accomodationist sentiment of a New South suspiciously like the old wherein blacks and whites could remain "as separate as the fingers." And given such a racial climate, there is even less wonder why Washington might find a need to encode message that might suggest otherwise. It is from this renewed understanding of a militant white Anglo-Saxonism that I suggest we, likewise, approach Sutton E. Griggs's Imperium in Imperio (1899). Like Washington's critics, Griggs's accused him of being an accomodationist, at best, and a "“white folks' nigger,"” at worst (qtd in Chakkalakal and Warren 7). Even modern scholarly reception has been divide. Although recent scholarship has taken strides to reclaim a space for Griggs within the canon of Black nationalist literature, others still deem his work as too conservative for placement (Coleman 21). ${ }^{130}$ However, I would argue that there's another important consideration: genre. For Griggs's choice of genre signifies his desire to critically engage with the white politics of the present and to imagine a new "program" for the nation of the future (Jameson 3). In fact, I would argue that Griggs turns to utopia in Imperium as a means to wage an "intervention into official [white] history," and, like Harper's Iola Leroy, to metacritically intervene into the white politics of the generic form itself (Ernest 188).

As the title suggests, Imperium in Imperio tells the story of a state within a state, or, more specifically, of a secret black society and government covertly operating within America. 
Despite the significance of imagining a utopian haven for black readers, however, for the first two-thirds of the novel Griggs interrogates the manifold ways in which anti-black racism and systemic white supremacy have shaped black male citizenship, chiefly. Beginning as an apparent Bildungsroman told in retrospect by Imperium member and narrator Berl Trout, the novel first explores how the one-drop rule and resultant colorism shapes the parallel development of two young black men who become the leaders of the Imperium. The children of single mothers - one rendered as ignorant; the other, secretive; and both as hollow characters - their boys meet at school. There they find a shared masculine model in the bigoted white schoolmaster, who berates the darker-skinned Belton and the other "black nigger brat[s]" he's been forced to teach while he coddles the lighter-skinned Bernard. The narrative, however, slightly favors the plight of the darker-skinned Belton Piedmont, tracing his rise from poverty to oratorical mastery in school to Imperium leadership. Belton's story is contrasted to that of his "mulatto" co-protagonist, Bernard Belgrave, who is later revealed as the son of a wealthy white politician, a secret long-kept from Bernard himself (12). Although rivals in high school and separated by their years at different universities and career paths, the two become reacquainted when Belton seeks Bernard's legal help later in life, just before the latter is elected as a Congressman in Virginia's Second District $(77,89-90,53)$. The men continue with their lives and find paramours, who, as characters, are, like the men's mothers, nothing more than hollow touchstones for each man's development. In fact, it is Griggs's sacrifice of Viola Martin by suicide that hastens Bernard to the Imperium; for rather than marry the partially-white Bernard and contribute to "slowly exterminating" the "Negro race," Viola writes, she's chosen to kill herself (84). Bereft and angry at the systemic white supremacy that has fostered such extremes, when Belton summons him shortly thereafter, Bernard hastens to the meeting. Belton again seeks Bernard's counsel, but this time under the 
pretense of betraying the Negro race should a race war come to pass, a proposition that Bernard indignantly refuses. However, we quickly learn that Belton's story is a ruse to test Bernard's mettle and trustworthiness before introducing him to both the Imperium and his proposed role as the New Government's leader. Theatrically dropped by trap door into the convened Imperium Congress, Bernard and readers alike come face to face with the black, male Imperium's "Unwritten History," as the subsequent chapter title puts it, and its official documents of state. ${ }^{131}$ Time passes as Bernard settles into his new role and learns the history of the Imperium until the lynching of Imperium member Felix Cook (in real life, Frazier Baker) convenes the Congress in special session. Again emphasizing the Imperium — and the novel — as a force for developing black masculinity, fifty widows of lynching victims sit voicelessly in the gallery listening to the arguments of black men who will determine their fate. ${ }^{132}$ After both Bernard and Belton speak, it is clear that the two vehemently disagree on the course of action to take. Bernard rejects Belton's more conservative plans for revealing the Imperium and advocates militantly claiming Texas (innocuously convening blacks there at an international exhibition) and seceding from the Union. The hurried pace of the novel's final quarter, perhaps mirroring the sense of anger and urgency felt by black citizens' whose rights were being increasingly deferred or denied in white America, comes to a cataclysmic close with the tyrannical Bernard ordering Belton's murder for attempting to interfere with his plan and the imminent lynching of the treasonous Berl Trout for revealing the Imperium through the very work in the reader's hands.

Despite the importance of the utopian Imperium within an ostensibly utopian novel, its long-delayed introduction within the work is one of Griggs's most curious narrative choices. However, I would argue that the delay fosters a purposeful revision of utopian convention itself. Griggs refuses to allow readers to leave the present and, as such, reimagines the conventions of 
the white, male narrative form as a means to foster black male resistance. For recognizing the white escapism enabled by the genre's typical displacement to an idyllic future (or, in the case of W.H. Bishop and F.P. Williams an idyllic South and/or past), instead of displacing black readers to a utopian future where the work of forging utopia has been long accomplished, Griggs suspends them in the present. Like Harper's in Iola Leroy, Griggs's grounding of his narrative in the present and recent past, amplifies the necessity and potential for action. In fact, even the framing narrative itself is a metaphor for suspension, as the tale is framed as narrator Berl Trout's “dying declaration.” Significantly, we never witness Trout's execution; we are suspended in a ceaseless present that continually raises the question of the future moment when Trout will be shot, but never resolves it. More than that, Griggs's focus on ongoing and unresolved current events such as the murderous lynching of Postmaster Frazier Baker (novelized as Felix Cook) in South Carolina and forthcoming trial as well as the bombing of the U.S.S. Maine and ongoing responses to it in the press, grounds the reader in the present, too. It also offers another reason Griggs's may have chosen the utopian form: to foster readers' knowledge and civic involvement. Recasting the present positions readers to intervene in the future; it claims a space for a black voice in documenting the present and in the recording of American history for the future.

Unlike other literary genres, the utopia demands some exploration of the past to explain the future. To that end, I would argue that Griggs's extension of the recent past and present become a means for intervening in white tellings of history, more recent and long past. For Griggs retells earlier historical events, too; he engages with the very documents of nation, such as the Constitution, as well as the means of governance, by critiquing the elective and legislative processes. Provocatively, he renders those alongside the Imperium's own history, state 
documents, and political tracts, a blending of real and fictive that lends the latter a provocative air of plausibility.

Perhaps a more compelling reason for Griggs's generic choice and focus on a ceaseless present is the intimacy — and potential activism—of its first-person narration. For this literary mode enables Griggs to counsel his black readers, a relationship supported by his desire "to create a national Negro literature" and his active selling of the work door-to-door (Levander 30). Aside from building rapport, Griggs wryly uses the form's conventional self-authentication and authorial disclosure to course his readers in the practice of reading critically. Presenting himself as the editor of the present manuscript, Griggs's foreword proclaims the work's veracity, cites the existence of "other documents" that Trout provided to dispute any "attempt...to pronounce him a liar," and concludes by offering to provide other "indisputable proofs" (2). In this way, from the novel's outset Griggs frames his black readers as skeptics; he challenges them to attempt to pronounce Trout a liar and to dispute the work as scholars engaged in a critical debate using "documents" and "proofs." In other words, Griggs reimagines the utopian form as a site for skeptical readership that simultaneously courses black readers to be (rightfully) skeptical of the utopian genre. For, as one scholar has aptly explained, even the very act of reading can be seen as a site of black resistance and activism. She points out that for the poor black readers who were Griggs's primary audience, "the stakes of reading and of reading intensively... are high," as the practice "would eventually whittle away the strictures imposed by Jim Crow" (Chakkalakal 164). However, I would argue that Griggs uses the utopian form to demand more of his reader in Imperium; the novel does not construct a ceaseless present and skeptical readership to "eventually whittle away" at Jim Crow, but to incite readers to action. In fact, I would argue that Griggs uses the utopian form which necessarily blends fact and fiction precisely to challenge 
black readers to sort "fact" from "fiction"- - and to point out the slippage in between, as with his juxtaposition of the fact of the bombing of U.S.S. Maine with the fictionalized story of Postmaster Felix Cook's (Frazier Baker's) lynching (100). In fact, Griggs continually points to the fictions of white history as told from the perspective of black readers, including: how segregation denies the nation's assertion of natural equality, how lynching goes unreprimanded despite assurance of "equal protection," and how the guarantees of citizenship have failed wholesale when "the Negro finds himself an unprotected foreigner in his own home" (89). In this way, I would argue that Griggs wages an intervention into white history by encouraging his original black audience to reconsider their certainty about what constitutes a "fact" and to ask what role uncertainty might play in both narrative and nation.

In fact, I would argue that Griggs realizes — just as Poe did - that there is power in raising doubt. Doubt causes us to question ourselves and to reflect on what we think we know; it demands immediate self-examination, including an examination of the means by which we came to such "knowledge." In this way Griggs uses the utopian form to courses his readers in a metafictive reading practice that calls attention to the constructedness and whiteness of categories like "knowledge" and "history," and, I would argue of the utopian form itself. For by using the utopian form to suspend black readers in the present and course them to recognize the manipulation of and slippage between the categories of "fact" and "fiction," Griggs destabilizes the (white) genre's presumption to "know" what might foster a utopian future. From this vantage point, I would argue that we should place Imperium in the lineage of critical utopias politically excluded from our historiography of the period as well as alongside other works mobilizing black nationalism in resistance to the rise in American Anglo-Saxonism post-Plessy. 
Perhaps the most overt signal that Imperium might be read as an articulation of black nationalist masculinity in response to American Anglo-Saxonism lies in the current events with which Griggs engages and the rhetoric with which he tells them. For Griggs pairs histories of black American gain with white reaction. For example, he evokes the "Black Second" in North Carolina, only to recall the secret white supremacist societies in New Orleans orchestrating attacks to prevent black Americans from voting. He draws attention to the Buffalo Soldiers' lauded and then shamed for their service to the nation in the Spanish-American War (evoked by the bombing of the U.S.S. Maine), only to focus on the brutal lynching and murder of Postmaster Frazier Baker (novelized as Felix Cook). In all of these instances, Griggs's examination of historical moments juxtaposes the black man's civic potential to violent acts of white retribution $(52,72,100)$. However, I would argue that it is Griggs's juxtaposition of the bombing of the U.S.S. Maine to the lynching of Postmaster Baker, events only days apart in readers' very recent history, that is rhetorically the most significant. For the lynching of Cook/Baker is the catalyst for convening the Congress of the Imperium on "the same day on which the Congress of the United States has under consideration...war with Spain” (100). In fact, Griggs overtly likens the Imperium's "horrified...indignation" to news of Cook's/Baker's lynching to that which "the destruction of the warship" fanned "in the bosoms of the Anglo-Saxons" $(100,89)$. In this way, he overtly reminds his black readers of the overlap of these two events in the press, of his treatment as "an unprotected foreigner in his own home" that he will soon be "call[ed] upon...to defend" in war $(100,89,101)$. Yet, in likening these two events, Griggs symbolically elevates Baker's murder to the level of national atrocity it is. He draws readers to consider how the popular press's headlines charging to "Remember the Maine!" overshadowed Baker's lynching, as it has in American memory now. More than that, the ongoing trials of the eleven white men 
indicted for the murderous lynching of Baker and his family stresses the immediacy of the work. It's likely, too, that their acquittal in the month after Griggs published Imperium reinforced the work's sense of a ceaseless present.

Griggs also uses Baker's lynching to channel the barbarian heritage of the term AngloSaxon with which black America's were figuratively at war. In Bernard's speech before the Imperium Congress, Griggs writes: "the same hammer and anvil that forged the steel sword of the Anglo-Saxon with which he fought for freedom from England's yoke, also forged the chain the Anglo-Saxon used to bind the negro" (102). Although Bernard is referring historically to the Revolutionary War, he alludes to the weaponry the Anglo-Saxons would have used at the dawn of their civilization in the fifth century, conjuring a lineage of brutality. In this way, the persistent, even excessive use of the terms "Anglo-Saxon" or "Anglo-Saxon race"-twenty times in one brief chapter-rhetorically allows Griggs to align Anglo-Saxonism with mob mentality and "Rough Rider" masculinity. Given the rhetorical weight of repetition, I would argue that even Belton's moderate follow-up oration, despite having "blasted away all opposition," cannot undue that rhetorical work of Bernard's speech—nor do I think Griggs's intended it to (118). In fact, even in Belton's closing lines he concedes that the Anglo-Saxon is "fierce" and "all conquering," reasserting a barbaric heritage (118). More significantly, Griggs disposes of Belton. Allowing Belton to be executed at Bernard's behest leaves readers suspended in the present with Bernard and Berl, a replacement racial moderate, who likewise awaits execution. Although I would argue that Griggs preserves each of the perspectives his characters represent and even symbolically merges them in his alliterative naming scheme, it is Bernard who survives, a suggestion that entertains the idea that the only way to meet Anglo-Saxonism is with Black Nationalism. 
Although scholars have long-aligned Griggs with Belton's more conservative message, I would argue that such an alignment overlooks his purposeful revision of the utopian genre and preservation of the radical voice, damn the cost. For while the text does not envision the revolution for readers, it "countenances openly the possibility of organized violence against Jim Crow segregation," which, arguably, makes the texts more threatening (Chakkalakal and Warren). Indeed, the work of revolution is left to the reader's imagination, the same reader implicated by and within the work's ceaseless present positioning him to act. But as with Washington's “Atlanta Compromise" address, a more conservative reading predominates. Yet, it is difficult to discount how Griggs manipulates both plot and genre to stress the immediate need for action, just as it is difficult to overlook Washington's suggestive hope that a possibly wrathful "God will come...in a blotting out"-a manner that darkens — to "administer absolute justice" (n.pag.). In fact, what if Griggs recognized the duality of Washington's message at the Atlanta Exposition - as well as the significance of W.E.B. DuBois's forthcoming "Exhibit of the American Negro" at the Paris Exposition Universelle in 1900? For Griggs concludes with two addresses on the future of black Americans that offer rival perspectives as did Washington's (Belton) and Du Bois's (Bernard). Likewise, he imagines a future world's fair at Galveston as providing the means to overtake Austin (and eventually all of Texas and Louisiana), details likely to have conjured for black readers the very recent Atlanta Exposition as well as the forthcoming Paris Exposition, among others (120). For although there had not yet been a fair in Texas, in little more than fifteen years between 1881 and 1897 the South hosted seven world's fairs, including three in Atlanta, Georgia and two in New Orleans, Louisiana, the second state Bernard suggested the Imperium overtake. From this vantage point, the suggestion to "hold a fair" held subversive potential, potential reinforced by plausibility when Griggs also offers 
readers a clearly labeled and numbered plan of action for organizing such a coup. In fact, we might even read Griggs's denial of such a revolution as subversive, as a refusal to envision and resolve change for readers precisely to compel them to act. For the novel ends in a question that beckons, even taunts the reader think about the future, by asking: "When will all the races and classes of men learn that men made in the image of God will not be the slaves of another image?" From this vantage point, we might also read Griggs's subtitle, A Study of the Negro Race, with renewed significance. We might apply it to Griggs's own exploration of hypothetical black responses to Anglo-Saxonism. We might also wryly and metafictively consider it as applying to Griggs's own study of his readers' responses to his work, that is, of whether his interpellated reader, suspended in the present and poised to act, will take up the pen or sword.

When we consider Griggs's revision of utopian convention as facilitating the writing of an activist text, we find that the text may be read as a jus ad bellum, a declaration of a justified war. That said, it is imperative to understand that Griggs, who earned a graduate degree at Richmond Theological Seminary and served as the president of the National Baptist Convention, was likely familiar with Thomas Aquinas's Summa Theologica (1274), the work that defines the jus ad bellum Griggs's work satisfies in several key ways. In fact, I would argue that his allusion to the Summa Theologica begins with Griggs's own Latin title, which stresses the text's creation of a sovereign governing body, a State for the black American with the authority to declare war. Moreover, it is not by happenstance that Griggs imagines the Congress of the Imperium convening at the same time the U.S. Congress was convened precisely to declare war. Nor does it seem coincidental that through this special session and the ensuing speeches Griggs raises and satisfies Aquinas's three conditions of a just war. Foremost, by likening the Imperium to the U.S. Congress and recounting the tally of ills the Anglo-Saxons have waged against black Americans, 
Griggs positions the Imperium as a state authority acting in the best interest of its people. Griggs then proceeds to satisfy in order Aquinas's two subsequent conditions — "just cause" and "right intention”- through Bernard's and Belton's speeches. Significantly, Bernard's speech begins with a lengthy "review" of the "horrors of the past" and the "treatment [black Americans have] received at the hands of the Anglo-Saxon race" so that the Congress might "arrive at a proper conclusion" for a course of action, which, in Bernard's estimation is a race war (102). More significantly, Griggs wryly crafts Belton's speech to satisfy the third criterion of a just war: right intention. Despite Belton's advocacy for the use of the "pen" rather than the "sword," Griggs nevertheless frames Belton's speech with a declaration of right intention. For Belton begins by beseeching Congress to "bear [...] witness" to his patriotism and "zealous... work of building up the Imperium," that is, by asking the Imperium to judge and find "right" his intentions. More than that, although Griggs uses Belton's speech to represent intellectual intervention, it, too, concludes with a call to arms, a call for the Imperium and reader alike to "be prepared...to buckle on our swords and go forth to win our freedom with the sword just as has been done by all other nations of men" (118). Indeed, although Belton's higher-road approach suggests a bloodless revolution would be the "crowning glory" of black achievement when no other nation has managed as much in relation to the Anglo-Saxon, Griggs, in fact, continues to remind us that no other nation has managed as much (118). For even Belton stresses three times that "other races," "all other races," and "all other nations" have won their freedom through bloodshed. To that end, I would argue that it is also significant that Griggs imagines Belton as “The Storm's Master," as the chapter title notes. For rather than titling the chapter "Quelling the Storm," which would pose a parallelism to Bernard's "Crossing the Rubicon," Griggs's title ominously 
reaffirms a coming storm, a war that even the conservative Belton imagines the pen may be unable to manage.

By reading Imperium as an activist text, I attempt to “consider the novel's problematic ending," as scholar Robert Levine suggests we must, and to reconsider our scholarly assessment and placement of Griggs as an author and a utopist (80). In reconsidering Griggs, we must negotiate how scholarship has pushed his work to the margins of both black nationalist and utopian literature. I would argue that we have been too quick to insist either that Belton's conservatism "speaks for the historical Griggs," or, conversely, that Griggs's perspective is alarmingly militant (80). And such polarization, aided by discounting the work's generic form, continues to push Griggs's work to the margins. To that end, I suggest that by reprivileging the work's genre, we find a way around simply exchanging binaries for dualism. We see Griggs's attention to multiple perspectives, as he interpellates a skeptical and critical reader continually redirected to re consider the details of how they remain oppressed and defined by whites in a ceaseless present. ${ }^{133}$ Although I am necessarily critical of the work's dismissal of women, particularly when Griggs's work follows Frances Harpers's nuanced development of women's role as central in defining the New Negro in her utopian Iola Leroy (1892), Griggs's reimagining of the genre's temporal conventions construct a space precisely for the reader to act, or, at the very least for the reader to recognize the need for action in a present of seemingly ceaseless black oppression. It is also significant, I think, that Griggs's oeuvre is punctuated by works that demand its readers think toward futurity, from Imperium to The Guide to Racial Greatness (1923) to his Plan for Solving the Race Problem (1929), which was among the last of his works. In fact, at least one Griggs scholar argues that Imperium is a "prefiguration of the political strategy outlined in Greatness" and that the texts, taken together, "represent the first and final 
efforts to formulate a method of political action," a method that doubtlessly informed his Plan (Levander 23, 24). It is also significant, I think, that Griggs begins his writing career with a fictive plan for reimagining the nation that his later works attempt to literalize in nonfiction, a turn that I would argue reinforces the central impulses of Imperium: encouraging black readers to think critically about the faces of systemic white supremacy and to be prepared to act. By considering his manipulation of utopian conventions in Imperium to foster skeptical readership and compel readers toward action, we begin to map a much more revolutionary black nationalism in Griggs's work from the start, one that, I would argue, recognizes and militates against the frameworks of utopian thought underlying the millennialist romance of American Anglo-Saxonism in literature as in culture by the century's end by reimagining those same conventions as a means to foster black activism.

\section{Conclusions: Toward Another Landscape}

In this chapter I have argued that the fateful decision in Plessy v. Ferguson and a millennialist reassertion of Anglo-Saxonism have long-shaped the racial politics of the nineteenth-century utopian form in America, despite our historiography's reluctance to engage with them. Arguably, it is the decision in Plessy that has enabled us to long overlook how the whiteness of scholarship itself has been long-skewed by the reach of Plessy. For Plessy enabled whiteness to remain standard, normalized, and ultimately naturalized, and, as such scholarship has long read utopia as racially unmarked. In this vein, it's conceivable, too, that our historiography may have even purposefully excluded works by white men that would reveal this façade. For just as there is no racially unmarked text in nineteenth century America, there is no utopia of the period beyond race, a fact that the utopias of Bishop, Davenport, and Williams make abundantly clear in their barring, blaming, or re-enslaving of black Americans. And, in this 
way, our exclusion of these white supremacist works skews our historiography of the utopian form as well as our cultural history.

When we enlarge our frame of historical reference to consider the zeitgeist of American Anglo-Saxonism as a version of millennialist utopian thought at the century's end, we are compelled to consider how that iteration of whiteness shaped utopian works of the time. For Anglo-Saxonism came to define the nation's self-image by the late nineteenth century. This was not only reinforced by Theodore Roosevelt's notion that "an American type combined the best racial characteristics of the Anglo-Saxon and Teutonic pasts," but in the nation's turn to AngloSaxonism as a way to mitigate the divide between the North and South, to facilitate national Reconciliation (Dyer 46). The success of American Anglo-Saxonism is recorded through the increasingly nativist hostilities and eugenic testing of "new stock" immigrants as well as through the increased attacks on black Americans (lynching) and their rights (Plessy). But it is also recorded culturally through our rhetoric of commemoration. For example, while most memory of the Atlanta Exposition has waned, it is nearly always recalled as the site of Booker T. Washington's “Atlanta Compromise," recasting the fair as an accomodationist concession to white rule. For despite the centrality of millennialist Anglo-Saxonism to the historical period and to utopian imaginings at the fair, our historiography avoids or excludes discussions of race.

As I have argued here, recovering Griggs's Imperium alongside the white-authored utopian works of Bishop and Davenport, Merrill and Williams, is a matter of telling a more accurate history, a matter of understanding how the white framework of utopian thought governed American practice and policy. For it is only through understanding the militant context of a millennialist American Anglo-Saxonism that we might come to see Booker T. Washington's “Atlanta Compromise" as a covert plea for action. It is only through our historiography's 
inclusion of the overtly white-supremacist utopian novels that we might come to see the significance of race to all of the nation's imaginings of an American utopia in the nineteenth century. It is only through the inclusion of works like Griggs's Imperium, or, as I argued in the previous chapter, Harper's Iola Leroy that metafictively call out the genre's inherent whiteness as an articulation of black resistance, that we come to see the utopian form as a battleground, as an overtly racialized framework for securing — or resisting — an Anglo-Saxon future. 


\section{Chapter 4: Articulating a Black Utopia: Intellectualism and a Black National Imaginary in Fair and Fiction}

Fiction is of great value to any people as a preserver of manners and customs-religious, political, and social. It is a record of growth and development from generation to generation

- Pauline Hopkins, preface to Contending Forces

The story weaved into the work is subordinate to the discussion of facts.

- E.A. Johnson, Preface to Light Ahead for the Negro

I want to write realistically, but constructively.

- Lillian B. Horace, in her diary

The Problem of the $20^{\text {th }}$ Century is the problem of the color-line.

- W.E.B. Du Bois, The Georgia Negro, Exhibit of the American Negro, 1900

As early as June 1895, three months prior to the opening of the Atlanta Cotton States Exposition, the Scientific American described at length the Exposition Universelle planned for Paris in 1900. Filling in informational gaps with romantic suppositions, the American periodical began generating an ekphrastic Parisian fairscape for its readers five years in advance of the fair. Of all the suppositions the article makes, one focus is particularly significant. Curiously, amid its romantic stroll through its imagined utopian fairscape of the future, the article directs the reader's gaze three times to the fair's proposed ethnological displays. It first mentions the "special foreign exhibits," then elaborates on the premier grounds that would be "chiefly devoted" to the "colonial villages" of the indigenous, and finally harkens to the to the memory of a "similar display" in Paris in 1889. Baiting readers to recall that celebrated display of indigenous peoples, the article asks them to wonder how any forthcoming village could "be more perfect." The article's insistent rhetorical repetition urges readers to recall a previous "human zoo," as scholars have come to call these exploitive exhibits, and demonstrates that ethnological displays were, indeed, a major attraction for fairgoers. ${ }^{134}$ 
Significantly, the Scientific American's 1895 reminder of Paris's 1889 colonial display comes at a charged historical moment. For the periodical's desire for readers to recall the 400person Negro Village that was the centerpiece of a fair for its 30 million visitors also waged an overtly racialized and hierarchical diversion from the present. For in a mere three months the world's first Negro Building — a building designed by, built by, and dedicated to the work of black Americans_-would open at the Atlanta Exposition (Rydell 56). The timing and scope of Scientific American's article on the forthcoming Paris Exposition can hardly been seen as coincidental. In the context of the imminent Atlanta fair the periodical barely mentions, the Paris article's displaced focus to a secured racial hierarchy in the future becomes an intentional distraction from the forthcoming Atlanta fair and its Negro Building. It becomes an anxietyfueled mitigation of the impending racial "threat" at home. By putting these two moments in conversation, we not only see the degree of anticipation surrounding world's fairs or the lure of these human zoos overtly engineered to amplify non-white primitivism, we see the anxious framework of white utopian thought in the press. We see a white anxiety to escape the present threat of a black America able to articulate its own identity and a longing to reassert a white racial order over the future.

The Scientific American's coverage of the Atlanta Exposition's opening in September offers further reason for interpreting the periodical's displaced Parisian focus as racially motivated. ${ }^{135}$ For even when the periodical writes about the Atlanta fair, it conspicuously neglects discussing the "Negro Building," whose novelty made it an instant attraction. From June through December in 1895, a period that covers the length of the Atlanta Exposition, the Scientific American mentions the "Negro Building" as a term only once to account for its square footage. ${ }^{136}$ In "The Opening of the Cotton States and International Exposition" published in 
September 1895 , the article frames the event as celebrating the (implicitly white) South's "free[dom] from the burden of slavery." More than that, it anonymizes Booker T. Washington as simply "a negro... with native eloquence," casts the fair as marking the day of "reconciliation between the whites and the negroes," and even commemorates the fair as marking the day whites "lifted up" blacks "to the same...rights as themselves." 137 In other words, the article literally centralizes the role of white experience; it was they who suffered the "burden" of slavery and must now facilitate black uplift. It also figuratively reasserts that the fair-and the America it shapes and reflects—remains the province of whites. For the Scientific American, with its racialized articulations and displaced focus on generating an ekphrastic utopian fairscape five years in the future, enacts a white escapism similar to that punctuating many American utopias. And following suit, the periodical remains markedly silent about black success in the future, as it ultimately neglects making mention of the Grand Prix and gold-medal winning Exhibition of the American Negro included at Paris Exposition of 1900. For in approximately 45 feature articles on the Paris Exposition that Scientific American published between January 1899 and December 1900, none mentions the Negro Exhibit. In fact, the periodical's single mention of "negroes" at the fair comes in an oblique reference, rather than a feature. For in September 1899, the periodical's "Science Notes" section recounts the fair's "curious shows" informing readers that the Paris Exposition would include "man-eating negroes and similar things" from the Congo. ${ }^{138}$ Pointing to a general trend in the mainstream press, during the same time interval nearly 250 feature articles were published on the "Paris Exposition" while only 4 of those discuss the Negro Exhibit. ${ }^{139}$ In the context of a press that ranges from avoiding discussion of black-defined black development to amplifying "negro" cannibalism, it's imperative that we read the Scientific American's 1895 displacement to an imagined Parisian fairscape of 1900 as an articulation of 
white anxiety. For it records an anxious rhetorical reassertion of white dominion precisely as black Americans were poised to write themselves into fair history and into an authorial role in the national narrative.

I begin with this glimpse at the Scientific American to map the overlap between the fairscape and utopia in the national imaginary and to point to the press as litmus test for the reaches of white anxiety in the face of black national advancement. As I will argue in this chapter, beginning with The Exhibit of the American Negro at the Paris Exposition Universelle in 1900 and tracing to one of the first wholly African American organized fairs, Chicago's Lincoln Jubilee and Exposition held in 1915, black utopian narratives collectively re-imagine black Americans as integral to shaping the nation's future. Beginning with the Exhibit of the American Negro, "black citizens formulated bold counternarratives to American Progress," narratives that included both "dissent" and "self-determination" (Wilson 7). They explored how to represent and "elevate" their status "against the rising tide of antiblack racism" and also asserted their necessity to the nation's future progress (7). To that end, it is rhetorically important that the Negro Exhibit was part of an American display in Paris. It gave black Americans a narrative and intellectual presence within the nation's past, present, and future - one that W.E.B. Du Bois's research amplifies and advances nationally and internationally. And emboldened by the success of the Negro Exhibit and Du Bois's work, several prominent black writers turn to the utopian genre, arguably a narrative site of exhibition, as a space for intervening in that national narrative and asserting their role in the nation's future. As one scholar of African American literature argues, at this time black Americans had entered an "era of...literary production" and were finding more "outlets for publication open," including in white periodicals (McDowell vii). More than that, they were not only "drawn to utopian fiction as a widely popular genre," but 
because it "sanctioned the political import of imagining alternative societies," and, like the fairscape, "provided an established...context for comprehensive socio-political analysis" (Yarborough xxvii, Fabi "Of the Coming of Grace" 163). With this historical context in mind, unlike France Harper's Iola Leroy (1892) or Sutton E. Griggs Imperium in Imperio (1899) incomplete visions for the future, the utopia works I discuss in this chapter, Pauline Hopkins's $O f$ One Blood (1902-1903), E.A. Johnson's Light Ahead for the Negro (1904), and Lillian Jones Horace's Five Generations Hence (1916), recover and reframe an absent black-authored past and give greater shape to a black future where accommodationism is insufficient. Instead, these works foreground the role of black intellectualism within the utopian program. More than that, they adopt more "formally traditional" utopian features, which renders their exclusion from a dominant historiography of the nineteenth century utopia that often reaches to encompass Charlotte Perkins Gilman's 1915 Herland, appear to be rooted all the more in racial politics (Fabi Passing 47). And while these works are guided in no small measure by W.E.B. Du Bois's growing prominence in the civil rights movement, I also argue that his The Souls of Black Folks (1903) keenly makes use of utopian literary conventions as well. I suggest that while black utopia persists in its "subversive revision of popular literary modes," it also wages a metafictive critique of utopia's generic whiteness and asserts a more complete visions of black utopia thought (Fabi Passing 45). As Hopkins imagines, these works collectively treat "fiction [as]... a record of growth and development" for black Americans. And as by writing utopian works they recognize the importance of writing "realistically, but constructively," as Horace puts, through a genre where the "story," as Johnson explains, is subordinate to its "discussion of facts." And it this aspiration for black literature, for black utopian narratives, that I suggest is traceable culturally as a site of resistance to white narratives of black identity. To that end, I conclude with 
a discussion of Chicago's 1915 Lincoln Jubilee Exposition. For the Exposition carves out a space for black Americans in the memory of the White City and deftly highlights "the problem of the color line," a white-defined line between "two worlds," one white and the 'other' — rife with the ostracism that word suggests—-black.

\section{The Exhibition Universelle, Du Bois, and the Roots of "New Negro" Utopian Thought}

Given the storied history of the primitive Negro periodicals like the Scientific American recirculates among whites at the mere suggestion of a world's fair, it's unsurprising that Thomas Junius (T.J.) Calloway recognized immediately the importance of lobbying for the New Negro's inclusion in Paris's Exposition Universelle in 1900. For as soon as the United States began to plan its participation in the Paris fair to "showcase" itself as a "nation at the forefront of social reform in the new century," Calloway say an opportunity for the nation to include black Americans as a measure of that reform. Recalling Booker T. Washington's success at the Atlanta Exposition and influence thereafter, Calloway believed the exposition would be a key forum for advancing the image of a New Negro for a new century — the image of a burgeoning intellectual developing well beyond restriction to mechanical trades (Wilson 84, 89). To that end, Calloway sought the help of Booker T. Washington and other prominent black Alabamans to lobby for the inclusion of a "Negro exhibit." By November of 1899, after Washington's clout with the National Education Association (NEA) secured Calloway an appointment to oversee an exhibit and the last remaining black Congressman, George H. White, helped him attain federal financing, Calloway became the organizer of the Exhibit of the American Negro (Wilson 84). In this way, this unprecedented international display would represent blacks within the American exhibit, as American citizens, and as contributing members to American society. ${ }^{140}$ 
Calloway recognized the role of the world's fair —and its press—in shaping American ideology and national identity at home and abroad. As a discontented Bookerite, former state commissioner at the 1895 Atlanta fair's Negro Building, and managing editor of the weekly periodical the Colored American, Calloway knew the importance of gaining a foothold in the American press nationally and internationally. He recognized that representation at the fair meant the possibility of advancing a black-defined image of the "American Negro" and the possibility of increasing coverage of Negro advancement in the white press. He also recognized that international exposure of the mistreatment of black Americans in a segregated nation wherein they continued to lose political ground to Jim Crow's gains could draw enough score to exert political pressure on the U.S. to change these practices. In a morose irony, as Calloway well knew, the fairscape offered a utopian glimpse at the potential for integration to work and it was one of the few sites remaining where blacks Americans could simply experience the type of national belonging they were ostensibly granted with citizenship. With this in mind, this section discusses the significance of Calloway's Exhibit of the American Negro and of the related PanAfrican Conference in London. I argue that rhetorical study of these sites helps us to map the advancement of a black-defined "New Negro" identity, the rise of W.E.B. Du Bois as an intellectual alternative to Washington's (perceived) accommodationism, and an advancing framework for black utopian thought.

At the same time, given Calloway's experience with the Atlanta Exposition, he would have understood that the utopian reaches of The Exhibit of American Negroes would be tempered by the larger racial context by both that of previous world's fairs and at the Paris Exposition. Just as the Atlanta Exposition's inclusion of a Negro Building displaying black progress had been contextually-limited by the Midway's "Old Plantation" and the series of racist 
caricatures Harper's Weekly ran about black fairgoers, reception of the Exhibit of American Negroes in Paris was affected by its surroundings. Despite America's monumental inclusion of the display, the exhibit remained mostly cordoned off from the larger American section by a walkway. Likewise, it was dubbed in official guides as "Negro Exhibit," dropping the "American" and suggesting a degree of distance, if not outright exclusion. And, as the Scientific America had imagined years prior, Paris included a grander and immersive "human zoo" of Africans from French colonies, which drew problematic visual comparisons for fairgoers. For example, while photographs such as "La Dahomey" and "Workmen from Dahomey," may capture a reasonable likeness of an African village or African attire, removed from the context of active village life and labor they bespeak stereotypes of the shiftless or lazy black American (see figs. 33-34). More than that these representations meld with racist caricature, even in France, affecting reception of both the Dahomey village and the Exhibit of the American Negro. In fact, the French Magazine Le Rire ran a full-paged cartoon caricaturing the African Dahomey (see fig. 35). However, given the cartoon's quip focuses on "blackness" (rather than African-ness) and the genre of caricature and its visual racism were well-known among American audiences, its application was easily extended to black American. Likewise, it's hardly coincidental that a seven-part series on the exposition in the New York Observer, which includes a final installment titled “Our Nation's Exhibits" lauding the nation's accomplishments, makes no mention of the Exhibit of the American Negro or the grand prize it earned. In fact, the series only mentions a "negro" to note in caricature the "laughing negro" of the "colonial exhibits" ("The Paris Exposition"). With all of this in mind, it seems Calloway correctly recognized the necessity of black self-assertion at the fairscape as a site of resistance to American - and even Europeanrepresentations of blacks as "laughing negroes." However, it's also important to consider that 
such representations, while intended to dispel white anxiety, also testify to an increasingly palpable black resistance.

Given the racial climate of the fin de siècle, the political stakes for the Exhibition of the American Negro were high, particularly for black American citizens. As I argued in the previous chapter, black Americans were met with a millennialist reinvigoration of Anglo-Saxonism reasserting white supremacy on a national scale. Lawful discrimination redoubled in the wake of the Supreme Court's decision in Plessy, lynching rates saw little decline, and overt redistricting was poised to oust the last remaining black men from the U.S. Congress by 1901. Other than the limited positions black Americans were able to secure in government agencies, cultural works like the world's fair were one of the few "useful public spheres where black Americans could intersect with influential white political and civic leaders" to shape policy and practice (Wilson 88). With this in mind, the Negro Exhibit's sponsorship by the NEA was also rhetorically important, since it signaled for an international audience the black American's citizenship and the prioritizing of black education. Although policies at home suggested otherwise, such a utopian representations and the press given them could help black Americans exert political pressure for change. And to some degree, it did. For the laudatory coverage of the prizes awarded The Exhibit of the American Negro in the white press helped to secure the exhibit's inclusion in America's next world's fair, the Pan American Exposition planned for Buffalo, NY in 1901, ultimately extending the resistance the Exhibit of the American Negro voiced to whitedefined images of blackness.

However, it was the content of the exhibit that waged the largest challenge to representations of the Negro as a "primitive" type best suited to mechanical labor. Provocatively, the exhibit afforded a public forum for the political self-assertion of an urban, intellectual black 
identity that differed radically from the humble black laborer Washington (strategically) advanced as the American Negro archetype. Testifying to the intellect of black Americans, Daniel P. Murray, another exhibit organizer and historian at the Library of Congress, sought to collect a copy of every pamphlet and book written by black Americans for inclusion. Perhaps more importantly, these works would later become part the Library of Congress, making a space for black literatures within the central record-keeper of the nation's history. Likewise, the exhibit compiled over 500 photographs documenting the rich and ranging contributions of black Americans beyond the mechanical trades. While such mechanical exhibits were included, the breadth of other inclusions showed a tremendous range of abilities outside of them. For example, fairgoers witnessed examples of black proprietorship and co-educational professional training as displayed in photos titled "Mr. Dougald's Drug Store" and "Dentistry at Howard University," of black Americans as classical musicians and as dedicated members of religious communities, as in the "Summit Avenue Ensemble" and "Sisters of the Holy Family in New Orleans" (see figs. 36-39). In these ways, the exhibit "talked back," as bell hooks would put it, to a white society unwilling to recognize the truth of black progress and to a self-limiting black message of accomodationism. For this reason, the exhibit's very inclusion was construed by some Americans, white and black, as "uppity" or as waging a political offensive; for it was, as Calloway intended, an homage to black intellectualism. ${ }^{141}$ It decreed that "blacks were the cultural equals of whites" and sought to "incontrovertibly prove" such claims by offering "sociological analysis," "photographic documentation," and whatever else necessary to counter white-determined images of black identity (Wilson 89, emphasis added).

However, it was perhaps the inclusion and subsequent fame of W.E.B. Du Bois's ongoing, unimpeachable research on black American success that waged the clearest political 
offensive to the nation's systemic racism. ${ }^{142}$ The manifold proofs and visual criticisms showcased in his exhibit titled The Georgia Negro was an unequivocal and comprehensive demography of black Americans in Georgia. Using Georgia, which offered a balance between rural and urban research and was home to the capital of the New South, Du Bois made inferences for black development elsewhere in America, confirming the power of such research to shape activism. For his work was the first comprehensive scientific sociological study of black Americans and the first analysis of the longitudinal effects of anti-black racism in numeric terms (94). Along with giving statistical shape to black progress, it catalogued evidence of systemic anti-black discrimination for fairgoers. It included, for example, a hand-written list of all of the "black codes" imposed across the United States as an explicit example of how systemic white supremacy wrote anti-black racism into the very laws of nation. Stressing the importance of reading black success against such an overt context of white supremacy, at least one graph rendered it visually for fairgoers. In a graph representing the increase in the "Valuation of Town and City Property Owned by Negroes," readers find the words "Ku-Kluxism," "Lynching," and "Disenfranchisement and Proscriptive Laws" demanding the increase in property value be read as a monumental gain in the context of overt political oppression (see fig. 40). Du Bois’s particular word choices accompanying a fluid, upward-moving linear graphic suggests a political equation among the terms: black advancement precipitated a proportional advancement in antiblack resistance among whites from fringe secret societies, to wider-spread mob violence, to lawful discrimination. However, the larger focus of Du Bois's resistance to racism comes through its representation of an official history of black Americans that envisioned blacks as integral "to the forward advance of civilization" rather than outside "the march of social progress," a task seemingly between a Herculean labor and a utopian dream (Wilson 107). And 
yet the reception of the exhibit proved it was not a dream. Celebrated with a gold medal, The Georgia Negro sealed Du Bois's notoriety as a sociologist, historian, and civil rights activist. For it was the first plate of The Georgia Negro that introduced his now-famous articulation of "the problem of the color-line," which itself waged an active criticism of the one-sided, blameplacing rhetoric of "the negro problem" plaguing the implicitly white nineteenth century (see fig. 41). More than that, his unprecedented findings and immersive methodology informed the field of sociology thereafter, a field that Du Bois well-knew helped to manufacture the nation's white utopian complex by transposing scientific racisms to social policies and laws of black exclusion (95).

Yet, perhaps the most salient moment of the Paris exposition for Du Bois's intellectual influence over black activism actually occurred during an interim and related trip to London for the first Pan-African Conference. For it is here that Du Bois begins linking the materiality of his research with a black utopian impulse and activist rhetoric in a public forum. Although in works prior to his conference-closing speech, such as "The Conservation of Races" (1897), Du Bois concludes with a plan for the future of The American Negro Academy (ANA) of which he was President at the time, the plan articulates a set of beliefs. While the essay charges that the ANA should "stand and proclaim...over the house tops" that "I will not equivocate, I will not retreat a single inch, and I will be heard," it resolves with a "creed," a series of seven "beliefs" to unite the ANA (Du Bois, "Conservation" 60). This is, of course, not to dismiss the importance of a creed or the significance of the organization as an alternative to the Bookerites, but to mark a shift in rhetoric. By 1900 when Du Bois delivers the closing address at the Pan-African Conference his language changes. He resolves in a call for action through a series of imperatives. Met by a seemingly-utopian London he calls "the metropolis of the modern world," surrounded 
by peoples of African descent eager to unite for a common good, and feeling he was among "racial equals for a change," Du Bois's "To the Nations of the World" address shows a transposition from research to political action that he later realizes more fully as a leader of the Niagara Movement, co-founder of the NAACP, and editor of The Crisis (qtd. in Wilson 115). However, in this conference-closing speech, at the brink of a new century already showing that modernity could bring closer together those of color throughout the world, Du Bois's work began moving rhetorically from an assertion of fact and creed to an imperative for change. In an overt "appeal" that implicates his audience in the work of reform through a series of imperatives, he intones: "[You] let the world take no backward step," "[You] Let no color or race be a feature of distinction between white and black men," and finally, "[You] black subjects...fight bravely [for the] incontestable right to be counted among the great brotherhood of mankind" (Du Bois "To the..."). And notably, those at the conference thought the address profound enough to be "adopted by the group and dispatched to leaders of the black world" (Wilson 115). This proliferation of Du Bois's work as a unifying voice solidified his role at the head of the Conference thereafter, despite his initially minor role in London. More than that, the dual notoriety of the exposition and conference multiplied mentions of W.E.B. Du Bois work and publications of it in the white press. ${ }^{143}$ By 1900 The Dial, for example, called the current discussion on the negro question "inadequate" and "wide of the mark," while reverently naming the "brilliant" work of "Professor W.E.B. Du Bois" a "model" for future "systemic and local studies" by blacks and whites alike (Henderson n.pag.). In 1901, The Atlantic would bill $\mathrm{Du}$ Bois's work alongside that of future president Woodrow Wilson as "the most important group of...studies of the Reconstruction Period," while by 1903 Outlook, the same periodical that published the work of Theodore Roosevelt, would publish his provocatively titled "The Training 
of Negroes for Social Power." The latter article concludes with a rather defiant direct address of his white readers as "brothers," implicates them as an impediment to black development, and culminates in the confrontational jab: "Are you afraid to let... [blacks] try?" (n.pag.). Indeed, in the three years following the Paris Exposition and the Pan-African Conference, Du Bois's work and its rhetoric added to the "bold counternarratives to American Progress" that "black citizens formulated" (Wilson 7). He transposed those narratives from the socially-removed ideological utopias of the fairscape or conference to the American landscape. And his rhetoric shifted, too, from clear recitations of social-scientific proof, to the statements of unifying creed among a Negro Academy, to the utopian rhetoric enabling an incisive critique of white society and black pronouncements for the future, a future he believed was rooted in black intellectual development.

\section{Du Bois and the Need for Black Utopian Thought}

To this point, I have suggested that the Exhibit of the American Negro at the Exposition Universelle in Paris and the Pan-African Conference in London were unprecedented representations of black intellectualism on a world stage. They enabled black intellectuals to craft and advance for the first time a self-determined narrative of black Americans' role in the nation's past, present, and future. They enabled leading intellectuals like Calloway and Du Bois to express their dissent to white-determined narratives of black identity, to "incontrovertibly prove" themselves the cultural equals of whites in an international forum, and to assert their necessity to the nation's future. But, of course, as I have argued here and throughout, whitedeterminacy does not idly persist in the face of black resistance, it amplifies. As we see in the press reporting on the fair, coverage largely neglected the narrative of the award-winning Exhibition of the American Negro and overtly redirected its readers' gaze to sensationalized narratives of barbarous "man-eating" Africans. As these anxious white narratives suggests, it 
seemed unlikely that the America on the cutting-edge of "social reform" showcased in Paris would extend to its black citizens at home.

In fact, at nearly the same time the celebrated Exhibit of the American Negro was on display in Paris to laud the "New Negro's" progress, reactive rhetoric on the homefront proclaimed the "negro's regression." In his keynote address titled "The American Negro, His Past and Future," which was so well-received that it was distributed to all of the medical societies in the South, white University of Virginia Professor of Medicine D.P. Barringer argued that he had biological proof of black regression to "barbarism." Although we cannot say with certainty that Barringer was responding to the Negro Exhibit at Paris or to Du Bois's work, the title, the tenor of the doctor's remarks, and the possibility that he had encountered Du Bois's 1898 study of "The Negroes of Farmville, Virginia" conducted in a town merely 60 miles south of the university where he taught, suggest the possibility. Regardless of whether or not Barringer was responding to Du Bois's work, his paper, in an era witnessing a growth of compelling selfdetermined narratives of black history and progress, presents a reactionary exertion of white control over the narrative of black life.

Actually, Barringer's oration offers a useful example of the reactionary tone white rhetoric takes in response to black America's increasing self-definition. From the outset of the address, Barringer reasserts his own (white) authority over black identity. He claims dominion over the "American Negro's" past and future and subordinates sociological study—notably, that in which Du Bois specialized— to biological study. Perhaps wittingly dismissing Du Bois's research and that of his field, he claims that "sociological problems are in most cases biological problems," thereby sharply asserting his own expertise (3). Yet, the entire premise of Barringer's 'biological' argument rests on a baseless racial history which begins with a likening of black 
men to dogs. Bestializing blacks, he analogizes their perceived decline in character to how crossbreeding dogs dampens useful specializations of breeds. He then cites a specious imperial fantasy of blacks as having lived "fifty centuries of historically recorded savagery" as further biological 'proof' (4-5). For Barringer concludes from this narrative that since "everything points to the fact that the phylogeny of the negro is carrying him back to barbarism," the only possible hope for the race is a renewal of benevolent white paternalism, a white-led "education of trade" by those who can teach him to "respect, obey, and work" (23). In other words, Barringer's "research," a work of scientific racism that mentions nary a biological detail let alone a fact, anxiously reasserts and attempts to naturalize as biological fact a white-determined narrative of black Americans' future. Further, I would argue that given Barringer's framing of his work as a critique of the sociological also conveys an increasing fear among whites of the attention paid and merit given Du Bois's studies. And while Du Bois's growing body of meticulous empirical research "incontrovertibly proved" the cultural equality of blacks, the devastating white supremacist fantasies of negro inferiority and regression would persist (Wilson 89).

With Barringer's reactionary white rhetoric in mind, this section discusses how the growing contest between black and white intellectuals over defining black identity bespeaks a larger struggle over access to the national narrative. I argue that while the success of the Exhibit of the American Negro and Du Bois's work helped to catalyze a utopian rhetoric for discussing the role of black Americans in the nation's future, it also seemed to redouble reactionary white narratives exerting their exclusive claims, as Barringer does, to defining black Americans and the nation's future. And those reactive white narratives began to take shape immediately. By 1901 black Congressman George H. White's loss of his congressional seat would usher in a 28-year period without black legislators, re-securing the government as the dominion of whites. While 
the year would also see the American Negro exhibit gain a wider national audience at the Buffalo Pan-American Exposition, Julian Hawthorne would almost immediately liken and subordinate the exhibit to that of the "real negroes" of "Darkest Africa,"” exerting the same anxious white narrative control he'd exerted a decade ago when opining similarly about the Columbian Exposition (Hawthorne, emphasis added). However, perhaps the best indication of the state of the nation's racial climate was the response to Theodore Roosevelt's extension of an invitation to Booker T. Washington to dine at the White House. The event which was almost immediately dubbed an "incident," caricatured in newspapers, and recycled in politics and the press for years afterward, yielded volatile anti-black rhetoric, particularly in the south and shockingly from a government official (“Mr. Roosevelt Explains...”). ${ }^{144}$ Of these, none were quite as vile as that of South Carolina Senator Benjamin Tillman, who, as Life magazine reported, seethed: "The action of President Roosevelt in entertaining that nigger will necessitate our killing a thousand niggers in the South before they will learn their place again" ("Senator Tillman"). Bespeaking the systemic white supremacy of the state, the south, and to some degree the nation, Tillman remained in office until 1918 despite his overt racism and open endorsement of lynching. He was nearly a symbol of the growing wave of "negrophobia" among whites (Hayes 4-6).

As I will argue here, by the first year of the twentieth century black intellectuals, who were organizing, researching, writing, and daring to opine about their role in the nation's future were met by a resultant white anxiety-turned-hysteria — and not just in the South. While the nation's shocking tally of black lynchings in the South remain steady into the first decade of the twentieth century, the era also witnessed countless race riots in the North and the rebirth of the $\mathrm{Ku}$ Klux Klan, all of which were fundamentally rooted in preserving the narrative of an American utopia predicated upon its whiteness. ${ }^{145}$ And this "negrophobia," rooted in a fear of 
literal and figurative miscegenation, was extended symbolically and rhetorically to immigrants through increased eugenic policing. For legislation against the newest wave of "undesirable" immigrants operated by the same racialized logic, that a "race" of immigrant would 'denigrate' or 'sully' the nation's stock. ${ }^{146}$ Northern whites, for example, hastened to form the Race Betterment Foundation in Michigan in 1906 and the nation's Eugenics Record Office opened in New York in 1911 (Dyer 122). ${ }^{147}$ But to a nation who had from inception defined itself as white largely against its black population, black citizens now posed the most imminent threat, a premise at the very core of the Supreme Court's decision in Plessy and one that enabled an increasingly negrophobic white nation to forge a veritable white utopia precisely through segregation. Recognizing the white utopian complex that segregation was ushering in, I argue further that Du Bois turns metacritically to utopian convention in The Souls of Black Folk to combat the everyday dystopian reality of black Americans living in a white America. Segregation enabled whites to increasingly cordon off black Americans, to entrap them and create a veritable white American utopia, or, as Du Bois put it in The Souls of Black Folk, to create "two worlds," one black, one white (i).

From the very outset of The Souls of Black Folk, Du Bois metaphorizes himself as a world-weary utopian traveler between two imperfect worlds, one white and the other black. For Du Bois, as we come to understand, is a member of the "talented tenth," arguably a utopian moniker of exceptionalism. This membership enables him to become a traveler between these worlds and symbolically reinforces the work's overarching argument that classical education is the means to racial uplift, the means to traveling to a different world. In fact, in the work's most lyrical closing chapter, Du Bois again personifies himself a traveler in the narrative's final line. And he is not merely a "the traveler [who] girds himself... and goes his way," rather, as the lyrics 
preceding the final line suggest, he is going a "heavenly way," or, in the abstract, traversing a path toward utopia $(53,133)$. Also like the conventional narrator of a literary utopia, Du Bois uses direct address throughout to encourage an active, participatory reader. He begins by imploring readers' involvement, asking them to "read with patience" and to "study" his words (i). More than he tasks readers to decipher the "strange meaning of being black," to uncover what "lie buried" within it, and, in another metaphor of concealment, to discover what lay behind the "veil" (i). In other words, he interpolates a participatory reader necessary to unearthing the meaning of being black in America, to uncovering how a black world has come to exist within a white one. And like the generic utopia, Du Bois maintains some semblance of his travelerpersona's first person narration throughout, nearly always reintroducing himself as an "I" that doubles as a foresighted "eye," gazing to the distance by analyzing the past—not unlike a sociologist does.

Utopian conventions allow Du Bois to transpose his sociological observation to activism through a recognizable and popular genre known to compel readers in a way pure science could not. In fact, I would argue that the use of utopian convention in Souls is a logical and lyrical, extension of his sociological work, a characterization reinforced by his citation of lyric poetry throughout as well. ${ }^{148}$ For utopian conventions allows Du Bois to translate a calculated projection of the future drawn from the meticulous study of black bodies in the past and present, and to a language that speaks, as the work's title aptly reminds us, to and of black souls. Given its lyrical, episodic form and its observant traveler, I would argue that we could read Souls as the product of a black utopist stranded in a dystopian America precisely to highlight the nation's dystopianism. In this way, Du Bois's utopian method is arguably similar to that of William Dean 
Howells, who makes use of his Altruian utopist Aristides Homos and an American setting to wage a similar type of critique.

Du Bois's traveler persona often appears at chapter endings as a way to intervene in history while his multitemporality lends his observations an air of prophecy and gravitas. For example, at the close of his second chapter, Du Bois's traveler persona reemerges in the final paragraph in a distinct break from the text preceding it, but it is the moment's overlapping temporality that is worthiest of note. Rendering the persona as nearly outside of time, Du Bois uses the figure's multitemporality as a means of narrative escape. For the persona at once says he "has seen" the King's Highway of an ancient Egypt and "three centuries' thought" about blacks in America, while simultaneously making a prescient pronouncement that the twentieth century's central problem will be that of the color-line (20). Here Du Bois points out that while history has been rhetorically manipulated by whites to exclude blacks it is also a mutable narrative through which blacks can wage resistance by reasserting their past. For example, at the close of his sixth chapter while Du Bois points to the intellectual prowess of blacks in mastering the great texts, he also suggestively reasserts a literary and representational past outside the present white-define black identity. There he "sit[s] with Shakespeare," likely to remind readers that while his Othello could imagine a valiant black man the same foolish white society was still looking to "wash the Ethiop white." And he moves "arm in arm... across the color line... with Balzac and Dumas," doubtless to remind readers of Dumas's literary fame and mixed-race ancestry as well as Balzac's “contemptuously calling him “le negre”" (Martone 91). By conjuring back intellectualism as both possible through education and as having a long history, the persona compels readers, particularly white readers, to see not only the contradiction in white arguments against the higher education of blacks, but proof of the opposite. In a series of provocative, even 
confrontational final questions, Du Bois asks of white America: "is this the life you grudge us...? Is this the life you long to change into the dull red hideousness of Georgia? Are you so afraid....we sight the Promised Land?” (55). Here, Du Bois implicates the power of white narrative to transform black lives and openly identifies fear as the crux of systemic anti-black racism in the white world. For, like the red clay of Georgia to which he alludes, whites "change [blacks] into" the image of blackness they desire, regardless of the truth. More than that, he also radically notes here that black Americans could improve the Promised Land, could improve the white world, arguing that black inclusion "may give the world new points of view...precious to all human hearts" (55).

However, it may be Du Bois's prophecy of “Awakening” that best melds his sociological work with utopian convention in Souls. Writing at the close of his tenth chapter, Du Bois opines that "The Awakening will come" when black Americans cannot just idly live their lives beneath the veil, at a time when "all the pent-up vigor of ten million souls" will realize that "all that makes life worth living — Liberty, Justice, and Right—is marked 'For White People Only'” (103). Drawing on his sociological understanding of "Negro religion" as a site of resistance and community, as "social center[s]" that were in some cases "governments of men," he prophesizes that the rhetoric of segregation will foster The Awakening (97). Although critical of the Church's fractioning, he nevertheless draws on a deep sociological understanding of religion that anticipates, or perhaps informs, Emile Durkheim's definintion of religion as a "unified system of beliefs...unit[ing] into one single moral community" in The Elementary Forms of Religious Life (1912) (47). From this understanding of religion as a force for unifying society, Du Bois's persona could simultaneously "prophesize" that the church would again stir the "deep religious feeling" necessary for a revival-esque civil Awakening to combat segregation and actively 
suggest it (Souls 97). And yet the lyrical quality of these chapter closings also seems to tap into another narrative form: the spiritual. For the lyrical quality of Souls recovers the black spiritual as the font from which the "African American utopian impulse...emerges" (Fabi 45). And while Du Bois, the utopist reminds us of the form's utopian activism, Du Bois the sociologist, reminds of the uniquely American and black character of the form, a form that, I would add, has long overlooked in our historiography of the utopian genre. As I have been suggesting, Souls melds the sociological with utopia as a rhetoric of the future, as a rhetoric of hope. For as a sociologist Du Bois identifies and maps patterns of progress and development to conjecture about the future, but as a prophetic utopist he might better speak to the souls of black folk. In this literary mode Du Bois's utopist persona might help to rekindle that "deep religious feeling" and hasten an "Awakening" among his people (103). While in the sociological, he might help his black readers to understand that being "shut out from their [white] world" in fear is nevertheless a "faint revelation of his power...to attain his place" in it $(1,4)$. And by bringing these generic worlds together in Souls, Du Bois historically grounds black utopian thought within a legacy of black American resistance to white supremacy.

However, Du Bois's use of utopian conventions in The Souls of Black Folk also wages a metacritical resistance to white narrative structures and their inherent delimitation of black narratives. Du Bois challenges both the generic utopia and the utopian frameworks that white Americans have used to build two worlds, that is, a white nation and white-defined subordinate place for black citizens within it. In other words, in Souls Du Bois engages in a critical study of whiteness. ${ }^{149}$ From the book's outset, Du Bois focuses on the power of white narratives of the past and present - and on the importance of blacks intervening within them. While highlighting white narrative erasure of blacks, Du Bois persistently reminds readers of black Americans' 
contributions to the nation's history and points specifically to black modes of storytelling as influential over whites. As Du Bois points out, "there is no true American music" but that of "the Negro slave" and no "American fairy tales and folklore" save that of Indian and African (132). As Du Bois well knew, many hymns sung in white churches grew from slave spirituals while white author's often drew on black folk takes, perhaps most notably, Joel Chandler Harris's tremendously popular Uncle Remus stories. With this in mind, Du Bois rightly points out that "America [would not] have been America without her Negro people," without these black cultural contributions that white American music and literature appropriated (132). For this reason, when Du Bois confrontationally asks his white readers "Your county? How came it yours?" in the work's final paragraphs, he also metacritically asks readers to consider the processes by which the nation was built (132). In raising the question of music and story as foundational works, Du Bois considers the physical labor of nation building alongside the narrative means by which the nation is built. He also points out that the nation's white narrative structure not only has vestiges of black narrative within it, but that this narrative be changed (132). In this way, Du Bois destabilizes our (largely white) preconceptions with the origins of American literary genres and, arguably, strategically mirrors the effect of the white world has had on the black American. When we consider that African and Indian narratives preceded white narratives for more than a century in America, even the very foundations of the nation's utopian impulse - and its whiteness - are called into question. In other words, Du Bois asserts a black influence over white narrative from the text's foreword. While some may read a conflict between his "Forethought," which suggests a "bar of the Sorrow Songs" precede each chapter, and the text, wherein the chapters are preceded by the poetry of Lowell, Byron, Wittier, and Omar Khayym, among others, I would argue that Du Bois is overtly asserting the influence of the 
"negro" over white narrative, an influence he would have us trace to Khayym's eleventh-century rubaiyat, at least. This is not to argue against other influences or against the lineage of utopian thought I have mapped elsewhere, but to argue that Du Bois's metacritical examination of genre purposefully disorients readers' gaze, interpellating them to look through the veil to critically study whites' narrative process. At the very least, Du Bois encourages readers to see the ways in which black cultural forms have influenced white culture and destabilizes whites' claims of cultural superiority, a claim arguably still used to justify their segregation from certain canons and historiographies.

Like Calloway, Du Bois recognized that centuries-long white narratives of black inferiority fueled and justified their physical segregation in a white nation. Waging a critical study of whiteness, these black intellectuals recognized that "nationalist ideologies drew... [on] the sociohistorical legacy of racial difference" to establish the "transcendent ideals... of a "national character"' (Wilson 113). To that end, they also recognized that the only way to produce "new national identities" was "to recalibrate" the narrative, a narrative that would need to include "new physiognomic evidence accorded by racial science" to reaffirm the fitness of blacks for citizenship and the development of their own culture (113). In other words, Du Bois's sociological method recognized that blacks would have to "form their own nation," cultivating “"Negro colleges, Negro newspapers, Negro business organizations, a Negro school of literature" if America was to prove "for the first time in the modern world that... Negroes are capable of evolving" a nation and culture that was not "a servile imitation of Anglo-Saxon culture" (“Conservation" 56). Du Bois recognized that black intellectuals needed to confront the dystopian reality of segregated schools, trains, hotels, restaurants, and churches in the South. They needed to confront the re-segregation of federal workplaces as having effectually removed 
black Americans from any role in the nation's administration even in the North. And they needed to clearly address how increasing "spatial segregation" through city ordinances "denied blacks access to urban housing markets," literally demarcated a white utopia (Massey \& Denton 19). As Du Bois recognized, black Americans needed to build a culture that could write a new narrative grounded in the facts of observation and science long-used against them. As Du Bois, Calloway, and others among the "Talented Tenth" recognized, black Americans were living a dystopian reality within a white America cordoning itself off from its "negro problem." And they knew that only a new narrative of negro and nation, a new rhetoric of "the color-line" that appropriated white ideological and narrative methods could begin to shift black Americans' future.

\section{The "New Negro" Utopia and the Problem of the Color-Line}

In the previous section I discuss the contest between black and white intellectuals over the national narrative and black Americans' place within it. Focusing in particular on Du Bois's work and rise to prominence as a leading black public intellectual after the Exhibition of the American Negro at Paris, I trace the shift in his own narrative from proof to creed to a call for action. I have noted that Du Bois rhetorically recasts the "negro problem" as the "problem of the color-line" largely drawn by whites to call attention to the power of white narrative in forging the ideology of the nation. For Du Bois keenly recognized that the white utopian framework guiding the national narrative began to cast racial segregation as the means to realizing a white utopian America, a narrative that simultaneously crafts a dystopian reality for black Americans. In this section I argue that the work of black intellectuals' writing self-determined narratives of the black past and future—and Du Bois's work in particular—are the catalyst for a new utopian impulse among black writers, one that fosters, too, the emerging field of critical whiteness study among black intellectuals largely overlooked. Heeding Calloway's and Du Bois's call to 
"incontrovertibly prove" black culture the equal of white, writers such as Pauline Hopkins, E.A. Johnson, and Lillian Jones Horace recognize that "fiction," and perhaps utopian fiction in particular, was "of great value" in measuring, recording, and influencing social thought about black Americans. I argue here that Hopkins's Of One Blood (1902-1903), Johnson's Light Ahead for the Negro (1904), and Horace's Five Generations Hence (1916), take up Du Bois's call for a narrative shift and target the epistemology of the white-drawn color-line. They recover a blackauthored past absent in white-determined narratives of nation and give shape to a black American future by using more "formally traditional" utopian features to carve a space for what we might call the New Negro utopia (Fabi Passing 47). Significantly, this "traditionalism" suggests that their exclusion from the dominant historiography of the nineteenth century utopia is rooted all the more in racial politics. For the period's historiography, which is often extended to include Gilman's Herland (1915), nevertheless sidesteps these black authored-works. It has typically dismissed serious racial inquiry by continuing to frame the white writer-including Gilman — not as a purveyor of racism, but as one who has "succumbed to her [or his] era's racial attitudes" (Roemer "Paradise" 98, emphasis added). While I will also argue that their traditionalism is at times complicit in re-casting the problems of the utopian form for black writers, I maintain that these utopias remain a "subversive revision of popular literary modes" (Fabi Passing 45). I argue that they continue to wage a metafictive critique of the inherent whiteness of the generic literary utopia to assert a more complete vision of black utopianism. In Of One Blood, chronologically the first of the novels I will discuss, Pauline Hopkins tells the story of Reuel Briggs's, a gifted black medical student at Harvard University who chooses to pass as white to advance his education there. From the outset, however, Briggs is rendered as a melancholic protagonist troubled not merely by his own "passing," by the inability 
to be "intellectual" and "black" in American narratives of race and nation. Hopkins stresses the "bareness and desolateness" of his apartment emphasizing his "loneliness" from the narrative's start. Questioning the "use" of his "persistent hard work for a place in the world" and contemplating suicide, I would argue that Hopkins stresses the psychological toll of racial passing as well as the fact that there is no "place in the [white] world" for a black intellect (1). More than that, like an African American folk tale recognizing the insufficiency of real means of intervention within a surreal society, Hopkins transubstantiates his anxiety through magical realism. For, his medical talent for treating "brain disease" is characterized as mesmeric (27). Jostled from his contemplative state by the arrival of his long-time mate (and unbeknownst halfbrother) Aubrey Livingstone and taken to a performance of the Fisk University Jubilee Singers, Briggs first meets black choir member Dianthe Lusk (later revealed as the half-sister to both men) whom he saves with his unusual talents a few weeks later, falls in love with, and from whom he conceals her forgotten blackness. Again reinforcing the novel's preoccupation with the psychological toll of blackness, it is here symbolized as a fate worse than death. Briggs, who soon falls in love with Dianthe goes on expedition to Africa to earn his fortune so that he might marry her, but Aubrey, who proves to be a "false friend" murders his own beloved Molly Vance, reveals Dianthe's true racial identity, and tries to coerce the latter to run away with him (69). Meanwhile, still in Africa Briggs learns of Aubrey's plot against him through a mixture of discovery and intuition perceives Dianthe's death. Bereft, he leaves the expedition intent on suicide when he wanders toward the utopian city of Telassar where he is intercepted, knocked unconscious, and taken within its gates. There he learns of his familial bonds to both Aubrey and Dianthe and that he is also the prophesied king come to "restore to the Ethiopian race its ancient glory" (114). With the aid of the Telassarans and the Vances, Briggs returns to America to 
avenge the deaths of Dianthe and Molly Vance before returning to Africa where he weds Queen Candace, teaches them all he's learned about the modern world, and awaits the arrival of white explorers (114).

Hopkins's narrative strategies in Of One Blood; or, the Hidden Self bespeak her belief in the "counterdiscursive power" of literature (Mc Dowell vii). From the outset of the novel, Hopkins begins to postulate a new teleology, a different way of interpreting science and history that better accounts for the role of the "Afro-American" within it. More than generating an 'elsewhere' per se, Hopkins uses the utopian form to question the rationality of the dominant white discourse and generate a plausible 'otherwise' for the readers of The Colored American, where the work first appeared in 1902 (99). In fact, although part of the narrative does take place in Africa and Briggs remains there at the novel's close, Hopkins focus remains the interpretation of American society, as Briggs remains in Africa to teach "his people all that he had learned in years of contact with modern culture" (198). However, I would argue that Hopkins centers the novel on correcting white supremacist discourse from the novel's opening scene, wherein readers find Briggs reading the philosophy of William James and Alfred Binet. Highlighting their work by direct quotation and purposeful misattribution, Hopkins uses the work of both white theorists to highlight the limitations of white scientific paradigms for understanding the anomalous, which soon includes Briggs himself. Importantly, within these first few paragraphs Hopkins suggests that a general limitation of white discourse is the root of Briggs's melancholy. For despite Briggs's intelligence — his resentment-inspiring "genius"- - he is forced to pass as white and is contemplating suicide. He is unable to reconcile his experience of his "hidden self" in a society wherein black Americans were routinely "denied rank among the human race, and...degraded into a species of talking baboons" (Hopkins 29, 105). But rather than focusing on Briggs's 
reactions as a personal response, Hopkins uses his philosophical contemplations to target systemic racism. She renders Briggs as a modern black Hamlet who recognizes "there are more things in heaven and earth...than are dreamt of in your [white] philosophy," a white philosophy that she appropriates to make that very point (I.v.167-168).

Blending the sociological work of W.E.B. Du Bois with that of William James's philosophy and Alfred Binet's psychology, Hopkins appropriates the work of white intellectuals who criticizes the limitations of traditional white epistemology. Although neither the work of James nor Binet is focused on the experience of being black in a white world, scholars have suggested Du Bois drew his notion of "Double Consciousness" from Binet's 1890 work. Further, Hopkins, who models Briggs on Du Bois and names Binet as the author of the philosophical work Briggs contemplates, also draws the novel's subtitle from James's essay “The Hidden Self" (1890). ${ }^{150}$ Far from merely alluding to these works, she makes use of their philosophical approaches. I would argue that she appropriates their work to critique the systemic racism of white epistemology, which, she suggests, renders it insufficient to account for black lives. For their racial biases, she suggests, has flawed our very ways of knowing. While Binet's work names the "doubling of personality" in those suffering from "hysteria," James's work, from which Briggs (Hopkins) quotes directly, resituates the personal experience of unexplainable phenomena within the social sphere, of phenomena "lying broadcast over the surface of history" (Binet 14, Hopkins 2). Rather than using these philosophies directly, Hopkins draws on their frameworks to work toward an epistemology that considers the phenomenological experience of being black. From Binet, Hopkins, even more so than Du Bois, suggests that in a hysterical white society, the psyche of the black man is split, doubled. In this way, Hopkins persistently directs readers to see Briggs's melancholia not as a personal failing, but as a phenomenological 
manifestation of a failing white system in which he has no place. While Hopkins likely imagines double consciousness as the root of Briggs's melancholy, she also necessarily endows Briggs with an other-worldly power, wryly pointing to the inability of a white system to contain or explain the phenomena of a black intellect. From the novel's first scene Hopkins redirects Briggs's suicidal thoughts, a response to a system that fails him, to "new discoveries" in science (2). Likewise, in a later scene Briggs's suicidal thoughts lead him to discover Telassar, the novel's utopian African society, replete with a new system of thought. And while there he finds personal ancestral belonging and confirms an alternate narrative of human origin rooted in black culture, not white. In this way, I would argue that Hopkins draws James's philosophy that Western systems of thought were presently unable to account for all of the phenomena within them. Although James is concerned with the existence of imperceptible or extrasensory phenomena, his argument in The Will to Believe (1897) that we must loosen "the boundaries of the white Western psyche" and "blunt the edge of the phobic rationalism that conceives science as a 'closed and complete system of truth"' applies as much to the category of the 'phenomenon' of the black intellectual, who has long been "legislated by science as outside the realm of normal existence" (Posnock 67, 65). Whether or not Hopkins believes in the science of extrasensory perception, it allows an established philosophical position from which to critique the insufficiency of epistemology to account for the realities of black lives. Hopkins recognizes the importance of advantageously aligning her work with a white tradition of systemic critique that allows her to endorse a new pattern of thought, a teleology outside the racialized limitations of the current system. However, I would be remiss if I didn't point out a problematic limitation to Hopkins thought here. For despite her own substantial contributions to early twentieth-century black society and the novel's preoccupation with the constrictions of the present white system, 
her framework largely reifies that "intellectual" is synonymous with "male." ${ }^{151}$ Despite this noticeable limitation, however, Hopkins usefully appropriates white thought. By making use of an established framework for critiquing the "closed and complete system"” of the "white Western psyche," she opens the philosophical space for an alternative discourse of black identity. In addition to waging a counterdiscursive affront to systemic white supremacy in the sciences, Harper uses utopian convention to interrogate the fictions of history that have grown from it. By addressing both the philosophical and the historical, Hopkins can give shape to an equally-plausible and rival "otherwise” for black readers. For, as one scholar of Hopkins's work has pointed out, in a nation where the black intellectual is already considered "an alien life form," a character like Briggs is already "a science fiction fantasy" despite, that is, the existence of a host of black intellectuals including Hopkins herself (Posnock 65). Further suggesting the purposefulness of her generic choice, Of One Blood is the closing work of a trilogy and the only one to make use of the utopian conventions, a gesture that may suggest a degree of confrontation, directed at both history and the reader. To that end, the confrontational and systemic qualities of the utopian form allow Hopkins to interrogate the systemic white supremacy of the present and think toward an "Afro-American” future (Hopkins 99). For this reason, I would argue that Hopkins's use of an omniscient narrator who often appears in the first person plural (rather than conventional singular) registers a purposeful and political change in order to privilege a unified — and provocatively interracial—voice that echoes the physical collectives within the work. For while the narrator is omniscient (and arguably a stand-in for Hopkins's point of view), the characters, who are almost always in gatherings - students, doctors, a choir, an expeditionnearly always use the word "we" to characterize their actions. In this way, Hopkins rhetorically positions her work as an extension of an integrated collective of voices that includes James, 
Binet, and Du Bois, a rhetorical reflection of her philosophical contention that systemic racism in inherently flawed since we are all "of one blood." However, despite this progressive play with narrative voice, her continued attention to blood and lineage_-reinforced when Briggs's birthmark reveals his Telassaran heritage — may be read problematic. That Brigg's blood carried a pure racial legacy participates in the same logics of blood establishing the racial hierarchy underlying segregation, anti-miscegenation laws, and even eugenics that she seeks to undo in her counterdiscursive affront to the whiteness of our dominant epistemology.

Nevertheless, utopia offers Hopkins a forum for re-presenting the history of civilization from its origin in Africa in a way a generic romance, like her first novel Contending Forces (1900), cannot. Although in Contending Forces she gestures to the racialized contest over Egypt and human origin in the early twentieth century, utopian convention relies on writers' recreation of our present society and understanding as a means for examination and critique (266-267). In this way the utopian form enables Hopkins to recast the theory of African origin as the backstory of a utopian civilization. And, thereby, she challenges our epistemology of anti-black racismand white privilege — since we are both ontologically "of one blood," and also of one black ancestry. ${ }^{152}$ Although it would be nearly a century before science could prove exactly this, for Hopkins an alternative origin narrative framed by philosophical doubt - even among white thinkers - allows her to raise readers' suspicions about what they've long construed as fact within an inherently racist system. For example, while Hopkins uses Briggs's melancholy to introduce the notion of systemic racism, it is the expedition's arrival in Africa that casts such racism in relief. For as soon as Africa is in sight, members of the expedition reveal that their understanding and expectation of Africa comes from racist caricature, as they anticipate their arrival on shore the next day will be "better than anything Barnum has ever given us even at a 
dollar extra reserved seat" (Hopkins 77). And, as we might expect, when the expedition's leading professor soon clarifies that the ruins for which they are searching, those of the first civilization, of "the pioneers of mankind in the untrodden fields of knowledge" are Ethiopian he is met by racist disbelief (98-99). As Hopkins rightly imagines, one among the party openly balks at the paradigm shift such new knowledge would require: "you don't mean to tell me that all this was done by niggers?" (99). And his "horror," as Hopkins well knew, would be nigh impossible to overcome in a society wherein a senator would endorse lynching to teach "niggers...their place again" and a doctor would allege his research proved the "negro" was regressing "back to barbarism." In the professor's response to Charlie, Hopkins uses the utopia's convention of historical retelling and wryly employs a white authority figure to recast the white narrative of a black past. From this vantage point, we come to understand that the novel's hidden self is not simply a metaphor for Briggs's passing. It's a metaphor for our own hidden selves that Hopkins's rhetorical use of James's philosophy ostensibly prepares readers to receive, that is, the revelation of their own ancestral black past, which is literalized by Briggs's (and readers') arrival at Telassar.

Significantly, Hopkins also uses Telassar to intervene in white epistemology and in the generically-white utopian form. From the moment of our arrival at Telassar, Hopkins stakes rhetorical claim within the utopian form. By rendering the city as an ekphrastic fairscape that literally reclaims the "city beautiful" as Ethiopian, Hopkins wittingly suggests a black cultural influence predating that of Greece. Further, by conjuring such a well-known phrase, she harkens to the racialized framework of the "City Beautiful Movement," and, perhaps, even to Chicago's "White City" (118). For when the scene returns to dialogue as Ai and Briggs gaze upon the city, both pointedly use the word "fair" to characterize it. Ai asks, "Do you find the prospect fair?," to 
which Briggs replies, "Fairer than I can...express" (119). More than merely doubling use of the word "fair," Briggs wryly comments on the scene's familiarity "as if somewhere in the past" he "had known just such a city as this," gesturing, perhaps, to the White City (119). Although the comment foreshadows Briggs's ancestral heritage which is revealed shortly thereafter, we cannot overlook the potential dual entendre. Significantly, in all of these ways Hopkins deftly uses the utopian form to centralize systemic anti-black racism as a narrative production — pointing to its ability to be revised. More than that, she provocatively indicts the narrative as pathological, as an adherence to "three thousand years" of belief that "the world has been mainly indebted for its advancement to the Romans, Greeks, Hebrews, Germans, and Anglo-Saxons" when the fact of another story is "lying broadcast over the surface of history" $(98,2)$.

Perhaps even more so than Hopkins, E.A. Johnson envisions the black utopian "story" as "subordinate" to the work's "discussion of facts," a remark with which he prefaces Light Ahead for the Negro (1904). Drawing reader's attention to fact and away from fancy, Johnson, too, seems to give credence to the "counterdiscoursive power" of black utopian literature. While the tack Johnson's takes in Light Ahead differs vastly from that which Hopkins takes in Of One Blood, their premise, a critique of the philosophical and cultural logics fostering systemic white supremacy, remains similar as do their revisions of the utopian form to metafictively critique the genre's whiteness. However, while Hopkins's work provocatively confronts white supremacy as the production of faulty reasoning from a flawed history, Johnson's work wages a more pragmatic affront to white supremacy's affects as detrimental to blacks, whites, and to the nation. Because Johnson's approach is pragmatic and appears to maintain some degree of white paternalism and racial segregation, some have read the work as accommodationist despite Johnson's lifelong activism for civil rights as both an educator and lawyer. In fact, at least one 
critic has suggested that the novel's "interventionist aims" are only "possible to appreciate" by "contextualizing" the work within its author's "lifelong commitment to advancing the race" (Fabi 67). However, I would disagree. It is, of course, very important to recall that Johnson wrote a school history textbook entitled A School History of the Negro Race in America and that, as a lawyer, became the first African American member of the New York state legislature a "within a year he wrote and helped to pass a new civil rights law that expanded the list of public places that could not discriminate," the novel's interventionism, I would argue, is not dependent upon them (Schneider 262). I would argue that suggesting such an approach is required overlooks the subversive use to which Johnson puts the utopian form. Rather than attesting to the work's conservative, I would suggest that Johnson's seemingly-conventional adherence to the utopian form offers him a strategy for critique. As I will argue here, Johnson makes use of the conventional time travel and recitation of history to historicize the white rhetorical manipulation of black identity and its fabrication of the "negro problem." Further, it allows him to transgressively employ a racially indeterminate narrator and, in mirroring Bellamy’s Looking Backward, to metafictively comment on the whiteness of the form (Fabi Passing 67). ${ }^{153}$

However, before we can consider Johnson's “discussion of facts" or subversive use of the utopian form, we need some sense of its "story." Light Ahead for the Negro is the tale of nineteenth-century protagonist Gilbert Twitchell's arrival in twenty-first-century Georgia. For Twitchell, a New Yorker of abolitionist descent, spends a century in suspended animation in Earth's upper atmospheres after a dirigible accident in 1906 only to awaken in 2006 when, by chance, his "archaic looking flying machine" descended one day in 2006 and landed in the yard of Dr. Newell. After a brief respite overseen by a nurse named Irene Davis whom the protagonist eventually marries, Twitchell is immediately expected to make a formal statement about the 
"Negro Problem" before the "“Chief of the Bureau of Public Utility"” (21). Twitchell's uninterrupted statement, presented in a chapter titled "Now and Then," accounts for about twothirds of the novel's length, marking its centrality and importance. In the chapters preceding and following, Twichell's admiration for Irene grows and he learns from both she and Dr. Newell of the changes in their own thought and society with regard to the Negro problem. Among these other chapters, however, perhaps the most important is the penultimate chapter titled "The Prize Essay." Here Johnson gives over Twitchell's narration to the essay of a nineteenth-century "Southern Negro from the state of North Carolina," who was the recipient of a prize for his thoughts favoring boarding school education after primary school as a means to deter crime, advance good citizenship, and foster blacks' development in all fields of study (not solely industrial) (120). Wryly reinforcing the importance of displaying those developments in the public sphere to intervene in public opinion of the negro question, Johnson concludes the chapter with Twitchell's voice. For Twitchell explains that to demonstrate the "fine showing" black citizens have made "in almost every field of human endeavor" a "great Negro Exposition...open to Negroes all over the world" is forthcoming in the novel's present, a testimony to Johnson's advocacy of black intellectualism and his recognizing of the sway of such cultural narratives (130).

The pastiche and reflective qualities of the conventional utopia allow Johnson to simultaneously advocate black intellectual development and critique white supremacist narratives in a way other genres could not. While A School History (1894) let Johnson trace the long history and honorable contributions that prove "the Negro has been a success in every avenue of life," a work critiquing whites as well never would have gained the approval of the North Carolina school board (180). In contrast, the utopian form allows Johnson a reflective 
space to tell a black history negotiating systemic white supremacy at every turn (180). For Johnson recognized, as Calloway, Du Bois, and Hopkins had before him, that in an increasingly literate society whose print culture merely continued to grow, the proliferation of white narratives of blackness fueled systemic white supremacy—particularly in the press. ${ }^{154}$ As Johnson's Twitchell explains to his twenty-first century audience: "newspapers mould (sic) public opinion," particularly about the "negro problem" (22). For the stories in white newspapers increasingly determined public opinion and treatment of "negroes." Headlines termed blacks "coon," "brute," "nigger," and criminal and sensationalized even a slight tussle between blacks and whites as a "race riot" (22). And further bespeaking the power of literary narrative within the era, they even used well-known characters like "Jim" and "Tom" as shorthand caricatures for 'types' of black Americans (22). As Twitchell's taxonomic accounting suggests, Johnson recognized the power white-determined narratives have over every aspect of black life and the necessity of intervening within those narratives by reaching a white readership. Dedicating his work to "the thousands of sympathetic and well-wishing friends of the Negro race," Johnson also likely adhered to the traditional utopian conventions of the popular white genre to appeal to his desired readership (v). Nevertheless, as even his prefacing remarks make clear, those same conventions could foster a "discussion of the facts" of white supremacy, the role of the press, and the horrific effect of such stories on black lives.

Utopia's philosophical character and conventional shift in time enable Johnson to write a historiography of the present from the vantage point of the future. The genre allows him to build a reflective critical context for white readers wherein he can cite a "history" of documentary evidence of how white supremacists used the press to orchestrate the "political annihilation" and "decitizenization of the Negro" $(23,66)$. Metacritically recognizing and even deferring to the 
force of the press's sway, Johnson creates a pastiche of press clippings in the chapter titled "Then and Now," clippings that often overtake his own narrative. Yet, more importantly, the form's temporal distance allows him to characterize the press as an Ideological State Apparatus (Althusser 121). Likening it to a government organization he terms it the "News Distributing Bureau" and then suggestively points to its capacity as an official agent that maintains and replicates the State's systemic white supremacy (22). These choices suggest that Johnson markedly recognizes the press as a means of advancing the onslaught of anti-black racisms that enable injustices from "Delaware to Texas" (24). Further, this shift to the future allows Johnson to generate a reflective historiography of anti-black racism for his white readers. Again making strategic use of utopia's convention of critical historical retellings, he offers a host of "documentary evidence" from the press to mitigate "hostile" readership (Fabi Passing 70). From this discourse on the slander of black Americans in the press, Twitchell's historiography centers on the rhetorical use of the "negro problem." He argues that the phrase was continually recycled to fuel antagonisms between black and white, Republican and Democrat, even North and South. In other words, through Twitchell Johnson makes important logical connections for readers by linking this discourse of the "negro problem" to justifications for terroristic "intimidation" tactics like those used by the KKK, literacy tests meant to disenfranchise, and ultimately to blacks' willingness to accommodate "peace at any price" $(53,64,23)$.

Rather than exclusively forging historical connections for readers, Johnson uses utopian conventions to interpellate a white reader who sees the continuity of anti-black racism in press, practice, and policy. By coursing his readers to see history from Twitchell's perspective, Johnson interpellates a reader who stands outside "the great mass of people" who "take newspaper reports as true" (27). Through Twitchell's narration readers are coursed to read "between the lines" and 
"realize[s] how heavy the odds were against the Negro race" $(27,28)$. Recognizing the potential efficacy of the form to alter readers' perspective, Johnson also directs Twitchell's narrative to ruminate on two racist white figures popular in the press of his own time. Drawing on readers' likely knowledge of the unabashedly racist Senator Benjamin Tillman's recent response to the Roosevelt and Washington dinner and Thomas Dixon's wildly popular romance of the Ku Klux Klan in the The Leopard's Spots (1902), Johnson seeks to reframe readers' understanding of both figures, particularly the later given the lasting and damning images of black Americans it creates. Johnson rehistoricizes Dixon's work for readers; he emphasizes that Dixon's work was preoccupied with "exceptional cases in Negro criminality" and maliciously intended "to convince his readers of the Negro's unfitness for citizenship" (29). For as Johnson doubtlessly knew, The Leopard's Spots's protagonist Charlie Gaston vehemently and explicitly resolves near the novel's close that America “is a white man's government, conceived by white men, and maintained by white men through every year of its history — and by the God of our Fathers it shall be ruled by white men until ...the end of time!” (442). By coursing white readers to read between the lines, signaling particular figures like Tillman and Dixon, and "pre-historicizing" the effect of such works for readers, Johnson's approach suggests that he recognizes the importance of rhetorically controlling — to any degree — whites' reception of the most rabidly racist white narratives. Eerily, such a control seems prescient in light of the increased circulation of Dixon's follow up. For not only was The Clansman was published in serial in the Atlanta Journal in 1905 it was subsequently dramatized, multiplying its reception among white readers-many of whom would not read between the lines and notice the representational errors (Lands 75). ${ }^{155}$

Johnson's work confirms an emerging pattern of thought within the "New Negro" utopia, of a body of works that grapple epistemologically with white supremacist narratives of nation 
and wage a metafictive intervention into white utopian forms. From the latter perspective, Johnson's most significant choices are those he makes about narration and plot. And while critics of Johnson's work have widely noted that Gilbert Twitchell is a "racially indeterminate narrator," few have considered its metacritical and political potential (Fabi Passing 66). While some have pointed out that choosing such a narrator was "far from unique" at a time racially indeterminate characters were deployed "in the hope of reaching and influencing a wider, mixed audience" and that an indeterminate narrator facilitates Johnson's stricter "adherence to the conventions of the utopian genre," I would argue the choice is more transgressive (66). In a strategized novel addressed to white readers that overtly discusses black lives, the effects of white supremacist narratives on those lives, and the tendency among white readers to accept such white-determined narratives of blackness as truth, we give Johnson too little credit if we read Twitchell's racial indeterminacy as tied solely to reaching an audience or adhering to a genre. Instead, I would argue that we should read Twitchell's racial indeterminacy as a means of further confronting white readership, as a means of, pardon the pun, making them twitch. If, as most scholars suggest, white readers would read Twitchell as a normative white character, how might those readers negotiate knowing or learning of Johnson's blackness or the layers of racial performance within the text? For we must keep in mind that at various points, Johnson, our black author, writes as Twitchell, our racially-indeterminate narrator, who re-presents articles and essays penned by white and black authors. We might even consider Twitchell's racial indeterminacy as another means by which Johnson encourage and even course his audience to read between the lines of society's dominate, white supremacist narratives.

Given Johnson's metafictive engagement with the limitations of readership, I would argue that Twitchell's racial indeterminacy forces white readers to confront their preoccupation 
with racial determinacy. Curiously, readers are offered no physical description of Twitchell, his ties to abolitionism could mean he is of either race or passing, and even his ability to study at Yale, in the wake of Du Bois's study at Harvard, is indeterminate. Further, if readers realize that Johnson is a black writer, reading Twitchell as either white or black may become unsettling for a variety of reasons. For example, if readers know Johnson is black but cannot help but read Twitchell as white, the narrative raises questions about the performance of racial identity and the threat of "passing," compelling readers to recognize the dominant pattern of racist thought at the core of their own need for determinacy. I would even argue that the physical description of Irene Davis as well as her marriage to Twitchell reflexively reinforces white anxiety about indeterminacy. For Johnson renders Irene's body as "strange," or perhaps as politically "queer," that is to say she is recognizably outside the logics of the dominate descriptive norms of Aryan fairness precisely to show the very limitations of those logics. And contributing to her queerness and to Johnson's progressiveness, readers are encouraged to see Irene as an autonomous person actively engaged in changing the future as a teacher of black children. She is not a mere measure for Twitchell's development, as even Queen Candace remains in Hopkins's Of One Blood. Despite Irene's brief appearances, she is drawn as a complex character, given a backstory, has a career, and is lauded for her "taste" and "sympathy" before her beauty (13). More significantly, Irene's physical description suggests Johnson's subversive use of the character to further engage white anxiety about racial determinacy. For shortly after meeting Irene, in one of the only physical descriptions Johnson offers of his characters, she is described as having "strangely" moved him, with her "black hair" and "large, good-natured black eyes," and her mouth "neither large nor small...showing a wealth of white pearls" (16). Significantly, her features are described as "black" and Johnson draws attention to the size of her eyes and mouth, the features most often 
exaggerated in racist caricatures of blacks. This may even suggest the possibility that she is passing, or, perhaps, that an undisclosed category of "mulatto" has quietly emerged in the future distinct from the "negroes" everyone appears to be discussing. ${ }^{156}$ For Johnson curiously excludes passing from his discussions of the "color line" and notes that Irene had attended a "training school" for nursing, harkening to the industrial education championed by Bookerites $(27,13)$. From this perspective, the novel's concluding marriage about which readers may feel simultaneously resolved and horrified, does not, in my estimation, signal a conventional integration of the utopian traveler within his new society. Rather, I would argue that it signals the possibility of queer new society emerging, a society that recognizes the "Negro Exposition" as "substantial proof" of the "great success" of blacks in America rather than their threat to it, a society that might witness the growth of a more self-aware white reader along with it.

Finally, I would like to suggest that $A$ Light Ahead poses another metafictive intervention into white readership and the utopian form through its mirroring of plot points from Bellamy's famed Looking Backward. Although Twitchell's mode of travel differs from that of Julian West's, like West Twitchell awakens a century in the future within the house of a physician under the care of said physician's female relation. Given the Looking Backwards's status as a best-seller, Johnson's mirroring of the plot in Bellamy's text seems a purposeful attempt to conjure the work in his readers' minds and, perhaps, to intervene in their memory of the work. For as any black reader of Bellamy's novel would have noted, he kills off the text's only "colored" (servant) character by the outset of his second chapter, the term "colored" disappears, and Aryan physical descriptions of characters thereafter point to the future's whiteness. It hardly seems coincidental that Johnson would mirror key aspects of Bellamy's plot and introduce "the Negro question" as his work's central theme by the beginning of his third chapter (14). To that 
end, I would argue that Johnson may purposefully raise this comparison to tacitly encourage white readers to reconsider Bellamy's dismissal of race. We might even read this allusion as another iteration of coursing white readers to "read between the lines" to recognize the white supremacist frameworks guiding both the press and ideas of utopia. In all of these ways, Johnson's racially indeterminate narrator poses a witting challenge to the whiteness of the utopian form and gives further voice to the metafictive tradition of the emerging New Negro utopia.

Like Hopkins and Johnson, Lillian Jones Horace uses the utopian form to indict systemic white supremacy in Five Generations Hence (1915). Although more than a decade passes between the publication of the former works and Horace's, one can trace a continuity and advancement of thought across the decade. Like Hopkins and Johnson, Horace recognized the novel as "an effective medium for social and political activism" against white supremacy, one that was "often advocated" by "black newspaper and periodical publishers" (Knight 156). And if the form of Five Generations Hence can be taken as an indication, to Horace the utopian form offered a way to intervene in a problematic white national narrative of blackness, a way to write "realistically but constructively," as she aspired to do in her journal (Knight 156). Like her immediate literary predecessors, Horace recognized the usefulness of utopian conventions for contextualizing the black experience in a white America and the importance of metafictively intervening in a genre whose frameworks drove the segregation narratives of a white nation. However, Horace's work also records important shifts within the politics of the New Negro utopia and among black intellectuals, shifts which are not all progressive. Like Hopkins, Horace imagines a black utopian future possible only in Africa. However, while Horace progressively centralizes a melancholic black female as an intellectual and traveler confronting the social 
sickness of white supremacy, unlike Hopkins she seems to reject (or is unaware of?) the history of early African civilizations. Likewise, although Horace comments on the importance of formal education to black intellectualism as Johnson does, she addresses a predominately black audience and provocatively criticizes the black race as "yet a child," which ultimately reifies white narratives of necessary paternalism (50). Nevertheless, Five Generations Hence, out of print for nearly a century, helps to map both the shifts in the black utopian form as well as the changing tide of black intellectualism's response to white supremacy. ${ }^{157}$

Set in 1899 , on the cusp of a new century, Five Generations Hence is the tale of melancholic protagonist Grace Noble's unfulfilled life as a black school teacher in Texas. Frustrated by the personal and the political, Noble laments the temerity of Lemuel Graves who she wishes would become her suitor, her unfulfilled desire to become a writer, and, most clearly, the systemic white supremacy of the world in which she lives. For it is after a week of particularly horrific headlines about the atrocities committed against black Americas, that Noble retreats to the woods where she has a vision of a black utopian future in Africa about which she wishes to write a novel. Shortly thereafter Noble becomes reacquainted with Violet Gray, a former classmate and aspiring African missionary she's not seen in a decade. While their reunion allows a temporal space in the narrative for weighing personal and political developments, it also serves as a way to comment on the imagined Africa of the present and to stress the importance that Noble write her utopian novel. ${ }^{158}$ Indeed, through a series of letters between Gray and Noble, readers learn that Gray fulfills her calling to become and African missionary just as Noble fulfills hers by becoming a wife, mother, and novelist. Accepting Noble's vision as a prophetic revelation, both women continue to focus on advancing black education to realize a vision of 
American Africans building "a civilization like to the white man's," a "new nation on the ruins of the old" five generations hence (49).

Significantly, I would argue that Horace minimizes and temporally displaces her utopian vision in order to focus on the everyday dystopian reality of disenfranchised black Americans. And such a displaced focus that nevertheless makes use of utopian narrative conventions allows her to map the effect of systemic racism on her characters' lives in the novel's present. For example, Horace links her own hesitation about writing and Graves's temerity to systemic perceptions of black Americans enabled by utopia's conventional reflection on the present from a temporal distance here rendered as memory. As she explains, Graves's embarrassed ruralism developed in a white society that has long denied black men opportunities because of their race; and, knowing his intelligence, she even conjectures that within a different setting he might have become the professor he once aspired to be. And she continues to catalogue in reflection or memory the everyday injustices of white supremacy that particularly target demonstrations of black advancement. By noting that she was in a "pearl of a city" that allowed "Negroes... free access to the public library," she points to the fact that segregation often forbade blacks access elsewhere (21). Likewise, her comments on her empty classroom in bad weather since "many of her pupils...lived great distances," points to the geographical hardships segregation posed for black Americans trying attain an education (31). As Horace reminds readers from the outset of the novel: the "great white hand [is ever] clutching at their [black] throats, more tyrannical, indeed, than in the days of slavery, ready to strangle out their lives if but the slightest provocation real or assumed was imagined" (24). By enabling Nobel to observe and characterize such a bleak reality, Horace also generates a space for black female intellectualism. For Noble is imagined as having the "impartial eye of a philosopher" and the mind of a sociologist, since she 
"spent her vacations in the city...study[ing] the various conditions of her people and their relations toward the white race" $(24,23)$. Importantly, Noble typologically replaces Hopkin's imagining of Briggs in Of One Blood and further advances the type of female intellectualism Johnson's Irene Davis represents in Light Ahead for the Negro, but clearly aligns it with blackness.

Like Hopkins, Horace links Noble's observations — driven by her melancholy — to the horrific and surreal phenomenological experience of living in a white supremacist society. Importantly, a combination of the phenomenological experience of being black in a white world and traveling a great physical distance away from this known white world enables her brief transport to utopia. For Nobel's vision of utopia comes to her only "after a few hours of sore travail" into the woods and after "a week of distressing reflections" of "a lynching not far away," of "men women and even children... attacked upon the streets...forced to flee like hunted beasts" (48). Here Horace alerts readers to lynching in Texas and alludes to the horrific massacre of black citizens in Slocum, Texas, and also introduces an element of magical realism within the present landscape as seemingly the only means of resistance black Americans have to the surreal narratives of systemic white supremacy. ${ }^{159}$ Yet, like Hopkins's focus on Briggs's mesmeric abilities, Horace's focus on the unexplainable phenomenon in the present metafictively highlights the artifice of the utopian form. For instead of a single event enabling readers to suspend disbelief and travel to a realistic future, Hopkins and Horace disallow that psychological movement. Keeping the element of magical realism within the present attempts to approximate the surreal phenomenon of being black in a white America, an experience that is so surreal. I would also argue that while Horace does make use of traditional utopian conventions-firstperson narration, temporal shifts, the revelation of a new system and society — she minimizes her 
discussion of utopia to refocus readers' attention on the everyday dystopian reality of disenfranchised black Americans. Moreover, she seems to wittingly reject the genre's white logics of escapism for imagining a resistant black utopia, which her reimagining of the utopian structure suggest must focus on intervening in the present.

However, Horace's work is not without limitations of its own for the development of a black intellectual rhetoric resistant to white supremacy. Unlike Du Bois and Hopkins whose works earlier in the century accepted the premise of humanity's African origin, Horace seems to reject such a thesis by arguing that the "negro has developed no marked civilization of his own" (49). More than that, she seems to have embraced the white logics of African barbarism, noting that many of her church congregation envisioned Miss Gray would be "eaten or tortured by the natives," those wayward "heathen[s]" in need of salvation $(42,94)$. And these characterizations also suggest the ideology of the imperialism Horace envisions black Americans using to build an African utopia, an ideology of caste hierarchy paralleling the racial hierarchy of white imperialists. Although common rather than an anathema among New Negro intellectuals in the second decade of the twentieth century, Horace advocates, too, for the dissociation from slavery. Noble argues that "the young Negro wishes to blot out slavery" while the "white man keeps it constantly before him" as a reminder of his inferiority, a break with intellectuals like Du Bois who would insist the opposite or like Johnson's A School History which was painstakingly crafted to disprove the contention that the "Negro race is yet a child" (50). Perhaps suggesting the degree to which Horace's own consciousness has been formed by the white logics of nation, she argues that "there can exist no equality between peoples so unlike in physical characteristics" and even lauds anti-miscegenation laws (50-1). Although she notes that the laws were rightfully abhorred for the racist logic of blackness as a contaminate, she nevertheless recovers them, 
waxing eugenic to call them "safeguards" that ensure the "perpetuation of our race," a position some black intellectuals (49). In these ways, Horace's work in comparison to that of Du Bois, Hopkins, and Johnson, reflects important shifts in black intellectualism between the first and second decade of the twentieth century, shifts underscored by segregation's increasinglydemarcated divide of the color-line.

In some ways, Horace's belief that no equality could exist between blacks and whites on American soil likely seemed justified to many of her readers in 1915 (50). Despite the fact that the year would see the opening of the Lincoln Jubilee and Half Century Exposition in Chicago, the decade also witnessed ever-increasing segregation, race riots, resurgences of Klan activity, and the monumental success of The Birth of a Nation, D.W. Griffith's incendiary and extraordinarily racist film adaptation of Dixon's Klan trilogy widely protested by the NAACP. ${ }^{160}$ And, as I've suggested here, when prejudice and fear-mongering white narratives circulated as rumors could incite a massacre like that in Slocum, Texas in 1910 and a mass migration of black Americans northward, Horace's notion of the impossibility of racial equality in America may have seemed rather accurate (Wilson 141). ${ }^{161}$ To her credit, though, Horace maintains an American setting wherein she highlights how utopian frameworks have enabled distortive narratives of black Americans and advocates for improving black educational opportunities and literary production, particularly among women. Indeed, despite her displacement of utopia to Africa five generations hence since equality in America seemed impossible, Horace's work ultimately argues for the necessity of active black resistance to the color-line of in the American present. 
As I suggested in the previous section, 1915, the same year in which Five Generations Hence was published, witnessed two revolutionary events rooted firmly on opposite sides of the color line and highlighting the chasm between. In February of 1915, D.W. Griffith's rabidly racist The Birth of a Nation opened. Recycling the white supremacy of Thomas Dixon's Klan trilogy, its sources text, the film nevertheless opened to "sold-out crowds in major cities" (Wilson 168). Six months later in August, Chicago’s Lincoln Jubilee and Half Century Exposition, organized by Black Chicago to celebrate fifty years of emancipation, opened to a crowd of 12,000 (Wilson 162). Converging in Chicago, these two histories advanced two vastly different narratives of blackness in the same city.

While the Lincoln Jubilee Exposition filled the halls of the Chicago Coliseum, Griffith's The Birth of a Nation was showing across town at Chicago's Illinois Theatre ("Chicago Courts Epic-Making Decision"). Dismissing entirely the "bitter" race arguments surrounding the film, the film periodical Motography reported that Griffith's “masterpiece,” which had recently prevailed over a suit seeking to prevent its showing in the city, has won a heroic "fight against censorship" (993, 994). As the periodical reports, Judge Fenimore Cooper rejected as absurd the premise that the film would foster anti-black racism. He held that he could not support the "issuance of injunction" on grounds that "the photoplay" would "engender a race animosity against the negro citizens of our community" and argued that such "ground is based purely on assumption" (“Chicago Courts"). Indeed, despite two hundred fifty years of slavery, fifty years of black codes and Jim Crow and lynching, fifteen years of increasing segregation, the U.S. Congress's refusal to allocate funding to black Americans two for an Emancipation Exposition two years prior, and the fact that periodicals even in the era linked Dixon's dramatized version of The Clansman as adding to the tinderbox inciting the 1906 Race Riot in Atlanta, it certainly 
would have been presumptuous to imagine that an incendiary film would "engender race animosity." Pointing to the skewed narrative of nation in press and legislation, Cooper dismissed protests that the film represented the black man as a "fool, a vicious rapist, a venal and unscrupulous politician, or a faithful but doddering idiot," as Du Bois put it, since theatre has long made villains of various nationalities without engendering such a response ("The Clansman," "Chicago Court's..."). Cooper even held that no one would believe the representation of the "negro race" therein was a contemporary one and argued that to rule against the film would require him to presume the audience was "stupid" ("Chicago Court's). Indeed, despite all national evidence to the contrary, Cooper's decision rejects the idea of anti-black racism as an operant logic and likely reaction, even as he argues for the role of the "theatre as an educator" (993). Yet, it was overtly clear from the response to Dixon's trilogy that the only education one would glean from Birth of a Nation was a negrophobic history lamenting the loss of the heroic, white Old South. Yet, Cooper's position was far from unique; his decision, like the periodical's tone, is easily read as a record of the amnestic white (and utopian) narrative of nation that distorts the reality of black American lives.

On the other side of town, the Lincoln Jubilee Exposition gave voice to a different narrative of black America. Designed to commemorate the significance of freedom from an enslaved past, the exhibition would also advance claims of African civility and help to foster a goddess-like image of Ethiopia as a symbol of black utopian thought, recalling white America's use of Columbia. Indeed, unlike Horace's suggestion that intellectuals "forget slavery" and reclaim "heathen" Africa, the Lincoln Jubilee "publicize[d] a cultural history of the Negro that was... a collective memory drawn from enslavement and a Pan-African history" (Wilson 167). The exposition reasserted the importance of Africa not merely to the development of the black 
race, but to the human race. More than that, recognizing the sway of the "emerging mass culture of movies and vaudeville" as medium through which cultural and racial narratives were advanced, the Jubilee featured two three-night performances of a historical pageant (167). Indeed, like Du Bois had recognized two years' prior when designing his Star of Ethiopia pageant for New York's official commemoration of Emancipation, "making grand appeals to public memory" was necessary to "social reform" (Blight 375). To that end, the Lincoln Jubilee presented the Historical Tableau and Pageant of Negro History. Staged amid an immersive exposition of the thriving black present, this spectacular theatrical experience of black history compellingly argued for a different narrative of black existence for an audience of as many as $762,000 .{ }^{162}$ And, like Du Bois’s Star of Ethiopia, it advanced a new and regal symbol of blackness: the Goddess Ethiopia (see fig 42). Simultaneous herald of and beacon for black utopian thought, she became an aspirational image for blackness as Columbia was for whiteness. In fact, Ethiopia became an iconic figure in black art; she was the central figure in still photographs of the Star of Ethiopia pageant, the subject of Fannie M. Stout's Awakening of Ethiopia exhibited at the Jubilee, and central in works like Meta Warrick Fuller's Ethiopia Awakening (1914) and Lois Mailou Jones painting The Ascent of Ethiopia (1932) long thereafter (see figs. 43-45). In a white visual culture rendering blacks in exaggerating low-brow caricature, Ethiopia reclaimed a regal African heritage and racial dignity long denied. Curiously, despite Horace's vexed representation of Africa, we might even read Grace Nobel as such an "Ethiopia," for she is described as a "high brown"” with "the expanded nostrils of the Ethiopian" who "ascended the hillside" to a "summit" and who likewise directs readers' gaze to a new black future $(19,48)$. A unifying image to rival the white fairscape's Columbia, Ethiopia, too, looked toward the future, and, like Stout's Awakening, ever-directed the viewer's gaze forward. 
Given how the voluble and volatile white-defined images of black identity had affected white perception of black culture, black intellectuals recognized the necessity of waging visual intervention. Reinforcing the rhetorical influence of the exposition and other visual narratives, the History and Report of the Exhibition and Celebration to Commemorate the Fiftieth Anniversary of the Emancipation of the Negro reported that "press all over the country was unanimous in its praise" for "the character of the exhibits and their value from and educational standpoint" (12). Their greatest value, however, was arguably in helping to recast the image of blacks worldwide. For rather than participating in white-commissioned ethnographic displays, exhibits from "the black republics of Liberia, Haiti, and Santo Domingo" evidenced their sociopolitical development (History and Report...15). Countering images of the "heathen" Africa, displays were not limited to tribal artifacts and there was not a human zoo to undercut representations of the black modernity as there was at Paris in 1900. Indeed, the Liberian exhibit, for example, was titled and approved by that nation's president and included samples of natural resources, books written and published in Liberia, and included a significant educational display (Wilson 164). But the overarching image of the Exposition was that of the black American patriot. To combat an increasing segregation crafting a much different visual narrative of America, black Americans tactically asserted their "allegiance to the nation's democratic values" and tacitly their citizenship (Wilson 163). Working to intervene in a national narrative of exclusion, the Exposition even convened an International Inter-Racial Congress, which the History and Report of the Exhibition waxed utopian in calling "a most impressive contribution toward the establishment of a permanent peace between the two races" (17). Although it lasted for only three weeks, in the abstract, the Lincoln Jubilee had advanced for nearly half the city a 
new narrative of black Americans, a narrative asserting a unified black voice in the long memory of the "white city."163

\section{Articulating Resistance: Blackness and Utopia}

As I have argued throughout this chapter and as we see at the Lincoln Jubilee, black intellectuals recognized the necessity of intervening within white-determined narratives of nation. As Calloway and Du Bois, Hopkins, Johnson and Horace recognized, such narratives increasingly rendering segregation as a national panacea to the negro problem, as the means to an American utopia. From Jim Crow caricatures of black Americans in white cultural works to medical professionals arguing for black Americans' verifiable regression "back to barbarism," it became increasingly clear to Calloway and Du Bois and to those writing in their wake that the proliferation of white-determined narratives of blackness were ever-advancing. Plessy's doctrine of "separate but equal" continued to grow from local and private sectors to state and federal levels, from churches, hotels, and train cars to libraries and Federal buildings. As segregation enabled whites to entrap blacks within a nightmarish imperium in imperio, Du Bois recognized the necessity of intervening in white utopian frameworks with a future-thinking utopian rhetoric of black identity in The Souls of Black Folk (1903). He recognized the necessity of forging a path for redressing the chasm between those "two worlds" of black and white and for rhetorically recasting the black-blaming "negro problem" as the white-forged problem of the color line. More than that, Du Bois's critical study of whiteness recognized the use to which white American narratives of exclusion had put utopian frameworks as they fashioned the "negro problem" as the barrier to a white American progress. Recognizing the white utopian complex as fueling the erosion of black rights, Du Bois's work documents the everyday dystopian reality of black 
Americans living in a white America and helped to transition black intellectualism to an interventionist utopian rhetoric.

Indeed, influenced by Du Bois's research and rhetoric, as I have argued here, works like Pauline Hopkins's Of One Blood, E.A. Johnson's Light Ahead for the Negro, and Lillian B. Jones Horace's Five Generations Hence intervene in the whiteness of the utopian genre and continue the critical study of whiteness advanced in Du Bois's work. Focusing on the scientific and philosophical, the ontological and epistemological, these works carve out a space for black intellectual thought within both narrative and nation while highlighting the ways in which the conventions of the genre are insufficient for black utopianism. Living in the dystopian reality of black America, black Americans cannot merely escape to a distant time or locality and ignore the present. Instead, these works manipulate the conventions of the form to target the whitedetermined narratives of the present and the anti-black racism inherent within its systems of thought. For as a didactic genre straddling the boundary between fact and fiction, politics and literature, the utopian form allowed black intellectuals to course their readers in the problems white-determined narratives posed for representing black lives in both novel and nation. For this reason, while white utopists use the conventional hybridity of the form to convey a sense of immersion, black utopists recast that hybridity to represent a fragmented or extrasensory experience of self in a white-defined nation. While typical first-person narration allows white utopists to forge an intimate connection with readers, black utopists play with varying narrative perspectives, metacritically highlighting the problem of univocal perspectives for those long without a voice. And most significantly, while white utopists use the conventional travelogue to imagine the experience of a future society for the reader, black utopists reimagine the travelogue 
as a means to intervene in white narratives of the past and present, to assert a black voice within a white-determined American narrative.

However, perhaps most problematic — and the most telling — is the exclusion of the works of Hopkins, Johnson, and Horace from the dominant historiography of the nineteenth century utopia. Indeed, since all of these New Negro utopias adopt more "formally traditional" utopian features, their exclusion seems from the era's historiography, a narrative recitation of the scope of the field, seems all the more suspect (Fabi Passing 45). While some may argue that the works simply fall outside the scope of the period, it's important to note that present historiographies of the nineteenth-century utopia often reach to encompass Charlotte Perkins Gilman's Herland (1915). Instead, I would suggest that these works are often excluded since bringing them into conversation would demand a wholesale reconsideration of the role race plays in defining utopia, both as a literary form and as a framework for nationalist thinking. Bringing these works into conversation would mean that utopian studies could no longer overlook the question of utopia's glaring whiteness or dismiss details like Sawyer's death or the fact that Herland's utopia of parthenogenic women was made possible by a slave revolt. ${ }^{164}$ It could no longer side-step critical discussions of racial erasure with a quick comment that the author had merely "succumbed to her [or his] era's racial attitudes," as though without agency in the process (Roemer "Paradise" 98, emphasis added). Instead, by recovering the work of Du Bois and Hopkins, Johnson and Horace as they advance a black intellectualism, articulate a national imaginary, and imagine utopia, our present historiography would have to critically confront its own whiteness - and the whitedetermined narratives of blackness our scholarship tacitly harbors in its reluctance to discuss race. 


\section{Conclusion: Toward a New Historiography, Toward a New Utopian Narrative}

What has become of Sawyer?... It only remains to assume that Sawyer lost his life in the fire or by some accident connected with it, and the rest follows naturally enough.

- Edward Bellamy, Looking Backward (1888)

A democracy like ours cannot afford to throw itself open to the world. Where every man is a lawmaker, every dull-witted or fanatical immigrant admitted to our citizenship is a bane to the commonwealth. Where all classes of society merge insensibly into one another every alien immigrant of inferior race may bring corruption to the stock. There are races... which we cannot assimilate without a lowering of our racial standard, which should be as sacred to us as the sanctity of our homes.

- Francis Bellamy, from The Illustrated American August 28, 1897

When Mexico sends its people, they're not sending the best. They're...sending people that have lots of problems and they're bringing those problems with them. They're bringing drugs. They're bringing crime. They're rapists. ... And some, I assume, are good people.

[When I am President] I would do various things very quickly...I will build a great, great wall on our southern border, and I will make Mexico pay for that wall. Mark my words.

- Donald Trump, Presidential Announcement Speech, June 16, 2015

Our historiography of the nineteenth-century American utopian novel has long read utopia as a racially-unmarked genre. We have rarely asked "what has become of Sawyer?" because in a society that has long naturalized the whiteness of nation, the narrative exclusion of those of color has quite literally "followed naturally enough." But for the sake of our literary and cultural history, our scholarship can no longer overlook the whiteness of the genre or its implications for our national imaginary of the past or for the future.

When we consider how the 'race question' informs the utopian frameworks governing the national imaginary, we find a broader history, a more truthful historiography, and an expanded canon. When we bring the nation's racial climate into conversation, it no longer seems by happenstance, for example, that avowed Nationalist Francis Bellamy publically advocated for immigration restriction on the ground of immigrants' races in the same year that his cousin Edward's Equality (1897), the sequel to Looking Backward, overtly envisioned restrictive 
immigration and racial segregation as the means to an American utopia. Indeed, at the same time Francis insisted in The Illustrated American in 1897 that "a democracy like ours cannot afford to throw itself open to the...inferior race" of new immigrants who would become a "bane to the commonwealth" and "bring corruption to the stock," Edward imagines the arrival of these "lowest, most wretched, and barbarous races of Europe- the very scum of the continent" as the nation's path to ruin (Bellamy Equality 298). And, as if to clarify that blacks, too, were a stock that America could not "assimilate without a lowering of our racial standard," Edward reassures readers that segregation would remain, that the "new system...involved no more commingling of races than the old" and remained "perfectly consistent" with "even the most bigoted local prejudices" (345). For an American utopia, both novel and editorial argue, is predicated on racialized exclusions to preserve the nation's whiteness.

But Equality garners very little scholarly attention. Although it was less popular than Looking Backward, in a field that centralizes Bellamy's earlier novel, his periodicals, and his long-reaching influence over other utopian works, reformers, and politics, our inattention to Francis and Equality's near exclusion are curious. It compels one reconsidering the historiography of the period to ask: why is the sequel to the period's defining work mentioned only in passing and never in detail? I would argue that Equality's treatment of race and the nativism Francis's well-known editorials would highlight therein almost certainly account for its exclusion. Bringing Equality into conversation would have meant having to read Looking Backwards's "rearrangement" of society "on a higher ethical basis" as overtly racialized, it would have meant critically confronting a generic whiteness our historiography has long helped to naturalize (Bellamy Looking 149). 
However, as I have argued here, we can no longer avoid critically discussing that whiteness and its implications. This is particularly true when we find that the Bellamys' xenophobic frameworks for a utopian America are not those of a bygone era, but those eerily at the fore of a national presidential campaign in 2015 . It seems crucial that we critically confront the whiteness both inherent to and long overlooked within the frameworks of utopian thought. For a historiography unwilling to confront the whiteness it harbors ultimately enables the infinite repetition of these xenophobic utopian impulses, impulses that continue to trace their “descendancy” to Sir Thomas More's Utopia (Jameson 3).

In remapping our historiography to acknowledge its inherent whiteness, I have argued that it's crucial to begin with More's Utopia and reconsider the utopian impulse in the early documents and histories of nation. As I have argued here, More's Utopia, which gives us the literary form and is among the first to imagine America as a utopia, also arrives at a significant time in history to give us a first "representation of space we now refer to as a nation-state" (Wegner 57). And in this way Utopia, alongside its representative democracy, national education, and striving for egalitarianism, also casts cultural and racial exclusivity as both central to maintaining the sovereignty of nation-state and as rooted in natural law. For whether or not Utopia was a direct influence on James Madison and Thomas Jefferson or on the Constitution's 3/5ths Clause or the Naturalization Act of 1790, we cannot overlook that Utopia, classified as a philosophical work alongside those of Rousseau and Hume, circulated the idea that a nationstate's sovereignty was predicated on racialized exclusions. Nor can we overlook this exclusion as inherent to the utopian literary form or the utopian impulses it inspires, such as George Bancroft's A History of the United States, which I've looked to as an ideological touchstone. For History not only participated in this dialectic of sovereignty and exclusion for more than a 
century of readers, it cast the nation and its institutions as an extension of divine will. In this way Bancroft wrote the history of the nation as a veritable divine right of whites, of a chosen AngloSaxon race fulfilling its destiny in forging a new Eden, a utopian America.

And, as I have argued here, this religio-racialized self-conception of a "chosen" people informed how we thought of and represented ourselves in both narrative and physical structure. Indeed, from the white neoclassical structures of the White House to the Columbian Exposition's "White City" in 1893 Chicago, nationalized structures literally enshrined whiteness and transmitted a racialized American ideal among ourselves and to others. To that end, we must also consider why our historiography of the utopian form overlooks the dominant neoclassical visual aesthetic of the era, an aesthetic often reiterated in the literary utopia's ekphrastic imaginings of the future. For when we look more closely at the fairscapes of the era, which co-emerge with the late nineteenth-century literary utopia, it is much harder to overlook the era's preoccupation with racial taxonomy and whiteness. For, as I've suggested, the fairscape was a nationalized and didactic expression of a utopian America, one that overtly excluded black participation, hierarchized the representation of races therein, and counted anthropological displays organized to advance this hierarchy among its most popular exhibits. And, significantly, these fairs also incited organized black protests, such as Ida B. Wells's and Frederick Douglass's The Reason Why, and organized black participation, as in the 1895 Atlanta Exposition's "Negro Building." To that end, the popularity, racialization, and even racial protest surrounding these utopian sites makes our historiography's whitewashed attention to "the eight-hour day, urban sanitation, reduced farm mortgages, and women's suffrage," for example, all the more suspect (Pfaelzer 3). For despite arguing that utopias have "always been a political issue," forces for reform or even "metahistories" that were "grounded in historical and contemporary evidence...to convince 
readers" of their vision, contemporary scholarship seems to routinely overlook racial dynamics (Jameson ix, Pfaelzer 3, Roemer 81). But when we bring fairs into conversation as the era's most unified expression of a utopian national imaginary, we cannot overlook calls for racial reform. As I've argued, the fair and its attendant literary fairscape help us to see how this white utopian complex replicates an exclusionary discourse nationally. We see this, as I've noted, in how Chicago's "White City" fosters a City Beautiful Movement targeting the racialized "city slums," and in whites' persistent recycling of Washington's "Atlanta Compromise" speech to advocate black "accomodationism" and censure the "uppity negroes" of the black intelligentsia. A usefully revised historiography will consider how the fair's racialized rhetoric, overt exclusion of black Americans, and spurring of an organized black resistance highlight how the literary and cultural imaginings of an ideal white America inform the nation's politics and policies.

However, the systemic white supremacy of these utopian frameworks of history and policy, literature and culture did not go unnoticed. Indeed, a revised historiography, as I've suggested would map alongside the present white topography a skeptical strain of utopian thought, emerging nearly in reaction to the type of dangerous elision of belief with fact evident in Bancroft's work. For when we bring a critical discussion of race into conversation, we see why and how our avoidance of the topic helped to push certain utopian works to the margins of the present canon. For Equality is, as I have argued, one of many utopian works mentioned only in passing, in part because of their overt discussions of race. In its company we find "negative utopias" by major white male authors like Edgar Allan Poe, Nathaniel Hawthorne, and Mark Twain as well as by major white female authors like Sarah Josepha Hale, Louisa May Alcott, Rebecca Harding Davis, and Annie Denton Cridge, whose works "make us more aware of our mental and ideological imprisonment" (Jameson xiii). Indeed, while both of these groups raise a 
critical discussion of race, they also raise a metacritical discussion of the utopian form, one that indicts the systemic whiteness and in many cases 'maleness' and 'middle-classness' of the genre. Moreover, attention to this skeptical strain of utopian thought helps to recover women and black utopists from our canon's margins and problematic displacement to subcanons. A historiography that attends to a metacrtical strain of utopian thought, quite simply, helps to redefine the canon. It fosters a necessarily palimpsestic literary and cultural history that recovers long-neglected works and long-silenced voices.

Finally, as I have argued most ardently throughout, a historiography that pays critical attention to race necessarily recovers the nineteenth-century black utopia as central to utopian thought. Our historiography could no longer passingly dismiss the black utopia as irrelevant for its perceived lack of volume. And that volume is, as I have suggested, greater than our present historiography imagines, particularly when we consider black utopian articulations of the fair and fairscape. And these 'irrelevant' works are all the more significant when we consider the literary utopia as a site that fostered the development of both black intellectualism and critical whiteness studies. Indeed, as I have argued, works by Frances Harper, Sutton E. Griggs, Pauline Hopkins, E.A. Johnson, and W.E.B. Du Bois overtly reimagine the conventions of the literary utopia to interrogate the systemic white supremacy of the form. Taken as a body, they challenge the absurdity of the one-drop rule and the logics of white male paternalism, the reject a whitedefined black identity and white-only telling of history, and, most importantly, they highlight how anti-black racism in inherent to nearly every system of thought whites have constructed, from their scientific 'facts' to the rulings of their Supreme Court. In other words, these black utopists capitalize on the hybridity of the utopian form precisely because it allows them to articulate a black philosophy and a black history, to advance black intellectualism, and to map 
how whiteness has governed blackness. For the black utopian form, guided largely by Du Bois's thought, helps to formally map critical whiteness studies as emerging from a black intellectual tradition.

Spectacular Struggles offers a starting point for a reconsideration of race in our historiography of the nineteenth century utopia. It offers a starting point for recovering a significant body of utopian works we've long pushed to the margins and for acknowledging that a racially-unmarked historiography distorts a nineteenth-century reality. It hopes that through such revision, we might also come to see the troubling rhetorical legacy of reading utopia as a racially unmarked genre. It hopes that we might come to hear the anxious xenophobic din in a corrupt utopian call to "make America great again." It hopes that we might no longer struggle to see the unexplored spectacles of whiteness distorting our visions of the past and for the future. 
Notes

${ }^{1}$ I choose the term "literary utopia" because "utopian novel" or "utopian fiction" conjure fictive genres alone, whereas the works that comprise the "fairscape," are, ostensibly, nonfiction works in periodicals helping to write utopia into being.

${ }^{2}$ As Ruth Levitas explains in The Concept of Utopia (1995), the commonality of these myths has led some to "speculate about the existence of a fundamental utopian propensity in human beings" (1).

${ }^{3}$ What I am suggesting here is that, fundamentally, the basic human impulse to innovate - to forge tools, to craft a representational image — is done with an eye toward improving the possibility of survival and might be construed of as a crude iteration of utopian thought. In fact, in her Preface to Encyclopedia of Utopian Literature, Mary Ellen Snodgrass suggests "cave art" and "the first scribbled pictographs" and even "hymns to deities" record a utopian impulse (ix). ${ }^{4}$ It is significant, I think, that we consider utopia a "program," as Frederic Jameson does in Archaeologies of the Future (2005). From its outset, utopian literature does not merely tell a story, it imagines a way to effect political change and direct readers toward that change. The text has a political intention of "founding a whole new society" (Jameson 3).

${ }^{5}$ Martin Waldseemuller's world map, the first to name America and give shape to the country, drew the continent as a crescent island, the way More describes Utopus as "the shape of a new moon" (Book 2, Ch 1).

${ }^{6}$ In fact, as Fatima Vieira points out in "The Concept of Utopia" in The Cambridge Companion to Utopian Literature (New York: Cambridge UP, 2011), in an early manuscript More used the word "Nusquama" to name his imagined island, a word that means "nowhere" and "in no place." She argues that the change to "Utopia" is a hopeful one, suggesting that More hoped the work 
would inspire change. Yet it is also significant that the word More did choose carries conflicted, nearly opposite meanings. Perhaps it also suggests More's sense of the project itself as conflicted and dependent upon his reader. For although he may have intended utopia to be thought of as a "good place," it may not be thought of solely as such. At its very core utopia remainsdoubtlessly refreshingly for some - a non-place as well keeping some of the pessimism of More's originally intended Nusquama (4-5).

${ }^{7}$ More directly engages with Plato in the text and the influence of Plato's Republic is noted by scholars. See J.C. Davis “Thomas More's Utopia: sources, legacy and interpretation” and Vieira's "The Concept of Utopia," for a more complete discussion; both in The Cambridge Companion to Utopian Literature (New York: Cambridge UP, 2011).

${ }^{8}$ Fatima Vieira's notion that the reader enters into a pact with the utopist is a useful concept that fosters the type of reciprocity the author tacitly expects from the reader: cooperative movement toward change. However, she also uses the work "game" to describe this relationship in the same passage, a term which my argument rejects. For the scope of my own work, I prefer the word pact—and think it's more accurate. The word "game" connotes not only the possibility of competition, but a suspension of reality for the sake of play; conversely, the word "pact" connotes mutual obligation, cooperation, an agreement beyond the terms of the book as, I think, utopia intends as a genre (8).

${ }^{9}$ For a more complete listing and brief discussion of early literary utopias that imagine America as a utopia, see Catherine O. Kaplan's Elihu Hubbard Smith's “The Institutions of the Republic of Utopia” (Early American Literature 35.3 [2000]: 294-336).

${ }^{10}$ By the early nineteenth century a host of theorists and several religious and secular intentional communities from the Shakers to the Fourierists believed their plans were the logical extension 
of the nation's founding visions. For example the Shakers immigrated to in the late eighteenthand early nineteenth-centuries to acquire land to form religious communities in the United States; the socialist Owenites would found the town of New Harmony, Indiana; the Fourierists or those following the utopian socialism of Charles Fourierism and the American writings of Albert Brisbane would inspire many to relocate to a number of communities, it would even inspired the established transcendentalist community of Brook Farm to declare itself a Fourierist community in 1844. Significantly, these utopists believed their projects rational rather than fanciful. As one scholar aptly explains Henri de Saint-Simon, Charles Fourier, and Robert Owen all "considered their responses to their era to be rational and scientific, not speculative and imaginative" as Karl Marx and Friedrich Engels would later charge in The Communist Manifesto (1848) (Roemer "Paradise Transformed" 83).

${ }^{11}$ Significantly, the novel boasts the first recorded use of the word "anxiety."

${ }^{12}$ In "So We All Became Mothers," Peter Fitting works toward a comprehensive cataloging of the "contents" and trajectory of this new surge in women's utopian writing and in so doing eloquently summarize some of the historical influences shaping this new emergence and interest in the field (177-178).

${ }^{13}$ In fact, scholarship still typically turns to Sargent's 1986 revision exclusively even as recent mass-digitization of nineteenth- and early twentieth-century periodicals have given us access to a much larger archive, and, potentially, to an enlarged canon.

${ }^{14}$ Although the Companion includes a chapter titled "Feminism and Utopianism," which meritously mentions African American author Frances Harper's Iola Leroy (1892), the essay quickly returns to building discussion around what has become the canon of white-authored 
women's works, such as Mary E. Bradley Lane's Mizora (1890) and Charlotte Perkins Gilman's Herland (1915) (Johns 177-179).

${ }^{15}$ Sargent lists the following traits of the postcolonial utopia: they are "frequently dystopian projections of what the settlers and exploiters had presented positively," they focus on reclaiming land, they're influenced by indigenous beliefs, they comment on the erasure of history, they are used to make a political point for the reader $(214-215)$. My argument focuses on the metafictive impulse of utopias written by black Americans, which do point out the flaws of the dominant utopia, reclaim space, and recast history to make a point about their cultural erasure. ${ }^{16}$ The following exhibitions of varying sizes, but featuring some degree of international inclusion, were held in America: Exhibition of the Industry of All Nations (New York, 1853), Centennial Exposition (Philadelphia, 1876), Milwaukee Industrial Exposition (1881), International Cotton Exposition (Atlanta, 1881), The American Exhibition of the Products, Arts, and Manufactures of Foreign Nations (Boston, 1883), Southern Exposition (Louisville, 1883), World Cotton Centennial (Atlanta, 1884), Piedmont Exposition (Atlanta 1887), Centennial International Exposition (Philadelphia, 1888), International Industrial Fair (Buffalo, 1889), Columbian Exposition (Chicago, 1893), World's Fair Prize Winners' Exposition (New York, 1893), California Midwinter International Exposition (San Francisco 1894), Cotton States and International Exposition (Atlanta, 1895), Irish Fair (Chicago, 1897), Tennessee Centennial and International (Nashville, 1897), Trans-Mississippi Exposition (Omaha, 1898), California's Golden Jubilee (1898), Greater America Exposition (Omaha, 1899), National Export Exposition (Philadelphia, 1899), Pan-American Exposition (Buffalo, 1901), South Carolina and Inter-State and West Indian Exposition (Charleston, 1901), Louisiana Purchase International Exposition (St. Louis, 1904), International Mining Exposition (New York, 1908), Alaska-Yukon-Pacific 
Exposition (Seattle 1909), International Mercantile Exposition (New York, 1911), National Conservation Exposition (Knoxville, 1913), Panama-Pacific International Exposition (San Francisco, 1915), Negro Historical Exposition (Richmond, 1915), Lincoln Jubilee and Exposition (Chicago, 1915).

${ }^{17}$ Most scholars, when they use the term "fairscape" apply it to the physical landscape of the fair; I'm using the term to discuss the rhetorical and ekphrastic construction of the fair in the press.

${ }^{18}$ For example, although it was written in 1850 , before an American fair was even in the planning stages, periodicals were imagining the fairs impact in superlative, comparative, and nationalist terms. Scientific American conjectured the fair would "attract more attention and draw together a greater concourse of people than anything which we have $[\ldots]$ read of in the pages of history," suggesting an imagined importance and presumed impact on the era. It was also imagined as a comparative and future-thinking event that would "place our nation at once far in advance of every other," reinforcing both its nationalist impulse and significance for the nation. ${ }^{19}$ As Steven Conn explains in Museums and American Intellectual Life, 1876 - 1926 (1998), the Columbian Exposition not only provided the permanent collection of Chicago's Field Museum via its Anthropology Building, but was the inspiration for and would become the founding collection of The Philadelphia Commercial Museum, when founder William Powell Wilson would negotiate and "acquire twenty-five railroad boxcar loads of material" from the fair (78, 118-119).

${ }^{20}$ I use the term "exhibition scholars" categorically, not to denote only those who study exhibitions only, but to include a wider range of scholars whose work focuses more broadly on exhibits such as those at world's fairs, state fairs, museums, and even early department stores. 
See Tony Bennett's “The Exhibitionary Complex” for a good characterization of exhibitionary culture. For an equally-enlightening history of the relationship between fairs and the birth of museum culture in the United States, see Steven Conn's Museums and American Intellectual Life.

${ }^{21}$ As I will later argue, we not only find iconic fairscape imagery in Bellamy’s Looking Backward, but actual exhibits or exhibitions imagined the following works: Nathaniel Hawthorne's The Blithdale Romance (1853), Ann Denton Cridge's Man's Rights; or How Would You Like it? (1870), Mary E. Bradley Lane's Mizora (1881), William von Swartwout's The Beginning: A Romance of Chicago as it Might Be (1893), William Dean Howells's "Letters of an Altruian Traveler" (1893), and Sutton E. Griggs's Imperium in Imperio (1899), to name a few. ${ }^{22}$ It seems important to note that Althusser's work appears shortly after Berger and Luckmann published The Social Construction of Reality (1966), suggesting it was a potential influence or starting point.

${ }^{23}$ Berger's and Luckman's is a sociological text that accurately describes the social means by which the social construction of reality operates and points to the problems of such structures, even Rydell calls their work a “cohesive explanatory blueprint” (2). By contrast, Althusser's political philosophy adds gravitas to this assessment by pointing to the nefariousness of how ISAs and RSAs operate toward systematized political oppression. While the former explains systemic dominance, the latter offers, in my estimation, a critic of those systems.

${ }^{24}$ In defining this relationship as a complex — an interrelated, mutually dependent set of relationships - I harken to Tony Bennett's term “exhibitionary complex.” In "The Exhibitionary Complex" (1988), Tony Bennett argues that "the institutions comprising "the exhibitionary complex,"” which include "museums, art galleries, expositions, and department stores," were 
"involved in the transfer of objects and bodies from the enclosed and private domains [...] into progressively more open and public arenas where [...] they formed vehicles for inscribing and broadcasting the messages of power $[\ldots]$ throughout society" (74). Bennett sees the exhibitionary complex as a constructive means of social control, an order-bearing form of spectacle that reveals a "nuanced set of relations through which power was exercised" (76). Attracting crowds en masse not only to witness but to participate in the spectacle, the exhibitionary complex performs an "ethical and educative function" within "the modern state" that contributes to "the development of the bourgeois democratic polity" (76). In other words, for Bennett the exhibitionary complex participates in a larger, systemic spectacle of state, one that acculturates its public to moral citizenship, through simultaneous display and censure of both wares and patrons themselves.

${ }^{25}$ Significantly, Rydell not only draws attention to the shared descriptive language, focus on nationalism, and image of an ideal citizenry between the literary utopia and the fair and fairscape, he draws attention to whiteness as a race, and, more than that, to whiteness as a primary force shaping readers' experience of the fairscape, of the literary utopia, and of the idea of America within in the national imaginary. Given the substantial visual archives of the fairs and the availability of these archives to the public whether or not they had been in attendance, it was virtually impossible for fair scholarship to ignore the representations of gender roles, class divisions, and racial hierarchy, representations that were nationalized as official representations of America for generations to come. To that end, for the modern scholar of the American fair, the politics of identity—of white male supremacy in particular—governed the fairscape's representation of utopia in both image and word and was epitomized by the Columbian's neoclassical "White City." It is from Rydell's and other fair scholars' sustained attention to 
whiteness and white supremacy that I suggest scholarship on the literary utopia has much to glean.

${ }^{26}$ I would be remiss here if I didn't also mention that some nations consciously engineered traditional and/or primitive displays as commercialized ventures. We might even read this as an acute recognition of the operant logics of the white utopian complex — and read its use as a marketing tool as what bell hooks has so accurately and succinctly theorized as "talking back" in her book of the same title (1989).

${ }^{27}$ Although Ku Klux Klan activity wanes in this period, as white democrats regain political and legislative control of the South they institutionalize Klan mentality by way of Jim Crow Laws and lynchings continued to rise. In 1892 black lynchings triples what they were in the decade prior.

${ }^{28}$ Although the first volume of History was published in 1834, I cite from an 1888 pressing of the first volume noted on the titled page as the "Author's Last Revision." As a final revision, it captures best the growth of Bancroft's tone.

${ }^{29}$ The suggestion of "providential design," of a nation called into being by God, cannot help but carry with it the mythos of Eden and a long history of Puritan Providentialism. And we see this belief in America as a new Eden not only in writings about the country's natural beauty and plentiful natural resources, but in Winthrop's sermon calling the nation the "citty upon a hill," in the nation's power to attract and foster many religious and secular utopists seeking to form communities, in playing host to the First and Second Great Awakening, even in the thematic foci of early American writings engage with Edenic mythos-Transcendentalists' focus on spiritualism and attempts at community formation, reform writing gathering support in religious 
communities, even interest in Swedenborg's claim to divine inspiration in his own writings and the Swedenborgianism that took shape following.

${ }^{30}$ While the first official Library of Congress was not formally legislated until an Act of Congress in 1800, most agree that the "list of books proper for the use of Congress" and overseen by James Madison was compiled in the 1790s in consultation with Jefferson when the two men stayed in the same Philadelphia boarding house. Suggesting the relationship between the list and politics, the National Archives gloss of the Madison Papers' "List on Books for Congress" suggests that list speaks to the primary issues before Congress at the time, reflecting Congress's need for the guidance of authoritative works on these topics.

${ }^{31}$ It's important to note here that early American societies and libraries were developing alongside the ideological and physical frameworks of government. For example, Charles Willson Peale's Museum dates to 1786, the Massachusetts Historical Society dates to 1791, the New York Historical Society dates to 1804.

32 Bennett's groundbreaking theoretical discussion largely focused on mid-nineteenth-century British and European exhibitions, the "exhibitionary complex" describes the co-emergence of works that are simultaneously physical, ideological, and national. He argues that in juxtaposition to the private, punitive measures of the prisons or asylums forming Foucault's "“carceral archipelago,"” an "exhibitionary complex" emerges in the development of museums, exhibitions, and department stores to acculturate the same ideologies of the "carceral" in a positive manner. At these sites, too, Bennett suggests, visitors learn decorum and are acculturated to a national identity and conduct. Although Bennett mentions several late-nineteenth-century American exhibitions, his attention to them is cursory by comparison; he draws sustained examples of how the exhibitionary complex operates from English and European sites of exhibition. To Bennett's 
credit, he acknowledges his own generalizing when he notes that "the precise trajectory of developments in Britain was not followed elsewhere in Europe," but nevertheless maintains that the "general direction of development was the same" (86, emphasis added). Significantly, he does not include America when drawing this trajectory. In fact, emphasizing the relative inattention he pays to American sites of exhibition, Bennett twice defers at length others' work on American exhibitions. More than that, the two sources Burton Benedict's "The anthropology of world's fairs" (1983) and Robert Rydell's All the World's a Fair (1984) offer rather conflicting perspectives on the significance of the fairs' midways, a conflict, which like his outsourcing, emphasizes his less-researched and less-nuanced treatment of American sites of exhibition.

${ }^{33}$ George Washington selected the site and lay the cornerstone for the White House in 1792 and select the plan for the United States Capitol Building in 1793.

${ }^{34}$ While Jefferson penned the Declaration of Independence and would help to organize the first Library of Congress, among other notable deeds centered on advancing knowledge, Franklin would found the American Philosophical Society (1843), the nation's oldest society for scholarly research, was instrumental in establishing the University of Pennsylvania, and was a newspaper publisher and editor dedicated to raising the knowledge (as well as the sense of nationalism) among the masses.

${ }^{35}$ We see this hierarchical order not only in the woman's visible loss of decorum (when compared to both the man's and child's composure) in Peale's portrait of "The Artist in his Museum," but Peale's treatment of his slave Moses Williams, whom he dubs "untalented, lazy, and worthless" (despite Williams nearly-exclusive and expert handling of the museum's physiognotrace), and in the museum's cataloguing of the exhibits of Native Americans' "cruelty and barbarism." More than that, by 1799 Peale would advertise an Ourang-Outang specimen by 
inviting comparison with an "Old Negro" and self-consciously position portraits of non-whites (James, a slave afflicted with vitiligo, a slave girl, and an Othahetian Chief) as outliers to the museum's meticulous organization. For more on the role of the non-white other in Peale's museum history, see particularly Ellen Sacco's “Racial Theory, Museum Practice: The Colored World of Charles Willson Peale," (Museum Anthropology 20.2, 1997: 25-32), as well as David R. Brigham's ““Ask the Beasts and They Shall Teach Thee': The Human Lessons of Charles Willson Peale's Natural History Displays" (The Huntington Library Quarterly 59.2/3, 1996: 183-206) and Charles D. Martin's The White African American Body: A Cultural and Literary Exploration (New Brunswick: Rutgers UP, 2002).

${ }^{36}$ While his sons' museums in Baltimore and New York saw only limited success, closing in 1831 and 1837, respectively, they helped to facilitate the sale of Peale's collection to P.T. Barnum in 1843. At the same time, the American Institute Fairs in New York, sometimes considered the nation's first world's fair despite their comparatively minor scales, were held from1829 to 1897. Likewise, state fairs, beginning with New York's own first held in 1841, would ensure a nation becoming increasingly fascinated by the culture of exhibition — and increasingly coursed by the patriotism developing therein.

${ }^{37}$ It seems important to note here that George Bancroft also helped to advance fair culture. He not only commented favorably Centennial Exposition, but he chaired the American Historical Association's committee to urge Congress to hold the Columbian Exposition. In fact, it was he who "brought the subject to the attention of President Cleveland," according to official accounts, and he who was slated to write its history before his death (13 July 1893).

${ }^{38}$ In June of 1835, the Southern Literary Messenger, for which Poe had recently become a critic and staff writer, published an unsigned review of Bancroft's History. However, although they 
catalogue the review, the Edgar Allan Poe Society of Baltimore website sides with scholar T.O. Mabbott's rejection of Poe's authorship. Nevertheless, as a staff writer and fellow literary critic for the periodical, Poe would have been aware of the work.

${ }^{39}$ Except for a single recorded day of African American admission in 1849, Barnum's museum was not open to black patrons until the $1860 \mathrm{~s}$.

${ }^{40}$ Although we cannot entirely credit P.T. Barnum with the overt nationalism associated with creating a moniker like the American Museum since the site was originally Scudder's American Museum, we can suggest that Barnum maintained the name because of its nationalist appeal.

In fact, we might read Barnum's popular "To the Egress" hoax as such a test. For not knowing the definition of the term "egress," patrons were duped and directed to the exit without readmission. We might see this not merely as a hoax, but as suggestive of a test of class, knowledge, and belonging - a microcosm of one's fitness for the American Museum, with particular emphasis on the American.

${ }^{41}$ Because the American Social History Project and Center for Media and Learning at The Graduate Center at CUNY and the Center for History and New Media at George Mason spent eight years recreating a virtual version of Barnum's American Museum from archival descriptions, we have a very good understanding of the arrangement of the work therein. We can observe, for example, that several Native American portraits are hung low on the walls while a host of portraits of white Americans hung near the ceiling, an echo of the arrangement in Peale's museum.

To see these arrangements, visit the Lost Museum site at www.lostmuseum.cuny.edu/barnum.html. 
${ }^{42}$ Joice Heth was Barnum's first popular display. the hoax which launched his career as a showman, draws on the public's hunger for its own history, its sense of itself as exceptional, and its grappling with the "race question." Sensing the public's interest, Barnum exhibited a slave named Joice Heth as the 161-year-old "Nurse to George Washington." While Barnum had only continued to market a tale constructed by Heth's previous owner and exhibitor, the tale itself, draws attention to the specter of slavery as formative of the nation and reveals an anxiety about the place of the African-American body in relation to an increasingly-nationalized white identity. The spectacle of her display, I would argue, is heightened by the existence of the quasi-immortal body of a dehumanized, monstrous black slave- - Heth was blind, toothless, and weighed no more than fifty pounds - who's body, as the story goes, literally fed the nation's most iconic figurehead (Hartzman 14).

${ }^{43}$ In fact, as Sarah Bird Wright notes in A Critical Companion to Nathaniel Hawthorne (New York: Facts on File, 2007) it was through the intersession of the Peabody family that George Bancroft came to offer Nathaniel Hawthorn the job as the inspector at the Boston Custom-House, a post that allowed Hawthorne to advance his literary career. And, in addition to the review of Bancroft's History that Poe may or may not have authored, Poe does make reference to Bancroft's work (as well as to the earlier review) also in the Southern Literary Messenger, when in March of 1836 he pens a review of Contributions to the Ecclesiastical History of the United States of America-Virginia (1836).

${ }^{44}$ By "race question" I mean both the "negro question" and the "immigrant question," to signify their conflation in the period and their discourse in the press.

${ }^{45}$ It's important to note that More's Utopia is a scathing critique of the English system in particular and that many have read the work as self-reflexively critical of utopia itself. Speaking 
to the tenor of its criticism, it was published first in Latin and not published in English during More's lifetime, largely for fear of reprisal for its critique. In fact, More was ultimately executed for treason philosophically rooted in the principles he set forth in Utopia.

${ }^{46}$ Importantly, the self-fashioning of an author-persona is not only a convention of the literary utopia, but of nineteenth century literary skepticism, genres that Hawthorne bridges herein. Perhaps taking a leaf from Herman Melville's rhetorical use of the sub-sub-Librarian's "Extracts" as a prefacing chapter to destabilize epistemology in Moby Dick (1851)—since the work is inscribed to Hawthorne — or from Poe's well-known meditation on epistemological method that begins "Murders in the Rue Morgue" (1838), the first of his ratiocinative tales, Hawthorne, from his very preface, encourages readers to interrogate systems of thought, to fashion a skeptical American reader.

${ }^{47}$ As Richard H. Brodhead notes in "Veiled Ladies: Toward a History of Antebellum Entertainment," in a letter to E.P. Whipple in May of 1852, Hawthorne mentions having considered titling the novel The Veiled Lady (American Literary History 1.2 [1989]: 273).

${ }^{48}$ Separated sisters, the ethereal Priscilla is concealed as a veiled Vestal while the carnally-linked Zenobia is exposed as the desirable Circassian. I suggest here that Hawthorne's juxtaposition and ekphrastic descriptions of Zenobia and Priscilla knowingly allude to the dynamic between these two sculptures, which were not only (uncoincidentally) just shown at the Great Exhibition but also noted or illustrated in the Exhibition Commissioners' Official Descriptive and Illustrative Catalogue (1851). Further, I suggest that drawing on these iconic images allows him to comment on the degree to which exhibition representations fail women - by acculturating even within the most reform-minded to these limited representations of women as sexualized art-object. 
${ }^{49}$ I use the term "whore" here to gesture to the politics of lodging such charges as a means to disempower. Since Zenobia's feminist ideology makes her a threat to the "settled systems" of patriarchy, she is, emblematically, the "whore" from a white, middle-class male's vantage point to Priscilla's "virgin."

${ }^{50}$ The role of the neoclassical nude in a Puritanical nineteenth-century America was complicated, as Laura Prieto explains in At Home in the Studio: The Professionalization of Women Artists in America (Cambridge: Harvard UP, 2001). While many considered The Greek Slave a "moral nude," whose makers of Christian virtue "tried to instruct the public's gaze," some still considered the work "obscene," for her life-like, objectified, nude body still challenged the conventional modesty of the era, bearing markers of vice (71).

${ }^{51}$ The role of the neoclassical nude in a Puritanical nineteenth-century America was complicated, as Laura Prieto explains in At Home in the Studio: The Professionalization of Women Artists in America (Cambridge: Harvard UP, 2001). While many considered The Greek Slave a "moral nude," whose makers of Christian virtue "tried to instruct the public's gaze," some still considered the work "obscene," for her life-like, objectified, nude body still challenged the conventional modesty of the era, bearing markers of vice (71).

${ }^{52}$ For arguments about how the utopian form may pose an impediment to change, see Jean Pfaelzer's The Utopian Novel in America 1886-1896: The Politics of Form (Pittsburgh: U of Pittsburgh P, 1984) and especially Frederick Jameson's Archaeologies of the Future: The Desire Called Utopia and Other Science Fictions (New York: Verso, 2005), whose argument is predicated on doubting utopia has any political efficacy. 
${ }^{53}$ Indeed, even Poe's "Mellonta Tauta," which directs readers to an even more distant future than Bellamy's, firmly roots readers in the present and recent past, for its farcical rendition of a muddled history requires readerly decoding to be understood.

${ }^{54}$ Looking Backward inspired at least one-hundred twenty utopian novels, a number of notable reform leaders, and “at least 165 'Nationalist Clubs"” (Pfaelzer 50, Roemer Utopian 9).

${ }^{55}$ In Race and Reunion (2001), David Blight adopts the term "reconciliationist" to characterize one of several types of Civil War remembrances that begin appearing nearly as soon as the war ends. Reconciliationists emphasized the brotherhood of the North and South and its whiteness by avoiding discussion of the war's causes, Reconstruction, or Emancipation.

${ }^{56}$ In fact, signifying Bellamy's alignment with this increasing conservatism, suffrage in Looking Backward is limited to retired citizens precisely to avoid the "ruinous" possibility of mob rule (Bellamy 111).

${ }^{57}$ Discussing contemporary politics at the dinner table, the Bartlett's become the representative elite-cum-nativist. For when discussion turns to the growing labor disputes, the family laud's the Chinese Empire for its exclusionary politics, which saw immigration as "nothing but dynamite in disguise" and refused to allow Western influence within the country (12).

${ }^{58}$ Bellamy clubs were "local propaganda and discussion clubs" which emerged across the nation to advance the Bellamy-inspired Nationalist Party. Although the party was linked to the 1896 campaign of William Jennings Bryan, they ultimately "had little, if any, impact on reform issues of the day" (Pfaelzer 49).

${ }^{59}$ Sylvia Strauss's argues in "Gender, Class, and Race in Utopia," that "Bellamy was profoundly inspired by Thomas Wentworth Higginson, an ardent abolitionist who enlisted in the Union army and commanded the first all-black brigade in the war." This suggests he was not only aware that 
Boston was "the soul and center of abolitionism before the civil war," but that slavery was the central cause of the war. While I am skeptical of seeing Higginson as influential on Bellamy's racial politics, given his questionable stance on racial segregation in Equality and avoidance of a discussion of slavery and African Americans in Looking Backward, the fact that he is coursed in abolitionist thought and acutely aware of a South Carolinian black war regiment led by a white Bostonian is significant to my argument here. For a fuller discussion of Bellamy's admiration for Higginson, see Sylvia Strauss's essay in Daphne Patai's collection of essays Looking Backward, 1988-1888: Essays on Edward Bellamy, (Amherst: U of Mass P, 1988).

${ }^{60}$ Presuming a gap of twenty years for each generation preceding West's own in 1857, one may surmise that his great-grandfather's investments in New England industry began in the 1790s and suggest his involvement in the textile industry, and, ultimately, with Southern cotton and slavery. It may be for this reason that we find the adjective "faithful" applied to the "servant" Sawyer, whose single name, a surname of Anglo origin, suggests the possibility of his ancestors' enslavement within the West family.

${ }^{61}$ Although women have some judiciary and legislative power in matters that concern them, women remain overseen and outvoted by men. Further, Bellamy notes that "our judges are simply widely informed, judicious, and discreet men of ripe years," emphasizing that the majority of judiciary power, too, remains in the hands of men (122, emphasis added).

${ }^{62}$ In fact, Julie K. Rose further links Bellamy’s futurescape to the fairscape. Despite Bellamy's critical opinion of the Columbian Expositions, Rose notes in her online archive of the 1893 world's fair entitled "The World's Columbian Exposition: Idea, Experience, Aftermath," that his "utopian ideas were gestured to in the [formation of the] White City." 
${ }^{63}$ For example, if we look to the image of Columbia in Harper's Weekly (See Fig 8, Appendix) we gain a sense of the fair's racialized organization and visual argument. The "Africans" at the bottom of the image are the most distant from the representation of the ideal white America/Columbia, who is literally on a pedestal. Although one figure holds shackles, suggestive of American enslavement, her attire, though scant, links her to Africa, perhaps visually representing her a visitor to rather than part of the nation. Further, the "African" figure's state of dishabillement, emphasizes a lack of civility that contrasts the obviously privileged white Columbia flanked on each side by icons of industrial progress. ${ }^{64}$ For example, in 2013 black writer Lillian Jones Horace's utopian Five Generations Hence (1915) saw its first complete reprinting since its initial publication.

${ }^{65}$ While Twain's Gondour advocates universal access to education as well as female suffrage and women in roles of political leadership, it openly criticizes the laboring classes - and freed slaves by extension - and their enfranchisement. For the tale is heartily critical of granting universal suffrage to the "poor" and "ignorant," when the white male elite merely reforges the oppression, privileges, and prejudices of the old. Although a bleak and not particularly progressive satire, Twain does critically nod to the blatantly undemocratic literacy exams used to deny African American suffrage in his indict of the "wild, intricate" exam questions administered prior to electing Gondour officials. Likewise, he criticizes Gondour's permanent judgeships and decades-long leadership as a way to prevent systemic change (12). ${ }^{66}$ Twain offers several clues suggesting he may have Looking Backward and Julian West in mind, most notably: Twain's novel appears only a year later than Bellamy's, Twain's work literally looks backward in time, they both make use of a mystical sleep as a primary plot device, both stories' actions ruminate on the violence of immigrant labor (although Twain, by Morgan's 
admission, suggests he "got a dose" of deserved retaliation), and begin on African-Americancentered, Civil War-related holidays (Bellamy's on Decoration Day, Twain's on Juneteenth). ${ }^{67}$ With the text's focus on slavery, Twain's choice to begin the novel's action on June 19, or Juneteenth as it was then popularly known, could not be happenstance. Although its popularity eventually waned, Juneteenth was the oldest-recorded African-American celebration commemorating Emancipation. The holiday takes its origin from Union Major-General Gordon Granger's reading of an Executive Order declaring "all slaves are free" to the people of Galveston, Texas, on June 19, 1865.

${ }^{68}$ Drawing from the scholarship of Hamilton Hill, Allison Ensor, editor to the Norton Critical Edition of the novel, notes that "Clemens has in mind the towers and turrets of P.T. Barnum's mansion" when our narrator M.T. first sees a picture of Morgan's Camelot (9 n.2).

${ }^{69}$ While "The Slave Driver" blends a Roman slave past with Jay Gould, an American financier and recognizable figure of the nineteenth century, in "Brother! - to dirt like this?," Beard illustrates the continuity of oppression from serf to plantation slave to immigrant laborer. ${ }^{70}$ With the mansion of American's consummate showman in the background of the text, it is unsurprising that Morgan's use of the word "effect"-and the meaning Twain's quotation marks conjure at the end of the text-is focused on the dynamic of performance and reception throughout. As Morgan reveals he plans "stage-waits...for effect" so that the "audience...work[s] up its expectancy"; manipulates technology for its "immense" or "fine effect"; and notes that he didn't know if he "ever...got happier spectacular effects" as those he garnered in Camelot $(124,33,181,183)$.

${ }^{71}$ It seems important to note the work's contribution to the etymological development of the word "queer," for here the term characterizes non-normative, non-white histories, linking the term to 
the marginalization of a racial (rather than sex) minority. For the so-called "queer" histories are those of Major General John C. Fremont's emancipation of Missouri slaves though a military proclamation of property seizure and Robert Gould Shaw, who not only commanded the first allblack regiment, but encouraged the men to demand pay equal to that of white troops.

${ }^{72}$ Although Alcott's “Transcendental Wild Oats" was first published in The Independent (18 December 1873), it was subsequently republished in at least two other publications The Woman's Journal (21 February 1874) and in the collection Silver Pitchers, Laurel Leaves: Original Poems, Stories, and Essays (Boston: William Gill, 1876).

${ }^{73}$ Readers likely assume given his "William Penn countenance" that he has been rescued by abolitionist Quakers.

${ }^{74}$ At times Alcott's rendering of Hepsey, the escaped slave with whom she works, is a troubling caricature of dialect and "mammy" or "aunty" description, particularly in descriptions such as: "Hepsey was a tall, gaunt woman, bearing the tragedy of her race written in her face, with its melancholy eyes, subdued expression, and the pathetic patience of a wronged dumb animal (n. pag., emphasis added). However, Alcott does render Hepsey with some degree of autonomy; her illustration in the text largely rejects common caricatures, resembling instead a classical bust and although Alcott uses Hepsey "serves" Christie by allowing her to assert her own limited thinking and that of her society, this is largely without sacrifice of or injury to Hepsey.

${ }^{75}$ I would argue that we might read her general derision for this "science" in her lack of specificity. While phrenology parsed and named areas of the head and their corresponding traits carefully, the clumsy, non-specific "larger organ of language," points to the ease with which such "scientific" knowledge becomes reductive and derivative. 
${ }^{76}$ I would argue that we might read her general derision for this "science" in her lack of specificity. While phrenology parsed and named areas of the head and their corresponding traits carefully, the clumsy, non-specific "larger organ of language," points to the ease with which such "scientific" knowledge becomes reductive and derivative.

${ }^{77}$ The periodical was founded to elect Woodhull to the presidency and served other pragmatic means, such as organizing women for various political purposes.

${ }^{78}$ For example, we might look to prolonged erection and neoclassical architecture of the Capitol building. Its construction, which spanned nearly a century from 1793 to 1891, voice such ideologies in the grandeur of its increasing use of an elite white marble and continued expansion to accommodate the growth of the men of government. From this perspective, it seems uncoincidental that the nation's first public museum, Peale's American Museum, would form within a decade of the Revolution and at the urging of Thomas Jefferson and Benjamin Franklin. For the museum, nearly from inception, was imagined as a "moral and educational center for the entire nation," and subsequently became an institution of the white (male) utopian complex (Miller 2.1: 11).

${ }^{79}$ As Titiana Holway explains in The Flower of Empire (2013), while "the idea for the Great Exhibition of 1851 originated with Henry Cole" it was only after gaining Prince Albert's attention that the affair grew in ambition and scope (228). For a more detailed discussion of how Cole advanced the Exhibition's interests by Prince Albert's involvement, see The Crystal Palace and the Great Exhibition (2002) by Hermione Hobhouse (11-13).

${ }^{80}$ For the most ardent reformers, the Age of Reform was woefully underwhelming. While reforms increased the franchise among men, they officially forbade women from voting; while they reduced child labor and began regulating factory conditions, they neither ended nor 
completed the task; while they recognized the corruption and exploitation of children in English grammar schools, the nation was modest and slow to begin English elementary education while the new prison system began to deter crime, the treatment therein was glaringly inhumane; and while existing structures and laws to help the poor were reviewed, the resultant Poor Law reforms were nothing short of "Prisons for the Poor," according to radical labor reformer Richard Oastler. For a useful summary of the extent and limitations of social and political reforms prior to the Great Exhibition, see Michael S. Smith's "Parliamentary Reforms and the Electorate" in $A$ Companion to $19^{\text {th }}$ Century Britain (2004) edited by Chris Williams (162-166).

${ }^{81}$ One of the first three literary uses of the term "city beautiful," a poem titled "The City Beautiful" published in the Maine Farmer in 1888, links to biblical ideation of heaven—laying at the Master's feet—as the city beautiful. It seems likely, too, that like the movement gestured to biblical conceptions of utopian such as the new Jerusalem or the promised "citty on a hill." However, what is more significant is that the term doesn't seem to first emerge in relationship to a distinct architectural movement, but within an article titled "Dead-Letter Office" (1884). While the article does mention architecture and gestures toward Washington, D.C. as the city that now rivals Paris, it also more generally suggests that the city beautiful is a distinct, ultimate, and utopian destination - a heaven.

${ }^{82}$ I cast the term "races" in scare quotes here to draw attention to how variegated whites were treated as nonwhite during the period prior to the advent and adoption of the term "ethnic," which itself bespoke to the success of some nonwhites in becoming white.

${ }^{83}$ After the Crystal Palace was build, the National American Institute Expositions relocated to the Palace, hence Witman's assessment of the Palace. 
${ }^{84}$ Reception of the Great Exhibition's American department was less than enthusiastic. As the Scientific American reported in reported in 1851, the London Times had "spoken slightingly of the poor show we make" while also reporting that "a number of letter writers to papers at home speak in the same strain." As if the increasing scale of later American fairs still responded to this initial showing, while the nation's Centennial Exhibition in 1876 drew nearly ten million people, by the Columbian Exposition of 1893 admissions counts would number 27.5 million, (Rydell 10). And the scale of those fairs was only bolstered by their meticulous design; in fact, Paul Greenhalgh's Ephemeral Vistas (Manchester: Manchester UP, 1988) would write comparatively of world's fair designs, emphasizing the innovation and didacticism of the American fairs bordered propaganda by the turn of the century (22).

${ }^{85}$ Although Henry Adams was discussing the Louisiana Purchase Exposition of St. Louis in 1904, his notion of their educational value and manifestation of a near-religious experience suggests his assessment speaks to a much longer history of fairs in the U.S. ${ }^{86}$ In Museums and American Intellectual Life, 1876-1926 (Chicago: U of Chicago P, 1998), Steven Conn maps the influence of British Museums on American display culture, and, later vice versa. He notes, in particular, in influence of "London's South Kensington complex" which "many Americans saw...[as] a model of sufficient scope and ambition for...American museum builders," which he extends to exhibitions as well (195).

${ }^{87}$ The first Fugitive Slave Act of 1793, a replacement for the Constitution's Fugitive Slave Clause, gave slave owners and their agents the right to search for escaped slaves within the free states, but required a trial wherein the owner had to prove the person was his property. Speaking to the politics of race as well as the acculturation of black inferiority, by the Fugitive Slave Act of 1850 , suspected slaves were not only denied a trial, but the new law mandated Northern 
citizens to aid in the capture of runaway slaves and penalized those who interfered with a $\$ 1000$ fine and six months in jail.

${ }^{88}$ By the 1890 s the nation's immigrants were a swelling population and the first waves of black migrants headed North, which fostered unprecedented population growth in major cities such as Chicago, New York, Philadelphia, and Washington, D.C. At the same time, a rise in labor unrest and notable strikes like Chicago's Haymarket Riot in 1886 and the Homestead Steel Strike in Pennsylvania in 1892 punctuated the landscape.

${ }^{89}$ While between 1870 and 1890 , the black population in Chicago tripled and by the century's end rendering it the fastest growing city in America, during the same period the nation's population of foreign-born inhabitants reached nearly $15 \%$. At the same time, four massive volumes of vital research conducted in Great Britain by England's Poor Law Commission, which first championed urban reform and inspired American urban planning, concluded that "indescribably dirty tenements, fetid courtyards, reeking rivers, [and] filth-laden streets" were directly causing "high mortality and morbidity and explained the frequent absences of laborers from work as well as their heavy dependence on charity and poor relief and a proneness to crime, drunkenness, and riot" (Peterson 31). And while modern critics recognize that the circumstances contributing to crime, drunkenness, and riot as far more nuanced, the American press would soon be flooded with similar contentions.

${ }^{90}$ The Court of Honor is the area of the fair colloquially dubbed the "White City."

${ }^{91}$ While researching, I found a poem and an essay that use the term "city beautiful" prior to Bunce and the Columbian Exposition to gesture to a utopian ideal. The first is a short essay by Mrs. Pattie L Collins entitled "The Dead-Letter Office" in The Chautauquan (May 1884) and the second is a poem titled "The City Beautiful" published in Michigan Farmer (15 Dec 1888). 
${ }^{92}$ In Races of Mankind (1854) Gliddon and Nott observe differences in the sculptures and minted images on coins throughout the Greek empire. In keeping with the notion that contact precipitates a racialized reactions, they note that the expressions of the most "ideal beauty," were those forged in regions of the Empire in the most direct contact with "barbarians," as though they "embellished representation of the purest Arian [(sic)] type" in their cultural works (165, 168). In other words, according to the authors' assessments of these representations, rather than marking difference along, the works in these contact zones reveal even in antiquity an acute awareness of a racial hierarchy, and awareness that Gliddon and Nott would like readers to believe they are documenting rather than fabricating.

93 "Ragpicking," the practice of rummaging through trash for usable swaths of fabric, was commonly associated with urban immigrants, particularly with women and children (Berkin, Crocco, Winslow 32). But while class remains stratified in the City Beautiful and living in poverty remained a harsh reality, in this utopia even the "poorest man's house" has sufficient space and he acts "cleanly" and shows "decency" (119). Of course, as it typical of many white male utopists, readers are given little to no explanation of how this is possible (119). ${ }^{94}$ The letters were eventually collected and republished as Letters of an Altruian Traveller in 1904, keeping Howell's notion of Altruia and sense of the fair in circulation a decade later. ${ }^{95}$ Importantly, Howell's uses Homos to impugn the political rhetoric that manipulated the decree that "all men are created equal" to suggest that each one of us is the "peer of any and every other American," despite the nation's pronounced, observable, and unchallenged divisions between the classes at the fair (31). In fact, Howells suggests well before Matthew Frye Jacobson would in Whiteness of a Different Color (1999) that the "contending forces" of "capitalism (with its insatiable appetite for cheap labor) and republicanism (with its imperative of responsible 
citizenship)...that have fashioned and refashioned whiteness," often work to unhinge would-be cross-racial alignments by reinforcing racial belonging among the "whitest" groups (Jacobson $13)$.

${ }^{96}$ Although Homos is Altruian, his wealthy, presumably white guide extends this priviledge and rank to Homos, through their companionship; they not only travel the fairgrounds together, but eat and sleep together (if only by suggestion), which transmit privilege to Homos.

${ }^{97}$ From the Naturalization Law of 1790, which named whiteness as a precondition for citizenship, a racial hierarchy governed the nation. This was reinforced not only by Adams's increased restriction on residency requirements for citizenship as part of the Alien and Sedition Acts in 1798 , but by the long history of black enslavement, the racialization of immigrants, the hesitancy to pass the Reconstruction and Amendments and the Black codes and Jim Crow that developed in response. And, in the late nineteenth-century, the fair was a hub for transmitting this racialized social and political history as the necessary foundation of modern America. ${ }^{98}$ In the first chapter of Obsolete Necessity (1976), Kenneth Roemer offers a very useful demographic analysis of the writers of late nineteenth century utopias, finding that most are white middle- or upper-class men (11).

Headlines often expressed disdain for immigration. In fact, articles titled "Undesirable Immigrants" appeared in the Times and Register (27 Feb 1892) and three times more in The Youth's Companion (8 Nov 1894, 14 May 1896, 25 Feb. 1897) while Forum asked of crime rates in 1891 "Are Immigrants to blame?" and the Medical and Surgical Reporter would discourse on "Immigrants and Skin Disease" (15 Nov 1890). Likewise prevalent was the discourse on the "Negro Problem" at the time. In fact, a closed search for the term in the American Periodical 
Series database retreives over 300 articles from 1890 to 1899 alone, and those results do not account for variations like "the Problem of the Negro" or "Problem Negroes."

${ }^{99}$ In the preface to The Reason Why (1893), the authors contend that "the colored people of this great Republic number eight millions-more than one tenth the whole population of the United States" (3).

${ }^{100}$ In fact as "the eugenic cast of the American immigration debate became more and more pronounced" it lead to an official U.S. Committee on Immigration (also known as the Dillingham Commission's) and an extensive 1911 report recommending immigrant exclusions, which guided immigrant restrictions acts in 1917, 1921, and 1924 (Jacobson 82).

${ }^{101}$ One of the most significant problems with the fair's American ethnographic display was its representation of Native Americans. In June of 1892 The Independent published Commissioner of Indian Affairs Thomas J. Morgan's “Columbus and the Indian," which served not only as an official announcement to include Native American representation at the fair but as the government's official position on Native Americans, one rooted in Morgan's own push for their assimilation. Reinforcing the salvation mythology of Columbus's "discovery," he concludes that the "twenty thousand Indian children now in school, clothed, fed, instructed and tenderly cared for by the Government" when they "contrast their lot with that of those children of the forest whom Columbus found when he discovered the continent" should "thank the great Father above who guided to our shores the frail bark of the bold navigator" (1892). Although an obviously contentious statement to the modern scholar, for contemporaries like Emma C. Sickels, it was no less contentious in its day. Sickels, pointed directly to Morgan and Putnam, she charged not only that "the exhibit of Indian life now given at the fair is an exhibit of savagery in its most repulsive form" but that it was explicitly contrived as such to "show the need of Government officials to 
civilize" Indians. If the exhibit were not arranged to overstate the importance of the government's role in Indian affairs she asks, "why did [...] Putnam ... and...Morgan agree to exclude from the fair all but savages and school children?" As she investigated the termination of the Congress and limited representation of Indians at the fair, she reports having discovered a memo which agreed that Indians "shall be presented only through the Indian Bureau."

${ }^{102}$ From The Critic's collection of "Impressions of the World's Fair" penned by public figures of note who often mention the "wild life of the Midway Plaisance" as a most memorable aspect of the fair, to scads of articles with titles like "Fair Barbarians" (Congregationalist, 24 Aug 1893) and "Village Life at the World's Fair" (The Chatauquan, Aug 1893) appearing in the popular press, to the myriad "official" guidebooks and commemorative such as John J. Flinn's Official Guide to the World's Columbian Exposition (Chicago: The Columbian Guide Company, 1893) or Rossiter Johnson's History of the World's Columbian Exposition held in Chicago in 1893 (New York: Appleton, 1897), all take up the white-defined racial hierarchy advanced at the fair-and reinforce them in perpetuity.

${ }^{103}$ By 1890 almost $15 \%$ of the population was foreign-born while more than $10 \%$ were black, a population that, if united, presented a sizeable and increasing threat to the white status quo if these populations would organize.

${ }^{104}$ I use the term "metafictive" to draw attention to Harper's self-conscious attention to literary device in the novel, an attention reinforced by the work's participation in an ongoing conversation on the relationship between gender, race, and genre sparked by Howells. Reading the work as metafictive, I suggest that Harper systematically draws attention to the work's use of device to document the centrality of whiteness to the utopian fictions forging not merely the literary representations of nation, but legislating its reality. 
${ }^{105}$ I am neither the first scholar to note that Iola Leroy is a utopia nor that its use of the utopian genre is nontraditional. As M. Giulia Fabi points out Passing and the Rise of the African American Novel (2001), the novel's utopian character is made more visible by the way it takes up themes of Harper's earlier work, Minnie's Sacrifice (1869), a novel serialized in The Christian Recorder (58). As Fabi notes, along with Harper's conventional rendering of Iola as a disillusioned traveler to a negative utopia of antebellum blackness, the changes made to the narrative drawn from Minnie’s Sacrifice highlight the "utopian features of the happy ending of Iola Leroy" throughout (59). For Minnie's death as a martyr to the cause of equal rights in the era of Reconstruction and Louis's loss of his wife, is recast by Iola's lasting marriage to Dr. Frank Latimer, their mutual community organizing and activism, and their open criticism of white supremacy throughout the text.

${ }^{106}$ Significantly, a literary relationship between William Dean Howells and Edward Bellamy has been fairly well documented. More importantly that friendship coalesce around the publication of Looking Backward, suggesting that for Howells was pondering, discussing, and writing about utopianism by 1889 . In fact, a study in the mid-1950s notes the authors" "mutual indebtedness" through an examination of their correspondence. See Joseph Schiffman's “Mutual Indebtedness: Unpublished Letters of Edward Bellamy to William Dean Howells" (Harvard Library Bulletin 12 [1958]: 370).

${ }^{107}$ All of the family, of course, was by affect, but only Iola was clearly sold. Her youngest sister, in poor health, died shortly after she learns of her lineage; Lorraine, the white cousin who made the inheritance claim against the Leroy's, kept Marie as his wife and moved her to Vicksburg where she "engage[d] in confectionery and preserving for the wealthy ladies of the city" and he 
died in the war; Henry, forewarned of the fate that awaited him in the South by Iola's letter, enlisted in the Union army.

${ }^{108}$ I would argue that the North Carolina settlement is more than a community, but a protosociety because it begins to forge its own infrastructure - they start a school, plan community engagement activities, and Uncle Daniel even divides and sell homesteads to those among the community.

${ }^{109}$ For example, in the wake of the passage of the Separate Car Act in New Orleans, citizens formed an interracial organization called the American Citizens' Equal Rights Association (ACERA) which wrote pamphlets and gave speeches in opposition to the Act Plessy v. Ferguson challenged.

${ }^{110}$ Although Plessy v. Ferguson would not reach the Supreme Court until 1896, the case first went to trial in 1892 in Louisiana and signifies how a lineage of state segregation laws and court decisions become codified in federal case law. Significantly, although Washington's address at the fair predates the Supreme Court's decision in Plessy by a year, his remarks are included verbatim in Up From Slavery (1901) which postdates Plessy by five years.

${ }^{111}$ This is not to suggest by any means that "Caucasian" is an apolitical construction of race, it certainly was not, but to recognize, as Reginald Horsman does in Race and Manifest Destiny (1981), that "racial Anglo-Saxonism" was an epistemology, a worldview of whites as the original, divinely-chosen race that Americans linked to a mythic "free Anglo-Saxon past" (81). ${ }^{112}$ This is a conservative estimate. At least one historian argues that fearing further reprisal blacks did not report injuries or deaths caused by the riot.

${ }^{113}$ As several modern scholars clarify, the idea of a Negro exhibit began in the black community. In A Clashing of Soul (1998), Leroy Davis clarifies "Black Atlanta leaders had actually 
approached white leaders about opening a black exhibit in the exposition"; however, as early as 1895 I. Garland Penn, Chief of the Negro Building, recalled in "The Awakening of the Race" that black Americans first approached whites (Davis 85, Penn 58-59).

${ }^{114}$ In fact, merely two years afterward Gaines would publish a historical study titled the The Negro and the White Man (1897) to "put his views on the so-called 'Negro Question' in permanent form," which he suggests had been his "purpose for years" (7). ${ }^{115}$ Presumably at The World Industrial and Cotton Centennial held in NOLA in 1885. ${ }^{116}$ About a dozen articles attest to the Negro exhibit as "most interesting," but more noteworthy is the white press's disproportionate silence about the building given the volume of articles on the fair. For example, Scientific American, despite running a number of feature articles on the Atlanta Exposition of 1895 only mentions the term "Negro Building" once and, at that, only to document the building's square footage in (2 Nov 1895).

117 "The Negro Leaned Exhausted Against the Wall" is a one of a series of illustrations from H.C. Bunner's "The Story of a New York House" first published in Scribner's in 1887. A second illustration from the same story may also have been one of the four Frost exhibited at the Exposition, as it is titled The Rioters- -A New York House," an image in the text captioned "Have you got a nigger here?," since a mob is searching for the African American character in the previous illustration.

${ }^{118}$ We can infer the proximity of these works given the Official Catalogue's sequential numbering of the exhibits.

${ }^{119}$ Suggesting that this covert communication was still a current and relevant topic of discussion by the century's end, Frances Harpers's Iola Leroy begins with an encoded conversation among slaves. 
${ }^{120}$ The Oxford English Dictionary notes that by the mid-nineteenth century the word "extremist" was used as a noun to characterize radical individuals or groups, as it is used today. ${ }^{121}$ In Manliness and Civilization: A Cultural History of Gender and Race in the United States, 1880 - 1917(Chicago: U of Chicago, 1995), Gail Bederman analyzes Hall's speech and its sharply critical aftermath. It is imperative to note, as she does, that Hall several times admonishes the "effeminacy" and sentimentality of the Kindergarten classroom in a roomful of female educators. His wholesale dismissal of women and girls in his focus on boyhood "savagery" fairly clearly marks his educational philosophy as both sexist and masculinist. As Bederman usefully points out, Hall's personal interest as an educator was "remasculiniz[ing] the civilized man," seeing civilization as harboring too much effeminacy, which he saw as a barrier to advancement. In other words, Hall's educational philosophy was much more a philosophy of national identity and program to acculturate the type of aggressive masculinity Roosevelt was known for; it is no wonder that he eagerly gravitated to it. See her important discussion of Hall, pp. $97-101$.

${ }^{122}$ In a letter to Southern Colonel Frank Lawton, for example, Roosevelt refuses to reject a black man's reappointment to a position on the basis of his skin color. It is worth noting, however, that Roosevelt's tone is markedly apologetic, as he twice notes his regret that he must disagree with Lawton and even suggests he would honor the request via relocation, if he could. In other words, while Roosevelt refuses to act with racial prejudice, his rhetoric nevertheless suggests regret that he could not act with racial prejudice. In fact, even an early biographer, William Roscoe Thayer, characterizes Roosevelt's actions in terms of "negro problem" ideology in light of his controversial dinner with Washington. See Theodore Roosevelt: An Intimate Portrait (1919), New York: Houghton Mifflin, 282-286. 
${ }^{123}$ By 1912 , Davenport had instituted the use of an IQ test at Ellis Island to determine "feeblemindedness"; the test was believed to prove the intellectual deficiency of immigrant "stock" despite the proven cultural and social biases measured in subsequent testing. Likewise, the long cultural association between those blackness and disability is well established in scholarship on scientific racism. For a useful example, see Siobahn Somerville's "Scientific Racism and the Emergence of the Homosexual Body" published in the Journal of the History of Sexuality [5.2 (1994): 243-266] offers a useful historical survey of how the black female body is socially and rhetorically constructed as disabled, degenerate, and queer.

${ }^{124}$ Importantly, Bishop also draws a direct association between the fairscape architecture and utopia, a recognition that I would argue he might also draw from Bellamy. For as I suggest in Chapter 1, Bellamy's ekphrastic descriptions of utopian architecture mirror that of the fairscape, rather than the Boston he knows, an observation that Yale Professor of literature W.H. Bishop may have recognized and recast more overtly in his own architecture of utopia, considering his work's dialogue with Looking Backward.

${ }^{125}$ For despite his Southerness, when we meet Colonel Green his dialect and speech pattern mirror that of Wayne and Stanley, both Northerners. Even if we would suggest that Colonel Green's social class accounts for the uniform speech pattern among the white speakers, other texts, such as Mark Twain's well-known Adventures of Huckleberry Finn (1884) published a decade prior, laid groundwork for writing several varieties of dialects, including lower, middle, and upper-class white Southern dialect. Characters in Twain who might represent a middle or upper class-Miss Watson, the Widow Douglass, the Judge, the Doctor-all speak with a regional dialect, including, at times, "incorrect" grammar or dropped endings. While Jim's dialect and the dialect of other non-whites does contrast—including malapropisms and mistaken 
consonant blends such as "dey" for "they" - no one's language remains unmarked in the way the speech of Bishop's Southern whites is. I would also argue that Wayne's and Stanley's trip down river on a small boat recalls that of Jim and Huck in Huck Finn, a prominent symbolic plot point in Twain's novel that readers are sure to recall.

${ }^{126}$ For in the same year an article entitled "Are the Americans Anglo Saxons?" circulated in at least two popular publications, argued that "the American people are as Anglo-Saxon as the British" precisely because "the ethos, morale and natural characteristics of the Republic are distinctly Anglo-Saxon" printed in The Living Age and reprinted from The Spectator (4 June 1898). In other words, the argument is predicated on the belief that the nation remains AngloSaxon because its forbearers were.

${ }^{127}$ Significantly, the image and phrase are reminiscent of the iconic images of crossed American and Confederate flags common not only during the war but afterward as the nation reconciled. Davenport was also co-editor of the periodical Blue and Gray: The Patriotic American Magazine, a devoutly reconciliationist periodical started in 1893, whose serialized frontispiece shows a Confederate and Union soldier in a filial embrace with the captions "Fraternity," "Union," "Now and Forever." The publication was nearly exclusively about the valor of the white soldiers of both sides; little, if any, attention was paid to "slavery" or to "slaves," who frequently appeared only in the periodical's fictions caricatured and defending the honor of her or his white masters. In other words, the periodical, like the novel, expresses not merely fraternity, but the fraternity of whiteness, emphasized in the novel by the attention to both "blood" and Anglo -Saxon "ancestry." 
${ }^{128}$ The novel's utopian traveler and narrator is an unnamed nineteenth-century man whose soul awakens in the body of a twenty-second century citizen named Richard Pangloss, who was undergoing brain surgery to remedy madness.

${ }^{129}$ One influential book of the period was Count Arthur de Gobineau's The Inequality of Human Races (1852), which argued that the rise and fall of civilizations were rooted in racial compositions and overtly advised whites to use "strict despotism" in management of black subjects.

${ }^{130}$ See Jim Crow Literature and the legacy of Sutton Griggs (2013) and a smattering of articles in the 2000s, including: Tom Knadler's "Sensationalizing Patriotism: Sutton Griggs and the Sentimental Nationalism of Citizen" (2007), Maria Krafilis's “Oratory, Embodiment, and US Citizenship in Sutton E. Griggs's Imperium in Imperio"(2006) and Lynn R. Johnson's “A Return to the Black (W)hole: Mitigating the Trauma of Homelessness in Sutton E. Griggs's Imperium in Imperio (2010).

${ }^{131}$ Echoing an early incident in the text wherein Belton embarrasses his cruel school master at graduation by having him fall from the sage into a well, Bernard is dropped through a trapdoor into the government chambers below.

${ }^{132}$ Although Griggs's focus on the development of black men may reinforce the novel's desire to combat the white Anglo-Saxonism of the American government and the hyper-masculinity of the typically white, male lynch mob it fosters, Griggs's utopian Imperium reiterates the patriarchy of the white system in failing to imagine political place or purpose for black women, a critical shortcoming necessary to address in more detail than I can offer here and one that greatly limits Griggs's imagining of a black utopia. 
${ }^{133}$ I greatly respect Robert Levine's reading of Imperium in "Hale's and Griggs's Men without a Country" as a strident attempt to allow the novel to dwell in possibilities previously denied it by scholarship casting it as either too accomodationist or militant. However, he seems to recast the novels binaries of conservative and militant thought as "dualisms" within the burgeoning black nationalist literature, whereas I argue that the utopian form helps to facilitate a plurality of reading experiences (81). Even at a formal level we are faced with three dominant charactersBernard, Belton, and Berl—whose assessment of black history and the present all differ and raise paralleled but distinct concerns about the current state of Negro advancement. Beyond these three voices, minor characters raise silenced, yet no less significant concerns as well. For example, while I am critical of Griggs's treatment of female characters, he does ground Antoinette Nermal's and Viola Martin's experiences in social realities question racial stigmas within the black community and the effect of eugenic research on the black community (when the research itself is typically conducted and published as a educative and preventative measure for whites).

134 The deplorable practice of displaying humans, who were increasingly caged as though they were zoo animals in later Paris exhibits, was most explicitly literalized in 1906 by William Hornaday and Madison Grant, the eugenicist and lawyer who would a decade later write a bestselling work of white superiority and positive eugenics The Passing of the Great Race; or, The Racial Basis of European History (1916). With the support of Grant, head of the New York Zoological Society, Hornaday displayed African pygmy named Ota Benga at the Central Park Zoo for a period of twenty days. Benga, a victim of human trafficking by today's standards, was captured and forced by his handler to spend time on display among the monkeys before being coerced into fulltime display therein for nearly three weeks. 
${ }^{135}$ Research in the American Periodical Series (APS) database narrowed by publication and year suggests that the magazine published three feature articles on the Paris Exposition of 1900 in 1895.

${ }^{136}$ Continuing my research in the APS database to trace the Scientific American's coverage of the Atlanta Exposition of 1895 (September 18 through December), I noted that despite the Negro Building's unprecedented inclusion, the periodical only mentions the term "Negro Building" once and only to document the building's square footage in its November 2 issue.

${ }^{137}$ The articles use of the word "native" bears consideration. On one hand, it seems to marvel that a "negro" might speak with the eloquence of a native speaker of English; on the other hand, it may suggest the quaintness of his speech, an eloquence "native" to the "negro." Regardless, the description conveys surprise at the speaker's competence.

${ }^{138}$ Using the APS narrowed by publication and the years 1899 through 1900, a search for "Paris Exposition" yields around 180 articles in Scientific American mentioning the fair. Of these articles, 45 were features articles on the fair, none of which mention the Negro Exhibit. ${ }^{139}$ Using the APS narrowed by date (January 1899 to December 1900), I searched for "Paris Exposition" and then for "negro" within the results, which yielded 1,500 and 94 mentions, respectively. Paging through results, I narrow my count to the 254 articles that include "Paris Exposition" in their title and the 4 within those that mention the Negro Exhibit. ${ }^{140}$ It's important to note that while part of the "Negro Exhibit," as it was listed in the official guide, was within the American Exhibit. However, two parts of the Exhibit of the American Negro were cordoned off by a walkway, segmenting it from the national display. This said, at least part of the exhibit visually integrates blacks as Americans in a way that some contemporaries argued that the negro building of American fairs segregated. 
${ }^{141}$ Aside from some whites who found the exhibit's mere inclusion offensive, the impressive showing of the exhibit, which overtly refuted the nation's white narrative of black inferiority, seemed to keep many official (white) histories from discussing it at length—or at all, at times. As David Levering Lewes notes in "A Small Nation of People: W.E.B. Du Bois and Black Americans at the Turn of the Twentieth Century," a featured article on the United States exhibit written by the U.S. commissioner-general and published in the North American Review does not even mention the Negro Exhibit.

${ }^{142}$ I use the word proofs here to intentionally gesture to the strength of Du Bois's statistical argument throughout.

${ }^{143}$ In the last decade of the 1890 s, the American Periodical Society database catalogues only 15 mentions of Du Bois's work, mostly of advertisements for The Suppression of the African Slave Trade, Vol 1. In the first decade of the $20^{\text {th }}$ century, mentions of Du Bois's work, including feature-length publications of his work leading white periodicals, rise to more than fifty. ${ }^{144}$ For example, the New York Times hailed the dinner an "incident" in an October headline "Mr. Roosevelt Explains the Dinner Incident" only to recast the dinner as an "incident" again a month later, speaking to persistence of the characterization.

${ }^{145}$ Bespeaking the white paranoia and "negrophobia" of the era, the use of the term "race riot" to characterize a conflict between races of people, typically black and white, increases in periodical headlines from a total of nineteen in the 1890 s to more than seventy in the first decade of the twentieth century.

${ }^{146}$ By the time Ellis Island opened in 1902, more than half of the United States had antimiscegenation laws banning interracial comingling between blacks and whites, focused on the union as an abomination. For example, in 1878 the Supreme Court of Virginia held that "the 
moral and physical development of both races... require that they should be kept distinct and separate" and because their "connections and alliances [were] so unnatural that God and nature seem to forbid them" they "should be prohibited" by law.

${ }^{147}$ It's important to note, that some black intellectuals—including Du Bois—supported eugenics, although he did not support the anti-black racism guiding white proponents of eugenics. However, while he advanced notions of positive eugenics as a means of uplift, he nevertheless identified a "submerged tenth" as the "germs of the race," reinforcing a notion of black contagion in The Philadelphia Negro (1899).

${ }^{148}$ Every chapter begins with a poetic stanza meditating on the chapter's central theme. While not all the poems are lyrics in a formal sense, they all convey an emotional response and lend a sense of musicality to the work, one reinforced by Du Bois's also occasional citation of the lyrics of black spirituals.

${ }^{149}$ I am indebted to Veronica Watson's work in "Lillian B. Jones Horace and the Literature of White Estrangement: Rediscovering an African American Intellectual of the Jim Crow Era" in Recovering Five Generations Hence. For a clearer understanding of the trajectory of whiteness studies she traces, see her book The Souls of White Folks:African American Writers Theorize Whiteness (Jackson: University Press of Mississippi, 2013).

${ }^{150}$ For a thorough discussion of influences on Pauline Hopkins's Of One Blood, see Hanna Wallinger's Pauline E. Hopkins, A Literary Biography (Atlanta: U of Georgia P, 2005). For a more in-depth discussion of developing black philosophies in a world of white philosophy, see Ross Posnock's Color \& Culture: Black Writers and the Making of the Modern Intellectual (Cambridge: Harvard UP, 1998). 
${ }^{151}$ Briggs is an homage to Du Bois, whom Hopkins analogously imagines as "the ideal American race leader, intelligent courageous brave and manly" (Wallinger 207). Despite being a female writer and a formidable intellectual of her own right, her female characters, like those in Sutton E. Griggs's Imperium in Imperio, serve little more purpose than advancing the black male leader's development. This seems a curious choice on Hopkins part. Perhaps she thought the type of critical work the novel does would be better received from a male protagonist given the seemingly hopeless strictures of black femininity she explored in Contending Forces (1900). Regardless of her reasoning, her hollow female figures deserve a more thorough critical examination than I can give them given the scope of my argument here.

${ }^{152}$ Although scientific findings would begin to point to an African human origin by 1925 , when Raymond Dart found a fossilized skull of an early hominid, Black intellectuals began arguing for an African origin much earlier. Indeed, even in The Souls of Black Folk Du Bois's insistent attention to the origin and order of the development of races places Egypt at the helm, a civilization that became a racial battleground for whites and blacks claiming ancestry. ${ }^{153}$ While M. Giula Fabi and other scholars have noted the narrator's racial indeterminacy, I would argue that they overlook its psychological and philosophical power to transgress when used within the utopian form, as I argue here.

${ }^{154}$ In 120 Years of American Education: A Statistical Portrait, the National Center for Education Statistics reports that from 1870 to 1900 illiteracy rates were cut in half among both whites (from approximately $12 \%$ to 6\%) and blacks (from approximately $80 \%$ to $40 \%$ ), marking the increase in potential readership.

${ }^{155}$ As the University of Virginian Institute for Advanced Technology in the Humanities notes in “Uncle Tom's Cabin in American Culture," The Leopard's Spots sold over 200,000 copies in 
1902. While the subscription circulation of the Atlanta Journal at the begin of the twentieth century was only 30,000 , those papers were often read by more than one person, ranging from family circulation to readings aloud in public places, suggesting a multiplication of readership in a particularly racially hostile southern environment.

${ }^{156}$ Presuming a third racialized category is admittedly a stretch. However, my point is that we must consider the possibility raised given the extent to which Johnson works to produce uncertainty.

${ }^{157}$ Until Karen Kossie-Chernyshev publication of Recovering Five Generations Hence: The Life and Writing of Lillian Jones Horace in 2013, the novel had been out of print since its initial printing in 1915, save for the inclusion of the first five chapters in Carol Farley Kessler's Daring to Dream (1995).

${ }^{158}$ Arguably, the onomastics of a name like "Grace Noble," which suggests the character possess both qualities, may wryly extend to the word "novel" as well, reinforcing Noble's calling to write a novel.

${ }^{159}$ The massacre of at least eight black Americans in Slocum, Texas is a horrendous testimony to the power of negrophobic white narratives. As accounts explain, two stories seem to be connected to the event. The first is that of a disabled white farmer's misunderstanding with a black shop owner a bill. The second was of an unofficial appointment of a black road worker to notify area residents of forthcoming road work. In the former case, the story quickly shifted to an uppity black bilking an infirmed white man. In the latter case, in retellings the black worker became an overseer of white road crews. Both of these led fodder to a third negrophobic and paranoid white narrative of an impending race riot—of secret meetings among the town's black population organizing to overthrow the white. In the wake of this rumor, white men met, locked 
their wives and children away in churches for safety, and beginning on July 29 and lasting for 48 hours, the white men hunted and killed unarmed black men (and likely women and children also). No evidence that blacks were organizing to riot was found. Also, since many black citizens fled from the region without a trace under rumor that "heavily armed white mobs" were in the area, many estimate the death toll was much higher when faced with a white mob of " 200 or 300" according to Anderson County Sherriff W.H. Black in 1910. ${ }^{160}$ Dixon's Klan trilogy includes: The Leopards Spots (1902), The Clansman (1905), and The Traitor (1907).

${ }^{161}$ Although the Slocum Massacre of 1910 was certainly not a direct cause of black migration to urban centers in the North, it represents the increasing hostilities of Southern whites driving the migration.

${ }^{162}$ While David Blight and Mable Wilson both point to 135,000 as a cautious estimate, the History and Report of the Exhibition and Celebration to Commemorate the Fiftieth Anniversary of the Emancipation of the Negro suggests fairgoers numbered as high as 762,000 , when one accounts for an error in the mathematics of the tally listing it as 862,000 (17).

${ }^{163}$ As Gilman explains, Herland began about 2,000 years ago when a "volcanic outburst," killed many men "save the slaves" who "seized their opportunity, rose in revolt, killed their remaining masters even to the youngest boy, killed the old women too, and the mothers, intending to take possession of the country with the remaining young women and girls." Despite the timeframe which puts the revolt in conversation with a much earlier history, among American readers the words "slave" and "revolt" as well as the brutality associated therewith would conjure the image of a black slave. 


\section{Appendix}

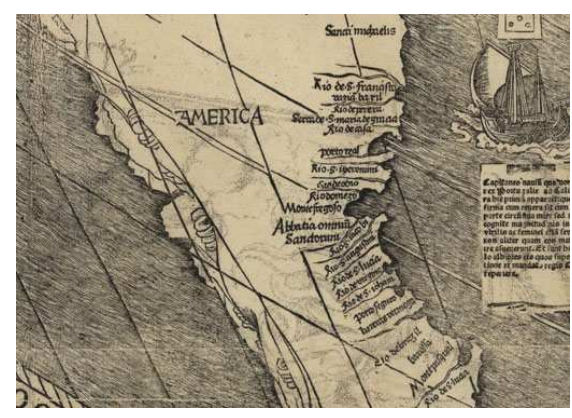

Figure 1. A detailed image of Martin Waldseemuller's 1507 map naming America. (The Library of Congress; Geography and Map Reading Room; 12 March 2014; Web).
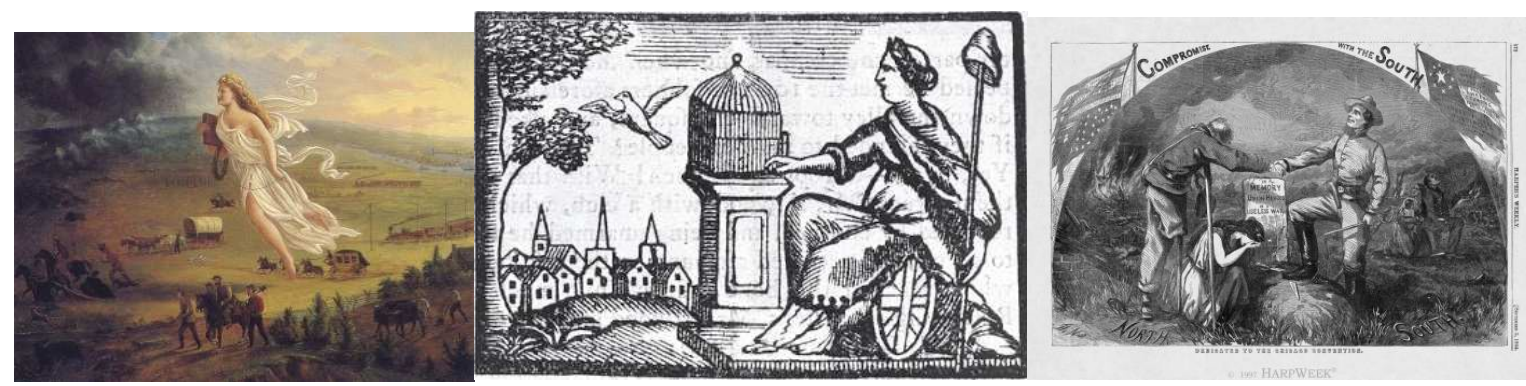

Figure 2. Images of Columbia, including John Gast's representation of Columbia as a symbol of manifest destiny in Spirit of the Frontier (1872), a Revolutionary War Era image of Columbia from the masthead of The Boston Gazette and Country Journal, and Civil War Era political cartoon from Harper's Weekly, September 3, 1864. (Web). 


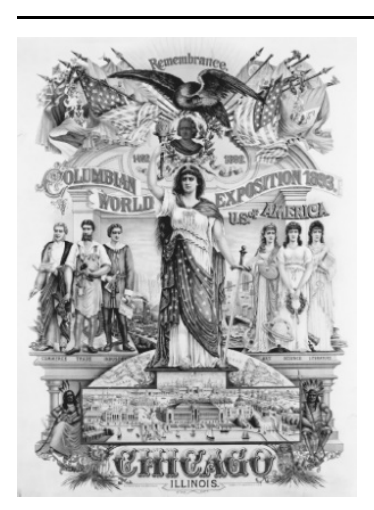

Figure 3. One official poster from the World's Columbian Exposition of 1893 featuring a bust of Colubus above an image of Columbia. (Gale: U.S. History in Context; Gilded Age and Progressive Era Library; Web).

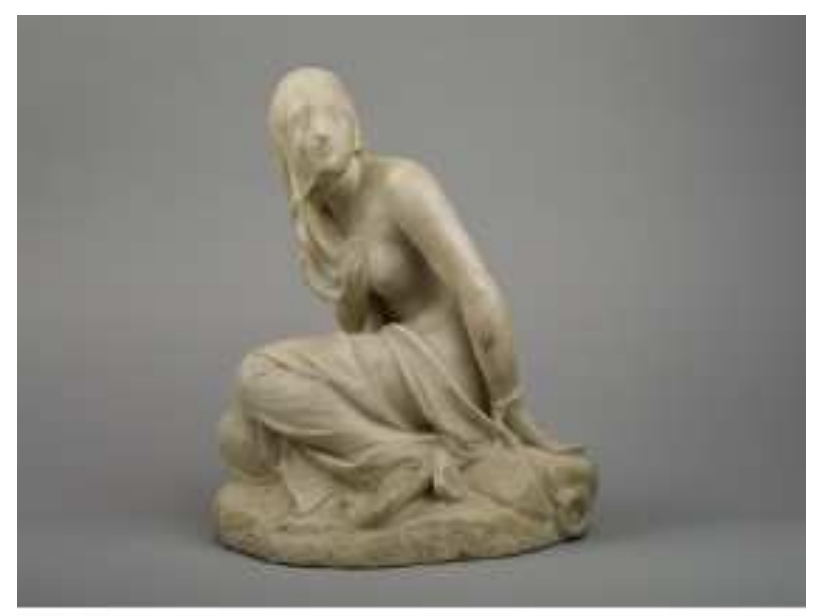

Figure 4. Raffaelle Monti's The Circassian Slave (1850). Photograph in The Wallace Collection Online. (Web). 


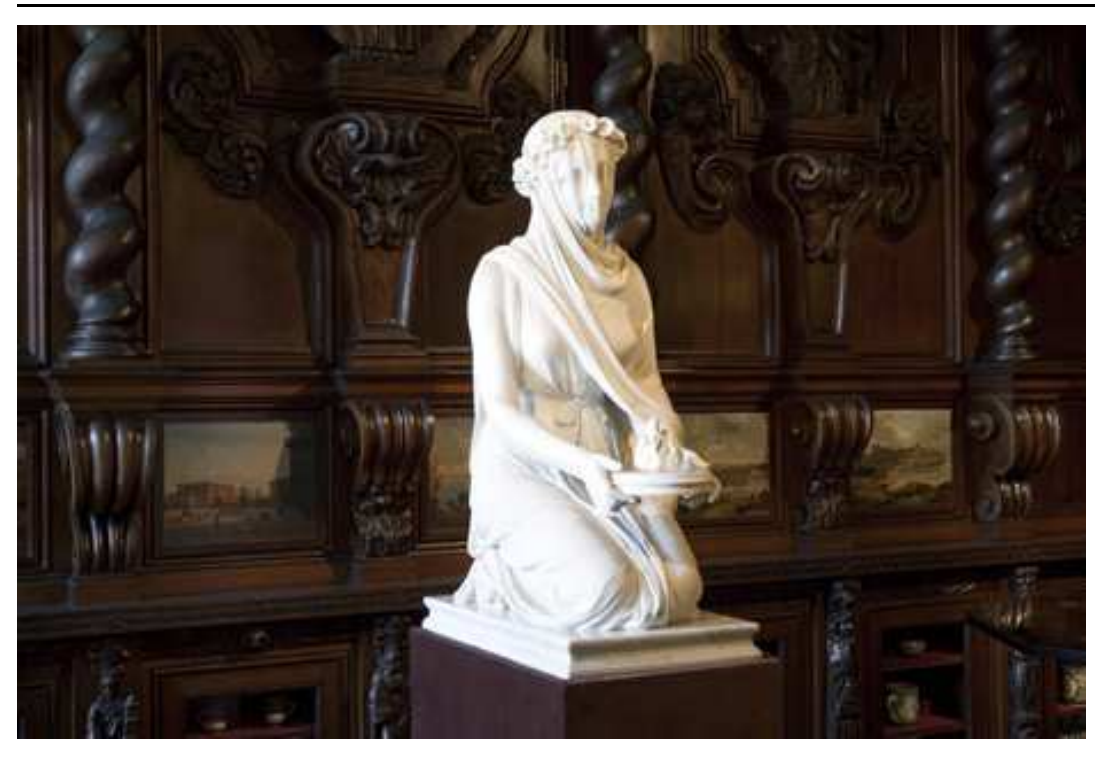

Figure 5. Raffaelle Monti's The Vestal Virgin (1846). Photograph from Chatsworth Devonshire Collection Online. (Web).

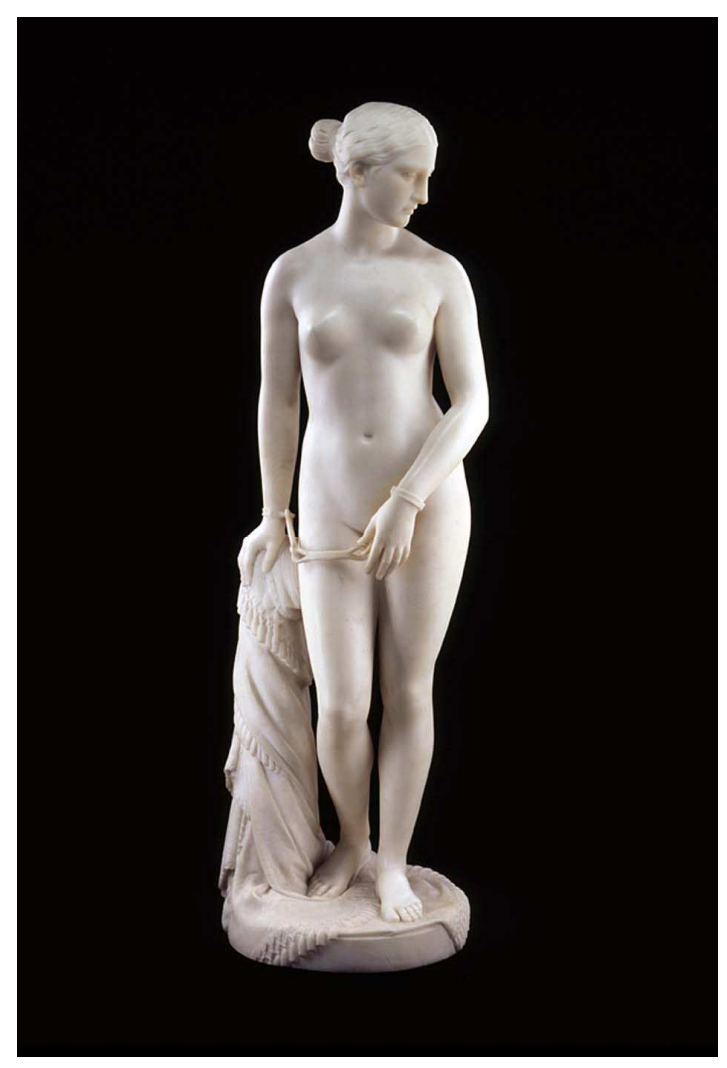

Figure 6. Hiram Powers's The Greek Slave (1873). Photograph from Smithsonian American Art Museum. (Renwick Gallery Catalogue; Web). 


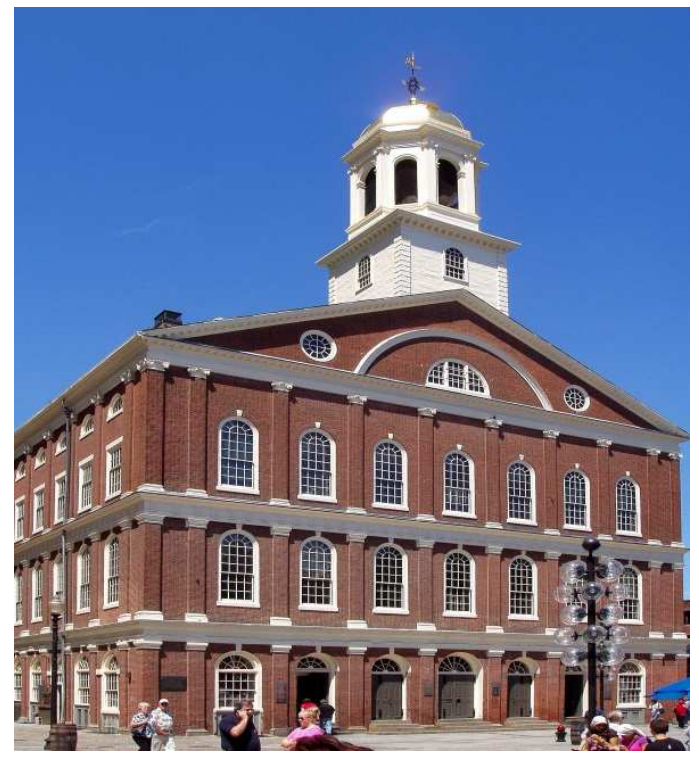

Figure 7. Contemporary image of Faneuil Hall's east side, Boston, MA.

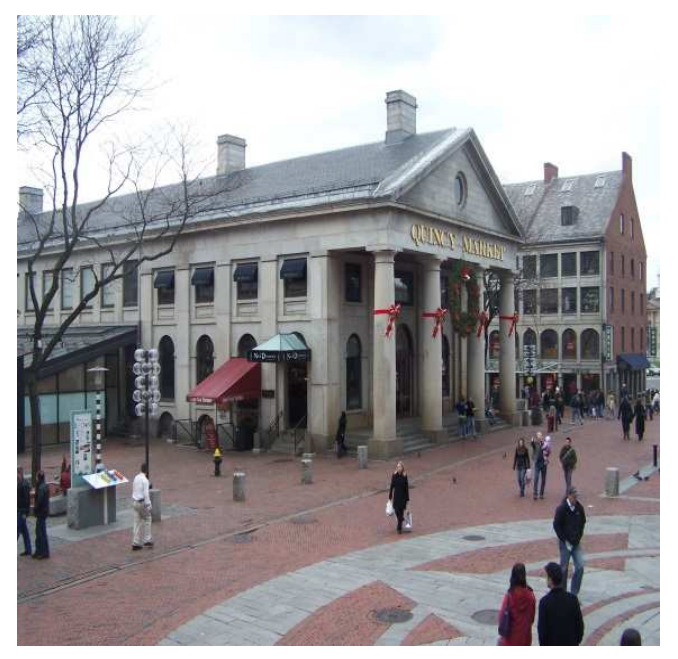

Figure 8. Contemporary image of Quincy Market, Boston, MA. 

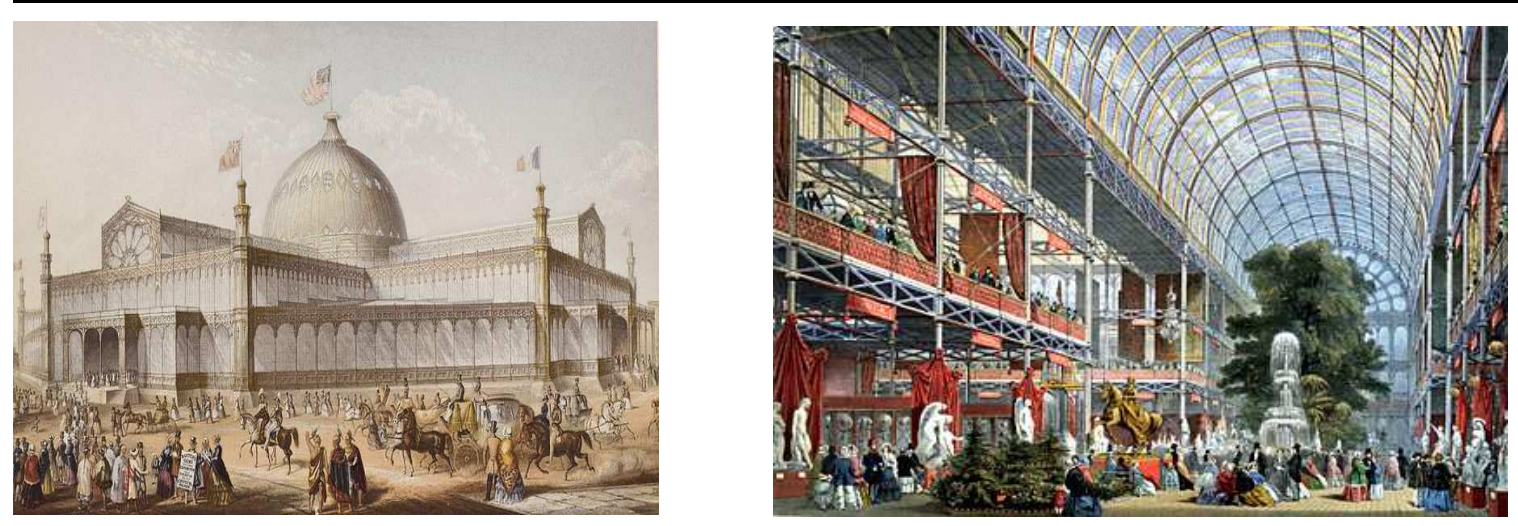

Figure 9. Exterior view of New York Crystal Palace (Oil-color plate by George Baxter; 1

September 1853; Web) and interior view of Joseph Paxton's “Crystal Palace” in London

(Drafted by J. McNeven; Ackermann \& Co. Publishing, 1851; Web).

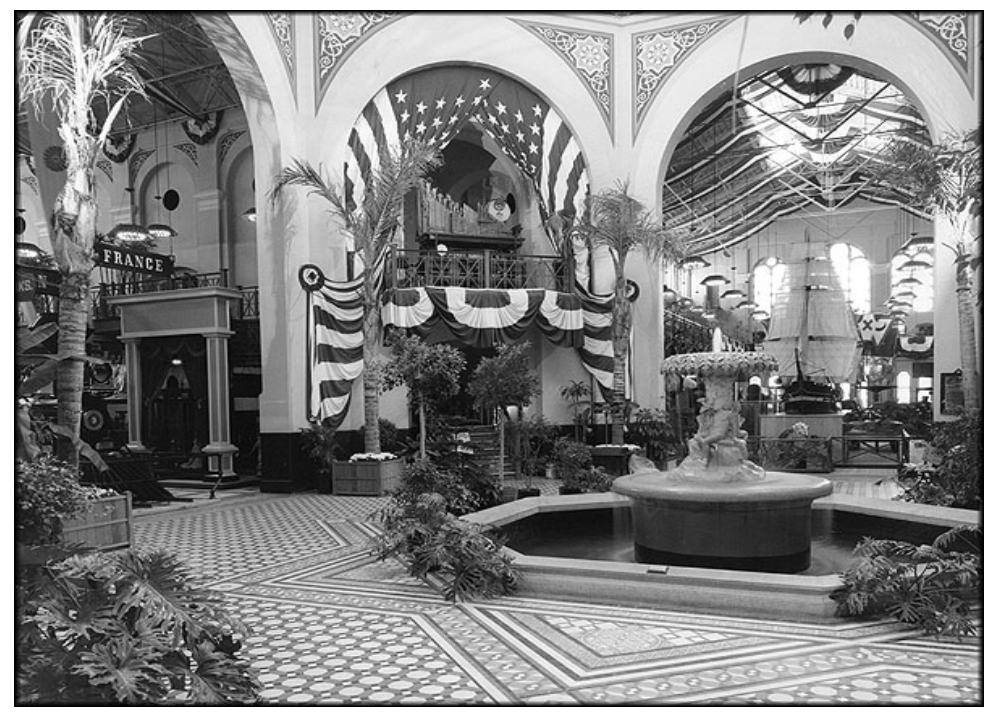

Figure 10. Interior replica of the Centennial Exhibition Arts \& Industry Building. (Smithsonian Institution Archives photograph; “1876: A Centennial Exposition”; 10 May 1976; Web). 


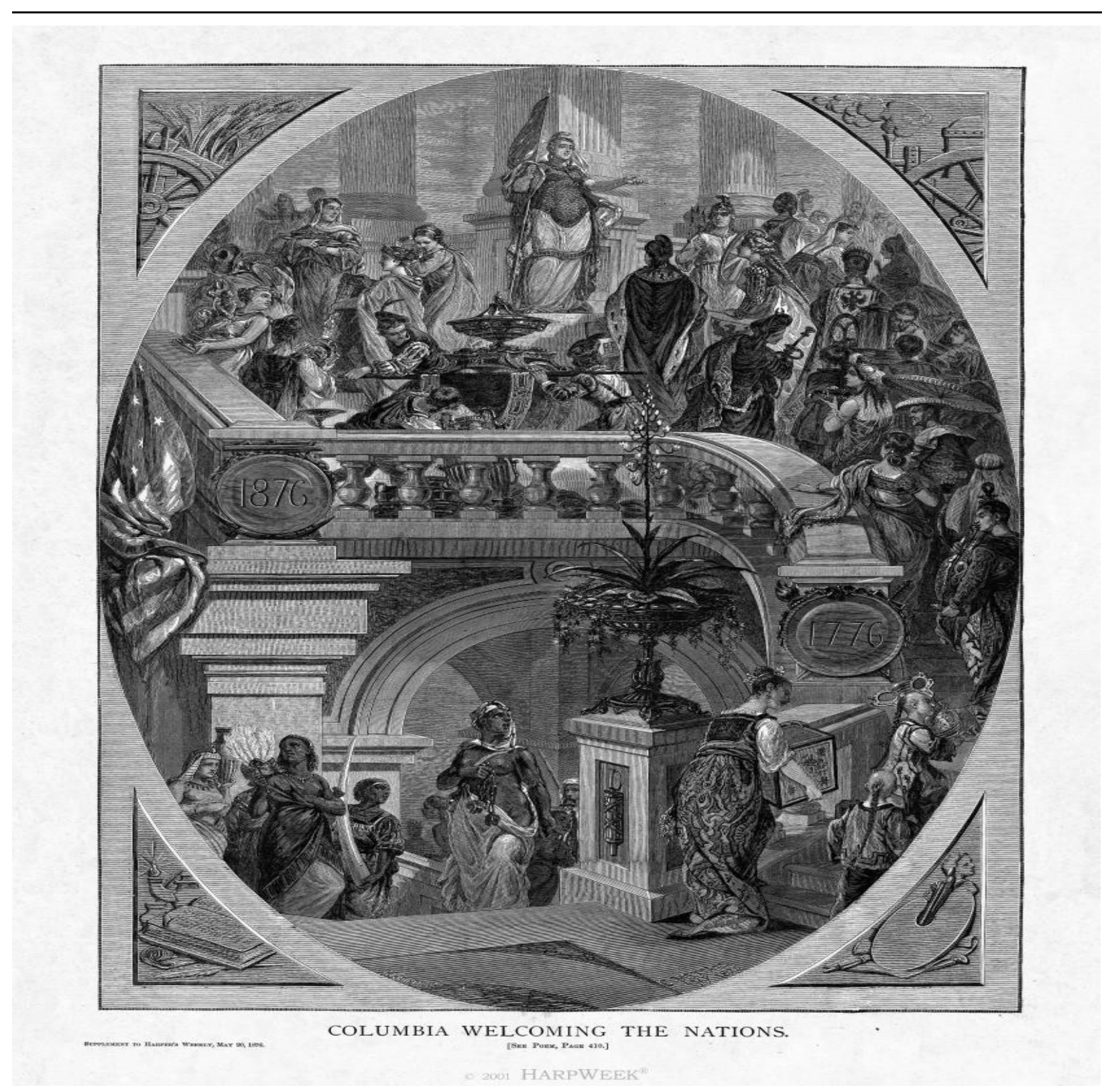

Figure 11. Image entitled "Columbia Welcoming the Nations," from the May 20, 1876 edition of Harper's Weekly. 


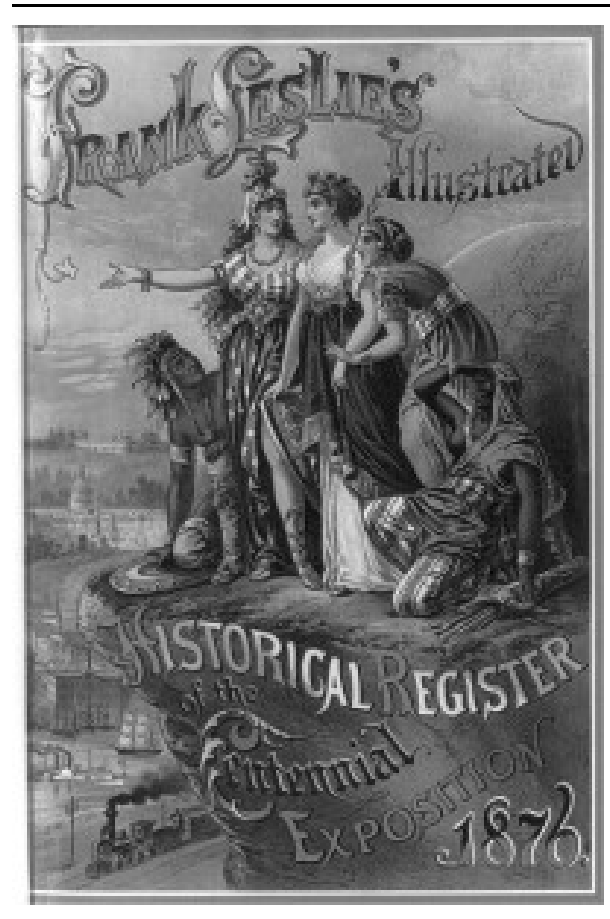

Figure 12. Cover image of Frank Leslie's Illustrated Historical Register of the Centennial Exposition, 1876. (Library of Congress; Prints and Photographs Online Catalogue; Web).

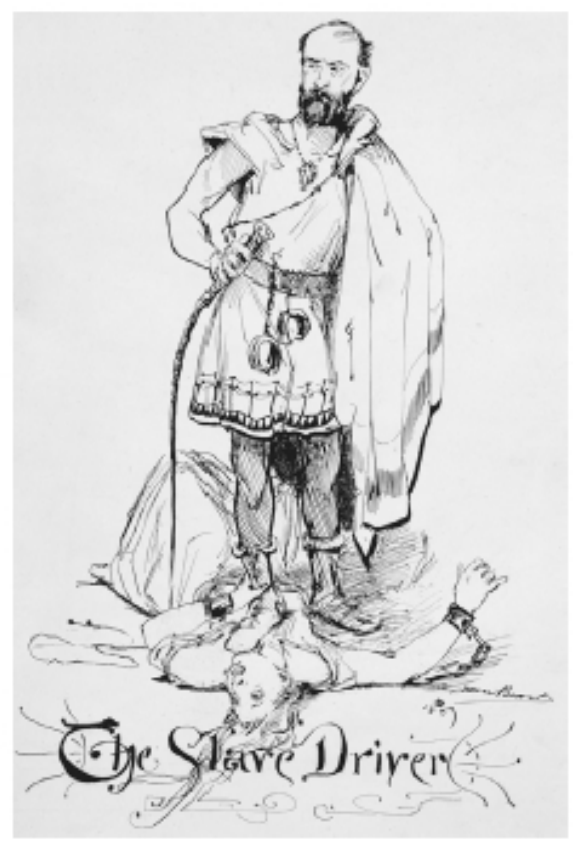

Figure 13. Daniel Carter Beard's illustration of “The Slave Driver” from Mark Twain's Connecticut Yankee. (Illustration Scanned from A Connecticut Yankee in King Arthur's Court; Allison R. Ensor, editor; New York: W.W. Norton \& Company, 1982). 


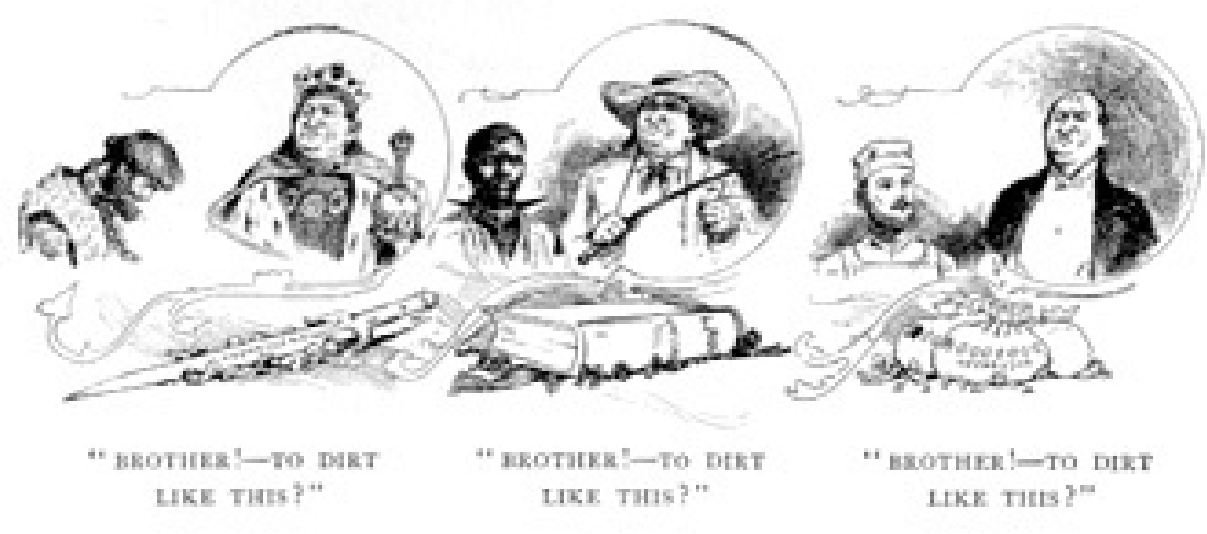

Figure 14. Daniel Carter Beard's illustration of "Brother!—-To Dirt Like This?" from Mark Twain's Connecticut Yankee. (Illustration Scanned from A Connecticut Yankee in King Arthur's Court; Allison R. Ensor, editor; New York: W.W. Norton \& Company, 1982).

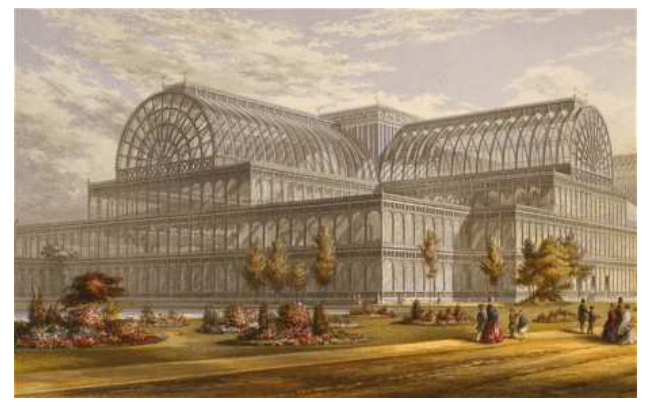

Figure 15. George Baxter's rendering of the exterior of London's Crystal Palace titled "Gems of the Crystal Palace, Sydenham. No. 1.” (Harvard Art Museums/Fogg Museum; Web). 


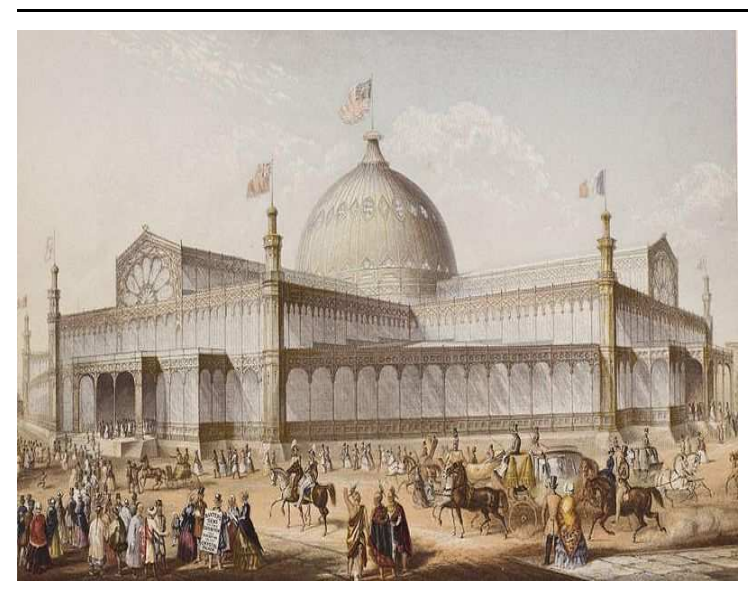

Figure 16. Exterior view of New York Crystal Palace (Oil-color plate by George Baxter; 1

September 1853; Web)

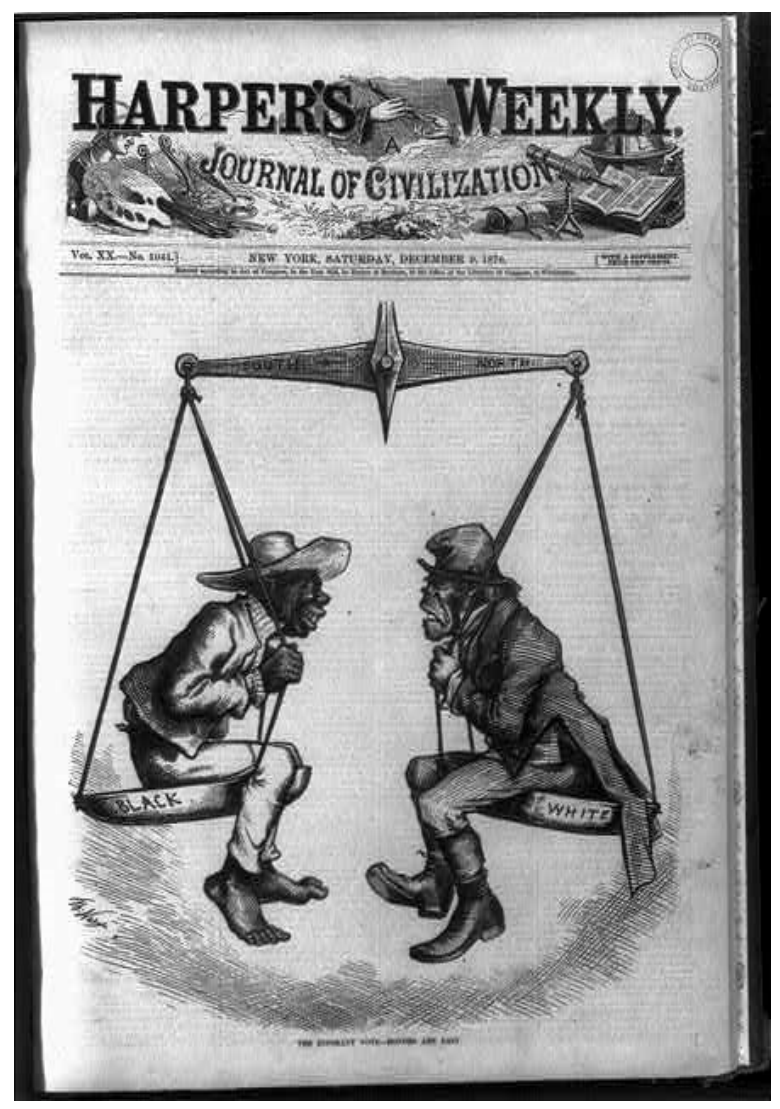

Figure 17. Thomas J. Nast's illustration of "The Ignorant Vote" published in Harper's Weekly on December 9, 1876. 


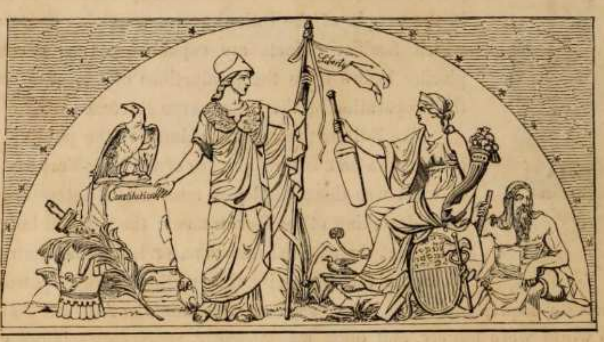

Figure 18. Columbia as frontispiece of The World of Science, Art \& Industry Illustrated from Examples In the New York Exhibition, New York: G.P. Putnam, 1854.

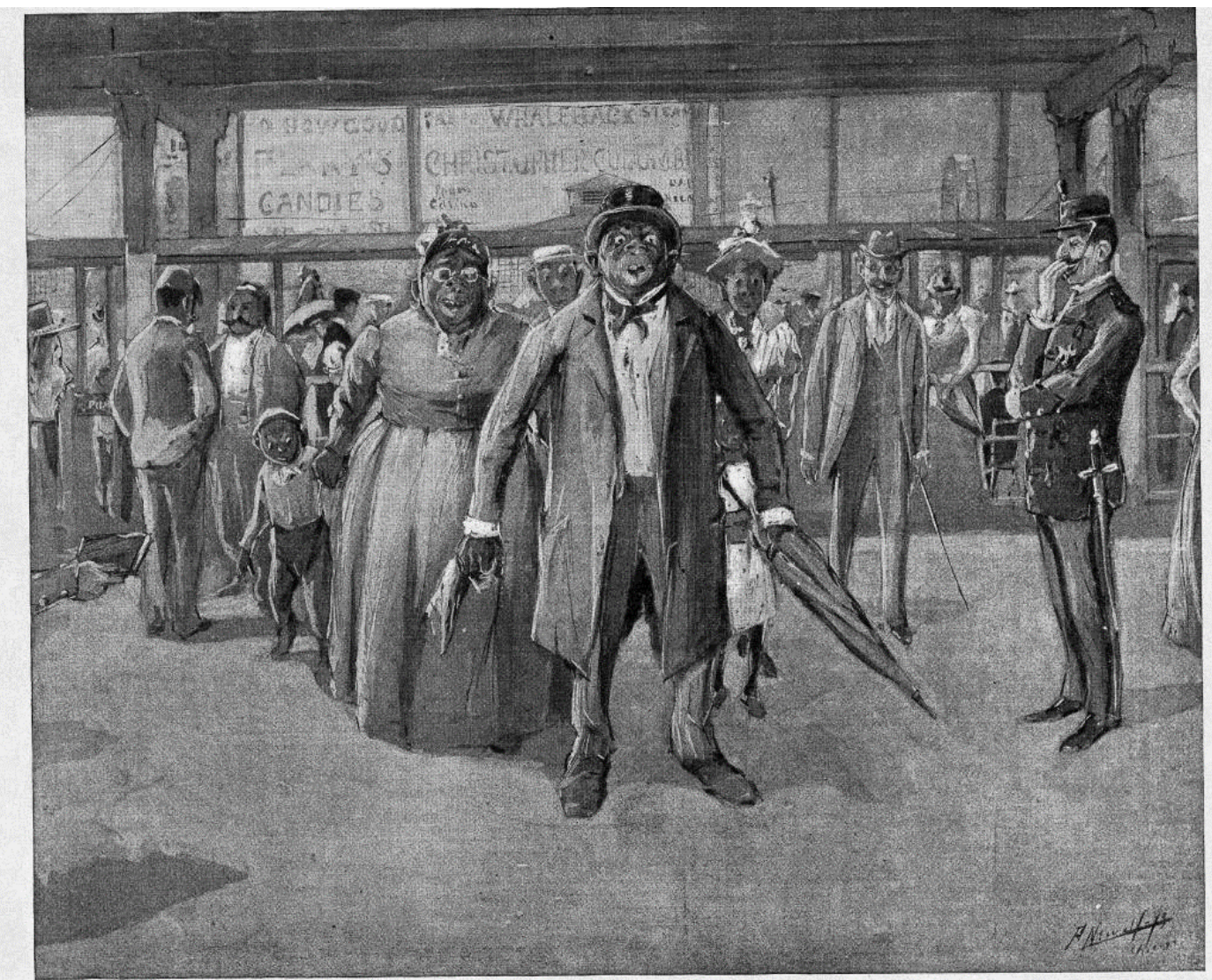

THE JOHNSON FAMULY VISIT THE GREAT WHITE CITY.

PATERfamilias (entering the gate at the head of the procession). "Great Lax', Gloriah ! I'd a giben dat spotred Mule ob mine for DE CONTRAO OB WHTEWASHIN' DIS YER PLACE!'

Figure 19. One of a series of recurrent caricatures of the black "Johnson family" at the

Columbian Exposition published by Harper's Weekly. This appeared in the periodical on July

$15,1893$. 


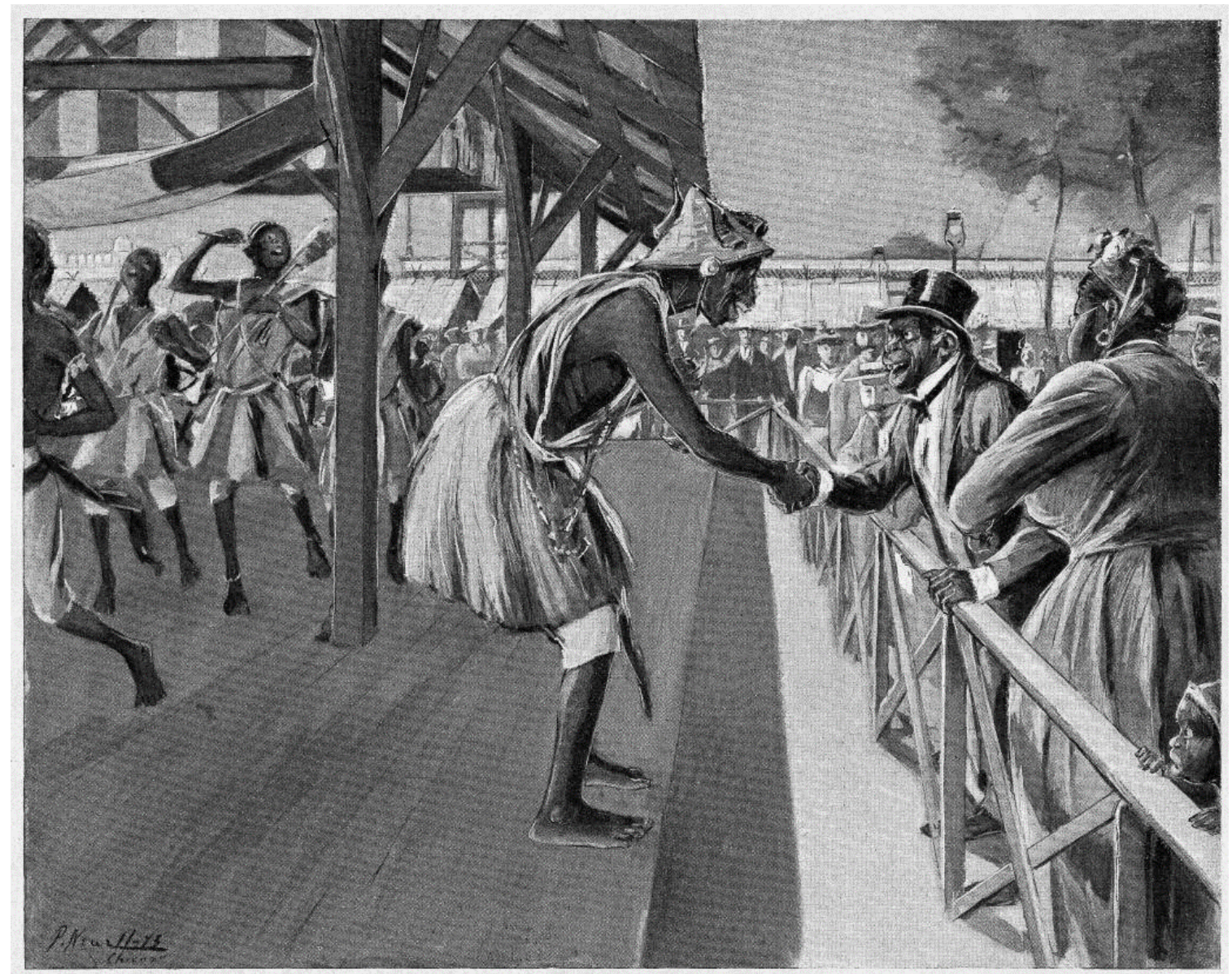

THE JOHNSON FAMILY VISIT THE DAHOMAN VILLAGE.

MRs. Johnson. “Ezwell Jomnson, stor shakin' Han's wid dat Heathen! You want de huli Fatr ter t'ink you's found a Poo' Relation ?"

Figure 20. Figure 19. Another representation of "The Johnson Family" at the Columbian

Exposition published in Harper's Weekly, August 19, 1893. 


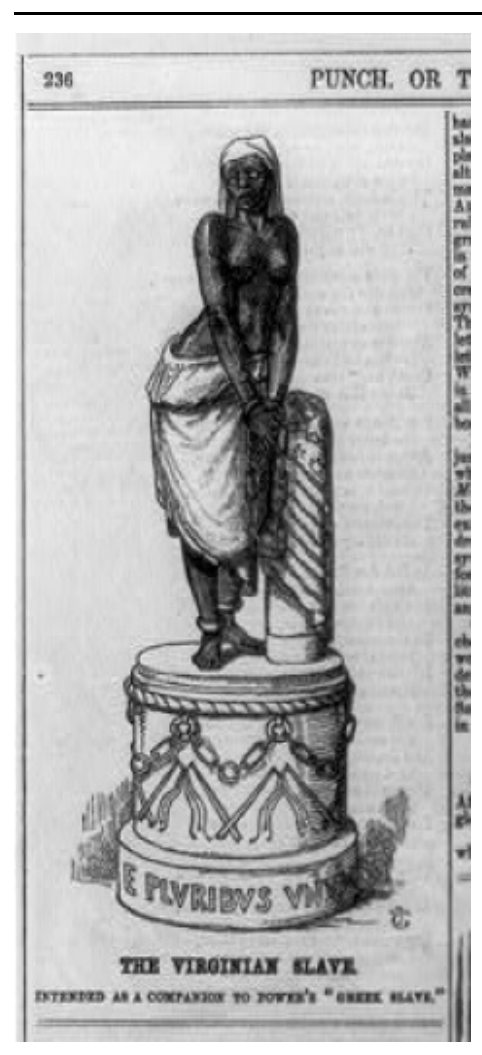

Figure 21. "The Virginian Slave" from Punch Magazine. Published during the Great Exposition of 1851 .

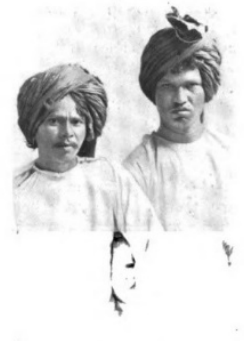

Hisnoos.

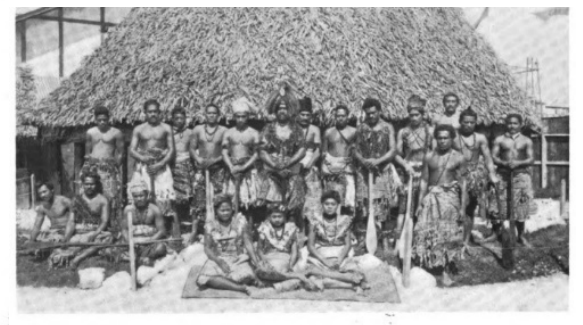

A GROUP OF SOUTH-SEA ISLANDERS.

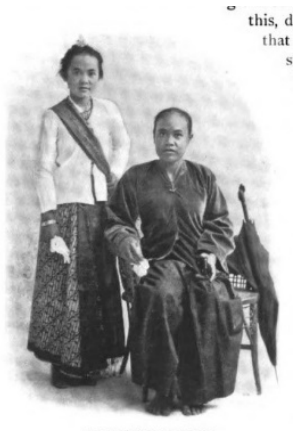

JAVANESE WOMEN.

Figures $22-24$. A selection of images accompanying Charles Mulford Robinson's essay “The Fair as a Spectacle," published in Rossiter Johnson's History of the World's Columbian Exposition held in Chicago in 1893 (New York: Appleton, 1897) 502, 504, 510. 


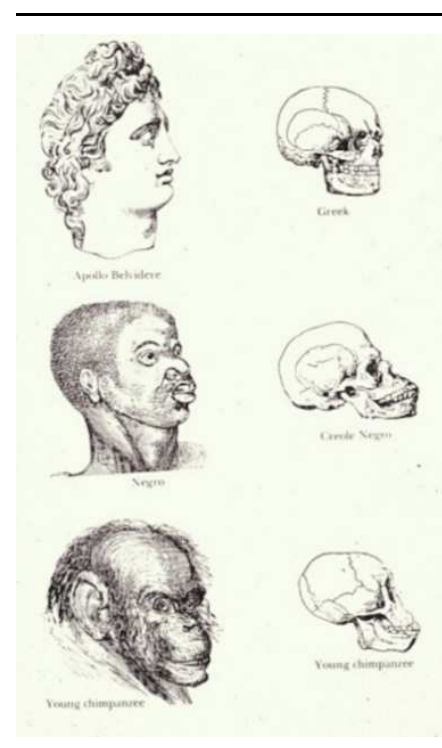

Figure 25. Illustrations from Josiah Clark Nott's and George R. Gliddon's The Indigenous Races of the Earth (Philadelphia: J.B. Lippencott, 1857).

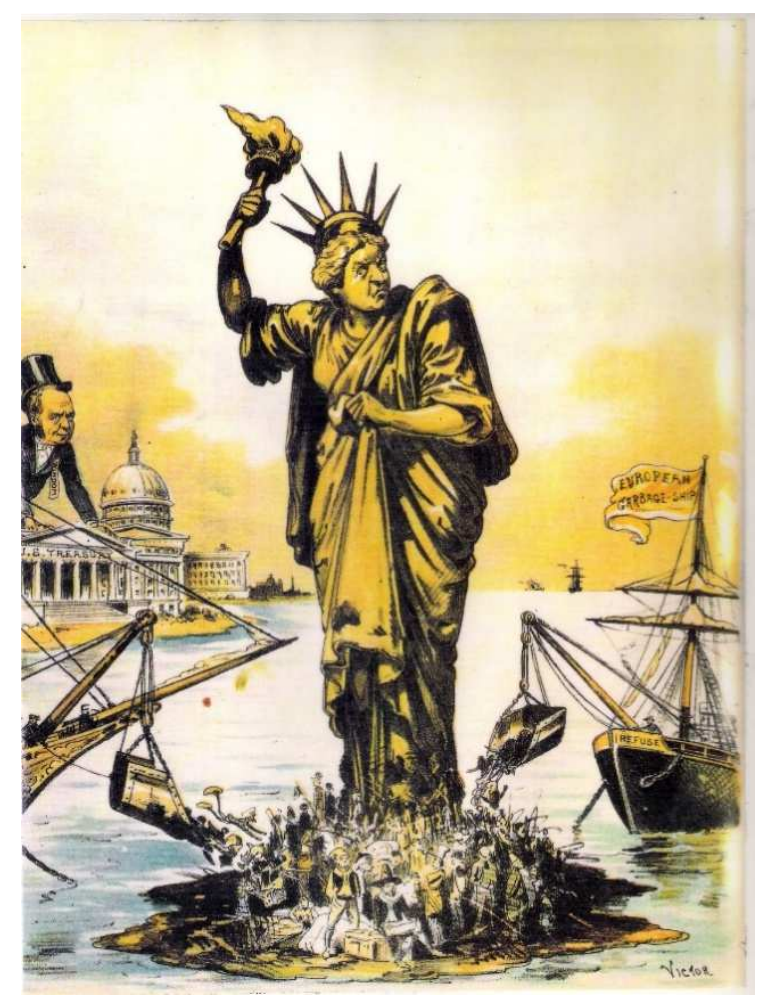

Figure 26. "Dumping European Garbage” published in Judge Magazine of March 22, 1890. 

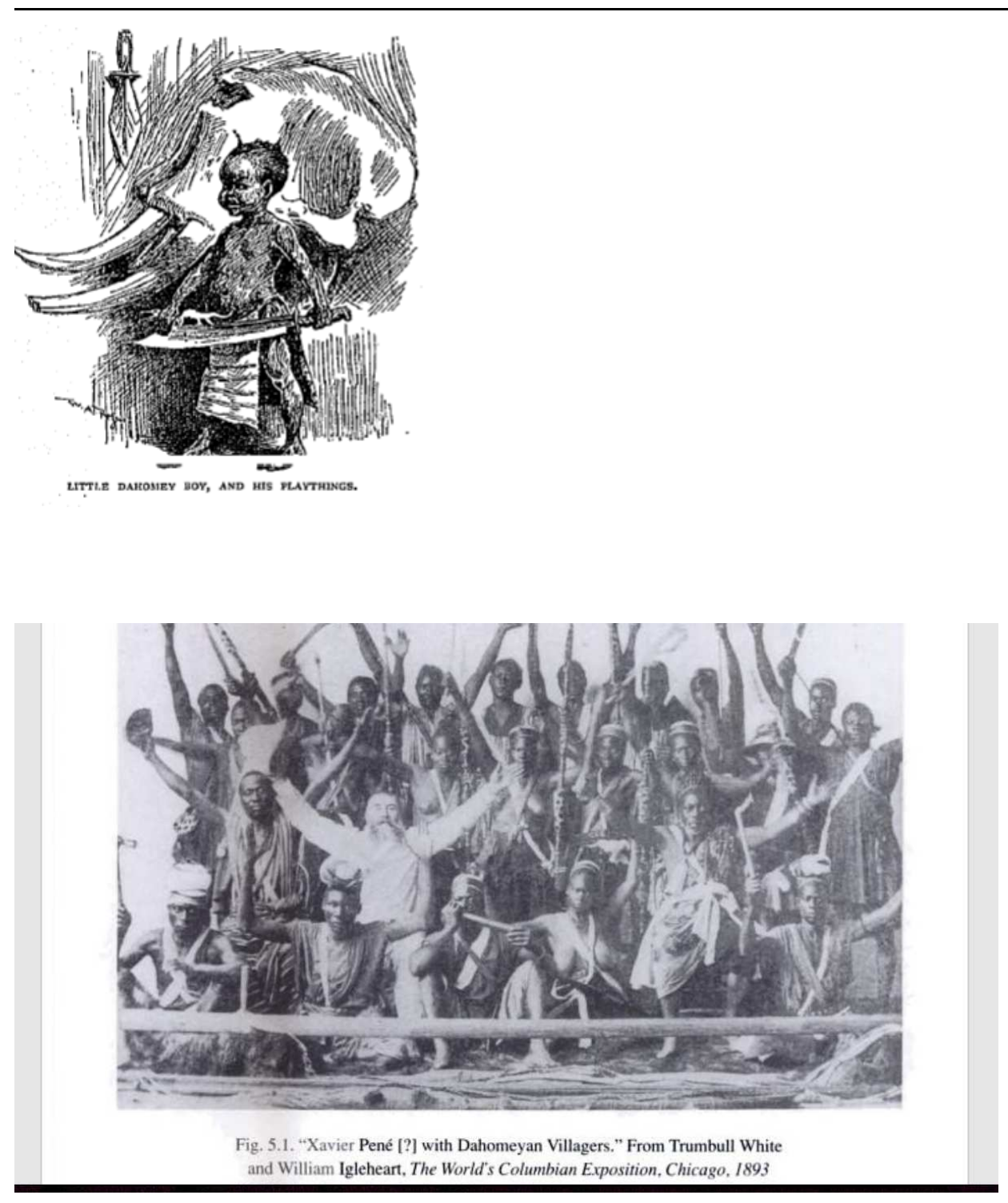

Figure 27. Typical representations of Dahomeyans, both from the World's Columbian Exposition, Chicago, 1893. The first is from Clara Doty Bates's "The Children of the Plaisance" for St. Nicholas magazine in November 1893 and the second is from Trumbull White and William Igleheart's The World's Columbian Exposition, Chicago, 1893 (Philadelphia: P.W. Ziegler \& Co., 1893; 581). 


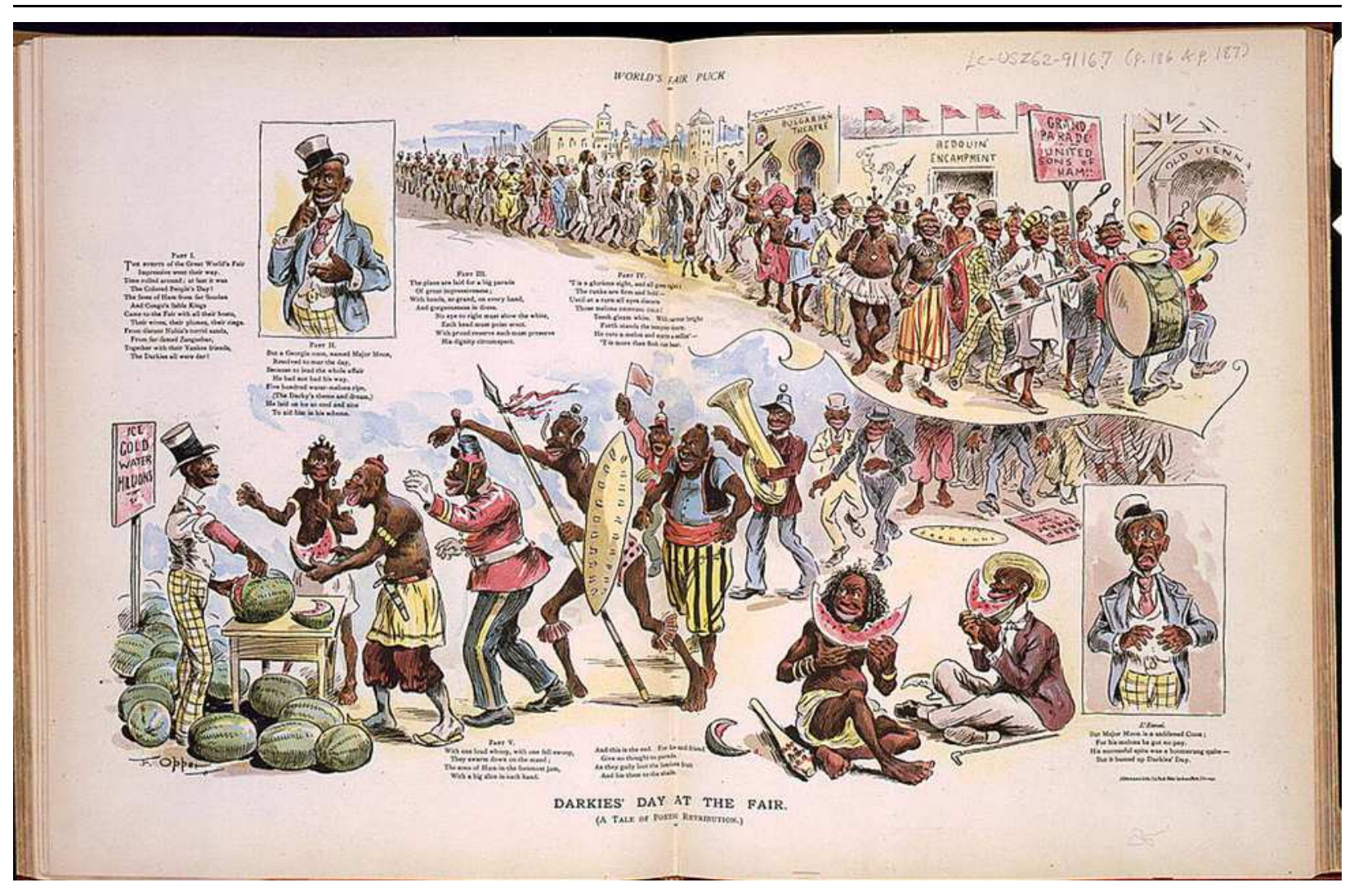

Figure 28. "Darkies' Day at the Fair" published in World's Fair Puck. (Prints and Photographs Division; Library of Congress; Web). 


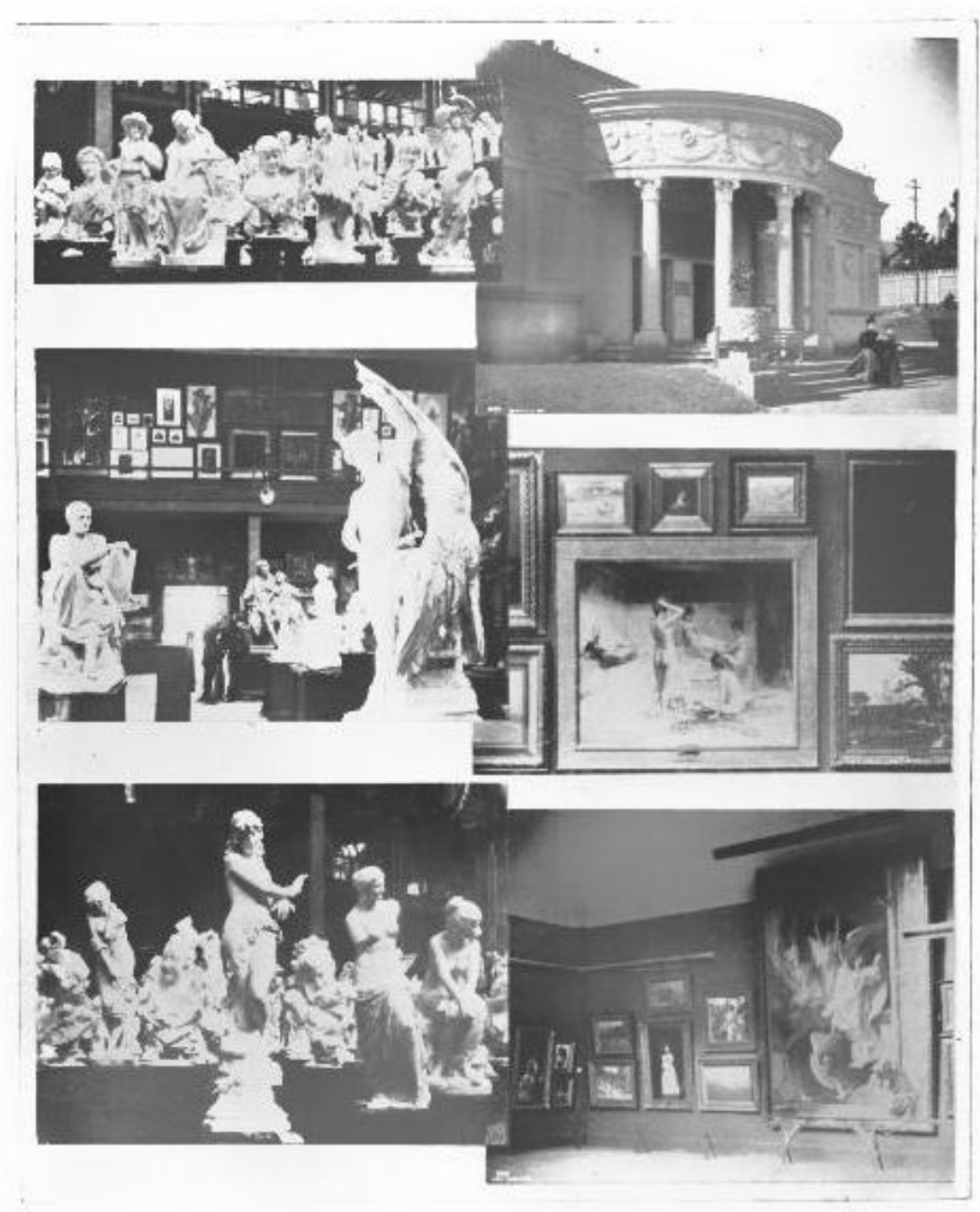

DROCP. FINB ARTS, MXNT'FACTCRES ANZ J.BRRAL ARTS, ETC

Figure 29. Fine Arts Building images from Official History. Image scanned from John J. Flinn's Official Guide to the World's Columbian Exposition (Chicago: The Columbian Guide Company, 1893). 


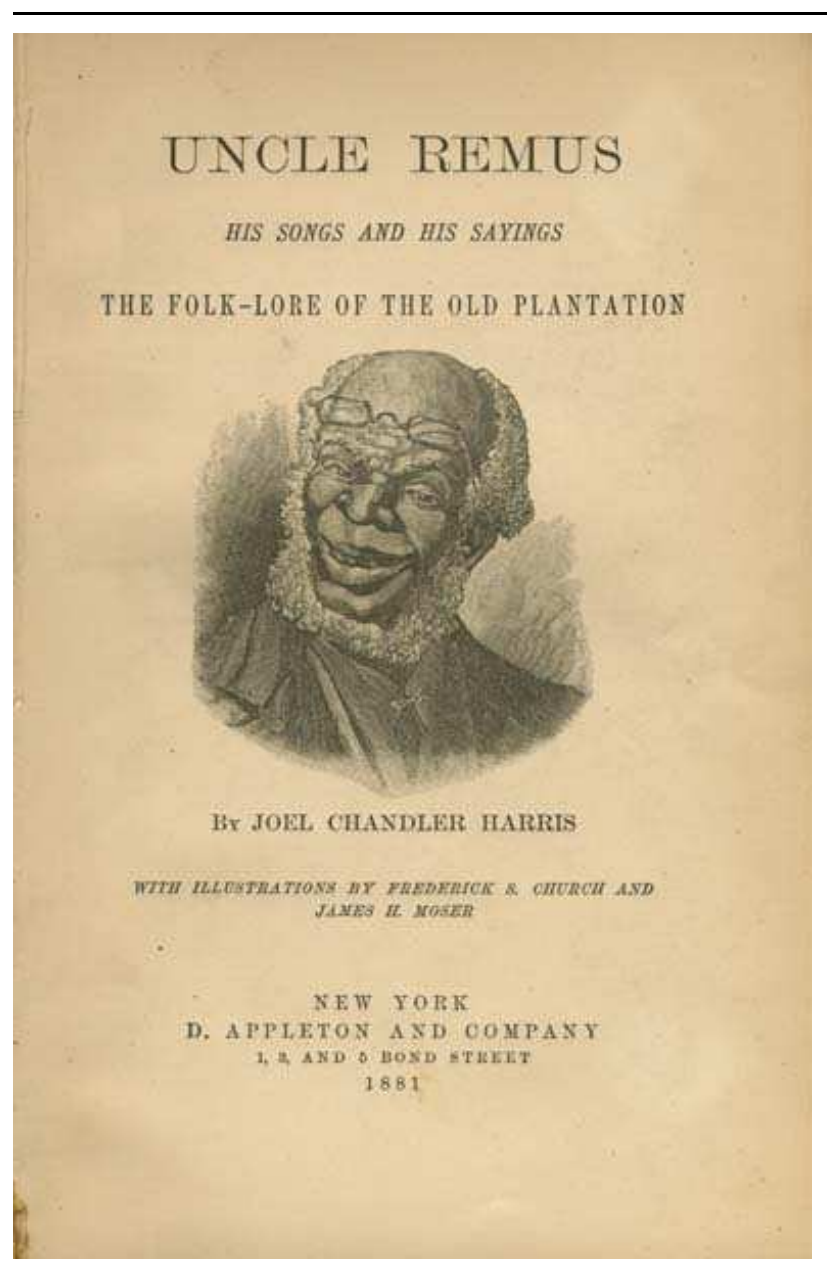

Figure 30. Title page image from Joel Chandler Harris's 1881 collection of Uncle Remus stories. 
132 The Story of a New York Howe.

half a minute the roar of the mob filled the strect with onc terrible howl and shriek of

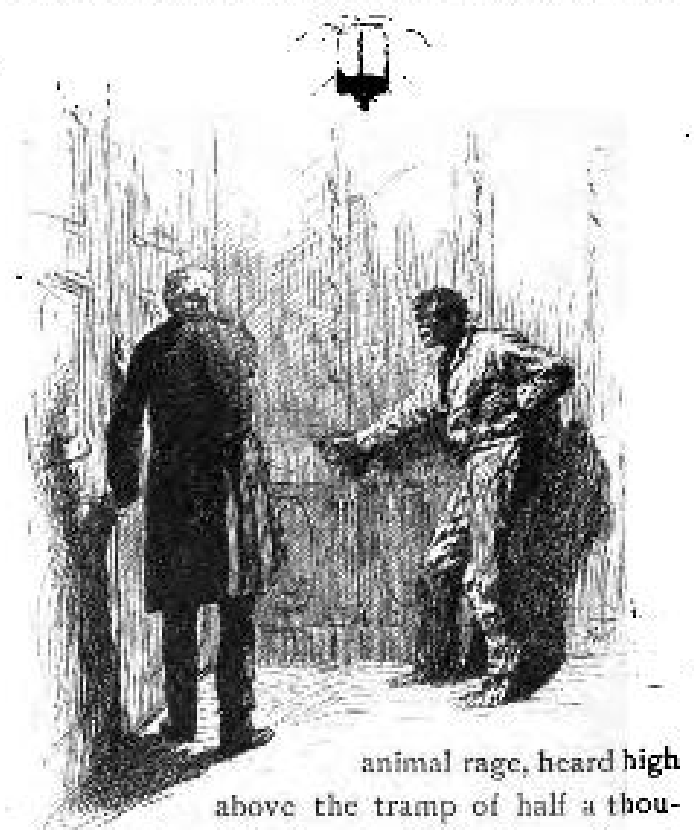
sand feet; and the beasts of disorder, gatherod from all the city's holes and dens of crime, wild for rapine and outrage, burst upon them, swceping up the steps, hammering at the

Figure 31. A.B. Frost's “The Negro Leaned Exhausted Against the Wall” as published illustration in “The Story of a New York House.” (New York: Scribner's, 1887). 


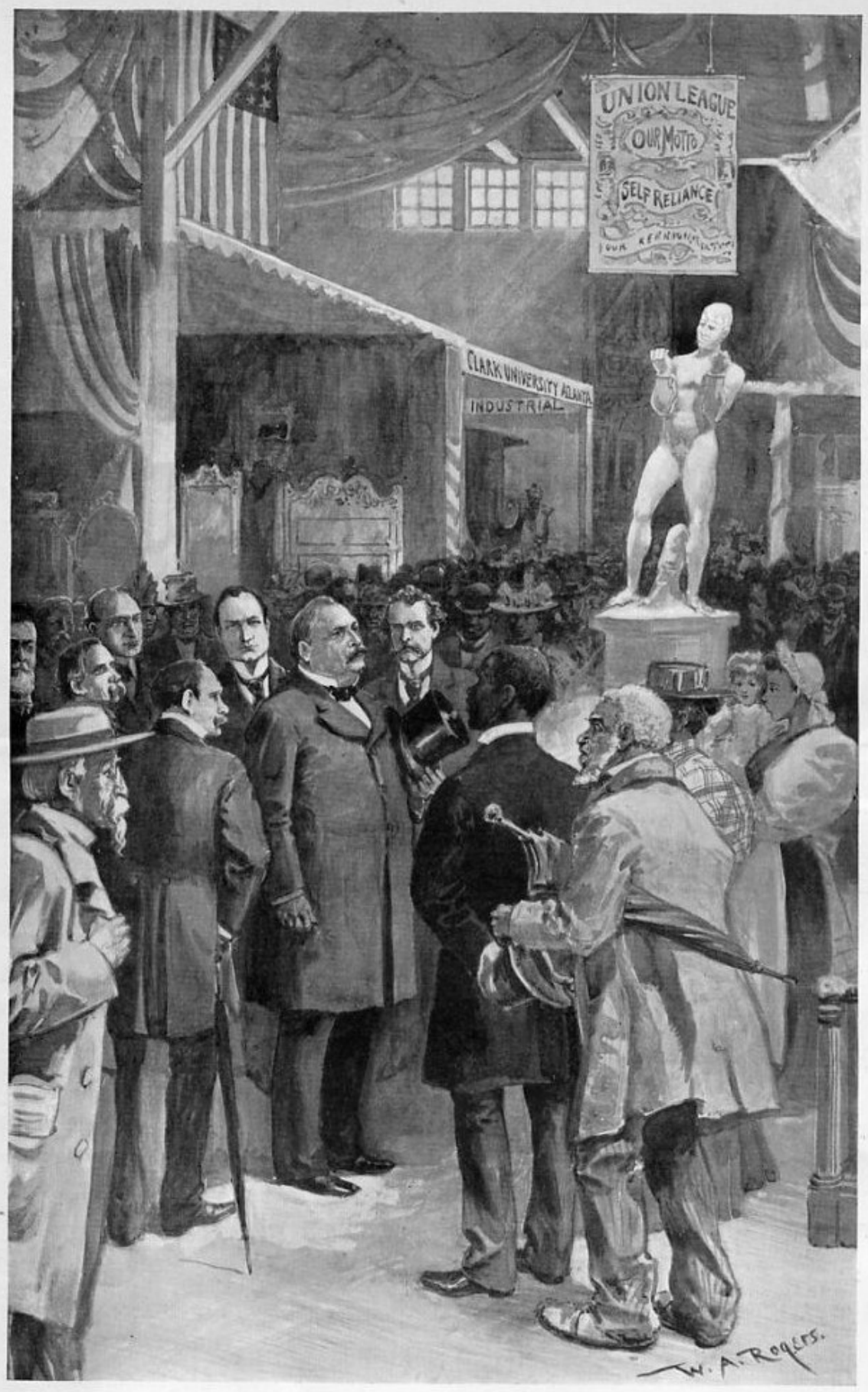

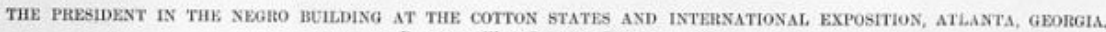
ias Paes legr.

Figure 32. W.A. Rogers's “The President Roosevelt in the Negro Building at the Cotton States and International Exposition, Atlanta, Georgia," published in Harper's Weekly, November 2, 1895. 


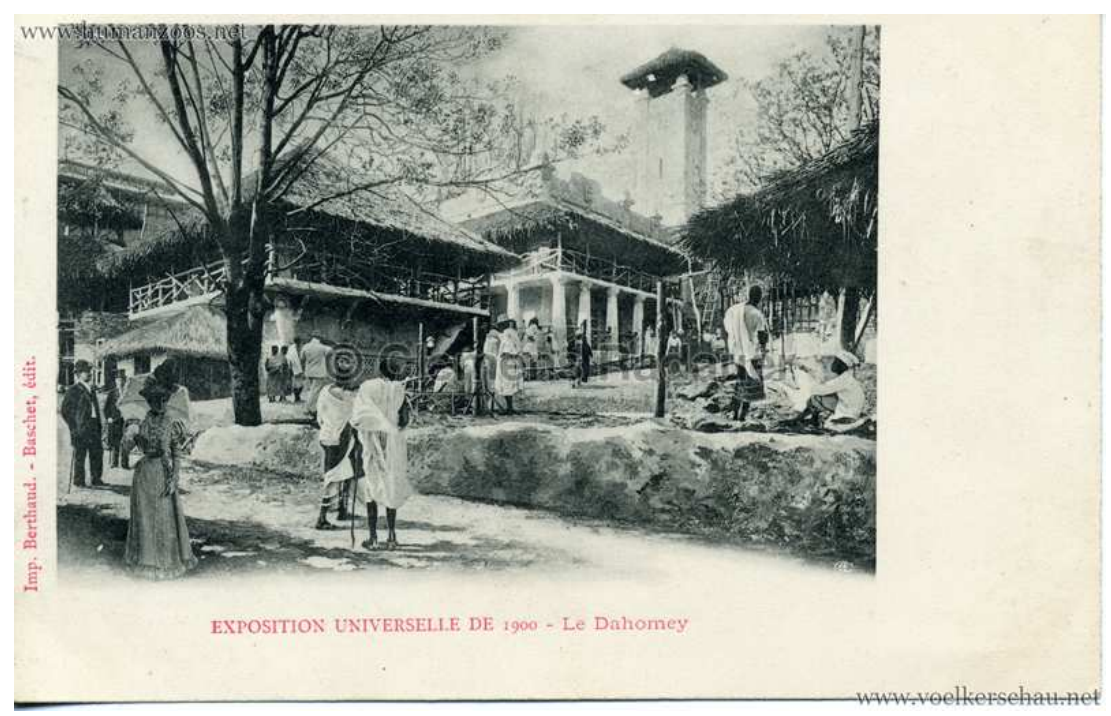

Figure 33. Photo of the Dahomeyan Village at the Paris Exposition Universelle, 1900.

(Illustration from the Collection Radauer; Online Archive of Human Zoos; Web.)

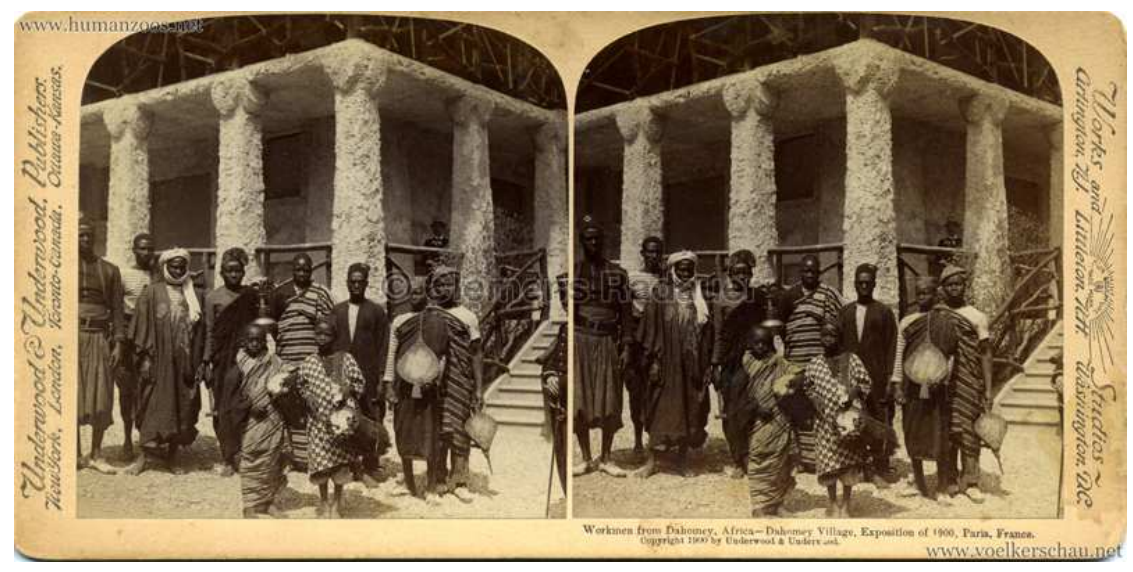

Figure 34. Group of Dahomeyan men and children at the Dahomey Village at the Paris Exposition Universelle, 1900. (Stereograph; New York: Underwood \& Underwood, 1900; Web.) 


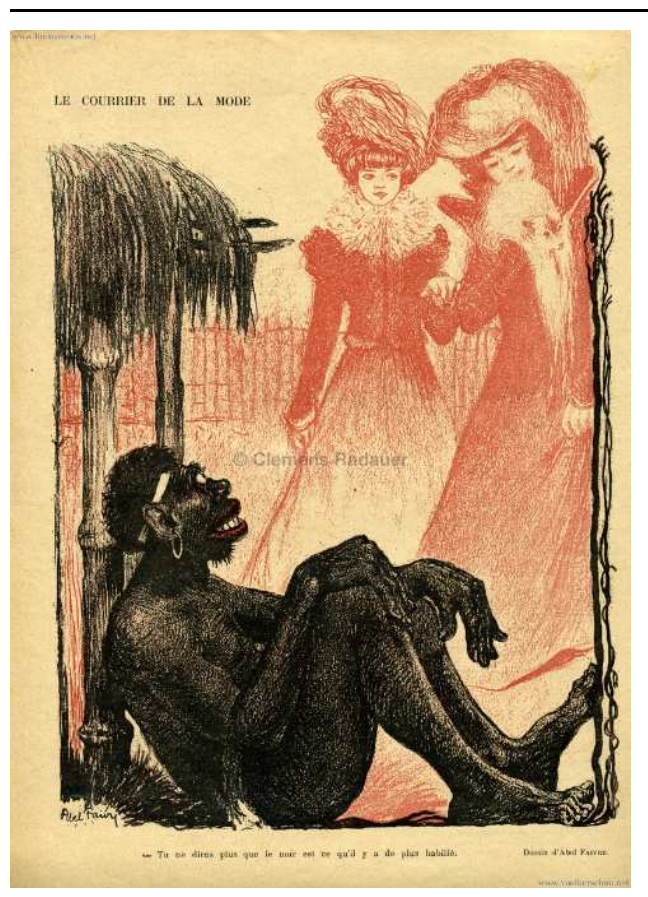

Figure 35. Caricature of African in La Rire magazine published during the Exposition Universelle, 1900. (Illustration from the Collection Radauer; Online Archive of Human Zoos; Web.)

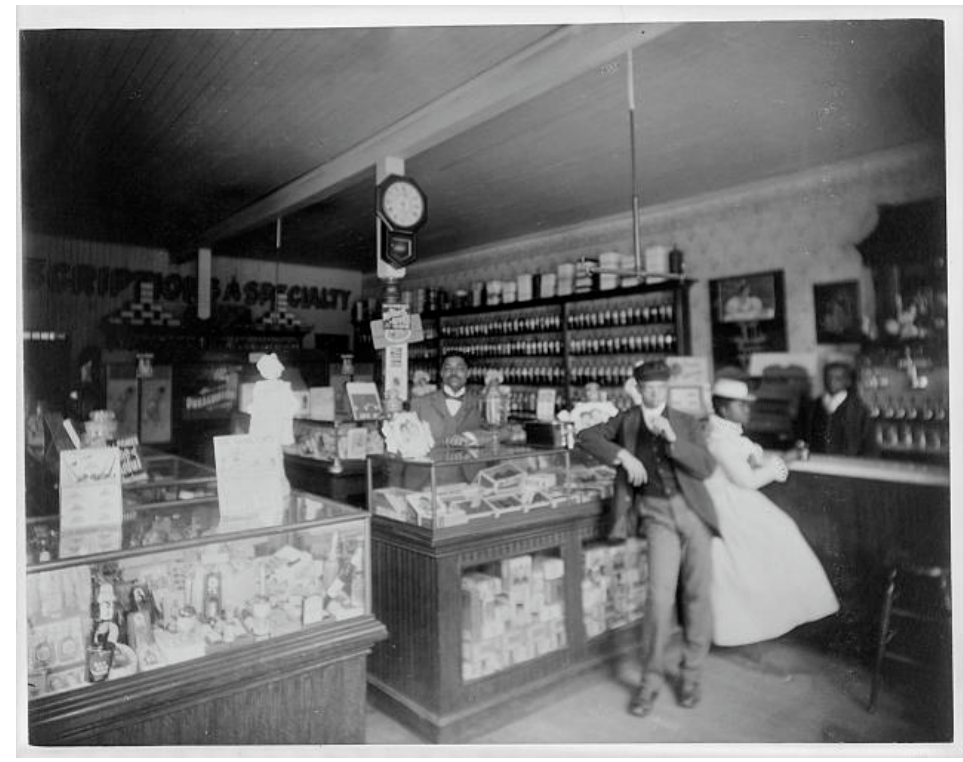

Figure 36. Photographer Thomas E. Askew's photo titled "Mr. Dougald's Drug Store" and collected by W.E.B. Du Bois for the Exhibition of the American Negro at the Paris Universelle. (Library of Congress; Web). 


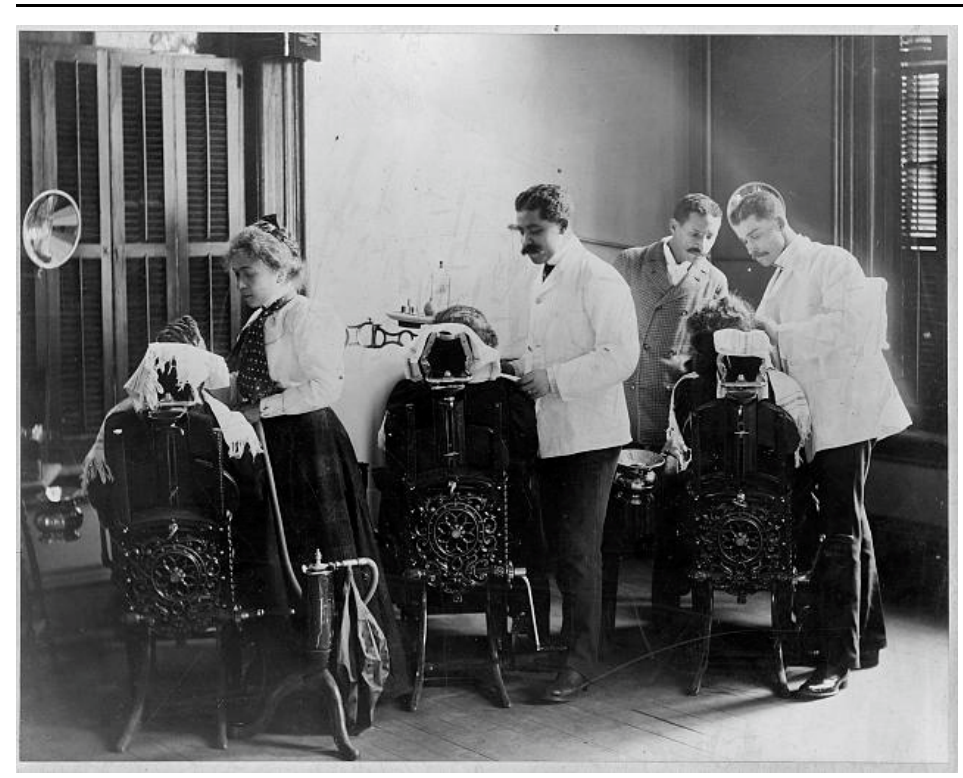

Figure 37. Photographer Thomas E. Askew's photo titled "Dentistry at Howard University" and collected by W.E.B. Du Bois for the Exhibition of the American Negro at the Paris Universelle. (Library of Congress; Web).

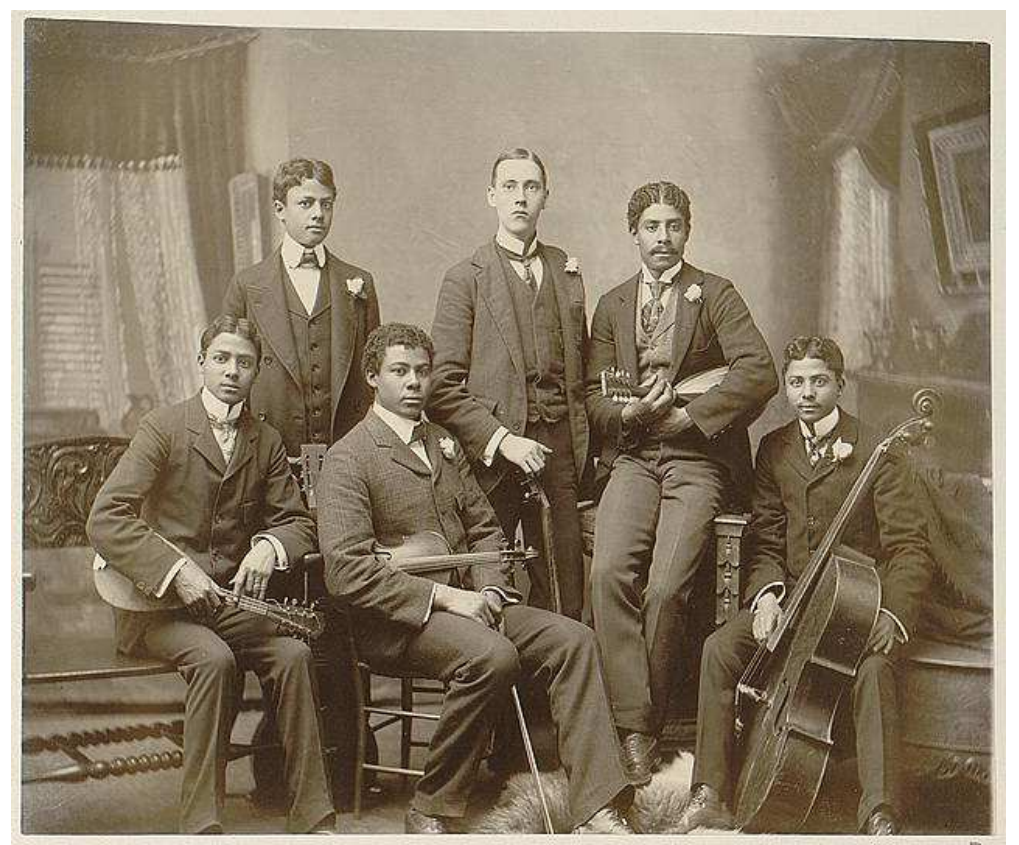

Figure 38. Photographer Thomas E. Askew's photo titled "Summit Avenue Ensemble" and collected by W.E.B. Du Bois for the Exhibition of the American Negro at the Paris Universelle. (Library of Congress; Web.) 


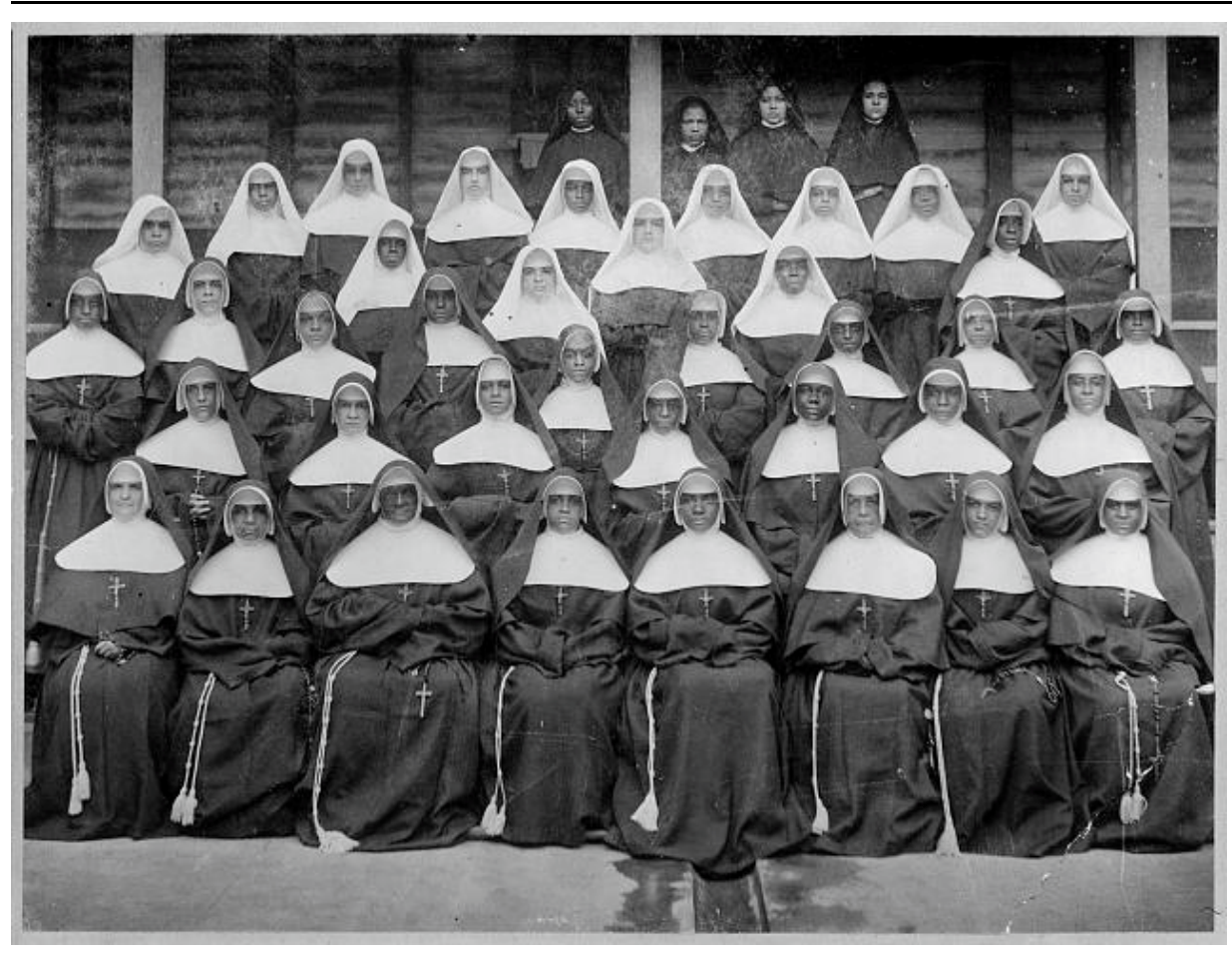

Figure 39. Photographer Thomas E. Askew's photo titled "Sisters of the Holy Family in New Orleans" and collected by W.E.B. Du Bois for the Exhibition of the American Negro at the Paris Universelle. (Library of Congress; Web). 


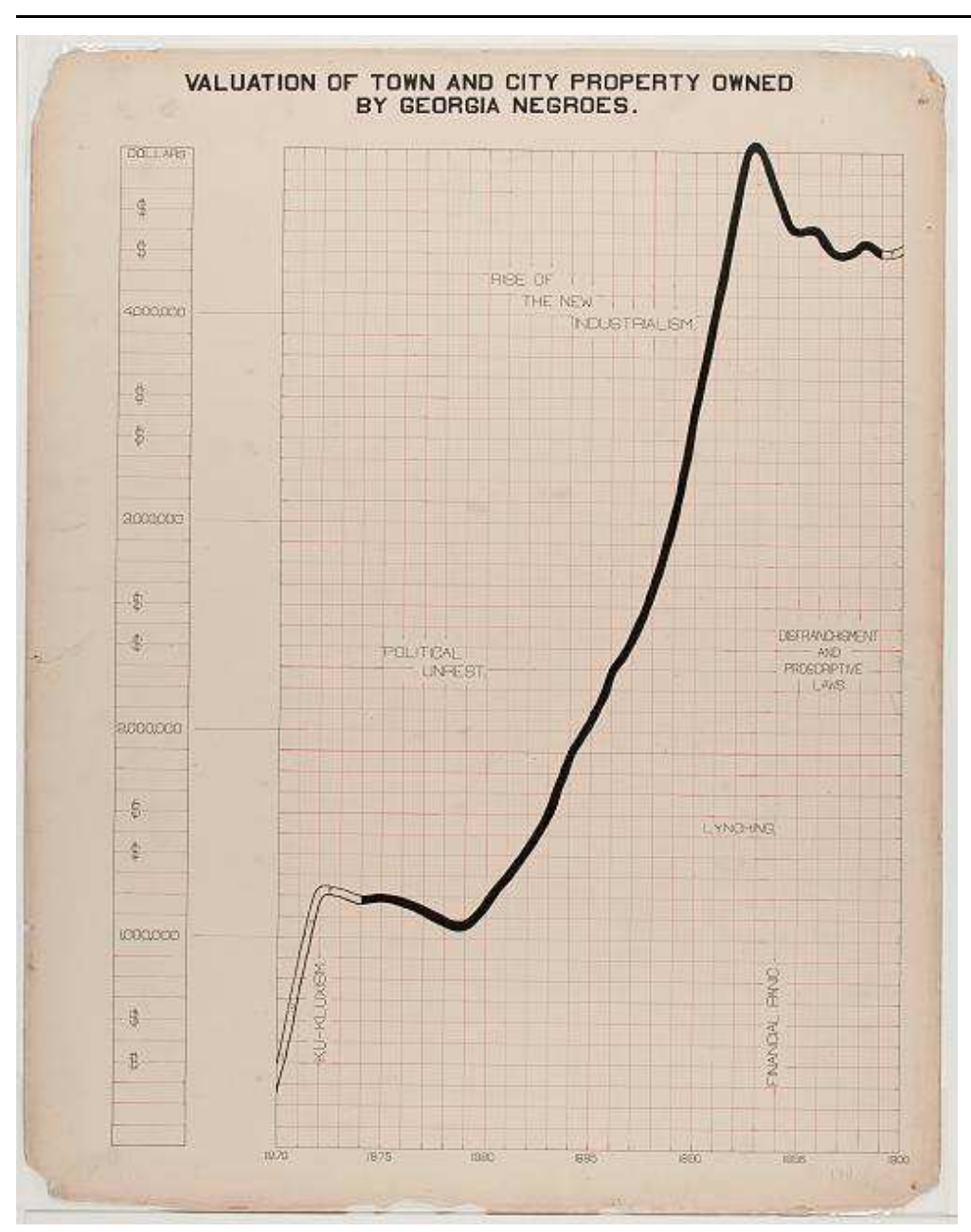

Figure 40. Graphic image on the valuation of property owned by Georgia negroes included as part of W.E.B. Du Bois's exhibit of The Georgia Negro at the Exhibition Universelle in Paris in 1900. (Library of Congress; Web). 


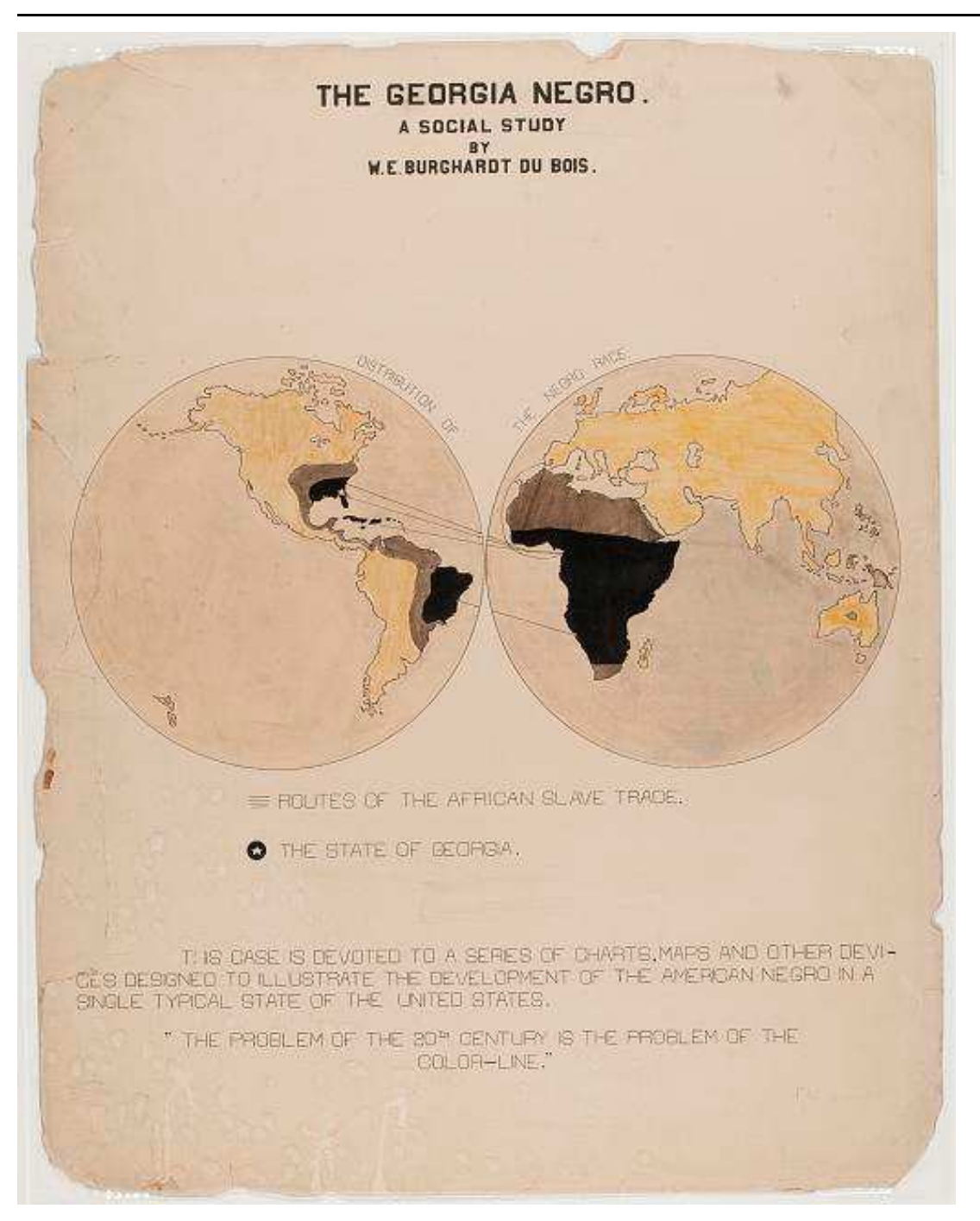

Figure 41. Title page from W.E.B. Du Bois's exhibit of The Georgia Negro at the Exhibition Universelle in Paris in 1900. (Library of Congress; Web). 


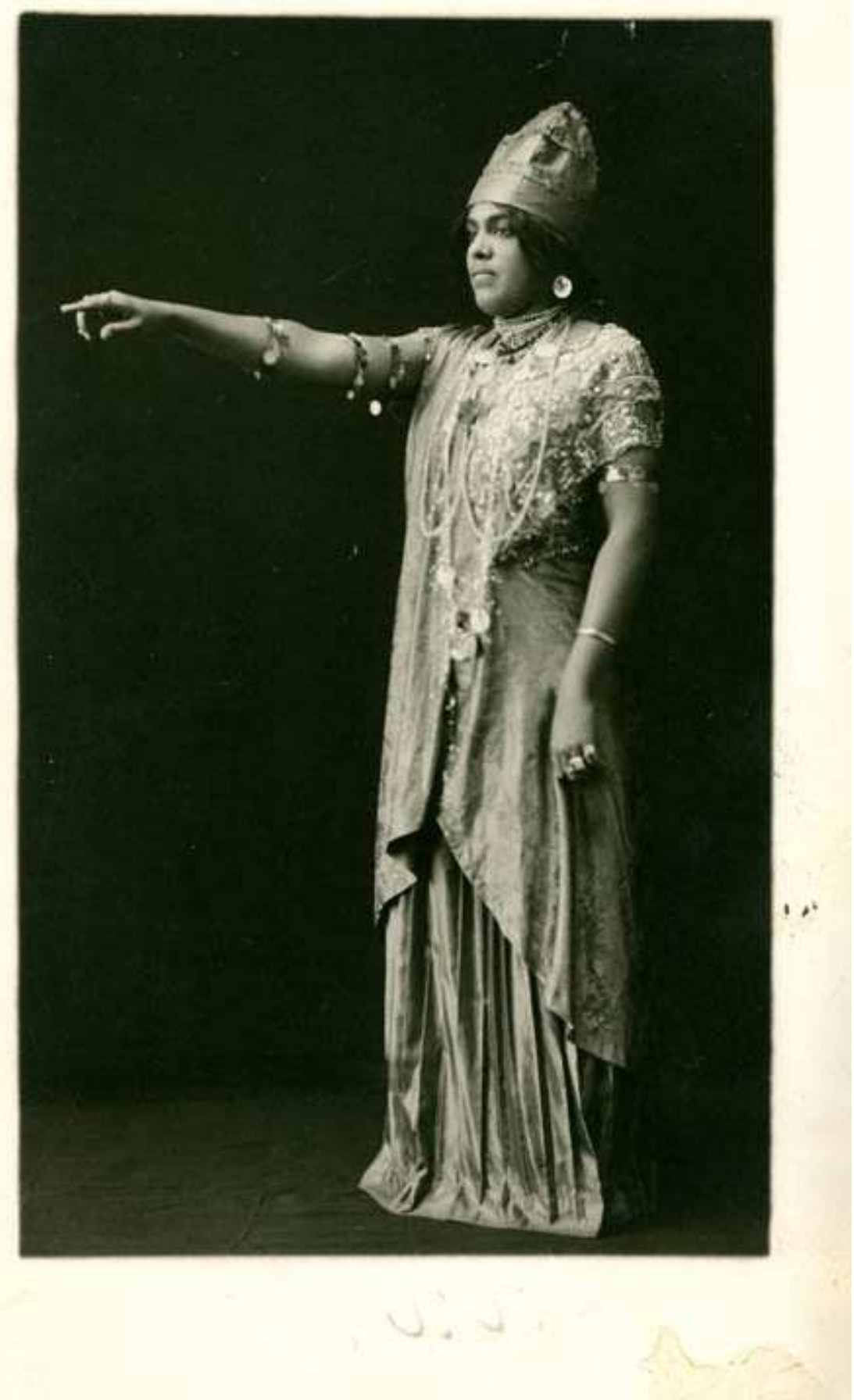

Figure 42. Still from W.E.B. Du Bois's Star of Ethopia pageant, image of "Ethiopia." (Library at UMass; "DuBoisopedia"; Web). 


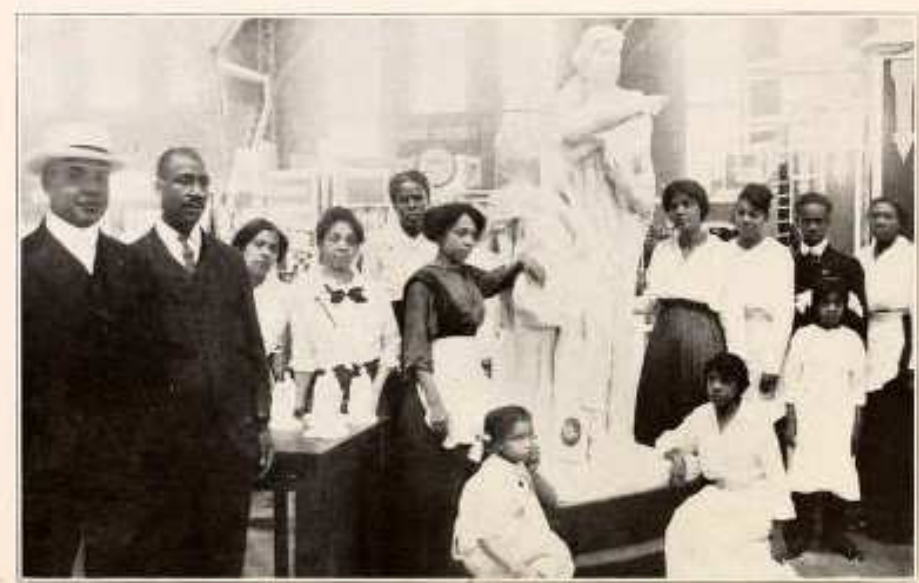

Awakenisg of Etriopta ax Faxnie M. Stout. Whot ts Leastng ox Statve.

Figure 43. Fannie M. Stout's Awakening of Ethiopia exhibited at the Lincoln Jubilee. Cropped image from John H. Ballard's Lincoln Jubilee Album: 50 th Anniversary of our Emancipation (Chicago: J.H. Ballard, 1915). 


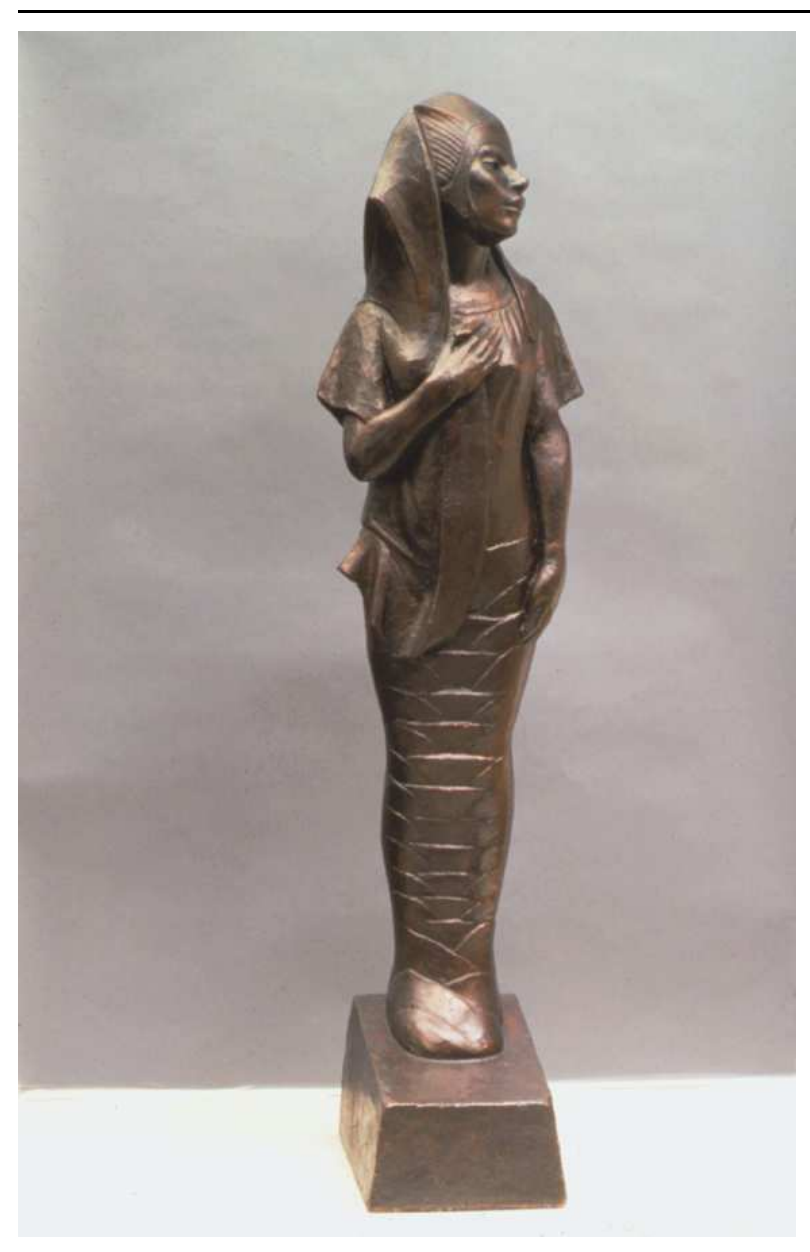

Figure 44. Meta Warrick Fuller's Ethiopia Awakening (1914). (Photograph of Scupture; Schomburg Center for Research in Black Culture; New York Public Library; Web.) 


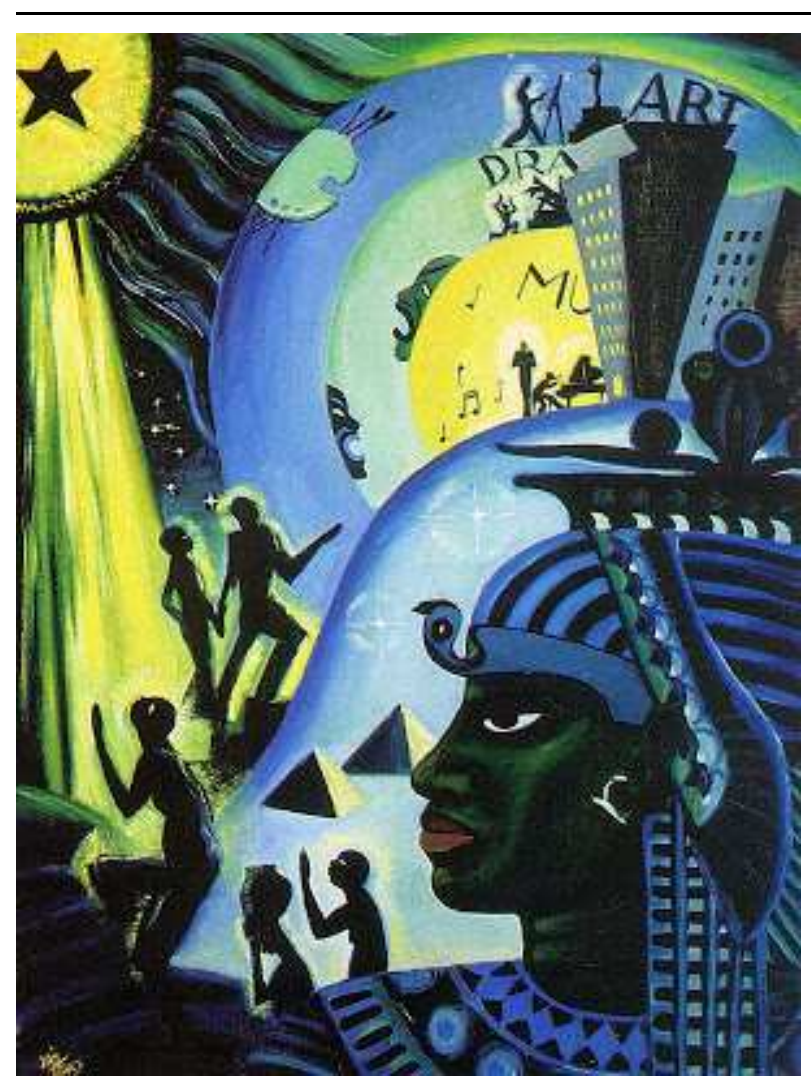

Figure 45. Lois Mailou Jones painting The Ascent of Ethiopia (1932) (Photography by John Glembin; Milwaukee Art Museum; Lois Mailou Jones Website). 


\section{Works Cited}

Adams, Henry. The Education of Henry Adams: An Autobiography. Boston: Houghton Mifflin Company, 1918. Web.

Adams, John. Letter to James Sullivan. 26 May 1776. Papers of John Adams Ed. Robert J. Taylor, et al. Cambridge: Harvard UP, 1977. Web.

Ahmad, Dorah. Landscapes of Hope: Anti-Colonial Utopianism in America. New York: Oxford UP, 2009. Print.

Alcott, Louisa May. Work: A Story of Experience. Project Gutenberg. Web. 18 May 2015. Boston: Little, Brown \& Co., 1901.

-----. “Transcendental Wild Oats." 1873. In Transcendental Wild Oats and Excerpts from the Fruitlands Diary. Ed. J. Streeter Fowke. Carlisle, MA: Applewood Books, 1981. Print.

Althusser, Loius. "Ideology and Ideological State Apparatuses." Lenin and Philosophy and Other Essays. Trans. Ben Brewster. New York: Monthly Review Press, 1971. Print.

Anderson, Benedict. Imagined Communities: Reflections on the Origin and Spread of Nationalism. New York: Verso, 1983. Print.

Baker, Lee D. From Savage to Negro: Anthropology and the Construction of Race 1896-1954. Oakland: U of California P, 1998. Print.

Bancroft, George. A History of the United States from the Discovery of the American Continent to the Present Time. Boston: Charles Bowen, 1834. Print.

-----. "Patriot Farmers of New York." in The Modern Farmer; or, Home in the Country. Ed. Rev. Blake. Cincinnati: Henry W. Derby, 1854. Web.

Bank, Rosemarie K. "Representing History: Performing the Columbian Exposition.” Theatre Journal 54.4 (2002): 589-606. Print. 
Barnett, Ferdinand L. "The Reason Why." The Reason Why the Colored American is not in the World's Columbian Exposition. 1893. Robert Rydell, Ed. Chicago: University of Illinois Press, 1999. Print.

Barnum, Phinneas T. The Humbugs of the World. New York: G.W. Carleton, 1866. Print.

Barringer, D.P. The American Negro: His Past and Future. Raleigh, NC: Edwards \& Broughton, 1900. Print.

Bederman, Gail. Manliness \& Civilization: A Cultural History of Gender and Race in the United States, 1880-1917. Chicago: U of Chicago P, 1995. Print.

Bellamy, Edward. Looking Backward, 2000-1887. 1889. New York: Oxford, 2007. Print.

----. Equality. 1897. Rockville, MD: Wildside Press, 2010. Print.

Bennett, Tony. “The Exhibitionary Complex.” New Formations 4 (1988): 73-102. Print.

Berger, Peter L and Thomas Luckmann. The Social Construction of Reality: A Treatise in the Sociology of Knowledge. New York: Anchor, 1966. Print.

Billias, George Athan. “George Bancroft: Master Historian.” American Antiquarian Society 111.2 (2001): 507 - 528. Print.

Binet, Alfred. On Double Consciousness: Experimental Psychological Studies. Chicago: The Open Court Publishing Company, 1890. Web.

Bishop, W.H. The Garden of Eden, U.S.A., A Very Possible Story. Chicago: Charles H. Kerr, 1895. Print.

Blackett, RJM. Building an Antislavery Wall: Black Americans in the Atlantic Abolitionist Movement 1830 - 1860. Baton Rouge: LSU Press, 1983. Print.

Blight, David. Race and Reunion: The Civil War in American Memory. Cambridge: Harvard UP, 2001. Print. 
“The Blithedale Romance: A Novel.” Christian Inquirer 14 Aug 1852. Web.

Boisseau, T.J. and Abagail M. Markwyn. Gendering the Fair: Histories of Women and Gender at World's Fairs. Chicago: U of Illinois P, 2010. Print.

Borgstrom, Michael. "Face Value: Ambivalent Citizenship in Iola Leroy." African American Review 40.4 (2006): 779-793. Print.

Brown, William Wells. Three Years in Europe; or, Places I have Seen and People I have Met. 1852. Print.

Bunce, Oliver Bell. “The City Beautiful.” The Story of Hippinolande and Other Legends. 1889. New York: D. Appleton \& Co., 1889. Print.

Burg, David F. Chicago's White City of 1893. Lexington: University Press of Kentucky, 1976.

Byrnes, Thomas. “How to Protect A City from Crime.” The North American Review. July 1894. Web.

Campbell, Helen. "Studies in the Slums: I.—Water Street and its Work." Lippincott's Magazine of Popular Literature and Science. 25 May 1880. Web.

Chakkalakal, Tess. "Reading in Sutton E. Griggs." Jim Crow, Literature, and the Legacy of Sutton E. Griggs. Eds Tess Chakkalakal and Kenneth W. Warren. Athens: U of Georgia P, 2013. Print.

----- and Kenneth Warren. Introduction. Jim Crow, Literature, and the Legacy of Sutton E. Griggs. Atlanta: U of Georgia P, 2013. Print.

Coleman, Finnie. "Social Darwinism, American Imperialism, and the Origins of the Science of Collective Efficiency in Sutton E. Griggs's Unfettered." In Jim Crow, Literature, and the Legacy of Sutton E. Griggs. Ed. Tess Chakkalalkal and Kenneth Warren. Atlanta: U of Georgia P, 2013. Print. 
Columbus, Christopher. “Journal of the First Voyage of Columbus." In Julius E. Olson and Edward Gaylord Bourne, eds., The Northmen, Columbus and Cabot, 985-1503, Original Narratives of Early American History. New York: Charles Scribner's Sons, 1906. Web.

"The Condition of the Slums." The Independent. 18 April 1895. Web.

Conn, Steven. Museums and American Intellectual Life, 1876-1926. Chicago: U of Chicago P, 1998. Print.

Cooper, Walter G. The Official History of the Exposition. Atlanta: Illustrator, 1896. Print.

Curry, Eric. "The Power of Combinations: Sutton Griggs's Imperium in Imperio and the Science of Collective Efficiency." American Literary Realism 43.1(2010): 23 - 40. Print.

Daugherty, Sarah B. "An Imperative Duty: Howells and White Male Anxiety.” American Literary Realism, 1870-1910. 30.3(1998): 53-64. Print.

Davenport, Benjamin Rush. Uncle Sam's Cabins: A Story of American Life, Looking Forward a Century. New York: The Mascot Publishing, 1895. Print.

----. Anglo-Saxons, Onward!: A Romance of the Future. Cleveland: Hubbell, 1898. Print.

----. Blood Will Tell: The Strange Story of a Son of Ham. Cleveland: Caxton Book Company, 1902. Print.

Davis, J.C. “Thomas More's Utopia: Sources, Legacy, and Interpretation.” The Cambridge Companion to Utopian Literature. Ed Gregory Claeys. New York: Cambridge UP, 2011. Print.

Davis, Leroy. A Clashing of the Soul: John Hope and the Dilemma of African American Leadership and Black Higher Education in the Early Twentieth Century. Athens: $\mathrm{U}$ of Georgia P, 1998. Print.

Davis, Rebecca Harding. “The Harmonists.” Atlantic 17.103 (1866): 529-539. Print. 
Dixon, Thomas. The Leopard's Spots. New York: Doubleday \& Page, 1902. Print.

Douglass, Frederick. "Introduction." The Reason Why the Colored American is not in the World's Columbian Exposition. 1893. Robert Rydell, Ed. Chicago: University of Illinois Press, 1999. Print.

-----. "Letter to Rosetta Sprague.” 1893. MS

Dowden-White, Priscilla A. Groping Toward Democracy: African American Social Welfare Reform in St. Louis, 1910 - 1949. Columbia: U of Missouri Press, 2011. Print.

Du Bois, W.E.B. "The Conservation of Races." 1897. The Problem of the Color Line at the Turn of the Twentieth Century: The Essential Early Essays Nahum Dimitri Chandler Bronx, NY: Fordham UP, 2013. Print.

-----. "To the Nations of The World." July 25, 1900. Web.

-----. “The Training of Negroes for Social Power.” Outlook. 17 October 1903. Print.

-----. The Souls of Black Folk. 1903. Lexington, KY: Eucalyptus Press, 2013. Print.

-----. “The Clansman.” The Crisis. May 1915. Print.

Durkheim, Emile. The Elementary Forms of the Religious Life. London: George Allen \& Unwin Ltd., 1915. Web.

Dutton, S.T. "Education as a Cure for Crime.” Journal of Social Science. 26 February 1890. Print.

Dyer, Thomas G. Theodore Roosevelt and the Idea of Race. Baton Rouge: Louisiana State UP, 1980. Print.

Emerson, Ralph Waldo. “Concord Address.” In The Selected Lectures of Ralph Waldo Emerson Ed. Ronald A. Bosco. Atlanta: U of Georgia P, 2005. Print. 
Ernest, John. Resistance and Reformation in Nineteenth-Century African-American Literature. Oxford: UP of Mississippi, 1995. Print.

----. "Harnessing the Niagara: Sutton E. Griggs’s The Hindered Hand." In Jim Crow, Literature, and the Legacy of Sutton E. Griggs. Ed. Tess Chakkalalkal and Kenneth Warren. Atlanta: U of Georgia P, 2013. Print.

Evelev, John. Tolerable Entertainment: Herman Melville and Professionalism in Antebellum New York. Boston: U of Massachusetts P, 2006. Print.

Fabi, M. Giulia. Passing and the Rise of the African American Novel. Chicago: U of Illinois Press, 2001. Print.

----. "Of the Coming of Grace: African American Woman Fiction, the Black Intellectual, and Lillian B. Jones Horace's Five Generations Hence." In Recovering Five Generations Hence: The Life and Writing of Lillian Jones Horace. Karen Kossie-Chernyshev, Ed. College Station: Texas A\&M UP, 2013. Print.

Farmer, William. "Extract of a letter from William Farmer, Esq. of London to William Lloyd Garrison, 26 June 1851." In Running A Thousand Miles for Freedom. William and Ellen Craft. 1860. Barbara McCaskill, Ed. Athens: University of Georgia Press, 1999. Print.

Finnegan, Terence. A Deed So Accursed: Lynching in Mississippi and South Carolina, 18811940. Charlottesville: U of Virginia P, 2013. Print.

Fitting, Peter. “'So We All Became Mothers': New Roles for Men in Recent Utopian Fiction.” Science Fiction Studies 12.2 (1985): 156-183.

Flinn, John J. Official Guide to the World's Columbian Exposition. Chicago: The Columbian Guide Company, 1893. Print. 
Frederickson, George M. The Black Image in the White Mind: The Debate on Afro-American Character and Destiny, 1817 - 1914. New York: Harper \& Row, 1971. Print.

Gaines, Wesley J. African Methodism in the South; or, Twenty-Five Years of Freedom. Atlanta: Franklin publishing House, 1890. Web.

----- The Negro and the White Man. Philadelphia: A.M.E. Publishing House, 1897. Print.

Gideon, Sigfried. Space, Time, and Architecture: The Growth of a New Tradition. Cambridge: Harvard, UP, 1967. Print.

Gliddon, George R. and J.C. Nott. Types of Mankind: Or, Ethnological Researches, $7^{\text {th }}$ Ed. Philadelphia: Lippincott, Grambo \& Co, 1855. Print. .

Goldberg, David Theo. Racist Culture: Philosophy and the Politics of Meaning. Cambridge: Blackwell, 1993. Print.

Greenhalgh, Paul. Ephemeral Vistas: The Expositions Universelles, Great Exhibitions and World's Fairs, 1851-1939. Manchester UP, 1988. Print.

Griggs, Sutton E. Imperium in Imperio: A Study of the Negro Race. 1899. Lexington: Greenbook, 2010. Print.

Gross, Ariela. What Blood Won't Tell: A History of Race on Trial in America. Cambridge: Harvard UP, 2008. Print.

Gruesser, John. "Empires at Home and Abroad in Sutton E. Griggs's Imperium in Imperio." In Jim Crow, Literature, and the Legacy of Sutton E. Griggs. Ed. Tess Chakkalalkal and Kenneth Warren. Atlanta: U of Georgia P, 2013. Print.

Gutheim, Frederick A. The Federal City: Plans and Realities. Washington: Smithsonian Institution, 1976. Print. 
Hale, Sarah Josepha. Liberia; or, Mr. Peyton's Experiments. 1853. Lexington, KY: U of Michigan Historical Reprints, 2011. Print.

Harlan, John. Plessy v. Ferguson, Dissenting Opinion. 163 U.S. 537. Supreme Court of the United States. 1896. Web.

Harper, Frances. Iola Leroy. 1892. Mineola, NY: Dover Publication, 2010. Print.

-----. “Woman's Political Future.” World's Congress of Representative Women. World's Columbian Exposition, Chicago, IL. 1893. Web.

Harrison, Les. The Temple and the Forum: The American Museum and Cultural Authority in Hawthorne, Melville, Stowe, and Whitman. Tuscaloosa: U of Alabama P, 2007. Print. Hawthorne, Julian. Letter. Lippencott's Monthly Magazine. April 1893. Web.

----. "Some Novelties at Buffalo Fair.” The Cosmopolitan. September 1901. Print.

Hawthorne, Nathaniel. The Blithedale Romance. 1853. New York: W.W. Norton \& Company, 2010. Print.

----. "Letter to E.P. Whipple.” Selected Letters of Nathaniel Hawthorne. Joel Meyerson, Ed. Athens: Ohio UP, 2002. Print.

Hayes, J.R. 'Negrophobia 'On the Brain,' in White Men, or An Essay Upon the Origin and Progress, both Mental and Physical of the Negro Race, and the Use to be Made of Him by the Politicians in the United States." Washington, DC: Powell, Ginck \& Co., 1869. Print.

Henderson, Charles. "Social Discussion and Reform.” The Dial. 1 June 1900. Print. Henning, Michelle. Museums, Media, and Cultural Theory. New York: McGraw-Hill, 2006. Print. 
Hoffer, Williamjames. Plessy v. Ferguson: Race and Inequality in Jim Crow America. Lawrence, KS: UP of Kansas, 2012. Print.

Hoffman, Nicole Tonkovich. "Legacy Profile: Sarah Josepha Hale.” Legacy 7.2 (1990): 47-55. Print.

Holloway, Vanessa A. Getting Away with Murder: The Twentieth-Century Struggle for Civil Rights in the U.S. Senate. New York: UP of America, 2015. Print.

Hopkins, Pauline. Contending Forces. Boston: Colored Co-operative Pub., 1900. Web.

-----. Of One Blood. 1903. New York: Washington Square Press, 2004. Print.

Horace, Lillian Jones. Five Generations Hence. In Recovering Five Generations Hence: The Life and Writing of Lillian Jones Horace. Karen Kossie-Chernyshev, Ed. College Station: Texas A\&M UP, 2013. Print.

Horsman, Reginald. Race and Manifest Destiny: The Origins of American Racial AngloSaxonism. Cambridge: Harvard UP, 1981. Print.

Howells, William Dean. Letters of an Altrurian Traveler. 1894. Clara M. \& Rudolf Kirk, Eds. Gainsville, FL: Scholars' Facsimiles \& Reprints, 1961. Print.

----. An Imperative Duty. New York: Harper \& Brothers, 1891. Web.

"Impressions of the World's Fair." The Critic: a Weekly Review of Literature and the Arts. 25 Nov 1893. Web.

Jacobson, Matthew Frye. Whiteness of a Different Color: European Immigrants and the Alchemy of Race. Cambridge: Harvard UP, 1998. Print.

Jackson, John P. and Nadine Weidman. Race, Racism, and Science: Social Impact and Interaction. New Brunswick: Rutgers UP, 2006. Print. 
Jameson, Fredric. Archaeologies of the Future: The Desire Called Utopia and Other Science Fictions. New York: Verso, 2005. Print.

Johns, The Cambridge Companion to Utopian Literature. Ed Gregory Claeys. New York: Cambridge UP, 2011. Print.

Johnson, E.A. Light Ahead for the Negro. New York: The Grafton Press, 1904. Reprint.

----. A School History of the Negro Race in America. Raleigh, NC: Edwards \& Broughton, 1894. Reprint.

Johnson, Mr. “The Great London Exhibition.” The Cultivator 6 May 1851. Web.

Johnson, Rossiter. History of the World's Columbian Exposition held in Chicago in 1893. New York: Appleton, 1897. Print.

Judd, Dennis R. The Infrastructure of Play: Building the Tourist City. New York: Routledge, 2015. Print.

Ketterer, David. The Science Fiction of Mark Twain. Hamden, CT: Archon Books, 1984. Print. Kirk, Clara M. \& Rudolf Kirk. Introduction. Letters of an Altrurian Traveler. 1894. Gainsville, FL: Scholars’ Facsimiles \& Reprints, 1961. Print.

Knight, Alisha Coleman. "To be a Publisher: Lillian Jones Horace and the Dotson-Jones Printing Company." In Recovering Five Generations Hence: The Life and Writing of Lillian Jones Horace. Karen Kossie-Chernyshev, Ed. College Station: Texas A\&M UP, 2013. Print.

Kumar, Krishan. Utopianism. London: Open University Press, 1991. Print.

Lands, LeeAnn. The Culture of Property: Race, Class, and Housing Landscapes in Atlanta, 1880-1950. Athens: University of Georgia Press, 2009. Print.

Lee, Maurice. Uncertain Chance: Science, Skepticism, and Belief in Nineteenth-Century American Literature. New York: Oxford UP 2012. Print. 
LeGates, Richard. Early Urban Planning, Vol 1. New York: Routledge, 1998. Print.

Levander, Caroline. "Sutton Griggs and the Borderlands of Empire." In Jim Crow, Literature, and the Legacy of Sutton E. Griggs. Ed. Tess Chakkalalkal and Kenneth Warren. Atlanta: U of Georgia P, 2013. Print.

Levine, Robert. "Edward Everett Hale's and Sutton E. Griggs's Men without a Country.” In Jim Crow, Literature, and the Legacy of Sutton E. Griggs. Ed. Tess Chakkalalkal and Kenneth Warren. Atlanta: U of Georgia P, 2013. Print.

----. Dislocating Race and Nation: Episodes in Nineteenth-Century American Literary Nationalism. Chapel Hill: U of North Carolina P, 2008. Print.

Lewes, Darby. Dream Revisionaries: Gender and Genre in Women's Utopian Fiction. Tuscaloosa: The U of Alabama P, 1995. Print.

Lhamon, Jr., W.T. Jump Jim Crow: Lost Plays, Lyrics, and Street Prose of the First Atlantic Popular Culture. Cambridge: Harvard UP, 2003. Print.

Looby, Christopher. "The Constitution of Nature: Taxonomy as Politics in Jefferson, Peale, and Bartram.” Early American Literature 22 (1987): 252-273. Print.

Macdonald, Sharon. "Exhibitions of Power and Powers of Exhibition: An Introduction to the Politics of Display." In The Politics of Display: Museums, Science, Culture. Ed. Sharon Macdonald. New York: Routledge, 1998. Print.

Massey, Douglass S. and Nancy A. Denton. American Apartheid: Segregation and the Making of the Underclass. Cambridge: Harvard UP, 1993. Print.

McCaskill, Barbara. "Introduction to Extract of a letter from William Farmer, Esq. of London to William Lloyd Garrison, 26 June 1851.” In Running A Thousand Miles for Freedom. William and Ellen Craft. 1860. Athens: University of Georgia Press, 1999. Print. 
McDowell, Deborah E. “Introduction.” Of One Blood; Or, The Hidden Self. 1902. Pauline Hopkins. New York: Washington Square Press, 2004. Print

Meier, William M. Property Crime in London, 1850 - Present. New York: Palgrave, 2011. Print. Merrill, Albert Adams. The Great Awakening. Boston: George Book Publishing, 1899. Print. Miller, Lillian B, et al., eds. The Selected Papers of Charles Willson Peale and His Family. 5 vols. New Haven: Yale UP 1988. Print.

Mills, Charles. The Racial Contract. Ithaca: Cornell UP, 1997. Print.

“Miss Sickels Makes Charges.” New York Times 8 October 1893. Print.

Mizruchi, Susan. The Rise of Multicultural America:Economy and Print Culture, 1865-1915. Chapel Hill: U of North Carolina P, 2008. Print.

More, Thomas. Utopia. 1516. Rockville, MD: Arc Manor, 2008. Print.

"Mr. Roosevelt Explains The Dinner Incident: Merely Wished to Consult Mr. Washington, He Says.” The New York Times. 20 October 1901. Print.

“Mrs. America Answers Mrs. England." Provincial Freeman. 24 March 1853. Web.

Negley, Glenn and J. Max Patrick, eds. The Quest for Utopia:An Anthology of Imaginary Societies. New York: Schuman, 1952. Print.

On “A Class of Immigrants Not Wanted.” New York Evangelist. 5 May 1887. Web.

The Paris Exposition VIII: Our Nation's Exhibits." New York Observer and Chronicle 27 December 1900. Print.

Penn, I. Garland. "The Progress of the Afro-American Since Emancipation." The Reason Why the Colored American is not in the World's Columbian Exposition. 1893. Robert Rydell, Ed. Chicago: University of Illinois Press, 1999. Print. 
-----. "The Awakening of a Race.” The Official History of the Exposition. Walter G. Cooper, Ed. Atlanta: Illustrator, 1896. Print.

Perdue, Theda. Race and the Atlanta Cotton States Exposition of 1895. Atlanta: U of Georgia P, 2011. Print.

Peterson, Jon A. The Birth of City Planning in the United States, 1840 - 1917. Baltimore: Johns Hopkins UP, 2003. Print.

Peyser, Thomas. Utopia and Cosmopolis: Globalization in the Era of American Literary Realism. Durham, NC: Duke UP, 1998. Print.

Pfaelzer, Jean. The Utopian Novel in America 1886-1896: The Politics of Form. Pittsburgh: U of Pittsburgh P, 1984. Print.

Platt, Rutherford H. Land Use and Society, Third Edition: Geography, Law, and Public Policy. Washington, D.C.:Island Press, 1996. Print.

Poe, Edgar Allan. "Eureka.” In Edgar Allan Poe: Poetry, Tales, and Selected Essays. New York: The Library of America, 1996. Print.

----- “Mellonta Tauta." In Edgar Allan Poe: Poetry, Tales, and Selected Essays. New York: The Library of America, 1996. Print.

----. "Philosophy of Composition." In Edgar Allan Poe: Poetry, Tales, and Selected Essays. New York: The Library of America, 1996. Print.

Pohl, Nicole. "Utopianism after More: the Renaissance and Enlightenment." The Cambridge Companion to Utopian Literature. Ed Gregory Claeys. New York: Cambridge UP, 2011. Print.

Posnock, Ross. Color \& Culture: Black Writers and the Making of the Modern Intellectual. Cambridge: Harvard UP, 1998. Print. 
Pregill, Philip and Nancy Volkman. Landscapes in History: Design and Planning in the Eastern and Western Traditions. New York: John Wiley \& Sons, 1999. Print.

Quest-Ritson, Charles. The English Garden: A Social History. Jaffrey, NH: David R. Godine, 2003. Print.

Reynolds, David S. Beneath the American Renaissance: The Subversive Imagination in the Age of Emerson and Melville. Cambridge: Harvard UP, 1989. Print.

“Riddle’s Fair." Scientific American. 10 April 1852. Print.

Riis, Jacob. How the Other Half Lives. New York: Charles Scribner's Sons, 1890. Web.

Robinson, Charles Mulford. "Modern Civic Art; or, the City Made Beautiful. New York: G.P. Putnam's Son's, 1904. Print.

----. "The Fair as Spectacle." History of the World's Columbian Exposition held in Chicago in 1893. Rossiter Johnson, Ed. New York: Appleton, 1897. Print.

Roemer, Kenneth. The Obsolete Necessity:America in Utopian Writings, 1888-1900. Kent, OH: Kent State UP, 1976. Print.

----. Utopian Audiences: How Readers Locate Nowhere. Amherst: U of Massachusetts P, 2003. Print.

----- "Paradise Transformed." In The Cambridge Companion to Utopian Literature. Ed Gregory Claeys. New York: Cambridge UP, 2011. Print.

Roosevelt, Theodore. “Kidd's Social Evolution.” The North American Review (1895): 109. Print.

----. "Negro in America." Outlook 95 (1910): 241-44. Print.

Rosenberg, Chaim. America at the Fair: Chicago's 1893 World's Columbian Exposition. Chicago: Arcadia Publishing, 2008. Print. 
Rosenthal, Debra J. Race Mixing in Nineteenth-Century U.S. \& Spanish American Fictions. Chapel Hill: U of NC Press, 2004. Print.

Rowe, John Carlos. Literary Culture and U.S. Imperialism: From the Revolution to World War II. New York: Oxford UP, 2000. Print.

Rudwick, Elliott M. and August Meier. "Black Man in the 'White City': Negroes and the Columbian Exposition, 1893." Phylon 26.4 (1965): 354-361. Print.

Ryan, Susan M. "Errand into Africa: Colonization and Nation Building in Sara J. Hale's Liberia." The New England Quarterly 68.4 (1995): 558-583. Print.

Rydell, Robert W. All the World's a Fair: Visions of Empire at American International Expositions, 1876-1916. Chicago: U of Chicago P, 1987. Print.

Sargent, Lyman Tower. “The Three Faces of Utopia.” Minnesota Review 7.3 (1967): 222-230. Print.

-----. “The Three Faces of Utopianism Revisited.” Utopian Studies 5.1 (1994): 1-37. Print.

----. "Colonial and Postcolonial Utopias." The Cambridge Companion to Utopian Literature. Ed Gregory Claeys. New York: Cambridge UP, 2011. Print.

“Senator Tillman.” Life. 7 November 1901. Web.

“Science Notes.” Scientific American. 2 September 1899. Print.

Schneider, Mark Robert. “We Return Fighting:” The Civil Rights Movement in the Jazz Age. Boston: Northeastern UP, 2002. Print.

Shor, Robert Francis. Utopianism and Radicalism in a Reforming America, 1888-1918. Westport, CT: Greenwood Press, 1997. Print.

“Social Studies: Realizable and Unrealizable Ideals." In The Unitarian Review, Vol 31. Ed. Joseph Henry Allen. Boston: Office of the Unitarian Review, 1889. Web. 
Stanton, Elizabeth Cady. "Declaration of Sentiments and Resolutions." In A History of Woman Suffrage, Vol. 1. Rochester, N.Y.: Fowler and Wells, 1889. Web.

Stanton, William. The Leopard's Spots: Scientific Attitudes toward Race in America 1815-59. Chicago: U of Chicago P, 1960. Print.

Steffensen-Bruce, Ingrid A. Marble Palaces, Temples of Art: Art Museums, Architecture, and American Culture, 1890-1930. Cranbury, NJ: Associated University Presses, 1998. Print.

Steffens, Lincoln. The Shame of the Cities. 1904. Google Books. 2012. Web.

Stokes, Melvyn. D.W. Griffith's the Birth of a Nation: A History of "The Most Controversial Motion Picture of All Time." New York: Oxford UP, 2007. Print.

Sundquist, Eric. To Wake the Nations: Race in the Making of American Literature. Cambridge: Harvard UP, 1993. Print.

Tractenberg, Alan. The Incorporation of America: Culture and Society in the Gilded Age. New York: Hill \& Wang, 1982. Print.

Twain, Mark. "The Curious Republic of Gondour." In The Curious Republic of Gondour and Other Whimsical Sketches. New York: Boni and Liveright, 1919. Print.

----. A Connecticut Yankee in King Arthur's Court. Ed. Allison R. Ensor. New York: W.W. Norton \& Company, 1982. Print.

-----. Pudd'nhead Wilson and Those Extraordinary Twins. 1894. Ed. Sidney E. Berger. New York: W.W. Norton \& Company, 2004. Print.

Vieira, Fatima. "The Concept of Utopia." The Cambridge Companion to Utopian Literature. Ed Gregory Claeys. New York: Cambridge UP, 2011. Print.

Von Swartwout, William. The Beginning, A Romance of Chicago as it Might Be. Chicago: Charles H. Kerr \& Co., 1893. Print. 
Wallinger, Hanna. Pauline E. Hopkins, A Literary Biography. Atlanta: U of Georgia P, 2005. Print.

Warner, Charles Dudley. "Impressions of the World's Fair." The Critic 1893. Web.

"Was Slavery the Engine of American Economic Growth?" National Expansion \& Reform, 1815-1860. The Gilder Lehrman Institute of American History. Web. 25 Sept 2016.

Washington, Booker T. “Atlanta Compromise.” Cotton States and International Exposition. Atlanta, GA. 18 September 1895. Web.

Watson, Veronica. "Lillian B. Jones Horace and the Literature of White Estrangement: Rediscovering an African American Intellectual of the Jim Crow Era.” In Recovering Five Generations Hence: The Life and Writing of Lillian Jones Horace. Karen KossieChernyshev, Ed. College Station: Texas A\&M UP, 2013. Print.

Wells, Ida B. "Class Legislation." The Reason Why the Colored American is not in the World's Columbian Exposition. 1893. Robert Rydell, Ed. Chicago: University of Illinois Press, 1999. Print.

-----. "The Convict Lease System." The Reason Why the Colored American is not in the World's Columbian Exposition. 1893. Robert Rydell, Ed. Chicago: University of Illinois Press, 1999. Print.

-----. "Lynch Law." The Reason Why the Colored American is not in the World's Columbian Exposition. 1893. Robert Rydell, Ed. Chicago: University of Illinois Press, 1999. Print.

Wegner, Phillip E. Imaginary Communities: Utopia, the Nation, and the Spatial Histories of Modernity. Berkeley: U of California Press, 2002. Print.

Welter, Barbara. “The Cult of True Womanhood: 1820-1860.” American Quarterly 18.2 (1966): 151-174. Print. 
Whitman, Walt. "Song of the Exposition.” Leaves of Grass. New York: New York UP, 1980. Print.

Williams, Frank Purdy. Hallie Marshall: True Daughter of the South. 1900. New York: Abby Press, 1996. Print.

Williams, James D. "The Use of History in A Connecticut Yankee." In A Connecticut Yankee in King Arthur's Court. Norton Critical Edition. Ed. Allison R. Ensor. New York: W.W. Norton \& Company, 1982. Print.

Wilson, Mabel O. Negro Building: Black Americans in the World of Fairs and Museums. Oakland: U of California Press, 2012. Print.

“World's Convention of Industry in America." Scientific American. 9 March 1850. Print.

Yarborough, Richard. Introduction. Contending Forces: A Romance Illustrative of Negro Life North and South. Pauline Hopkins. 1903. New York: Oxford UP, 1988. Print.

Young, Paul. Globalization and the Great Exhibition: The Victorian New World Order. New York: Palgrave Macmillan, 2009. Print. 